


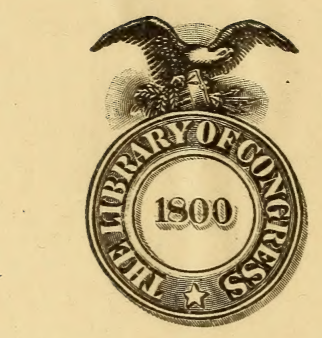

Class SF Y 47

Book I 922

Copyright $\mathrm{N}^{\circ}$.

COPYRIGHT DEPOSIT. 







$$
8
$$




\title{
PRIVATE PRESCRIPTIONS
}

\author{
AND \\ LECTURES
}

A Perfect Mantal and Complete Hand-Book on

\section{DISEASES OF STOCK,}

CONTAINING THIRTY-FOUR PLAIN AND COMMONSENSE

LECTURES ON DISEASES OF HORSES, CATTLE, POULTRY, HOGS, SHEEP AND DOGS, AND THEIR TREATMENT, TOGETHER WITH INDISPENSABLE INFORMATION TO THE FARMER AND STOCKMAN, ÁND HUNDREDS OF THE ,BEST PRESCRIPTIONS AND TREATMENTS KNOWN TO THE VETERINARY PROFESSION.?

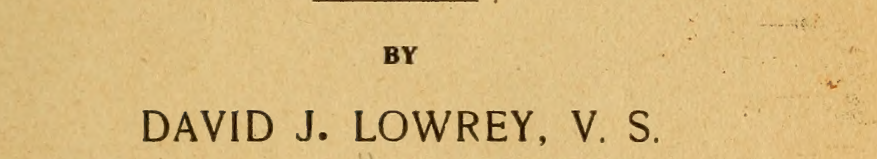

SECOND EDITION-REVISED,ENLARGED AND ILLUSTRATED.

1904:

DEMOCRAT PUBLISHING CO., Weatherford, Texas. 

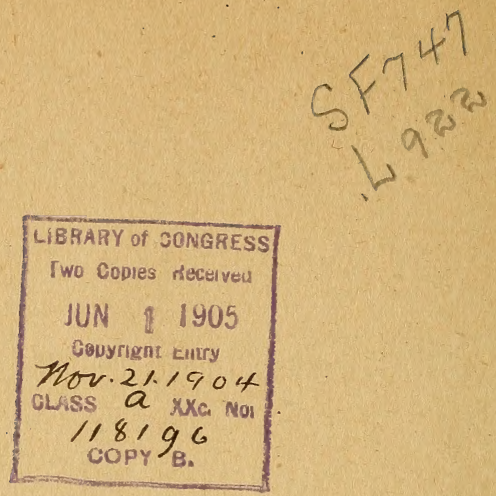

Entered according to Act of Congress in the year 1904, by DAVID J. LOWREY, V. S.

In the office of the Librarian of Congress, at Washington. 


\section{AGREEMENT.}

I

having purchased Copy No of "Private

Prescriptions and Lectures," by D. J. Lowrey, V. S., obligate myself to neither give away nor lend this bouk or its prescriptions to any one, but I reserve the right to apply all the information I may obtain from these pages upon any oncasion.

Signed

In presence of Agent. 


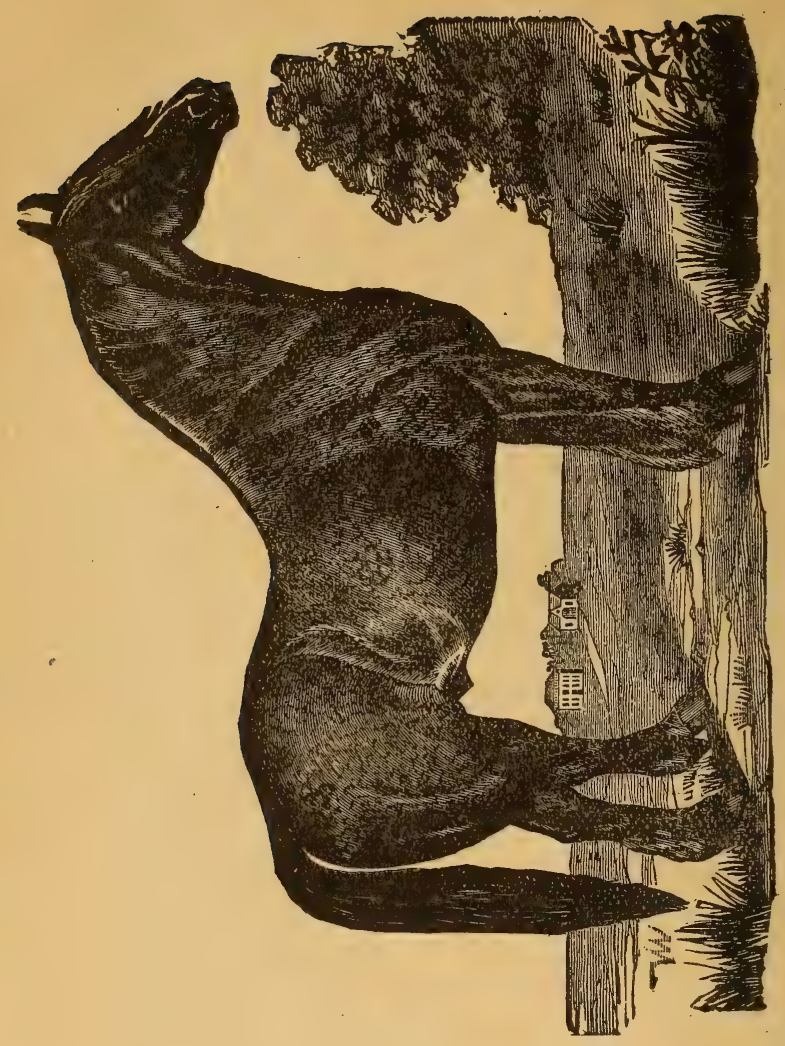




\section{PREFACE.}

After years of delay and many broken promises made to friends and former pupils the author submits this volume with the hope that it will meet the expectations of those who have urged the work upon him.

In the preperation of these pages my object has been to give to the American farmer and stockman, whose onerous duties allow but little leisure for consulting more comprehensive works, a practical common-sense hand-book, through which he may be enabled to preserve the lives and usefulness of the most valuable assets of the farm.

I have endeavored to eliminate everything not of some practical worth and have striven to express myself in plain and simple language to the end that anyone who can read may understand, no matter what his advantages in life may have been.

In speaking thus plainly I feel that I can more readily secure the attention of those whom I desire to reach and I cannot believe that the simplicity of my work will cause it to prove less acceptable to them.

THE AUTHOR. 


\section{TABLE OF CONTENTS.}

DISEASES OF THE HORSE-HOW TO KNOW THEM CAUSES - PREVENTION AND CURE.

\section{CHAPTER I.}

The Horse in Health-The Pulse of the Horse-The Temperature-

The Respiration in Health-Actions and Inclinations of Disease-Importance of Prompt Treatment-Know what Yon Are Treating-Be sure Medication Is Indicated-How to Give Medicine-Nursing and Feeding Sick Stock.

\section{CHAPTER II.}

The Age of Your Horse and the Care of his Teeth-How to Tell the Age of Your Horse from Birth to Twenty-One Years of AgeCare of the Teeth-Sharp, Irregular, Uneven and Elongated Teeth-Tooth Ache-Lampas-Sore Mouth-Tongue Laceration-Pharyngitis-Choaked Horse.

CHAPTER III.

Diseases of the Respiratory Organs-Tumor in the False NostrilsAcute Catarrh-Chronic Catarrh-Nasal Gleet-Laryngitis -Quinsy-Acute Bronchitis-Chronic Bronchitis-Pneumonia-Distemper or Strangles-Heaves or Broken Wind-Congestion of the Lungs-Pleurisy-Chronic Cough. 


\section{CHAPTER IV.}

Diseases of the Stomach and Bowels-Gastritis-Stomach Staggers -Indigestion-Bots-Bilious Colic-Wind Colic-Rupture of Stcmach-Rupture of Diaphragm-Constipation-Dysentery-Suppuration-Gut-tie-Inflammtiaon of the BowelsIntestinal Worms.

\section{CHAPTER V.}

Diseases of the Urinary Organs-Inflamation of the KidneysCongestion of the Kidneys-Inflamation of the BladderSpasm of the Neck of the Bladder-Diabetes-Paralysis of the Bladder-Eversion of the Bladder-Rupture of the Bladder-Bloody Urine-Dribbling of the Urine-Stricture of the Uretha-Gonorrhoea-Urinary Calculi-Foul Sheath.

CHAPTER VI.

Diseases of the Liver-Congestion of the Liver-Inflamation of the Liver.

\section{CHAPTER VII.}

Diseases of the Blood-Influenza-Pink Eye-RheumatismAbscesses-Glanders-Farcy.

\section{CHAPTER VIII.}

Diseases of the Heart and Blood Vessels-Diseases of the En docardium-Enlargement of the Heart-Aneurism-Thumps.

CHAPTER IX.

Diseases of the Brain and Nervous System-Inflammation of the Brain-Meningitis-Apoplexy-Lock-jaw or Tetanus-Sunstroke-Blind Staggers-Loco Poisning.

\section{CHAPTER $\mathrm{X}$.}

Diseases of the Eye-Moon Blindness-Glass Eye-Inflamation of the Iris-Cataract-Weeping Eye-Torn Eyelids. 
CHAPTER XI.

Parasitic Troubles and External Affections of the Body-Lice -Mange-Ringworm-Itchy-Tail-ItchySkin-Surfeit-Hide Bound-Eczema--Warts-Saddle Galls--Set-Fasts-Poll-Evil Fistulous Weathers--Caries-Necrosis -Wire Cuts-Dropsy -Rupture.

\section{CHAPTER XII.}

Affections of the Legs-Wind Galls-Scratches-Greece HeelCocked-Ankle--Ring-Bone--Splint-Bone--Spavin--Bog Spavin -Blood Spavin - Sweeny - Shoulder Lameness - StifledHipped-Hip Lameness.

\section{CHAPTER XIII.}

Diseases of the Feet-Corns-Quittor-Pricking-Nails-WoundsQuarter Cracks-Thrush-Narrow Heel-Gravel in the Foot Stone Bruises - Canker-Side Bones-Acute FounderChronic Founder.

\section{CHAPTER XIV.}

Diseases of the Organs of Generation-Inflamation of the TesticlesEvil Results of Castration-Wounds ol the Penis-Inflammation of the Womb-Inflammation of the Ovaries-Parturition Fever.

-Abortion-How to tell When a Mare is in Foal-Puerperal

CHAPTER XV.

Operations on the Horse-Bleeding-Stopping Blood-Extracting Teeth-Removing Tumors-Opening an Abscess-Operating in Blood Spavin-Tapping the Chest-Tapping the ColonCastrating.

CHAPTER XVI. JOCKEY TRICKS.

How to Make an Old Horse Appear Younger-How to Make a 
Horse Go Lame-How to Fatten a Horse for Trading-How to Make a Slow Horse Fast-How to Make a Horse Quit Eating.

\section{PART TWO-DISEASES OF CATTLE.}

CHAPTER XVII.

Introduction-Sign of Disease-Pulse-Temperature-Respiration.

CHAPTER XVIII.

Diseases of the Organs of Respiration-Bleeding from the NoseBleeding from "the Lungs-Laryngitis-Diptheria-Bronchitis-Pneumouia-Pleurisy-Chronic Cough-Heaves.

CHAPTER XIX.

Diseases of the Digestive Organs-Sore Mouth-Loss of CudChoking-Hoven-Impaction of the Rumen-Impaction of the Ommasum-Dry Murrain-Chronic Indigestion-Constipation-Diarrhœa-Dysentery-Inflammation of the Bowels Intestinal Worms-Tape Worm.

CHAPTER XX.

Diseases of the Urinary Organs-Inflammation of the KidneysRetention of the Urine-Dribling of Urine-Bloody UrineInflammation of the Bladder-Stone in the Bladder.

CHAPTER XXI.

General Blood Diseases-Blood Poison-Tuberculosis and Pulmantitis - Rheumatism - Contagious Pleuro PneumoniaRinderpest-Texas Fever-Anthrax or Black Leg.

CHAPTER XXII.

Diseases of the Brain and Nervous System-Congestion of the Brain -Inflammation of the Brain-Concussion of the BrainProstration from Heat-Paralysis-Lock Jaw. 


\section{CHAPTER XXIII.}

Diseases of the Eye-A Foreign Substance in the Eye-Cataract -Torn Eye Lids.

CHAPTER XXIV.

Diseases of the Organs of Generation-Congestion of :Testicles Inflammation of Testicles-Parturation-Prolong After-Pains Retention of After Birth-Abortion-Miscarriage-FloodingEversion of the Womb-Puerperal Fever.

\section{CHAPTER XXV.}

External and Parasitic Troubles-Lock Jaw-Exzema-Water Blisters-Boils-Warts-Snake Bites-Mange-Ring Worms Lice-Ticks-Grubs in the Back-Buffalo Gnats-Home Flies -Screw Worms-Fleas.

\section{CHAPTER XXVI.}

Afflictions Peculiar to Cows in Milk-Inflammation of the UdderCongestion of the Udder-Chapped and Sore Teats-Suppression of Milk-Bitter Milk-Bloody Milk-Milk Fistula.

CHAPTER XXVII.

Diseases of the Calves-Joint Ill-Abscess of Nave1-Navel Rupture-Constipation-Scorning.

CHAPTER XXVIII.

Operations - Setting Broken Limbs-Dehorning-Tapping the Chest-Tapping the Paunch-Tapping the Bladder-Castration.

PART THREE-DISEASES OF SWINE.

CHAPTER XXIX.

Diseases of Swine Their Prevention and Cures-How to Care for

Hogs-How to Prevent Diseases-Quinsy-Choaking-Stunted 
Hogs-Worms in Hogs-Constipation--Diarrhoea--Blind Staggers-Fits in Pigs-Pneumonia-Hog Cholera-Sows Pigging - Bustler Pigs-How to Give Hogs.Medicine.

\section{PART FOUR-POULTRY.}

CHAPTER XXX.

Poultry and Their Diseases, Cause and Prevention-How to Keep Poultry Healthy-Egg Production-Crop Bound-Diarrhoea -Cholera-Roupe-Catarrh-Bronchitis-Gapes-Pip - Sore Head-Leg-Weakness-Lice-Fleas-Mites.

\section{PART FIVE-SHEEP.}

CHAPTER XXXI.

Sheep and Their Disease Prevention and Cures-Travel SoresSore Feet-Gravel and Swollen Feet-Foot Rot-MaggotsLiver Fluke-Ringworms - Bloating-Colic-Inflammation of the Bowels-Grubs in the Head-Scab.

\section{PART SIX-DOGS.}

CHAPTER XXXII.

The Dog, their Diseases Prevention and cures-Mange-FleasLice-Ringworms-Inflammation of the Eye-Canker of the Ear-Distemper-Constipation - Worms - Fits - Cholera Hydrophobia-Poison in Dogs. 



\section{PRIVATE \\ PRESCRIPTIONS AND LECTURES}

\section{THE HORSE.}

\section{CHAP TER I.}

To be able to successfullv meet the various pathological conditions which so often arise in the great equine family, the student must first turn his attention to, and master the horse in a state of perfect health; when this is done he is in a position to distinguish the presence of disease. The normal or healthy horse is one in which there is an entire absence of any pervertion of nature, either external or internal. External or local troubles can in most instances be readily determined by even the unlearned, but internal lessions cannot be distinguisbed or understood satisfactorily without accnrate information as to the pulse, temperature, respiration, actions and inclinations, in fact everything that is in any way expressive of either the feelings or physical condition of the animal must be cart fully studied. 


\section{PULSE.}

If there is any one thing which can be classed as being of vital consequence, of supreme importance to the veterinarian, it is a perfect.understanding of the pulse. The pulse is the barometer by which we are governed in the ad-

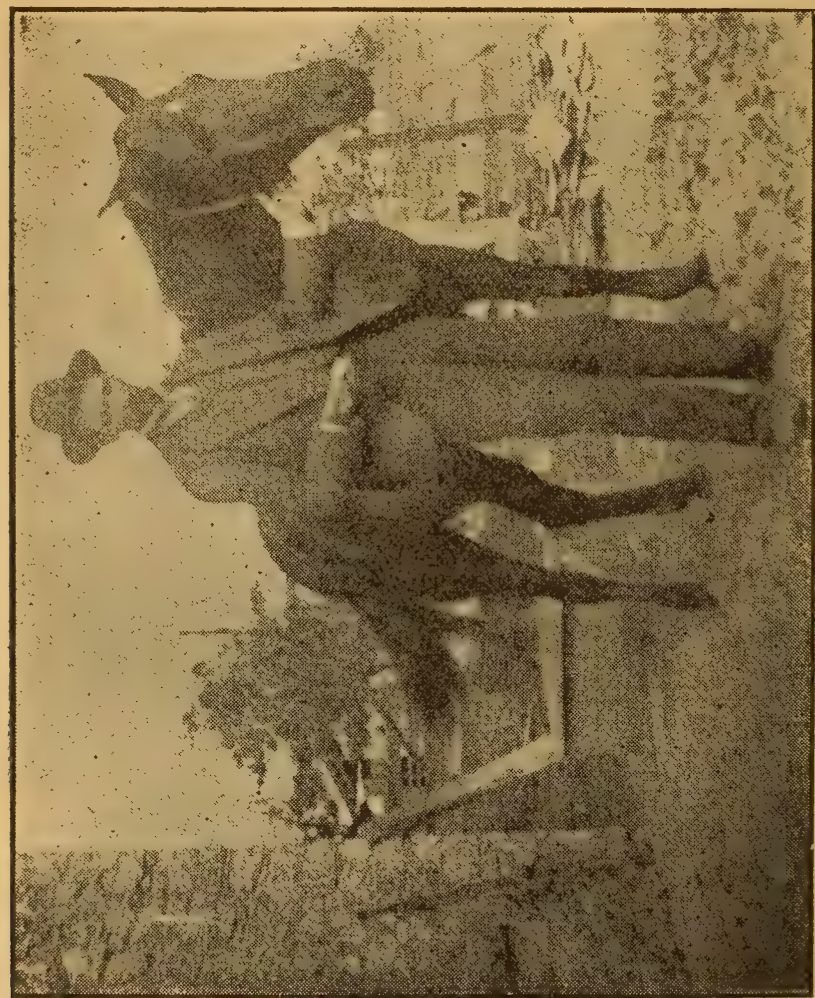

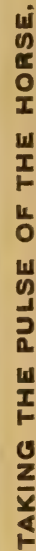

ministration of medicines in all internal diseases. It is evidence of the circulation of the blood which passes through the arteries at the rate of about ninety feet per minute. It 
is the key to the nervous system, for the circulation is produced and its volume regulated by the sympathetic nerves. The pulse indicates the condition of the heart, and whether or not disease is of a depressed or exalted character. In inflammations and fevers the frequency of the pulse is increased according to stage of the disease. In debilitated conditions we find it usually depressed, but some times quick, then natural. The normal or pulse of health in the full grown horse is from 33 to 36 , and in rare instances, 40 beats per minute. In young stock it is more frequent, under one year of age it runs from 42 to 48 beats per minute. There are many places at which the pulse can be gotten, but the best place for taking it is, in my judgement, from the submaxillary artery as it passes on the inner angle of the lower jaw, this being the most convenient. We have many pulse variations which will be fully treated under the heads of the diseases in which they prevail.

\section{TEMPERATURE.}

When we speak of the temperature of a horse, we do so with reference solely to the amount of heat prevailing in the economy of the animal. Through the agency of a thermometer, and by no other means, are we able to secure the correct temperature of a horse. io take temperature insert clinical thermometer in rectum, always turning to one side so as to have it press against the side of bowels, allow it to remain from 3 to 5 minutes, remove carefully and note any deviation from the normal. The normal temperature of the horse is from 99 to Ioo degrees. In severe cases the temperature should be taken every 4 to 6 hours, 
while in mild cases once or twice a day is sufficient. The temperature may somelimes run as low as $78 \mathrm{I}-2$ degrees and the horse will survive, but when it reaches 75 degrees it is my judgement that death is :apidly approaching.

\section{RESPIRATION.}

In health the horse breathes from I2 to I4 times per minute, work or excitement increases this, however. The num. ber of respirations per minute can be readily counted by the heaving of the flanks. It requires no special skiil to distinguish the soft rustling sound of the healthy respiratory murmur, but considerable experience is required to make one a first-class judge of the scunds obtained by percussion. Percussion is the act of striking smartly a finger of one hand, (resting gently over part to be examined) with the first three fingers of the other. In connection with the respiratory organs we place the finger over the lung in the region of the 6 th rib, do our striking and in case of health we find a clear resonant sound, but should disease exist everytbing is changed, depending entirely upon the nature and extent of the trouble. The abnormal sounds which prevail in diseases of the air passages and lungs will be treated under the heads of the various diseases with which they are associated.

In studying the horse, his every act as to position in standing and lying, rolling, kicking, pawing, jumping, etc., must be taken into consideration with its initial reference to disease. These along with inclinations in the way of appetite, for either food or drink, are expressive of the 
feelings of an animal, and are all we have to rely upon in the diagnosis of disease, aside from the pulse, temperature and respiration. By depicting an animal when suffering from a derangement of an internal organ, is our only means of illustrating an internal disease.

Under this head I desire to direct the reader's attention to and urging upon him the importance of a painstaking consideration of the habits and constitutional conditions, as well as the color anc quantity of excretions of every animal which he is treating, to the end that he may be able to distinguish when nature is aiding him.

\section{Importance of Prompt Treatment.}

The sooner disease is recognized and given the proper treatment the sooner bealth will be restored, making the liability of a fatal termination and consequent loss, very much less and. from a humane standpoint, the less the animal will suffer These is nothing to which the old adage that "a stich i? ime saves nine," applies more forcibly than in th- tre tment of the ailments of all kinds among stock, "o mattrr whether the trouble be local in character or of internal rigin. For instance, a horse goes lame from a cir., if properly attended to it can be cured in a few days, but if neglected, it fe:ters and spreads, works, up through the foot and breaks out around the top of the hoof, forming quittor, which with the best of attention cannot be cured in less than 5 or 6 weeks. Another instance, a horse may catch a cold and have a catarrhal discharge from the nose, sore throat, a cough and loss of appetite; if promptly and 
properly treated he may be restored to realth and usefulness in from 2. to Io days, but if neglected for a day or two the disease will in all probability find its way into the lungs, starting an irritation most painful in character, and disease of lengthy duration, with the possibility of a fatal termination.

\section{Know What You Are Treating.}

Let me urge as a matter of utmost importance, that when treatment of any kind is indicated, whether it be local or internal, that the proper remedies be applied promptly and thoroughly. But I would remind you to be sufficiently cautious in every instance; always be sure you are on the right track then go ahead with energy and persistence. Do not be caught treating an ankle because it is cocked, when every particle of the infiammation causing the lameness is in the foot. Neither would I have you make the mistake of "dosing" a horse for the "Bots," when the trouble is either Pleurisy or an affection of the kidneys. Many errors similar in character to these, have come under the observation of the writer in his practice. One notable instance in which many were deceived was supposed to be a case of "Sweeney" in which I was called. I found the horse very lame, and blistered on both shoulders and withers by the too free use of some patent liniment of questionable utility. I made a careful examanation, and through it the fact was disclosed to me that this horse was suffering from a thorn in his foot. This I removed and the patient was all right in a few days. I relate this merely to lllus. 
trate the worth of accurate information, and the absolute necessity for careful examination, and intelligent deliberation before beginning with any treatment. But when the disease is cleariy defined, when it is exclusively located by a process of exclusion, begin at once the careful administration of the remedies indicated in such disease, provided however, that in case of internal medication, the nature and stage of disease makes such a course necessary.

The reader must bear in mind the important fact that medicine alone never cured man nor beast. It merely assists nature in effecting a cure. Observation and experience have forced the conclusion upon me, that more stock are killed through the administration of stuff called medicine by the ignorant and irresponsible than would have died, had nature alone been depended upon for a cure. I have found it necessary to physic only about one half the stock which I am called to see. Nature and disease are diametrically opposed to each other. The one puts forth every effort by means of natural law to build up the system, while the other exerts all those baleful influences which have a tendency to bring about decay and death. In the treatment of the internal diseases of the horse, I would advise that nature be relied upon entirely, until the pulse reaches 50 beats per minute; should the pulse go beyond this, medication is indicated and I would suggest that its administration be promptly begun. But I recommend that a dose of medicine for any internal disease be never repeated so long as the pulse is on a stand still or shows an inclination to come down; under these circum- 
stances simply give nature a chance, and in most cases she will do her work well.

\section{How to Give Medicine.}

Medicine for horses is usually either in a liquid or powdered form. Powders may be given incorporated with the food; when the horse will not take it in this way, a good plan is to use a long handled spoon, pull his tongue out and empty powder by means of spoon far back on the root of it. Another way of giving powders is by making them into a ball or placing them in a capsule which ball or capsule, as the case may be, is thrown into the fauces or throat of the patient. Liquids are best given in the way of a drench. To drench a horse secure a long necked bottle and place the desired amount of medicine in it, elevate the head of the horse, insert neck of bottle in side of mouth and pour contents slowly into throat, keeping head elevated until all is swallowed. If horse should cough while being drenched, let his head down at once regardless of the loss of medicine, for if kept up, drench is liable to pass into the lungs instead of the stomach and result in something serious. Never be so brutal'and ignorant as to attempt drenching a horse through the nose, for it is an inhuman practice, aside from placing the life of the animal in jeopardy.

Small doses of medicine can be given by means of a little syringe. To do this open the mouth of horse with one hand, insert the syringe containing medicine at the side with other, and shoot contents into throat. 
The hypodermic method of administering medicines is very unsafe for any but experienced practioners, for by this method they are assimilated much more readily, and act very much more powerfully than when taken tbrough the stomach. The dose hypodermically of most drugs is about half that administered internally.

\section{Nursing and Feeding.}

Much might be written under this head and from time to time, we intend wedging in a lut of matter in this con. nection which we consider of worth to every one. At this stage we will simply give a few practical hints.

In order to care for an a imal intelligently and properly the nurse must familiarize himself with his habits and requirments in a state of health. It is of the greaterst importance in case of sickness that a horse should be made as comfortable as possible in both summer and winter; always allow plenty of fresh air to breathe, but in every instance avoid a draft. Have bedding dry and clean. Food vants to be simple, clean, nutritious and as easy digestable as possible. All water given should be fresh, pure and clean. Be careful about over-feeding; this is often a detriment and hiadrance. Sick horses should be fed 4 or 5 times per day, but in very small quantities. Colts should have their rations every 2 or 3 hours. A patient with fever sbould have plenty of pure water by him all the while, and be allowed to help himself, but those suffering with Diarrhœa or Dysentery should be given water 4 or 5 times per day in sparing quantities. Ar animal should always have a few days rest after being sick; many cases prove fatal from working them too soon. 


\section{THE AGE OF THE HORSE FROM BIRTH TO TWENTY-ONE.}

In buying or trading for a horse, age is always a matter which must necessarily enter into the consideration, for upon it largely depends the value of the animal, from a monetary standpoint, age also cuts quite a figure in the service which "is expected of the animal. It is very essential that farmers and stock owners, should study the teeth very closely, that they might be able to judge for themselves the age of their stock, for there is no other way of approximating the age of a horse except by the teeth. I shall endeavor to tell in as plain language as possible the conditions which will be met with from the birth of the colt to twenty-one years of age.

Ist. Adult horse has forty teeth in all, twenty-four jaw teeth or grinders, twelve above and twelve below. He has twelve front teeth or nippers, six above and six below. He has four tusks. two above and two below. The mare has thirty-eight teeth, twenty-four grinders or jaw teeth, and twelve front teeth or nippers. She has two tusks after she passes seven years of age, but never has any above.

2nd. The colt at birth has no teeth at all, but in two weeks old we find four front teeth, two above and two below. At twelve weeks old he gets four more, two above and two below, the two are called the lateral teeth. At nine months old he gets four more front teeth called the corner teeth, two above and two below. So at nine months old the colt has a full mouth of milk or temporary front teeth. There is not munh change in the teeth until the 
colt gets two years old. At two and a half years he sheds four of his front teeth, two above and two below. which are called the center teeth or nippers and gets in permanent teeth. At three and a half years old he sheds four more which are called the lateral teeth, two above and two below. At five years old the teeth in front are all even, this is what we call a full mouth of permanent teeth; each one of the front teeth has a black cup in it. At six years old the black cups disappear from the two center teeth below. 'At seven the black cups from the next two disappear from below. At eight years old the black cups from the two corner teeth disappear. At nine years old the black cups from the two center teeth above go out. At ten years old the black cups from the two next teeth above are smooth. At eleven years old the two corner teeth above are smooth. At twelve years old a groove starts at the gum margin but is not noticeable before the horse reaches thirteen years old. This groove will travel about one eight the length of the tooth till the horse ge's twenty one yea's old, then we can te'1 no more. 


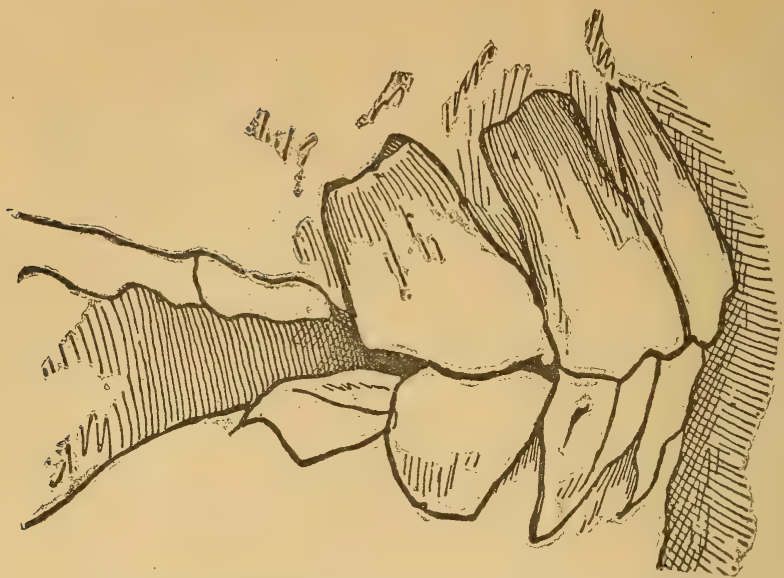

No. I. Showing Mouth at 4 Years of Age.

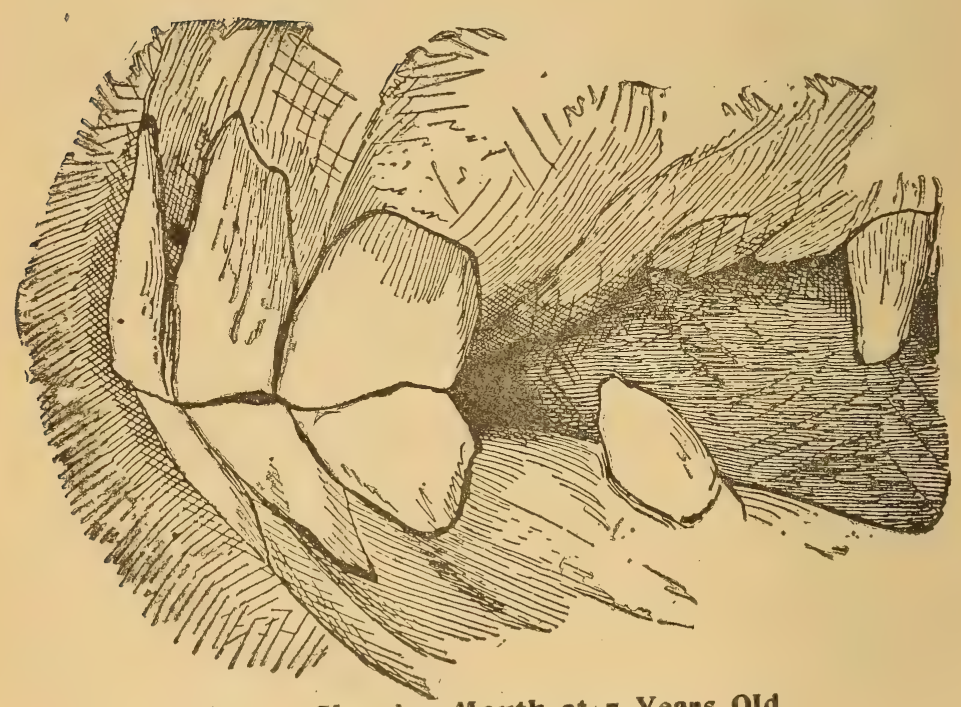

No. 2. Showing Mouth at 5 Years OId, 


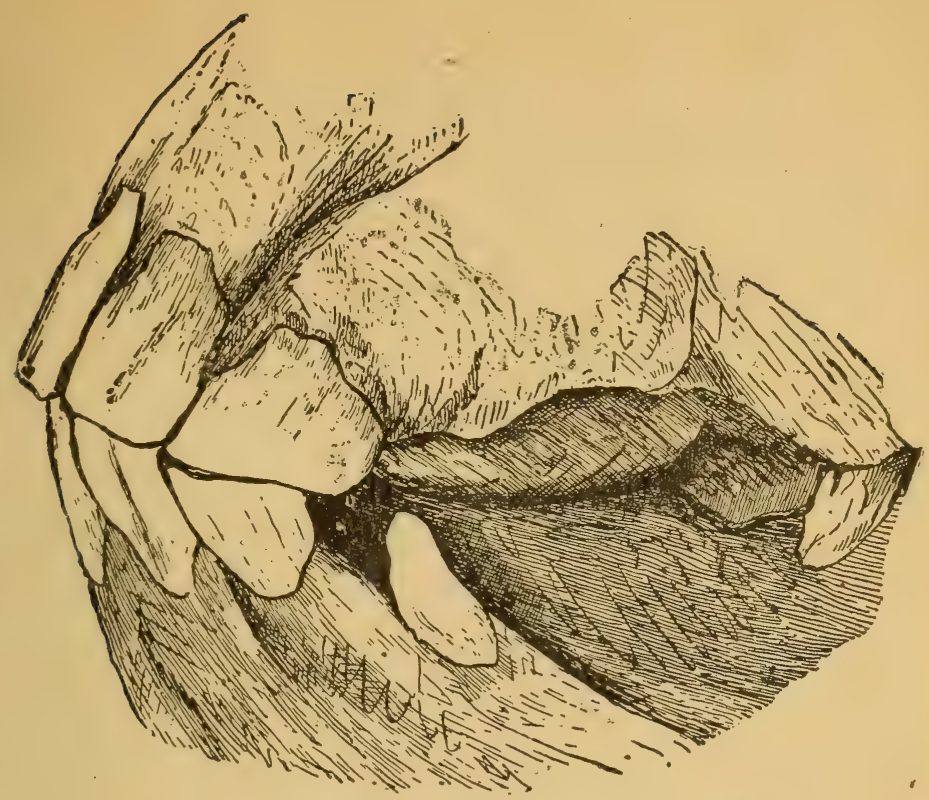

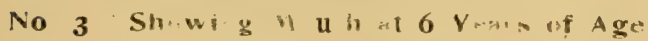

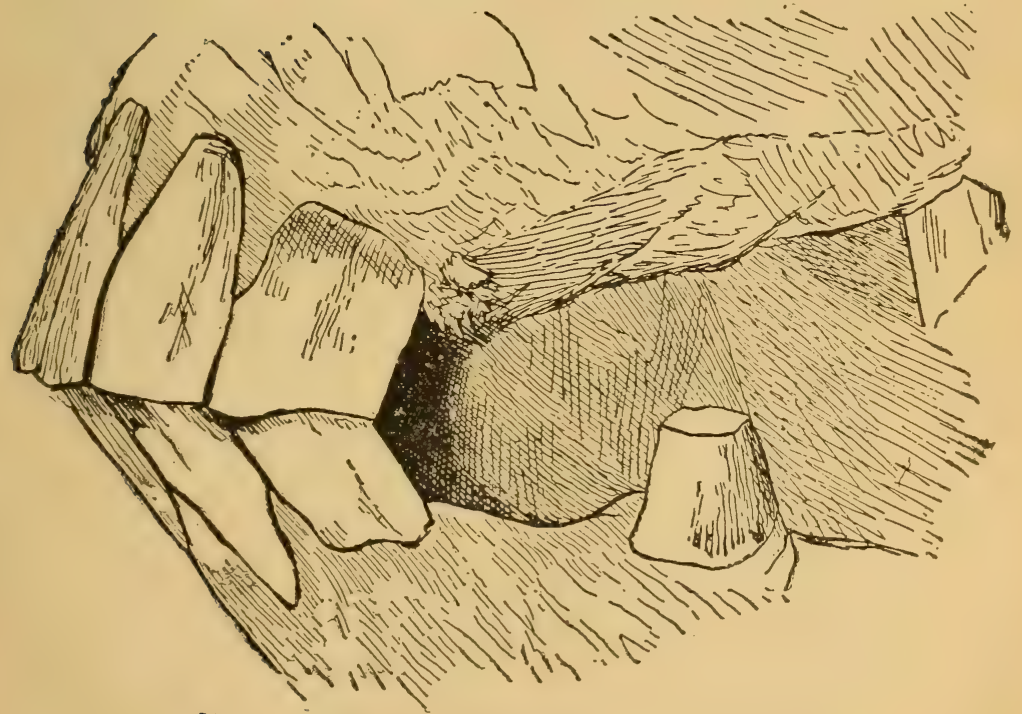

No. 4. Showihg Mouth at 7 Ye-rs of Age 


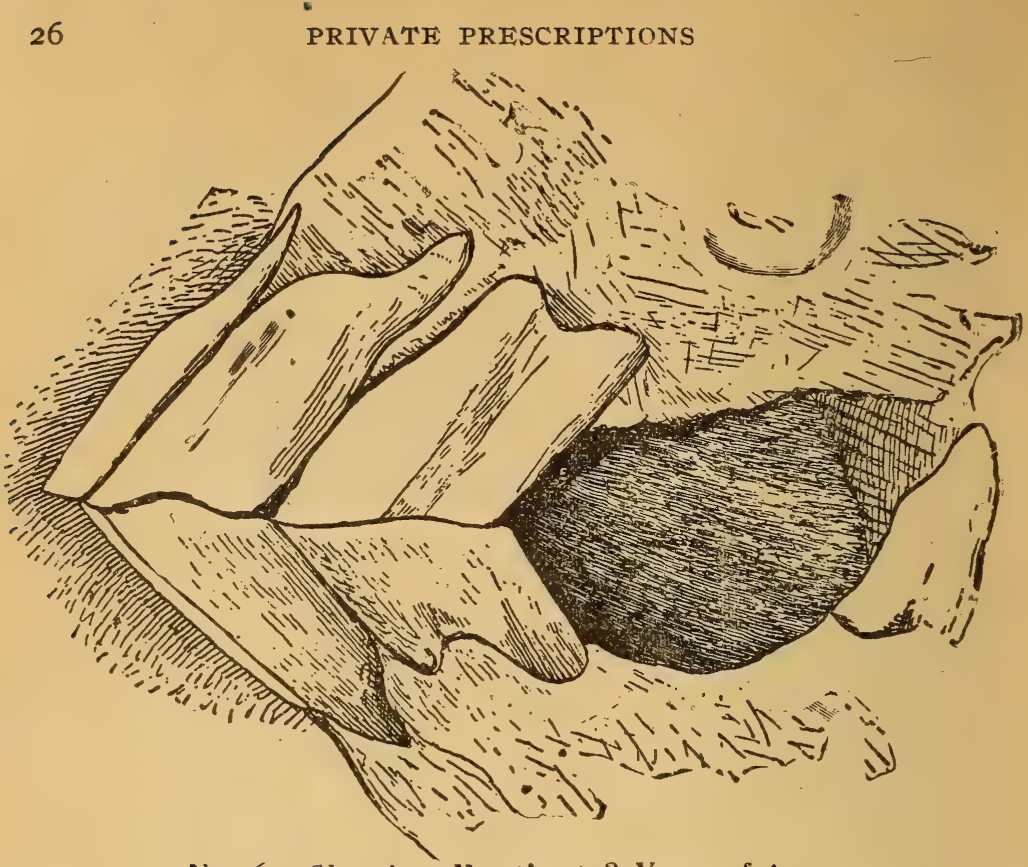

No. 6. Shewing Mouth at 8 Years of Age

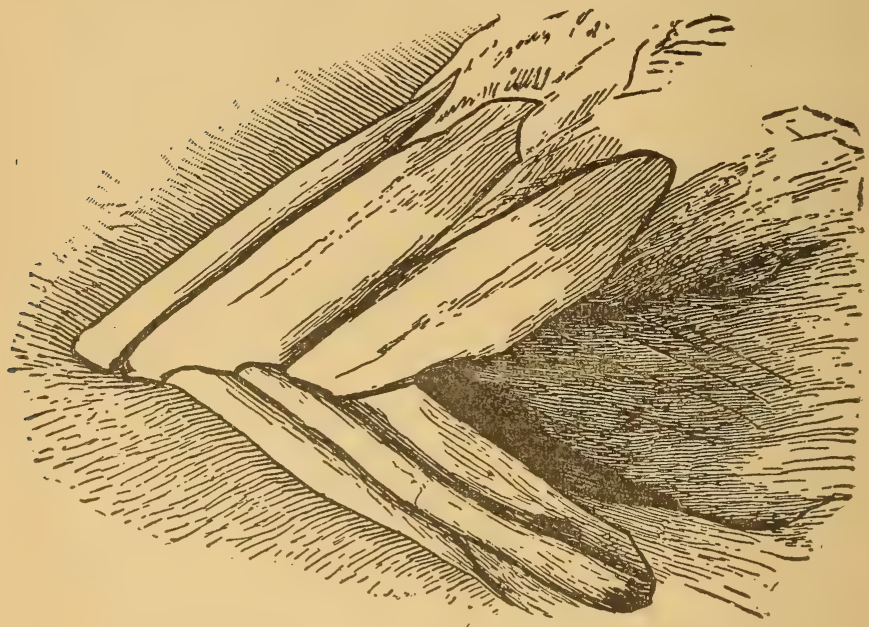

No. 7. Showing Mauth at 20 Years of Age. 


\section{DISEASES OF THE TEETH, MOVTH AND THROAT.}

Under this head we will consider everything of importance in connection with these organs, and form those affections of the throat, which are intimately connected with, and have a direct bearing upon the air passages.

\section{Sharp, Irregular, Uneven and Elongated Teeth.}

Eitber of these is worthy of our careful attention, for they often prevent a horse from properly masticating his food, and in some instances make eating a very difficult accomplishment.

Cause-These irregularities are usually produced by a res tention of the milk teeth beyond the time when they should be shed, by the uneven wearing away of the permanent teeth in masticating hard food, and through a lack of proper acclusion.

HOW TO KNOW THEM.

A sight of the animal when trying to eat in connection with an examination is sufficient.

\section{WHAT TO DO.}

Cut teeth down evenly and smoothly, being careful to leave no sharp corners. This is accomplished by means of an instrument called a "float," which resembles a coarse file or rasp. If there is an irregular or elongated tooth, which precludes the possibility of establishing a propped acclusion by floating, extraction should be resorted to. 


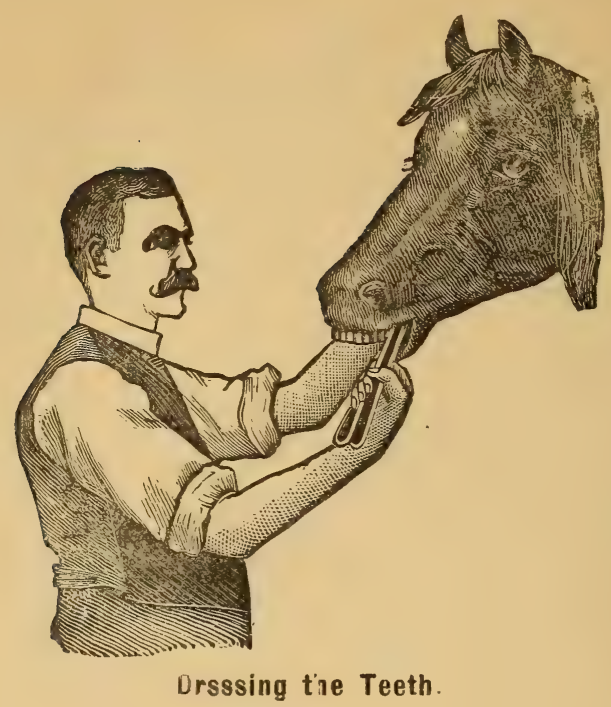

Tooth Ache.

The tooth ache is of more common occurrence in the horse than is generally supposed and it very often produces a condition, with reference to the health of the animal, of grave importance. No horse is in trim to perform his full complement of work when he is stopped from eating his daily ration by the pain engendered in the act from an exposed and irritated nerve, neither is he fit for service when racked and tortured by the excruciating and deep seated pain of an abscess on the fangs of a decayed tooth.

Cause-It is brought about most generally by the formation of a cavity through common decay, and occasionally from a kick or blow upon the mouth by which the teeth 
are cracked, broken or otherwise injured. Sometimes injuries to the teeth are the results of efforts at masticating very hard corn.

HOW TO KNOW IT.

The action of the horse while eating, coupled with an examination of his teeth, will disclose the trouble; he will throw it from side to side as if trying to remove food from a sore in the mouth, and act much the same way when drinking cold water. He loses flesh rapidly from being unable thoroughly to masticate his food. If there is ulceration or abscess of the tissues surrounding the fang of a tooth; we often find an enlargement or swelling which contains pus. Occasionally this abscess breaks into the nose, causing a discharge from the nostril on same side as diseased tooth. On account of the disagreeable odor emitted, a discharge of this kind is sometimes taken for Nasal Gleet, and occasionally for Glanders. A careful examination of the teeth, and a reference to chapter on Gleet and Glanders, in this work will demonstrate the wide difference in these troubles.

WHAT TO DO.

If, after a careful examination, you are satisfied that the patient is suffering from an affected tooth; immediate extraction is the proper thing to resort to.

\section{Lampas.}

This is simply congestion lof the buccal membrane and 
is accompanied by more or less tumefaction, which is more particularly noticed in the bars of the mouth.

Cause-In old horses we attribute this condition to irritating substances or medicines, while in colts it is generally the result of teething.

HOW TO KNOW IT.

The bars of the mouth will be swollen, sometimes extending below the teeth. In bad cases there will be a constant flow of saliva, and the horse can not masticate his food properly, and in many cases the breath is very offensive.

$$
\text { WHAT TO DO. }
$$

Scarify the first bar well with some sharp instrument, and rub in coarse salt for three consecutive days. Never cauterize for Lampas.

\section{Sore Mouth.}

This trouble is quite common, and is in most instances the result of neglect or carelessness.

Cause-Very often a sore mouth is produced by the use of a severe bit; occasionally by the caustic properties in either food or medicines, and sometimes from grazing when the dew is heavy.

HOW TO KNOW IT.

It is a very easy matter to look into a horse's mouth and discover an irregularity of this kind. When the bone or 
roof of the mouth is injured, we will find considerable soreness and some swelling.

\section{WHAT TO DO.}

In case the trouble arises frow bit used, try another of more gentle persuasion, or else keep it out of mouth entirely for a few days. If properties in food or medicine are cause, make a change in them, and in case the trouble comes from grazing when dews are on, keep patient off of pasture until the sun is well up in the morning and lot him before dew falls in the evening. To remove the cause is generally sufficient to effect a cure, but in the event the mouth is raw, and you desire to aid nature, use the following:

PRESCRIPTION.

Acid Tannic . . . . . . one half ounce.

Acid Acetic Dilute. . . one ounce.

Water, add sufficient quantity, one pint.

Mix and apply 3 times a day as a lotion to the mouth.

In case the bone is injured or exposed cleanse it well 3 . or 4 times a day with carbolized water.

\section{Tongue Laceration.}

Though of uncommon occurence, it is well that we understand how to treat such a condition to the best advantage.

Cause-In falling, an animal sometimes has his tongue between his teeth, and by this means it is bitten; again he strikes his mouth against something and the tongue is 
injured. The bits or a sharp molar tooth are in some instances the cause of laceration.

HOW TÖ KNOW IT.

A sight of the tongue will readily convey to the mind of any one what the trouble is.

\section{WHAT TO DO.}

Wounds of the tongue heal very quickly and satisfactorily, but they do not always heal as evenly and smoothly as we would like. In severe cases where a portion of the tongue is torn or cut more than half off, it is advisable to cut severed portion entirely away and use the following:

\section{PRESCRIPTION.}

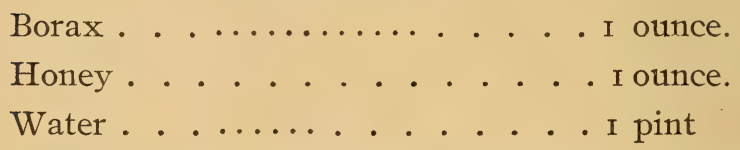

Mix and apply to wound (after drying it) 3 or 4 times per day.

\section{Pharyngitis.}

By Pharyngitis is meant an acute inflammation of the Pharynx, which is an organ situated at the back part of the mouth and is the connecting link between it and the tube leading directly into the stomach.

Cause-It is usually brought about through some foreign substance, such as oat straw or wheat beards, lodging in its passage from the mouth into the esophagus, the latter being the tube leading to the stomach. 
HOW TO KNOW IT.

We find the throat and glands of the neck more or less enlarged, considerable tenderness upon pressure, neck stretched and head extended. It will be noticed that it is very painful for the animal to swallow, if indeed he can do so at all. In his efforts at drinking, water returnis by way of the nose. This desease presents many of the symptoms which are found in Laryngitis, a disease of the air passage, but is much easier controlled; about the only difference of any note in the symptoms of the two are the hacking cough and high fevers found in Laryngitis. The treatment employed is very similar in both diseases.

WHAT TO DO.

First, examine the throat and if any foreign substance be found, remove it. After this is done apply a counter irritant to outside of throat. A mustard plaster is good, and the following has been used with considerable success by the author:

\section{PRESCRIPTION}

Ammonia Liquor .........

Turpintine, Oil of ........

Linseed Oil, each : ..... 2 ounces.

Mix and rub in well once per day until blistered.

In case patient should have any fever use 
PRESCRIPTION.

Aconite, Tincture of . . . one drachm

Niter, Spirits of ..... I I-2 ounces

Potash, Nitrate of . . . . I I-2 ounces

Water, add sufficient quantity . . . I pint

Mix and give one tablespoon every 2 hours until fever gives away. Give soft feed, such as bran mash, and in case patient cannot swallow this, try him on meal gruel in the way of a drench. Should this fail, injections of oat meal gruel into :he rectum must be depended upon. Prepare this same as for table.

\section{Choked Horses.}

While an uncommon occurence, yet we occasionally run across a horse that is choked, and it becomes our duty to relieve him, when such a course is possible.

Cause-The lodgment of anything in the throat. In most instances it is caused by eating dry food, such as thrashed oats, fodder, hay, etc., without these being properly incorporated with and moistened by the saliva. These accumulate in great lumps in the gullet, usually about six inches below the pharynx.

HOW TO KNOW IT.

There is little room for mistake in diagnosis when a horse is "choked, for his every act plainly indicates the trouble. We notice the choked horse elevating his head and stretch- 
ing his neck, he is coughing hard at intervals, as if trying to expel something from the throat, and the saliva runs freely from both sides of the mouth. In some instances the flanks are distended.

\section{WHAT TO DO.}

Make a thorough examination, and if obstruction can be reached, remove it with either hands or forceps. Should you fail in your efforts at removing it in this way, administer a few swallows of raw Linseed oil, a half dozen raw eggs; if these do not soften lump and lubricate gullet sufficient to allow it to pass on to the stomach, force must be used. There is a probe made expressly for work of this kind, but a smooth buggy whip well greased, or small rub. ber tube is all right. By exerting gentle pressure with probe upon obstruction, it can in most cases be readily forced into the stomach. Great caution must be exercised in introducing any of these things into the throat, to avoid pushing them through the walls of the gullet, and never allow them to remain for longer than a minute at a time, as the patient cannot breathe with an instrument of this kind in his throat. 


\section{CHAPTER II.}

\section{Diseases of the Respiratory Organs.}

It is very essential that diseases confined to these organs should have prompt and careful attention, for in very many instances the life of the animal depends upon our efforts in this direction. Intelligent treatment, coupled with every advantage of disease, with reference to duration should be our motto.

\section{Tumor in the False Nostril.}

The false nostril is a small pouch on the inside of the lower edge of either nostril. Tumors sometimes form here and partake more of the nature of abscesses, in that they are filled with pus of a cheesy consistency, but are tumors in that they form slowly and do not point and break like an abscess.

Cause-We can give no satisfactory reason for a malady of this kind. It may come from an external injury and again the cause may arise through a lack of functional activity upon the part of some of the sebaceous glands. 


\section{HOW TO KNOW I'T.}

A small swelling is often apparent on the outside, but the main dependence is to be placed in an examination of the nostril, when it will be found almost closed by an enlargement, generally about the size of an egg; there is no soreness, but we notice more or less wheezing in the act of breathing, this being due to the diminished capacity of the air passages.

WHAT TO DO.

There is not the slightest danger in operating here. Cut into tumor from inside of the nostril, making a free opening for the pus to escape. Wash out wound thoroughly 2 or 3 times a day with carbolized water.

\section{CATARRH.}

Some writers treat this subject under three different heads, viz: Acute, subacute and chronic, but for all practical purposes I think a more simple classification justified, hence we consider it as being only acute and chronic.

\section{Acute Catarrh.}

This is an inflammation of the mucous membrane of the nostrils; it is simple in itself, but all inflammations of the air passages are liable to extend to the bronchi and lungs and thus produce bronchitis or pneumonia, either of which is of serious import.

Cause-Exposure to raw winds, cold rains and snow 
storms, more particularly when the animal is exhausted from overwork, or is overheated from any cause.

HOW TO KNOW IT

First we notice sneezing and shaking of the head, which are in many instances signs of pain in the horse; these are followed by a change in the mucous membrane of the nostrils from the normal pink to a deep red color. Soon a watery discharge from the nose makes its appearance, but changes in a few days to a mucilaginous state of yellowish-white color and may be profuse. The temperature rises, pulse runs from 44 to 60 beats to the minute, the fever depending upon the amount of surface involved. The appetite is often lost and the patient becomes debilitated; he does not cough unless the throat is affected, but expels air through his nostrils often in a manner which may be aptly called "blowing his nose." In very acute cases we find the eyelids swollen considerably as seen in pink eye and tears flow freely over the cheeks.

WHAT TO DO

Shelter well and blanket if necessary; give soft feed and plenty of fresh well water to drink. Syringe out nostrils 3 or 4 times a day with carbolized water and should throat become affected apply mustard plaster on under side from ear to ear. If pulse should go over 50 beats per minute use this: 


\section{PRESCRIPTION.}

Aconite Tincture of........... I drachm

Belladonia Fluid extract of . . 2 drachms

Water, use a sufficient quantity . . 4 ounces

Mix and give one tablespoon full 3 or 4 times a day and should there be a lack of appetite try the following as a tonic:

PRESCRIPTION.

Potash Nitrate of . . . . . . 2 ounces

Potash Bi-tartrate of ..... 3 ounces

Iron Sulphate of . . . . . 2 ounces

(Black) Atimony . . . . . I ounce

Sulphur . . . . . . 8 ounces.

Mix and give a tablespoon full once per day.

\section{Chronic Catarrh or Nasal Gleet.}

The seat of this desease is usually the sinuses of the head. Some care must be exercised in passing upon the troubles of this kind as horses have been condemned as glandered when there was no ailment aside from "nasal gleet." Study well in connection with this disease the symptoms of glanders and you will be competent to render a safe opinion whenever called upon. Most generally the health of the animal suffering with chronic catarrh is not materially affected unless the case be of long standing.

Cause-Neglected or obstinate acute catarrh which fails. to yield to treatment. 
HOW TO KNOW I'T.

It is manifested by a presistent discharge of a thick white or yellowish-white matter from one or both nostrils most commonly from one. This discharge may be intermittent, some days great quantities being thrown off and again very little if any. The eye on same side as discharging nostril may present a peculiar appearance and look somewhat smaller than its fellow on opposite side. There may be an enlargement or bulging of the bone over affected part between and below the eyes. The breath may be offensive, but this is very unreliable as it may come from a bad tooth. When you tap on the bones between and below the eyes and above the back teeth if the sinuses are filled with pus the sound emitted will be the same as if you had struck a solid substance, but if not we get a hollow drum like sound. In this disease we do not have the ragged sores found on the mucous membrane of the nose in glanders. There may be a dry cough and sometimes loss of appetite.

WHAT TO DO.

If there be no bulging of the bone and sinuses are not entirely closed by inflammation, syringe out nostrils well night and morning with carbolized water. When this is done take a pail of hot water and hold it under patient's nose forcing' him to inhale the steam as it rises. Stir water in pail with a twig and steam will pass off much more rapidly than if left at rest. Give internally: 
PRESCRIPTION.

Iron Sulphate of . . . . I and I I-2 ounce Potash Nitrate of . . . . . . I ounce

Gentain powdered...... I ounce Blood Root....... I and I-2 ounce

Mix and divide into I6 powders; give one night and morning. In case the sinuses of the head are closed and bulging of the bones has taken place, trephining is the only course left open, but this is a very difficult operation and will require the services of a skilled veterinarian. (See chapter on operations.)

\section{Pharyngitis.}

This is an infiammation of the larynx, an organ situated at the upper part of and is continuous with the wind-pipe. It is what is familiarly known as the "voice box" in man.

Cause-Exposure, standing in cold draft of wind when warm; driving animal until he is hot and then allowing. him to cool quickly.

\section{HOW TO KNOW IT.}

There is short, hurried breathing which may assume a noisy character and the patient sometimes seems as if threatened with suffocation. The cough which is usually the first symptom noticed is a dry hacking one. A violent fit of coughing may be induced by exerting pressure upon the larynx. In some instances the difficulty in swallowing is so great that water and sometimes food are returned. 
through the nose. The head is generally poked out and carried stiffly, and saliva dribbles from the mouth. The temperature commonly runs from $\mathrm{IO}_{2}{ }^{\circ}$ to $\mathrm{IO}_{4}{ }^{\circ}$ and pulse will be found quick and small, running from 55 to 75 beats per minute, depending upon the amount of fever.

WHAT TO DO.

Clothe warmly and shelter from storms. Rub mustard paste well in on throat from one ear to the other, and should this fail to give the desired relief in twelve or fourteen hours, try a Linceed meal poltice, having it as hot as patient can bear it. In all cas commence to steam the head with boiling water, with one tablespoonful of Spirits of Turpentine in it. Let him inhale it for fifteen or twenty minutes at a time every one or two hours until he gets relief If the pulse should run up to 55 or 60 beats per minute, give this for a $f$ days:

PRESCRIPTION.

Belladonna Fluid Extract of . . . 2 drachms Aconite Fluid Extract of . . . . I drachm Water, add sufficient quantity, . . . 4 ounces

Mix and give one tablespoon full every 2 or 3 hours, as the case needs it. You will always find the throat sore on ithe inside of the mouth. So use this as a gargle:

PRESCRIPTION.

Tincture Ferri Chlorate.... I-2 ounce 
Chlorate of $\mathrm{Po}^{+}$ash...... I ounce Glycerine . . . . . . 2 ounces Tincture Aconite. . . . . . I drachm Water, add to make. . . . . I2 ounces

Mix. Use as a gargle 4 or 5 times a day. Give the patient one tablespoon full of Nitrate of Potash in the drinking water twice a day; then give this Prescription night and morning:

Quinine Sulphate...... I-2 ounce

Gentian (powdered)..... 2 ounces

Sulphate of Iron . . . . . I and I.2 ounces

Mix and divide into 8 powders and give one night and morning. When the patient begins to recover, the following tonic will prove beneficial in this, as well as most all other troubles where the appetite is involved or the blood is bac:

PRESCRIPTION.

Mustard (ground)...... 4 ounces

Sassafras Bark (powdered)... 2 ounces

Sulphur......... 3 ounces

Gentian (powdered) . . . . . I ounce

Foenugreek (powdered). .... I ounce

Antimony, Black...... I-2 ounce

Mix and give one tablespoon full once a day in bran mash, and then give the patient several days rest. 


\section{Quinsy.}

Quinsy in the horse is nothing more than laryngitis of a superative type. This disease resembles tonsilitis in the human family.

Cause-The inflammation in laryneitis is occasionally of such a deep seated and persistent nature as that there is a breaking down of tissue, and abscesses form, quinsy being the result.

HOW TO KNOW IT.

We find all the symptoms of laryngitis. The throat swell's and gets very sore, the patient refuses to eat and generally has a small amount of fever which runs along from day to day until abscess breaks when there is a flow of pus and the sufferer gets almost instant relief.

WHAT TO DO.

We can do but little, aside frum treating as we would laryngitis. Nature seems to take her own good time in assisting these abscesses in pointing and breaking. Should the patient get beyond eating or drinking and stay in such a condition for any great length of time it becomes our duty to.administer nutriment by way of the rectum. Large injections of water through this channel will quench a burning thirst. 


\section{BRONCHITIS}

Bronchitis presents itself to us in different forms, hence we classify it in'o Acute and Chronic, and study each under a seperate head. In some sections of the United States these troubles are very prevalent, and it can in no way prove a waste of time for us to study them closely.

\section{Acute Bronchitis.}

This is simply an acute inflammation of the bronchi, these being the tubes or passages leading from the wind-pipe into the lungs.

Cause-The causes of this irnuble are much the same as that of those diseases of the air passages. previously described.

HOW TO KNOW IT.

Generally we find a chill to be the first sign of this disease, but it is not always observed, this passes off and the reaction brings on fever, the temperature rises, the nostrils are distended and breathing is short and hard; at first there is a dry "barking" cough. The membranes of the nose are red; the patient will stand with his head down and won't move around much; his appetite is 1ndifferent and his ears and legs are cold $\pi$ hen we place our ear to chest of fatient we hear a thick unnatural cound, a kind of hissing or wheezing when small tubes are affected, and a cooing or suoring when the larger ones are involved All of the symptoms may be observed in first ten hours, and 
in the next twenty-four the pulse may go up to 65 or 70 beats a minute, and temperature to $104^{\circ}$ or $105^{\circ}$; the pulse will be small but freqnent. The cough will increase but will be of a moist rattling character. Urine will be highly colored and scanty.

\section{WHAT TO DO.}

If initial chill is observed, give immediately aud at one dose four ounces of good brandy in a pint of warm water. When this is done wait an hour and begin the following:

PRESCRIPTION.

Aronite, Tincture of . . . . . I drachm

Belladonna, Fluid extract of . . 2 drachms

Nitre, Spirit of . . . . . . I ounce

Water, q. s. ad . . . . . . 6 ounces

Mix and give one tablespoon full every 2 or 3 hours as indicated, In case the pulse should, at the expiration of twenty-four hours, run above 60 beats per minute change your treatment to this:

\section{PRESCRIPTION}

Nitre, Spirits of . . . . . I I-2 ounces

Ammonia, Muriate of . . . . I-2 ounce

Aconite, Tincture of . . . . . I dráchm

Belladonna, Fluid extract of . . . 2 drachms

Gentain, Tincture of . . . . . I ounce

Water, q. s. ad ....... r6 ounces

Mix and give 3 tablespoon full every 2 hours until pulse 
approximates 50 beats per minute, and has a downward tendency. Give patient fresh air to breathe and bave plenty of clean water by all the time. If there is much soreness of either lungs or throat use this:

\section{PRESCRIPTION.}

Turpentine, Spirits of . . . . 3 ounces

Camphor (gum)......3 drachms Cedar, Oil of . . . . . . . I ounce Sassafras, Oil of . . . . . . I ounce Alchohol . . . . . . . . 4 ounces

Mix and bathe freely parts directly over soreness, and sbould this blister, rub in well once it day fresh lard Use same constitutional tonic as reccommended in laryngitis.

\section{Chronic Bronchitis.}

Cause-From taking cold on the acute form not having been treated at the proper time and in the right way. I sometimes think it is brought on through an animal eating food stuffs containing either dust or smut.

HOW TO KNOW I'T.

There is a confirmed cough, more or less severe in character and sometimes a discharge from the nostrils. The cough usually seems worse early in the morning, or when patient is subjected to exercise than at any other time. The temperature will be about normal, and the pulse will run from 42 to 45 beats per minute being full and regular. When the ear is placed to the chest we dis- 
tinguish a rattling rubbing sound, more, llke passing the hand over a piece of dry paper than anything else. There will be heaving of the flanks and shortness of breath from the mere presence of these, this trouble is often taken for heaves. With chronic bronchitis a horse can do moderate work and stay in fair flesh.

WHAT TO DO.

Avoid long drives and be cautious about feeding too much bulky food. Give soft feed and pure water in liberal quantities. Be sure that you dampen every particle of feed allowed and let patient run on grass as much as possible. Give the following:

PRESCRIPTION.

Aloes Barbadoes . . . . I and I-2 ounce Potash Nitrate of . . . . . . 2 ounces

Potash Chlorate of . . . . . 2 ounces

Blood Rorit (powdered). . I and I-2 ounce Lobelia Seed (powdered). . . I ounce Tartar Emetic....... 6 drachms Nux Vomica (powdered)... 3 drachms Mix and divide into 6 powders and give one every night.

\section{Pneumonia.}

Pnenmonia is an acute inflammation of the tissues of the lungs; it is by no means rare and is most commonly con- 
fined to the right lung. Horses may have it at any season of the year, but it is most prevalent in winter or early spring. Bronchitis is a common cumplication with pnuemonia.

Cause-The cause of pneumonia is much the same as that of the other diseases of the air passages with the cold settling upou the lungs instead of elsewhere.

HOW TO KNOW IT.

First, the shivering chill in which there is a rush of blood to the lungs followed by high fever, the temperature running up to possibly ro5 $5^{\circ}$ or $106^{\circ} \mathrm{F}$. The pulse will run anywhere from 55 to 65 beats per minute and upward, the pulse will be soft and weak. The tips of the ears, and feet and legs will be cold. The urine will be scanty and a high color. The breathing will be hot and laborious; the number of respirations runnning up to 25 or 30 per minute, and the hair of the animal looks dry and dead; he stands with his head down and his appetite is poor. By placing your ear over the affected lung, (which is on the right side) you will observe a dry cracking sound, something like salt thrown on fire. These symptoms are usually present for the first twenty-four to forty-eight hours and sometimes longer before it reaches the second stage of the disease. These symptoms are seen in the first stage or the stage of congestion, the second stage or stage of red, hepatization. On examination there is a loss of the expansive powers of the chest, on affected side, the respira- 
tions are had and painful in character, on percussion there is a dull sound observed over the affected lung, which the sound will be like tapping a barrel full of water, then place your ear over the affected lung the reis no respiratory murmur heard. The lungs seem to be hard like liver, the pulse will stand at about 65 to 70 beats per minute the breathing will be from 30 to 40 per minute and he will stand on his feet all the time and never lay down. When he gets to where he will lay down you can look for a speedy recovery. The horse will live any where from i 2 to 25 days, without any treatment before he dies.

In the third stage the affected lung becomes more moist and the pulse get faster and weak runs to 75 to 85 beats per minute and the temperature will stand at about ${ }_{102}{ }^{\circ}$ to Io3 ${ }^{\circ}$, On placing your ear to the affected side there will be a moist wheezing sound heard, on pescussion the soundness will be found to be getting less marked.

\section{WHAT TO DO.}

First if you find the patient with the chill on him, blanket him well, and put him in a comfortable place as possible with plenty of fresh air to breathe, but always avoid a draft, and allow plenty of good water to drink. While the chill is on him give him a stimulant about four ounces of good brandy or whiskey in half pint of warm water. If you don't see him with the chill on, give this until you get the fever reduced. 
PRESCRIPTION

Spirits Nitre....... 2 ounces

Tincture Aconite . . . . . . . 2 drachms

Tincture Opium ......2 ounces

Water to make....... 4 ounces

Mix and give one ounce every hour in half pint warm water; if the cough is very bad and the patient seems to be suffering much pain, give him a few doses of the following:

PRESCRIPTION.

Tincture Opium .......2 ounces

Tincture Digitialis . . . . . I drachm

Water to make...... 4 ounces

Mix and give one ounce at a dose every hour in half pint of water. Should the patient become constipated, give the following physic:

\section{PRESCRIPTION.}

Aloes Barbadoes . . . . . 4 drachms

Linseed Oil, (raw) . . . . I pint

Mix and give at one dose and repeat in 24 hours if bowels don't move.

In the second and third stages of this disease you want to watch the heart and fever, give patient stimulants, such as Alchohol or good brandy in 2 to 3 ounce dose, 4 or 5 times a day, after the patient gets on the road to recovery and the appetite is coming brck give the following as a tonic to build him up. 
PRESCRIPTION.

Quinine . . . . . . . I-2 ounce

Sulphate of Iron . . .... 2 ounces

Gentian ........ 2 ounces

Foenugreek ........ I ounce

Mix, divide into I2 powders and give one night and morning in bran mash, let him have plenty of exercise but keep him in the dry, in bad weather.

\section{Distemper.}

While I am willing to admit that when the morbid condition of an animal is such as to favor direct transmission this disease may prove infectious, yet I cannot accept the theory of many writers upon the subject who contend that it is a contagious blood disease. Its attacking and running through an entire herd of horses, I will admit, is evidence in favor of the theory of contagion, but this is by no means proof positive, for in all probability every horse of the herd has been subjected to the same identical conditions. But no matter whether it be contagious, infectious or of spontaneous origin the vital fact remains that stock have it, and it becomes our duty to study methods for getting rid of it.

Cause-The cause of distemper is entirely problematical; it may arise spontaneously, and again it may be the result of cold. One thing we do know and that is the fact of its being more prevalent in low damp sections of the country than upon higher ground. 


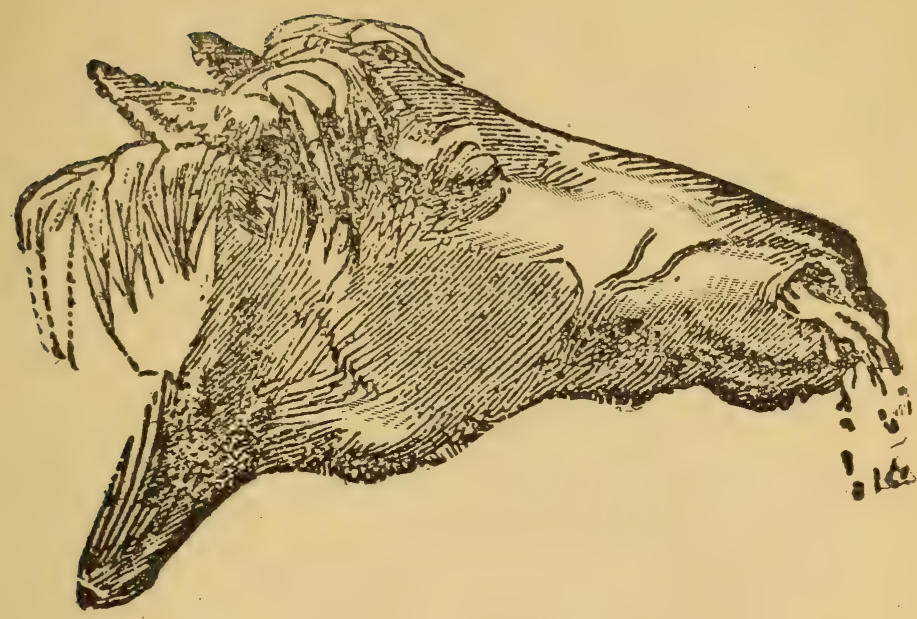

In Third Stage of Distemper.

HOW TO KNOW IT.

The coat of a distempered horse is usually dry and uneven; he suffers from loss of appetite and is in many instances apparently prostrated. The pulse will be quick and weak and the temperature will run up to IO2 ${ }^{\circ}$ or IO $3^{\circ}$. The feet legs and tips of ears are cold. In two or three days the throat begins to swell on both sides and sometimes between the lower jaws; this swelling is in some cases enormous, causing sufferer to hold his head and neck stretched like a child with mumps. There is usually a cough and inability to swallow, with a discharge from the nose which takes on a purulent character in a very few days. The eyes are weak and watery. The swelling referred to is painful and sore upon pressure being applied and in most cases it breaks within a week or ten days 
discharging pus. If the lungs should become involved we will by auscultation distinguish a wheezing sound.

\section{WHAT TO DO.}

Keep the patieni as comfortable as possible and use the following:

Alum, (powdered) . . . . . 2 ounces

Blood Root, (powdeered). : . . I ounce

Gentian (powdered) . . . . . I ounce

Mix well and divide into 5 powders, give one the first night, skip the second day entirely, "on the third day give one morning and night, skip the fourth day and give one each night of the fifth and sixth days successively. Bathe the throat of patient thoroughly with this liniment:

\section{PRESCRIPTION}

Turpentine, Spirits of ....3 ounces Camphor Gum ....... 2 drachms Cedar, Oil of ....... I-2 ounce Ammonia, water of ..... I-2 ounce Water, add sufficient for . . . . 6 ounces

Mix and apply to throat 2 or 3 times a day, and should it seem to blister, grease with hog lard. If abscess forms and there is an indication of pus in the tissues of the throat make an incision directly over abscess and in line with the hair about a half inch deep and one and a half inches long, this is generally sufficient to reach the pus. Cleanse wound thoroughly three times a day with carbol- 
ized water and give in connection with other treatment the general tonic recommended in laryngitis. Should the lungs become involved and the pulse run as high as 55 or fo beats per minute, give the following:

\section{PRESCRIPTION.}

Opium, Tincture of ..... I ounce Aconite, Tincture of . . . I drachm Belladonna, Fluid Extract of . . . 2 drachms Niter, Spirits of . . . . I and I-2 ounces Water, add sufficienty quantity . . . 4 ounces

Mix and give two tablespoon full every hour until pulse comes down to 50 beats to the minute, then discontinue. See that bowels of patient are kept open; if they are in the least costive use purge reccommended in case of pneumonia.

\section{Heaves}

This is one of the most dreaded diseases with which stock are afflicted. To understand why this is so we have but to turn our attention to the lungs for a moment to be able to see why it is that nature's herculean efforts as well as our own feeble ones fail to relieve it. The lungs are composed of tissues fibrous in character and innumberable small air cells; the tissues are endowed to a very great extent with the properties of elasticity and contractility. By virture of these peculiar properties the tissues of the lungs are capable in a great measure of expelling air from and drawing it into them without any effort upon the part of an animal. Sometimes many of these small air cells are 
ruptured, larger ones being thus formed by reason of the fact that they break into each other. When this happens that portion of the lung involved loses largely its power of involuntary contraction; in this event the diaphragm, ribs and abdominal muscles are brought into play in expelling air from the lungs, the exercise of these giving rise to the twitching seen in the fianks.

Cause-It is sometimes produced by rapidly driving in the face of heavy wind, particularly when the horse is not in condition to stand it; and it may be brought on by exercising too freely when the stomach of the animal is too full of bulky food to allow free expansion of the lungs. Again it may be caused by too violent exercise when the lungs are weak from cold, a severe spell of sickness or where the horse has been fed on dusty or smutty food.

HOW, TO KNOW IT.

There will be a deep cough, and instead of the regular, easy breathing there will be a twitching of the muscles of the flanks or a kind of secondary effort upon their part at every respiratory act. The nostrils will be distended, and by auscultation we observe a popping, crushing sound. When this sound is heard we can not be mistaken, for it is present in no other disease. An animal thus affected will have no fever, the pulse will run a little aboye normal, however. If you are buying or trading for a horse that you have any reason to suspicion is one that the heaves have been "shut down" upon, (as the jockeys call it) I would

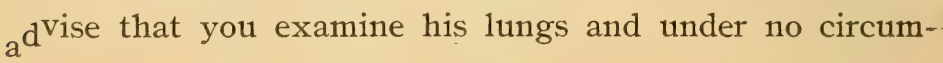


stances buy or trade for him if this popping, crushing sound be present, unless you naturally wish to posess an animal with this malady. The cough and hard breathing can be gotten rid of for a short time, but no jockey can rob a horse for a minute of the above sound when he has the heaves.

\section{WHAT TO DO.}

A well developed case of the heaves can not be cured, but can be helped by careful feeding. Always feed with a riew of getting the greatest amount of nourishment from the smallest amount in weight and bulk of food, and be sure to dampen every particle of dry food the patient gets. If grass in pasture be green and growing it is a good idea to follow free range, but if grass be dead this is not a good plan. Allow no access to stalk-fields at any time. To relieve the cough and improve the general health the following can be used with benefit:

\section{PRESCRIPTION.}

Lobelia Seed, (powdered) . . . 2 ounces

Blood Root . . . . . . . . . I ounce

Gentian. . . . . . . I ounce

Linseed Meal. . . . . . . 2 ounces

Mix and divide into I 2 powders, give one night and morning. After giving these, rest for a week or ten days and repeat. Heaves in the first stage can be cured. We recognize the first stage by the presence of every symptom of a well developed case aside from the popping, crush- 
ing sound. When this peculiar sound is absent we can rest assured that the air cells hare not been ruptured, and we may effect a cure if we will but treat the patient right and employ the following in the way of internal treatment:

PRESCRIPTION.

Aloes Barbadoes. . . . . I and I-2 ounces Potash, Chlorate of ...... 2 ounces Potash, Nitrate of ...... . 2 ounces

Tartar Emetic.............6 drachms

Nux Vomica, (powdered) . . . 3 drachms

Gentian................ drachms

Mix and divide into 12 powders and give one a day. Dampen all feed and under no circumstances must patient be exercised severely.

In some states it is a violation of the law to tamper with the heaves for trading purposes, and it should be. I do not give the following with the intention of assisting any one in an illegitimate practice, but as a means of protection, I merely let the reader know how they are usually "shut down". About ten grains of extract of Stramonium wrapped around the bits in a piece of cloth will stop heaving of flanks and cough and have animal ready for trade in ten or fifteen minutes; this does not stop the characteristic sound of heaves observed in the chest. An animal should not be exercised very much, nor allowed to get too hot, or drink to much water for several hours after Stramonium has been used, 


\section{Congestion of the Lungs.}

Congestion of the lungs is not very common in the horse, but nevertheless we occasionally run across it in this animal. It is simply a turgescent state of the tissues of the lungs produced by stagnation of the capillary blood ves. sels. Under favorable conditions this disease improves readily and total recovery is the result, but in some instances inflammation of the tissues of the lungs takes place, resulting in pneumonia.

Cause-Over exertion when animal is not in condition to stand it. The blood being rich or overloaded with fatty products, or the patient's being in too heavy flesh may be the cause of the congestion, and again the trouble may arise out of a weak pair of lungs, made so by a spell of sickness or otherwise. This trouble has been brought on by driving too fast and too long when horse has not taken exercise for $\mathbf{2}$ week or two.

HOW TO KNOW I'T.

The horse suddenly stops all out of breath, his nostrils are distended and his countenance has a look of profound anxiety upon it; he looks around as if in search of fresh air and pars the ground. The pulse is small and quick and in the first stage there will be little or no fever.

WHAT TO DO.

Let patient stop if traveling and turn head towards the wind; loosen any part of the harness which may in the 
least interfere with the breathing. It is a very good plan to bleed in the mouth about the first or second bar. Allow animal thus affected cold water to drink, but in very small quantities at a time. Use the following:

\section{PRESCRIPTION.}

Aconite, Tincture of . . . . . I drachm

Belladonna, Fluid Extract of . . . 2 drachms

Water, q. s. add . . . . . 4 ounces

Mix and give tablespoonfull every two hours until breathing is better, and pulse is down in the neighborhood of 45 beats per minute. If congestion does not yield to this treatment, look out for a case of pneumonia and adopt

without delay treatment prescribed in it and apply it vigorously. The approach of pneumonia will be indicated by a rise in temperature, which, if it goes to IOI I-2, and breathing continues to be labored you may know without any guess work what the trouble is.

\section{Pleurisy.}

The lining of the chest and the covering of the lungs are serous membranes or sacks which enclose the lungs, and protect them from friction with any other portion of the chest or frame work of the body by means of the serous slippery secretion which comes from these membranes and lubricates, as it were, the lungs proper. These membranes are called the Pleura, and any inflammation of them is called Pleurisy, which disease is usually attended by great pain, 
and is often followed by hydrothorax, or filling of the chest with water. Pleurisy may exist alone, or in combination with pneumonia. When it appears in combination we call it Pleuro-Pneumonia.

Cause-Sudden exposure to cold rains and the like. A draft in the stable, especially if the horse comes in warm, or any shock in the way of a quick change when the animal has any tendency whatever to take cold.

HOW TO KNOW IT.

The horse generally has a chill which is followed by high fever and great pain in the chest, which pain is evidenced by the animal acting as if he had colicky pains; he has his nose turned around to his side; the ears and legs are cold and the breathing is hard. The elbows of the patient are turned in and he suffers from loss of appetite. Great pain is evidenced upon pressure with the fingers between the ribs. The temperature will run from IO3 ${ }^{\circ}$ to $105^{\circ}$ and pulse will make from 55 to 75 beats per minute. In placing the ear to the chest a rough dry sound is observed. - If recovery takes place it is usually in 3 or 4 days; and should the pleurisy run longer there is an effusion and the chest begins to fill with water. If chest does not fill more than one-third full the effusion may be absorbed and patient recover. When there is water in the chest we hear a sound like sloshing water in a pail, upon placing our ear over affected lung. 


\section{WHAT TO DO.}

If chill is observed and pleurisy is suspected, blanket animal well and keep him in doors. Give the following at once:

PRESCRIPTION.

Brandy, . . . . . . . . . . 4 ounces

Ginger, Tincture of . . . . . I drachm

Mix and give at one dose in a pint of warm water and follow in an hour with:

PRESCRIPTION.

Niter, Spirits of . . . . I and I-2 ounces Gentian, Tincture of . . . . . . . I ounce Potash, Nitrate of . . . . . . I ounce Ammonia, Muriate of . . . . . . I ounce Belladonna, Fluid Extract of . . . I drachm Aconite, Tincture of . . . . . 2 drachms

Water, add sufficienty quantity. . . I pint

Mix and give two tablespoonsfull at a dose every 2 or 3 hours as indicated. Should the pulse be above 60 beats to the minute in the beginning, double the above dose in the first instance. Feed lightly but put a pail of water by and allow patient to drink when he likes. Bathe affected side thoroughly with:

PRESCRIPTION

Turpentine, . . . . . . 2 ounces

Camphor Gum . . . . . . 2 drachms 
Sassafras, Oil of . . . . . . I drachm

Alcohol, add sufficient quantity . . . 3 ounces

Mix and apply, repeat application in 6 hours and then grease. When fever is broken and pulse is running below 50 beats a minute discontinue fever mixture and begin with the following blood purifier:

PRESCRIPTION.

Sulphur . . . . . . . . 3 ounces

Mustard, (ground)...... 4 ounces

Blood Root,(powdered) . . I and I.2 ounces

Gentian (powdered)....... I ounce

Sassafras Bark, (powdered). . . 2 ounces

Foenugreek, (powdered)..... I ounce

Mix and give one tablespoonfull once a day. Should there be an effusion put fly blister on parts directly over lung involved.

\section{Chronic Congh.}

A trouble of this character among stock is quite common in the United States and is of much more frequent occurrence in animals which have but little or no advantages in the way of pasture than where they have free range upon either prairie or meadow.

Cause-The cause of this trouble is largely a matter of conjecture but it is reasonable to suppose that it is brought about through an inflammatory condition of either the larynx or bronchial tubes, these being constantly irritated and kept in this condition by the presence of dust in the feed 
or atmosphere. Some writers claim and I am not prepared to refute it, that these coughs are sometimes brought on by neglect and improper treatment of catarrh and distemper.

\section{HOW TO KNOW I'T.}

The cough is recognized as being dry, husky and hacking. Where in health it is strong and full and usually followed by a sneeze to clear the nose. It may be that the animal thus affected will cough but little at a time, and again he may have a spell of coughing lasting several minutes, followed shortly by another spell of like character. This cough can in some cases be brought on by pinching the larynx, and in others speeding of the animal is necessary to develop it.

WHAT TO DO.

A chronic cough of long standing is incurable, but most cases can be benefitted, and in the beginning of disease, cured by the following:

PRESCRIPTION.

Cedar, Oil of . . . . . . . 2 ounces

Ether, Sulphuric.... . I and I-2 ounce

Sassafras, Oil of . . . . . . 4 ounces

Ammonia, Water of ... . . I-2 ounce

Camphor Gum . . . . . . 3 drachms

Alcohol, q s ad . . . . . . . . I pint

Mix and apply to throat, rubbing it in well from ear to ear. Give internally the following: 


\section{PRESCRIPTION}

Camphor Gum . . . . . I and I-2 ounces

Digitalis, (powdered) . . ... I ounce Linseed Meal........ . 2 ounces Gentian, (powdered) . . . . . I ounce

Mix and divide into 12 powders, give one of these night and morning, and should this fail to relieve patient try this:

PRESCRIPTION.

Balsam Fir . . . . . . . . 2 ounces

Balsam Copaiba....... 2 ounces

Lobelia, Tincture. . . . . . I-2 ounce

Mix and give one tablespoon full night and morning.

Some authors reccommend a mechanical counterirritant in the way of old-fashion Seton inserted under the skin of the throat, but I consider this of doubtful worth.

Just here I desire to add a word of wholesome advice Do not under any circumstances attempt to hold a horse's head up and drench him when he has a cough. The best plan when liquids are used is to throw them into the throat with a syringe. 


\section{CAP'TER III.}

\section{DISEASES OF THE STOMACH AND BOWELS.}

In this connection we purpose studying all of those important troubles which arise in the alimentary canal from the stomach backward. We will no doubt treat some affections in this chapter which it might seem right and proper to consider elsewhere in this work, but if the reader will think for only a moment he must realize that those which seem out of place (like rupture of the diaphragm, etc.,) are a direct result of some trouble along the alimentary canal. This chapter, the writer feels, will prove of much value to every reader, for in it we will consider some of the most common and yet most important diseases to which stock are liable.

\section{Gastritis.}

This is an inflammation of the stomach, and though by no means common, yet it is of sufficient occurrence to demand our attention, 
Cause-It is caused by over-eating in most instances, and occasionally from eating poisonous herbs.

\section{HOW TO KNOW IT.}

Upon examination we will find some of the symptoms of wind colic present. A horse thus affected will lay down, but will roll but little if any, usually remaining very quiet. The food not being digested rapidly enough decomposition sets in and leads to some swelling in the bowels; the pulse will be soft and jerky at times and the patient is not likely to have any fever.

\section{WHAT TO DO.}

Give a complete change of food and if in season allow patient to run on grass, otherwise give as soft food as possible and use this:

PRESCRIPTION.

Ginger, Extract of . . . . . . I ounce Gentian, Tincture of . . . .. . I drachm Linseed Oil . . . . . . . . I pint

Mix and give at one dose, and repeat in 4 hours if patient is not relieved. 'If there seems to be much pain give with the above this:

\section{PRESCRIPTION.}

Morphine Sulphate...... . 3 grains Water, q. s. ad ....... I-2 pint 
Mix and give at one dose and repeat every 30 minutes until patient seems easier. When attack is passed use the following:

PRESCRIPTION.

Iron, Sulphate of . . . I and I-2 ounces

Potash, Nitrate of . . . . . . 2 ounces

Foenugreek, (powdered). . . . I-2 ounce

Mix and divide into 12 powders, and give one morning, noon and night.

\section{Stomach Staggers.}

This is a very peculiar condition, but it is simply an acute attack of indigestion in which fermentation sets up in the stomach.

Cause-Overloading the stomach.

HOW TO KNOW IT.

The patient is usually found standing in a kind of stupor or asleep, and perfectly quiet; he is without appetite for either food or drink. The pulse will be very soft and it will not run very high for Io or 15 hours. The temperature will be found anywhere from $\mathrm{IO}^{\circ}$ to $\mathrm{IO}^{\circ}$, and $\mathrm{pa}$ tient will stand with his head down all the time.

\section{WHAT TO DO.}

Remove from food of any kind and sit a pail of water by. Give the following as a purge: 
Linseed Oil (raw) . . . . . . I pint

Aloes Barbadoes...... 4 drachms

Nux Vomica, Tincture of . . . . . I drachm

Mix and give at one dose, and repeat in 8 hours if bowels have not moved freely. After the second dose give injections of warm water every hour until you get the desired action. If after the bowels more the temperature should run as high as $103^{\circ}$, use this:

PRESCRIPTION.

Aconite, Tincture of . . . . . . I drachm

Belladonna, Fluid Extract of . . . 2 drachms

Niter, Spirits of . . . . . . 2 ounces

Water, q. s. ad . . . . . . . 4 ounces

Mix and give one tablespoon full every hour until fever is reduced. After bowels have acted and fever has subsided, commence the following:

PRESCRIPTIONS.

Iron, Sulphate of . . . . . 2 ounces

Cinchona Bark . . . . . . . 2 ounces

Mix and divide into 12 powders, and give one night and morning. Feed light and exercise but little for some time.

\section{Indigestion.}

This trouble seldom occurs in the horse, but we some times run across a case of it. 
Cause-High feeding is commnnly the cause, but bad teeth which interfere with mastication may produce it.

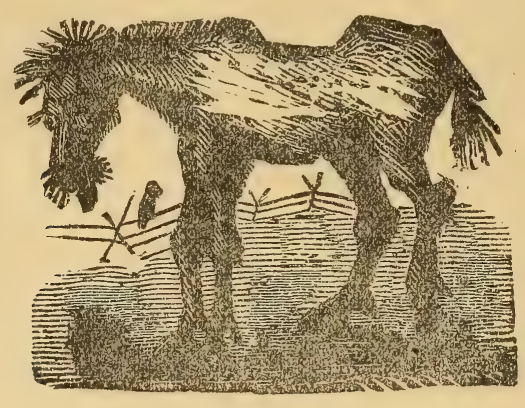

HOW TO KNOW IT.

The coat is rough, dry and staring, the horse will be thin and present a generally unthrifty appearance. The dung is of a peculiar yellowish color and offensive smell. The appetite is geuerally indifferent, but in some instances is ravenous for a moment then it is all over and he leaves the remainder of his feed or merely nibbles at it.

\section{WHAT TO DO}

If caused from a bad tooth, extract it, and if from high feeding give a complete change of food. A good treatment is to give purge same as in pneumonia, and follow with tonic powders recommended in laryngitis.

\section{Bots.}

We find "bots" in every horse from start to finish, and instead of proving harmful as many would think, it would 
be impossible for a horse to live without their presence in the stomach; as nature provides for these little worms so is she able to care for them. But there is a worm hatched sometimes in the stomach of the horse from the egg of a "'gad fly," or "nit fly," which, when passed by the horse, is taken for a bot; these resemble bots very much, but a comparsion of the two will demonstrate a difference. You may take a worm from the egg of a "gad fly," place it in a bottle, and inside of twelve days it develops into a perfect "gad fly," where a bot similarly placed is at the end of twelve months still a bot. As before stated all horses have bots, but these are niot the cause of the mutilated condition of the stomach, which we find soon after the death of a horse, this condition being brought about by the action of the gastric juice-in fact it is a kind of self digestion of the stomach by itself. Bots never have killed a horse and I would advise that you be not guilty of giving bot remedies for you can put nothing in the stomach that will kill a bot without killing a horse. A bot will live fifteen minutes in turpentine or strong tobacco juice and from eight to ten minutes in carbolic acid. When you see a horse rolling or giving forth any of the signs of disease, study the symptoms to the end that you may learn what the trouble is, always remembering to let the bots take care of themselves. In many cases the trouble is bilious colic instead of "bots," this being a very common mistake-in fact the most common one in this connection. 


\section{Bilious Colic.}

A colic of this kind is quite different to the others, and possibly ought to be studied under the head of diseases of the liver, but owing to the fact that many make the mistake of saying a horse has the "bots," when bilious colic is the trouble, I deem it proper to consider it here.

Cause-The cause is a want of functional activity on the part of the liver, that is the liver fails to perform its part of work in the economy of the animal.

HOW TO KNOW IT.

The patient gets down and rolls, throws his head around to his side, turns up his upper lip and shows by his every act that he is suffering in pain in either stomach or bowels and probably both. The pulse will beat hard and regularly and there will be $n o$ swelling of the flanks. This is the only disease with no swelling in the flanks, in which the pulse is hard and regular.

\section{WHAT TO DO.}

In most instances this condition is easy to relieve. When first symptoms are noticed use this:

PRESCRIPTION.

Chloroform . . . . . . . 2 drachms

Cloves, Oil of . . . . . . Io drops

Syrup, Simple . . . . . . 4 ounces

Mix and give at one dose, in a pint of warm water or 
sweet milk; repeat every half hour until patient shows no sign of pain. After pain is relieved administer the following as a purge:

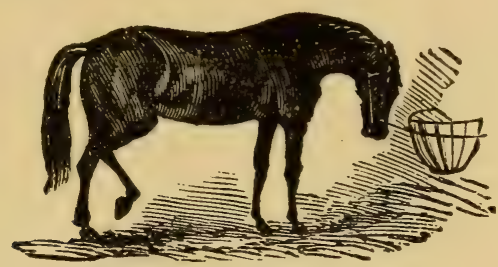

In First Stage of Bilious Colic.

PRESCRIPTION .

Linseed Oil ... . . . . . . . I pint

Aloes Barbadoes . . . . 3 drachms

Calonel. . . . . : . . . . 6 grains

Mix and give at one dose and patient will be all right in a few days. Remember when a case of this kind has been cured that it was bilious colic and not "bots."

\section{Spasmodic Colic}

The term colic means a pain in the abdomen. Any kind of colic is dangerous from the fact that it may result in inflammation of the bowels, which trouble is very fatal, though not necessarily so. Spasmodic colic is so called on account of the spasmodic contraction of the muscular coats of the stomach and intestines.

Causc-Often the cause is exercising a horse until he is warm and allowing him to cool too quickly. Sometimes a horse is exercised until he is very warm, and as a matter 
of fact he is very thirsty; then under these circumstances he drinks excessively if permitted to do so; this causes a sudden contraction of the muscles of the stomach, and Spasmodic Colic is the result.

In the first stage the patient will appear uneasy and will be noticed looking around; he will stand first upon one foot and then upon the other, quit his feed if eating and

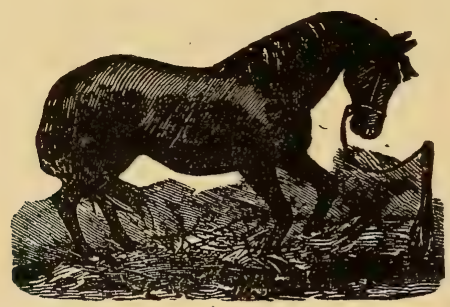

Second Stage of Spasmodic Colic.

walk around as though he was going to lay down. In the second stage he drops down suddenly showing signs of the great pain he is in; he rolls very violently and gets up and down very often. There will be periods of relief in which the horse will be quite free from pain, but they are fleeting. A horse exercises himself more with this disease than with any other. When symptoms have been noted diagnosis can be verified by the pulse. We find two hard beats of it and then a fluttering fluctuation. When this is found we can be sure of Spasmodic Colic, for no other disease presents this fluctuation of the pulse. We can not always go by the way a horse acts, for where there is any pain (no matter as to its character) in either stomach or bowels, he will roll more or less. 
WHAT TO DO.

If the pulse is under 60 and above 50 beats per minute, use the following:

PRESCRIPTION.

Chloroform ......... I drachm Ether, Sulphuric...... I-2 ounce Opium, Tincture of . . . . . I-2 ounce Canibus Indicus, Fluid Ext. of . . . Io drops

Mix and give at one dose in a half pint of warm water; repeat this every half hour until pulse is on stand still or inclined to come down. Should the pulse run over 60 and under 75 beats a minute, double the above dose in the first instance but never afterward unless pulse should increase rapidly. If the pulse should run above 75 beats to the minute give 3 times the amount prescribed in the beginning and then drop back to original prescription. Allow patient a few days rest and be careful in feeding to insure best results.

\section{Flatulent or Wind Colic.}

This is the most dangerous and fatal of all diseases to which stock are liable. From this fact it ought to command our close and careful attention. It is not very prevalent; possibly if it was we would become better acquainted with it, and more accomplished in handling it.

Cause-We might say the primary cause of this trouble is indigestion, the food fermenting in the stomach. It is 
in most instances brought about by exercising a horse immediately after a heavy feed of corn has been eaten, the active exercise retarding or entirely interrupting digestion, and the moment digestion stops decomposition sets in and the evolution of gases begins. As before stated this is a very fatal malady. It lasts from two to twelve hours.

The patient gets down and rolls, but not so much as in Spasmodic Colic. By the time the pulse reaches 45 or 50 beats per minute the horse will begin to swell in the fianks. The pulse will be hard and regular all the time, (by regular we mean without any fluctuation.) This is the only disease where there is swelling of the flanks in which the pulse is hard and regular all the time, so there is no room for mistake. If a rupture of the stomach or diaphragm should take place the pulse will get weak and small and patient will sit on his haunches like a dog.

\section{WHAT TO DO.}

When the first signis of Flatulent Colic are observed, and the pulse has reached 50 beats per minute give the following:

\section{PRESCRIPTION}

Ether, Sulphuric . . . . 2 drachms Opium, Tincture of . . . . . I-2 ounce Asafœtida, Tincture of, . . . . . . I ounce Ammonia Aromatic, Spirits of . . 2 drachms Linseed Oil to make. . . . . . . . . I pint Mix and give at one dose. Should the patient not get 
relief from this in 30 or 40 minutes, repeat the above dose, but leave the linseed oil off and use warm water instead of the oil. Should the gases continue to collect in the colon; Chlorate Hydrate, is also beneficial in this form of colic. It is an anti-ferment and a pain reliever. It is well adapted to the treatment of Wind Colic. It should be given in one-half ounce doses, diluted in one pint of warm water.

As this drug is irritant to the throat and stomach it should be well diluted. Oil Turpentine is an antispasmodic and can be given in Wind Colic, with good results, in two drachn doses, every two or three hours until two or three doses have been given. Powdere 1 charcoal is a!so good in two ounce doses. If this treatment can't be obtaincd or should fail to have the desired effect, I have spiendid results with this:

PRESCRIPTION.

Bi-Corbonate Soda . . . . . . r ounce

Peppermint, Tincture of . . . . I drachm

Opium, Tincture of ..... I-2 ounce

Aconite, Tincture of . . . . . I5 drops

Mix and give at one dose in half pint of warm water, and repeat this dose every 30 minutes until the pulse shows a disposition to come down. Should the pulse be above 60 beats per minute in the beginning, double the above dose and should they be above 75 treble, but only in the first instance.

This is the only disease which has a limitation to the pulse. When the pulse reaches 85 beats per minute the 
patient has only i 5 or 20 minutes to live unless he gets immediate relief. Then, when the pulse reaches 85 beats per minute, we have but one resource left and that is to tap the sufferer on the left side, half way between the end the last short rib and the point of the hip. It is very dangerous to tap a horse before the pulse reaches 85 beats per minute, for the colon has not reached the diaphragm. Experts may tap on right side but I would not advise inexperienced hand to try it.

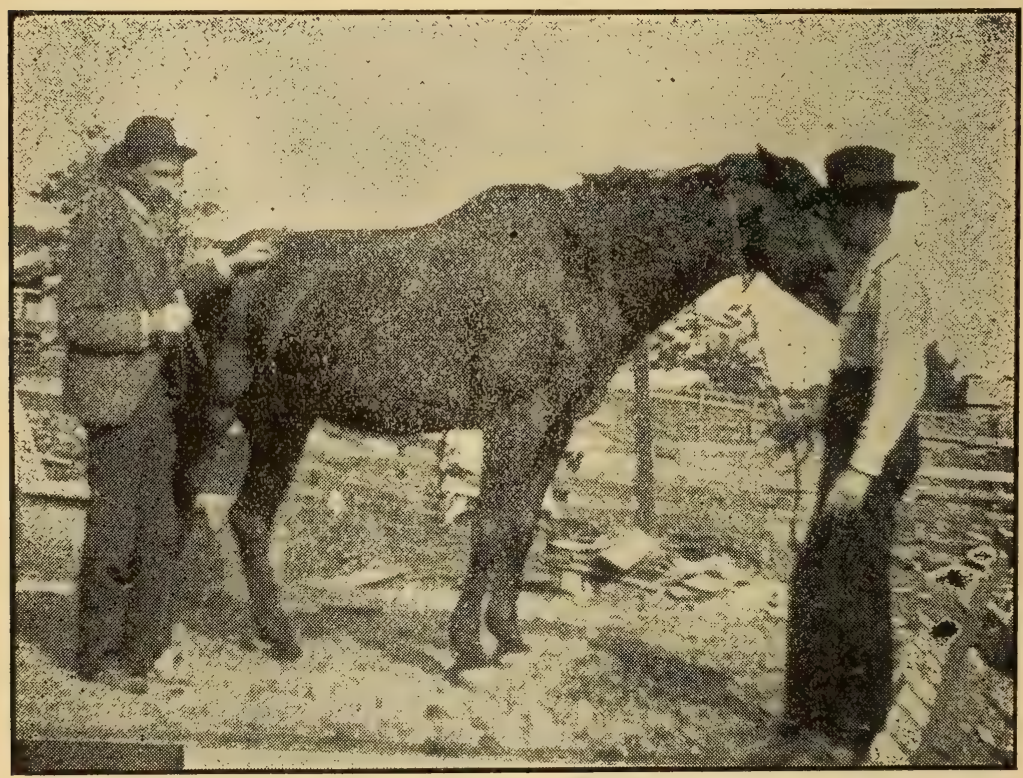

Tapping the Horse for Wind Colic.

In tapping a horse a trocar is the best instrument to use. Should you not have one, then use a knife, with a blade about two and a half inches long and a half inch wide 
When incision is made I introduce a quill or something of the kind to permit the escape of gas. In tapping a horse at night some care must be used in not having a light too close to the animal, as the gas may be caught and cause considerable trouble.

\section{Rupture of the Stomach or Diaphragm.}

Either of these may occur in violent cases of wind colic

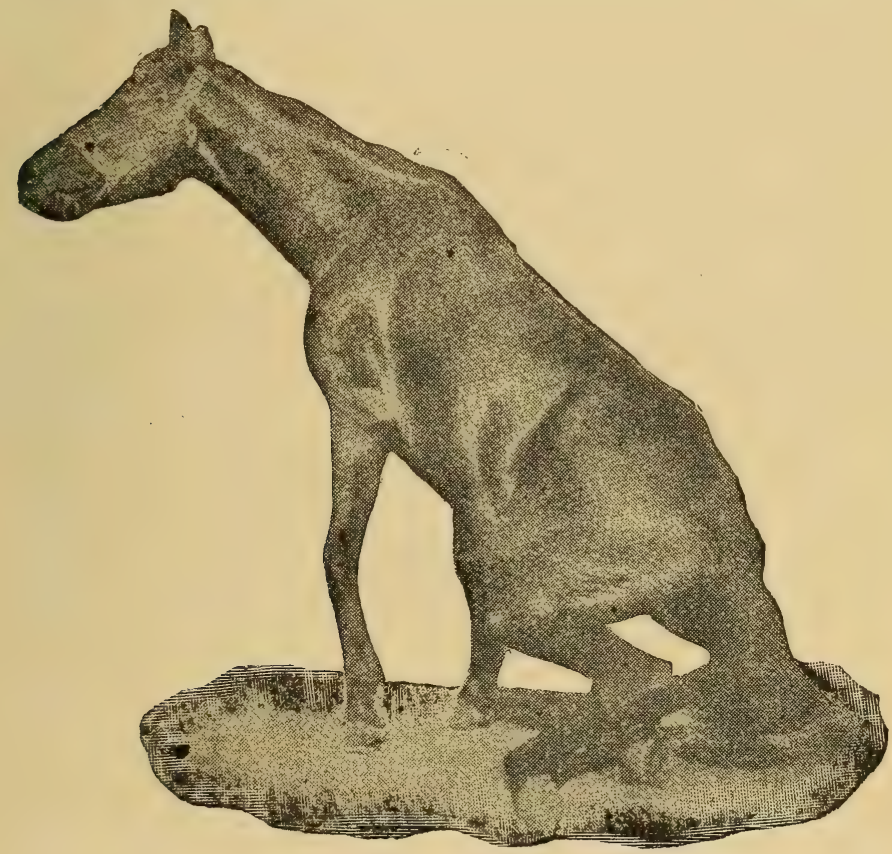

In Last Stage of Rupture.

and both are fatal, this being the case we simply give cause and how to know it, without any treatment.

Cause-In most cases this trouble is brought on by ex 
cessive generation of gases in wind colic, these gases distending the stomach beyond its capacity, thus producing a rupture, or else forcing the colon up against and through the diaphragm. In rupture of the stomach the partially digested food and gastric juices are turned loose in the abdominal cavity, where in rupture of the diaphragm the intestines are permitted to pass into the chest among the lungs and heart. Sometimes these ruptures are the result of violent kicks or blows about the abdomen and again from animal falling when stomach is full of food.

HOW TO KNOW IT

The patient will sit on his haunches like a dog, his nostrils will be distended and his breathing labored, he will turn up his lip as though his stomach was nauseated, and appear as if trying to vomit, but this he can not do on account of the peculiar formation of the stomach. The muscles of the legs will tremble and shake as if he was having a chill, his legs get cold and cold sweat breaks out in spots upon him. The pulse is rery small and fast, and when it passes 35 keats per minute, death soon claims the patient.

\section{Constipation.}

When fecal matter in the intestines becomes dry and hard or from any cause resists the paristaltic efforts of the bowels to pass it on, or when paristaltic àction is interfered with or suspended for a time and the fecal matter lays quiet in one place, there is to all intents and purposes an ob- 
struction formed. This condition is called constipation or costiveness.

Cause-It is due to a drying and hardening of matter in the bowels, which is brought about by there being an insufficient quantity of water present, this state being produced by most of the water going to the kidneys, or horse not drinking enough. Again the cause may be from the liver and other glands not secreting enough of the typical juices necessary to supply nature's wants in the bowels.

HOW TO KNOW IT.

But little if any fecal matter will be passed, that, which is, will be dry and hard and will emit an extraordinarily bad odor. The patient will show signs of having some colicky pains, which will be mild in the beginning; he may continue to eat and appear all right otherivise; but as trouble runs on, pains will become more frequent and more severe, resulting in inflammation of the bowels if not attended to. In constipation the pulse is full and regular, generally.

\section{WHAT TO DO.}

If the pulse is not above 50 beats a minute, and colicky pains are not frequent give an injection of warm soap suds by way of the rectum and give internally this:

PRESCRIPTION.

Linseed Oil . . . . . . . . I pint

Nux Vomica, Tincture of . . . . 2 drachms

Aloes Barbadoes...... . 3 drachms

$\mathrm{M} 1 \mathrm{x}$ and give at one dose and repeat in 8 hours if bow- 
els have not moved. Keep up injection every hour with this until free action is obtained. Should pulse run as high as 60 beats to the minute and pains be of frequent occurrence use the following for relief:

PRESCRIPTION.

Morphine, Sulphate of . . . . . 2 grains Opium, Tincture of . . . . . I-2 ounce Aconite, Tincture of . . . . . . 20 drops

Mix and give at one dose in a pint of warm water, aud repeat every hour so long as indicated.

\section{Diarrhoea.}

This is a watery discharge from the bowels and represents the very opposite of constipation.

Cause-It is often induced by the animal eating green or watery food in large quantities, and sometimes it is due to the present of an irritant in the bowels which produces excessive secretion of the intestinal juices. It may be brought about by the administration of large doses of purgative medicines, when it is, we call it superpurgation.

\section{HOW TO KNOW IT.}

There is a watery discharge from the bowels, the patient becoming weak after this condition has prevailed for a time. The pulse will be found feeble and weak, and the eyes and nose pale; the patient grinds his teeth and refuses 
his feed. The temperature of the body will, in all probability be in the region of $95^{\circ}$; should it run as low as $92^{\circ}$ there is a strong probability of this trouble proving fatal.

\section{IVHAT $\% O$ DO.}

If the cause of trouble be watery or green feed give a complete change of diet and use this:

PRESCRIPTION.

Alum, (powdered)...... 2 ounces

Opium, (powdered) ..... 2 drachms

Mix and give one tablespoonful every 2 hours until four doses have been given. If this does not give relief in due time we can take it for granted that one of the latter causes is present or else we have a very obstinate case, and it becomes necessary to change our treatment to this:

\section{PRESCRIPTION.}

Chalk, Precipitated...... I ounce Ginger, (ground)....... I-2 ounce Opium, (powdered)...... I drachm Ether, Sulphuric...... I drachm Starch water. . . . . . . I pint

Mix and give at one dose, and repeat in 3 hours if necessary. Give starch or flour water to drink, but in small quantities and 3 or 4 hours apart. 
This disease is very uncommon in the horse; it is what we sometimes call "blody flux," and is inflammatory in character, affecting the large intestines.

Cause-It is produced by the animal eating grasses from low lands which are unfit for food, or poor food of any kind, and hard work may be the cause.

\section{HOW TO KNOW IT.}

It begins as a case of diarrhoea in most instances, the feces becoming bloody in appearance and it may be that shreds of the mucous membrane of the bowels will be passed. The patient. will have some fever and appear greatly prostrated; the pulse will be quick and irritable and thirst will be intense. : There will be frequent and painful evacuation:; which will increase in number and violence as the disease progresses, the fecal matters passed being very offensive ............

\section{WHAT TO DO.}

Place patient in a warm and dry, but well ventilated, stall and blanket; give starch or flour water in small quantities and food that is light and easily digested. Medicinally use this:

PRESCRIPTION.

Castor Oil ........ . 8 ounces

Opium, Tincture of ...... I ounce 
Mix and give at one dose. In 3 or 4 hours begin the followitig:

PRESCRIPTION.

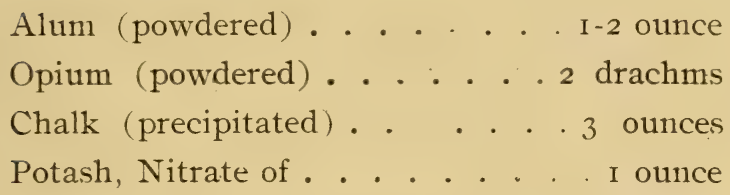

Mix and divide into 5 powders, and give one every 2 or 3 hours as indicated.

\section{Superpurgation.}

This condition is the result of the administration of a physic and occurs sometimes when every reasonable precaution has been taken to avoid it.

Cause-Too large a dose of physic, driving a horse when purging or giving large quantities of cold water while physic is operating.

\section{HOW TO KNOW IT.}

When purgative medicine has been given and horse presents the symptoms which are attendant in diarrhœea, you may rest assured that he is suffering from an overpurge.

WHAT TO DO.

Treat as you would a simple case of diarrhœa. 


\section{Gut Tie}

In the human family this trouble is known as Invagination or Intussusception; it is the falling or slipping of one gut or portion of it into another. It is rather uncommon in horses, but several cases have come under the observation of the writer.

HOW TO KNOW I'T.

First we find that patient has the symptoms commonly found in bowel troubles; colicky pains are present but they come on gradually; he looks around at his side, paws the earth and stretches out at full length; he lays down, but does not roll much and gets up and down very often. The pulse rises from 50 to 80 beats per minute and will be hard and weary. The legs get cold and cold sweat breaks out by the time pulse reaches 70 beats per minute; after this the pulse is small and hard, the muscles tremble and death soon follows.

\section{WHAT TO DO.}

If the pulse should run as high as 50 beats per minute and patient should have any colicky pains when first symptoms are noticed, give him this:

PRESCRIPTION.

Linseed Oil . . ... . . . . . 2 pints

Aloes Barbadoes......3 drachms

Nux Vomica, Tincture of . . . I-2 ounce

Mix and give at one dose and give injections into the 
rectum of warm water every hour. Use hot water rugs on the belly. If there is no apparent relief in 2 hours use this:

\section{PRESCRIPTION.}

Chloroform . ...... . 3 drachms

Aconite, Tincture of . . . . . 20 drops

Linseed Oil . . . . . . . . I-2 pint

Mix and give at one dose, and repeat every hour until the third dose has been given. Should patient appear thirsty give him all the water he wishes

\section{Inflammation of the Bowels.}

This is a disease which prevails at all seasons of the year and in every section of country; it is often mistaken for colic.

Cause-In looking for a cause we find several things which produce a condition of this kind. It may be caused by another disease and a change of food may produce it, particularly from dry to green, or allowing too much green feed when animal is not accustomed to it. Feeding upon grain and driving hard immediately afterwards is conducive to such a condition. The horse catching cold is in some instances the cause.

\section{HOW TO KNOW IT.}

When first taken the patient does not seem to be in much pain; he lies down and stretches out upon the ground, but does not roll much in the first stage. As the 
pulse goes up to 60 beats a minute and above, the pains get harder and he rolls more. The pulse is the only means through which we can definitely distinguish this trouble from colic. In inflammation of the bowels the pulse gives forth two hard beats and a soft or intermediate beat; (see colics.). This is the only disease which presents this character of pulse-hence we can not be mistaken.

\section{WHAT TO DO.}

Give the following internally:

\section{PRESCRIPTION}

Opium, Tincture of . . . . . 3 drachms

Digitalis, Fluid Extract of . . . 6 drops

Aconite, Fluid Extract of . . . . I5 drops

Water, q. s. ad . . . . . . 6 ounces

Mix and give at one dose and repeat every hour until pulse is on a stand still, or inclined to come down. Should the pulse run over 60 beats a minute the above dose should be doubled in the first instance, but never afterward.

\section{Intestinal Worms}

Innumerable kinds of worms are at times found in the intestines of horses, some being of little moment while others prove very injurious to the health of the animal harboring them. The treatment for all worms being the same we will do nothing more than to give the reader the symptoms and remedies, so as that he may detect the presence of them and employ the proper treatment. 
HOW TO KNOW WHEN THEY ARE PRESENT.

A horse suffering from worms generally presents a "pot

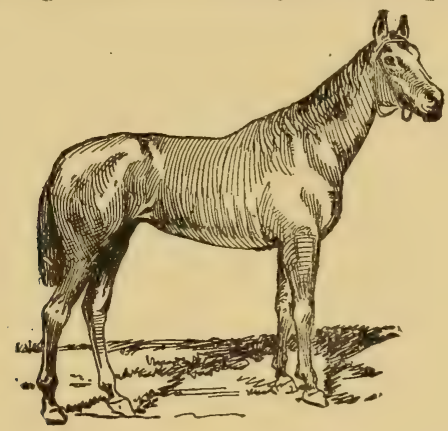

gutted"' appearance, has a ravenous appetite usually, and a very dry, staring coat; he is in very poor condition, hide bound, and is particularly fond of salt. There will be switching of the tail and frequent evacuations with some straining, and the afflicted animal will often rub his rump against the fence or stall, and will sometimes pass worms in his dung.

\section{WHAT TO DO.}

In case of worms, the following has always proven effectual with the writer:

\section{PRESCRIPTION.}

Iron, Sulphate of . . . . . I drachm Tartar Emetic . . . . . . I drachm Sage (pulverized).... 3 drachms.

Mix and give at a dose 3 times a day for 4 days, and then give this: 
- PRESCRIPTION.

Turpentine . . . . . . . . 3 drachins

Linseed Oil. . . . . . . . . I pint

Mix and give at one dose, and follow with a good tonic for several days. 


\section{CHAPTER V.}

\section{DISEASES OF THE URINARY ORGANS}

Many diseases of these organs are quite common, and they are of equal importance in so far as the health of a horse is concerned with any of his many affictions in other ways. Diseases of the urinary organs are very much more common where stock do not have free range than where they have it. This can be accounted for in only one way, and that is through the theory that an animal has a kind of instinct, or peculiar intelligence, which teaches him how to "doctor' ' himself if he can but get at the various grasses and herbs which contain the medicinal properties he needs in effecting a cure or warding off disease. If the reader will but study carefully the diseases treated under this head he will never be caught dosing a horse for colic or pleurisy when the trouble is in either the kidneys or the bladder.

\section{Inflammation of the Kidneys}

This trouble should always have our close attention from the fact that it is very deceptive in its actions; sometimes we may think a horse on the high road to recovery with this disease and he will lie down and die in thirty minutes.

Cause-The most common cause is from the use of very strong medicine when not indicated. Eating faulty food 
is a cause, and standing where water can drip on the loins sometimes produces it. Indigestion or any derangement of the digestive organs may be the cause.

HOW TO KNOW IT.

The patient will get down and roll as if he had the colic, but does not seem to be in much pain until the pulse reaches 50 or 55 beats per minute. When he rolls he exhibits an inclination to stop on his back, this is from the fact that the pressure of the bowels against the kidneys gives him some relief. By exerting pressure orer the kidneys the patient will kinder flinch or give way; demonstrating that soreness is present, and he will stretch out as though he desired to urinate. The pulse will be found soft and regular.

$$
\text { WHAT TO DO. }
$$

First make sure of your diagnosis and then proceed with the foilowing:

PRESCRIPTION.

Linseed Oil. . . . . . . . . I pint Aloes Barbadoes. . . . . . 3 drachms Nux Vomica, Tincture of. . . . . I drachm Mix and give at one dose, and in thirty minutes begin this

\section{PRESCRIPTION}

Opium, Tincture of . . . . . . I-2 ounce
Nitre, Spirits of . . . . .
I-2 ounce


Cubebs, Oil of . . . . . . I-2 drachm

Aconite, Tincture of . . . . . 20 drops

Mix and give at one dose in a pint of warm water and repeat every 40 minutes until pulse goes below 55 beats a minute; after this give it every hour if indicated. Give patient several days' rest.

\section{Congestion of the Kidneys}

This is a condition in which there is an excessive flow of blood to the kidneys, and in most instances it results in inflammation of these organs.

Cause-Any interference with the working of the kidneys may produce it. A common cause is the blood being heavily charged with fats, but it is by no means necessary that a horse must be fat in order to have this trouble; high feeding without sufficient exercise is a very prolific cause.

HOW TO KNOW IT.

If the horse is being worked the first sign we notice is the apparent stiffening of one of his hind legs, the other soon presenting the same peculiarity. The patient breathes hard, staggers, seems very weak in the loins, and finally drops down. (If he is able to pass any urine at all it is thick and ropy and has a dark coffee color.) There will be swelling over the kidneys and patient will show signs of great pain when pressure is exerted upon them. There will be some colicky pains; the pulse will be strong and hard until it gets in the neighborhood of 80 beats a minute, when it becomes small and feeble, 
First empty the bladder as soon as possible by means of a catheter and use this:

\section{PRESCRIPTION.}

Opium, Tincture of ..... . I ounce Aconite, Tincture of . . . . . . I drachm

Nitre, Spirits of........ . I ounce

Potash, Nitrate of .... . . I ounce

Water, q. s. ad . . . . . . 6 ounces

Mix and give two tablespoonsful every two hours in a pint flax seed tea. Use injections of warm water in rectum every hour, and if bowels do not move inside of 3 hours give this as a purge:

PRESCRIPTION.

Linseed Oil. . . . . . . . I pint

Aloes Barbadoes...... 3 drachms

Mix and give at one dose.

\section{Inflammation of the Bladder}

This is by no means of common occurrence, yet it is very essential to us to be able to diagnose a case of it and know the remedies to be applied should we ever be called upon to treat it.

- Cause-Prolonged retention of the urine, too free use of diuretics, and in some instances the application of fly blisters over extensive surfaces, are the principal causes, 
HOW TO KNOW IT.

Frequent passages of urine in small quantities, with some nucous in it; straining and high fercr are nstrally the symptoms we first notice. The patient will look around at his flanks and show other signs of pain. There will be marked tenderness when pressure is applied in the flanks. Bladder can be felt per rectum and is tender to the touch. The gait is stiff and straddling; the loins are rigid and the tail is constantly switched.

\section{WHAT TO DO.}

It depends upon the cause; if it be from dinretic medicines, stop or curtail their use, and if from fly blisters, remove them. Always remember to empty the bladder by means of a catheter first, then give the following internally:

\section{PRESCRIPTION.}

Opium, Tincture of ...... I ounce

Nitre, Spirits of. . . . . I ounce

Aconite, Tincture of . . . . . I drachm

Water, q. s. ad........ 3 ounces

Mix and give at three doses an hour apart. Use the following for several days:

\section{PRESCRIPTION.}

Flaxseed Meal. ....... . 6 ontnces

Gentian (powdered) . . . . . . . I ounce

Mix and give two tablespoonsful 3 times a day. 


\section{Spasm of the Neck of the Bladder}

This is a spasmodic closure of the neck of the bladder by contraction of the circular muscular fibers in this region. It is most common in the horse, but is by no means unknown in the mare.

Cause-It is usually caused by retention of urine when patient is being driven or worked, that is, where animal is not allowed an opportunity to pass it off. The administration of spanish fly or the application of large blisters and the use of dieuretics; when not indicated as well as stone in the bladder may be the cause.

\section{HOW TO KNOW IT.}

The patient makes frequent and repeated attempts at passing water and if any is forced out it comes from severe strainning and in very small quantities. The sufferer will show signs of pain; he, will look around at his flanks, both while standing and lying, and there will be greatitenderness at the lower and back part of the belly. By introducing the hand into the rectum the bladder will be felt on the floor of the pelvis in a full and distended state. The pulse will beat small and regular.

\section{WHAT TO DO.}

Let patient have such exercise as he or she, as the case may be, may like; use all means to induce passage of urine in the way of warm water injections into the rectum, and by the use of the catheter passed up the penis in the 
horse. In case of patient being a mare all that is necessary is to insert a finger into the neck of the bladaer. Give an-ti-spasmodic prescriptions as this:

PRESCRIPTION.

Nitre, Spirits of

Opium, Tincture of

Aconite, Tincture of

Ginger, Extract of
I Ourice

2 drachins

20 drops

I- 2 ounce

Mix and give at one dose and repeat every hour until relief is secured.

\section{Diabetes.}

This is a condition in which the kidneys secrete wn excessive amount of very clear urine, and is not very common in the horse:

Cause-Long continued cases of lung trouble and stomach troubles, which in most instances create a burning thirst, produce it.

HOW TO KNOW I'T.

The patient exhibits a very great thirst and passes urine in excessive quantities, it being as clear as spring water; his appetite is lost and his coat looks rough and dry; he soon becomes hide-bound. Sometimes he shows an inclination to lick the wall of stable and eat his bedding in preference to clean food. We occasionally find the patient suffering 
from palpitation $i$ the heart along with general weakness and slight fever

$$
\text { WHAT TO DO. }
$$

Give a complet: change of food and use the following:

PRESCRIPTION.

Iodine, Tincture of . . . . . I drachm

Gentian, Tincture of ..... . 2 drachms

Mix and give at one dose in a pint of warm water and repeat every day for 4 days. After the fourth day change treatment to this:

PRESCKIPTION.

Epsom Salts ....... 6 ounces

Potash, Nitrate of ..... 3 ounces

Soda, Bi-Corbonate of . . . . 3 ounces

Linseed Meal ....... 6 ounces

Gentian (Powdered) . . . . I ounce

Mix and give one tablespoonful night and morning, and allow patient to run on pasture as much as possible.

\section{Paralysis of the Bladder.}

A condition of this kind seldom ever occurs, but when it does it becomes our duty so relieve it when possible.

Cause-Long continued distention of the bladder from the urine being held too long. Diseases which confine a 
horse to a lying position, such as rheumatism, broken limbs, etc., often are the cause.

\section{HOW TO KNOW IT.}

The urine dribbles away as it is secreted and scalds the inside of the legs and sheath. 'The horse thus afflicted does not seem to suffer much pain, but a condition of this kind is very trying upon him, and we find some fever along with a soft and regular pulse.

WHAT TO DO.

Use the following:

\section{PRESCRIPTION}

Nitre, Spirits of . . . . . . 2 onnces

Opium, Tincture of . . . . . . I ounce

Aconite, Tincture of . . . . 2 drachms

Gentian Tincture of . . . . . . . I ounce

Water, q. s. ad . . . . . . 8 ounces

Mix and give 2 tablespoonsful 3 times a day in a half pint of warm water. Allow food and drink in very sparing quantities.

\section{Eversion of the Bladder.}

Eversion is an affliction of the female alone and is of rare occurence.

Cause-Protracted labor or straining is generally the cause, the bladder being forced back into the pelvis and turned inside out. 
HOW TO KNOW IT.

The bladder will be seen from the lower part of the Vulva, and the entrance of the Uretes (tubes of the kidneys) can be plainly seen near the neck of the bladder with the urine dripping from them.

WHAT TO DO.

First wash bladder clean in carbolized water, to which a little laudanum has been added, then place it back in its proper position, using sufficient care not to push the fingers through the walls of it. Should the temperature of patient run up to IO2 $^{\circ}$ use the following:

\section{PRESCRIPTION}

Nitre, Spirits of . . . . . . . I ounce

Aconite, Tincture of . . . . . 2 drachms

Belladonna, Fluid Fxtract of . . . 3 drachms

Water, q. s. ad . . . . . 6 onnces

Mix and give two tablespoonsful 3 or 4 times a day.

\section{Rupture of the Bladder.}

Like many of the other diseases of the bladder this is also very uncommon.

Cause-The bladder is sometimes ruptured by violent rolling on the part of a horse which has the colic, particularly when it has some obstruction in it or is filled with urine. This trouble occasionally occurs in females during parturition when the mare fails to empty her bladder before labor begins. 
HOW TO KNOW I'T

The animal will tremble all over the entire body, the pulse will be found weak and jerky and it will be run up to 75 or 80 beats a minute directly the body will soon become cold and examination per rectum shows bladder empty. The introduction of a hypodermic needle into the middle of the belly will let out urine which can be smelled. Inflammation sets up among the viscera, and death is the result.

\section{WHAT TO DO.}

We can do nothing but relieve patient until death claims him. For relief we can use this:

PRESCRIPTION.

Morphine, Sulphate of .... 4 grains

Water, q. s. ad ........ 6 ounces

Mix and give at one dose and repeat every hour.

\section{Bloody Urine}

This is a condition in which a horse passes blood along with the urine; it is of serious import.

Cause-It is generally caused by violent treatment of animal through which the lions, kidneys or bladder may be affected. Cancer or abscess of the kidneys, and eating poisonous herbs may produce a condition of this kind.

\section{HOW TO KNOW IT.}

The urine will be blood stained; the horse will be drowsy 
and without appetite and will lose flesh rapidly; his coat will be rough, dry and staring, and the pulse soft and regular with some fever.

\section{WHAT TO DO.}

In case of a profuse flow of blood, dash cold water over patient's back and loins, give flaxseed tea to drink 3 or 4 times a.day in small quantities and use the following:

\section{PRESCRIPTION}

Tincture, Muriate of Iron ..... I ounce

Tincture, Gentian . . . . . . . I ounce

Water, q. s. ad . . . . . . . . 8 ounces

Mix and give two tablespoonsful 3 or 4 times a day in a pint of cold water.

\section{Dribbling of the Urine.}

Some might think that a constant dribbling of the urine in paralysis of the bladder might constitute this disease as the sole cause of the dribbling, but such is not the case for we occasionally find it without the presence of any paralysis whatever.

Cause-When not caused by paralysis it may be due to a weakness of or injury to the bladder, and again the cause may by calculi.

HOW TO KNOW IT.

Upon examination it will be found that the horse thus 
affected has no control over his urine; it dribbles from him continually. At times he will stretch out as though he has a desire to make water, but it will come only in very small quantities.

\section{WHAT TO D}

If the trouble be brought about by the presence of calculi we must do our best to remove the cause. By the introduction of a catheter we can usually determine the prsence of a stone. In using catheter pass the hand into the rectum to guide the point over the curve. Give the following:

\section{PRESCRIPTION}

Nitre, Spirits of ...... 2 ounces

Balsam Copaiba...... . I ounce

Alcohol, q. s. ad . . . . . . 8 ounces

Mix and give one tablespoonful every 2 or 3 hours until patient is better. If the cause be a weakness or injury give a change of food and the following:

PRESCRIPTION.

Epsom Salts . . . . . 6 ounces

Linseed Meal . . . . . . 6 ounces

Nux Vomica (powdered)... 4 drachms

Cinchona bark (powdered)... . 2 ounces Mix and give one tablespoonful 3 times a day. Keep patient dry and comfortable. 


\section{Stricture of the Vrethra.}

This is a condition in which the urine is retarded or obstructed in its passage through the Urethra by the formation of a stricture in this passage.

Cause-The causes are, irritating ingredients in the urine strong injections in cases of gonorrhœa, and contraction of the lining membrane of the urethra which may occur during the healing of ulcers in this canal.

\section{HOW TO KNOW IT.}

The urine is passed in a small stream, the patient being a long time at ii, and showing by his actions that he is suffering some pain; he occasionally stands stretched out for some time as though he wished to urinate. This trouble is by some, who do not know any better, called "chronic gravel."

\section{WHAT TO DO.}

First, examine the end of the penis to see if the trouble is there; if no obstruction be found here, then pass in a catheter gently; this is to be done once or twice a day during treatment. Give patient the following which you can best prepare yourself:

\section{PRESCRIPTION}

Gather one gallon of prickly pear leaves, place them in three gallons of water and boil down until you have but one gallon left. 
In mild cases give one pint of this fluid once per day, and in serere cases give it two or three times a day as indicated.

\section{Gonorrhoea.}

This is an inflammation of the urethra and is mostly confined to stallions.

Cause-Irritating substances in the urine, excessive capulation, connection with a newly delivered mare or one which has an irritating discharge from the womb, and injury to the penis in passing small stones may all be classed as causes.

HOW TO KNOW IT.

By soreness in the sheath and penis, both being swollen some. The patient will pass water in small jets, and will show that the act of urinating gives him pain. The head of the penis will be found sore and hot and there will be a discharge of pus.

WHAT TO DO.

Keep the bowels of the patient well open and bathe all the sore parts well with warm water once a day and follow with an injection into the penis of this:

\section{PRESCRIPTION}

Lead, Acetate of . . . . . . I-2 ounce Zinc, Sulphate of . . . . . 3 drachms Water, q. s. ad ....... I6 ounces 
Mix and shake well, 'inject an ounce or two once a day into urethra. After the sixth day change to this:

PRESCRIPTION.

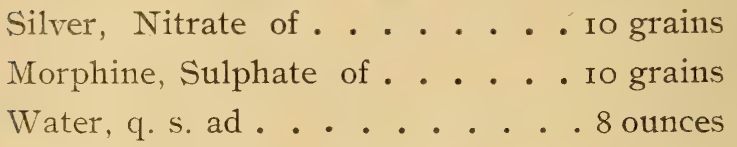

\section{Urinary Calculi.}

The corbonates of lime and magnesia are the principal components of the calculi of the horse, and they are due to a large proportion of vegetable acids in the food, these acids being transformed and uniting with the lime and magnesia of the blood, thus forming corbonates of either of these elements which are within themselves the calculi.

Cause-The transforming of vegetable acids into corbonic and which in turn unites with the lime or magnesia of the blood of the system forming solid corbonates. By some it is thought that the drinking of hard water is a cause for calculi, and the reasons they advance for such opinions are good, but we will not attempt to discuss them.

\section{HOW TO KNOW IT.}

Calculi in the kidneys and ureters produce colicky pains, a straddling gait, tenderness over the lions and sometimes blood in the urine. By introducing the hand into the rectum we may sometimes feel the calculus in the ureters. Calculi in the bladder often get into the urethra or outer passage and obstruct the flow of urine, in which case they 
give rise to frequent straining efforts upon the part of the horse in his attempts at emptying. the bladder. Under these conditions the urine passed comes in small jets with a sudden arrest of the flow. If the stone does not make its way into the urethra the fiow of the urine is checked, but blood in clots may be passed; which is a strong indication that the mucuous membrane or lining of fhe bladder has been wounded by the stone. The presence of a stone in the bladder of the male can be determined by means of an examinatson through the rectum. In the female it can he reached easily with the finger through the short urethra.

WHAT TO DO

In case the trouble be in the kidneys or ureters there is but little that can be done, aside from the administration of medicaments to relax the walls of the ureters and to relieve the pain. The following will prove efficacious:

PRESCRIPTION.

Opium, Tincture of . . . . . . I ounce Belladonna, Fluid Extract of . . . 2 drachms Aconlte, Tincture of . . . . . . I drachm Water, q. s. ad ........ 4 onnces

Mix and give at two doses one hour apart.

In case the calculus be in the bladder or urethra it can be removed by crushing it with forceps made for the purpose, and when crushed the bladder should be washed out thoroughly. For several days after this operation put a tablespoonful of bi-carbonate of soda in daily allorance of water. 


\section{Foul Sheath.}

The sheath of most horses at times becomes foul and needs cleaning. The glands in the region of penis secrete a fluid, which lubricates the parts, and it is sometimes secreted in excessive quantities, and the result is an accumulytion of a black gummy substance in the sheath which should be removed.

\section{WHAT TO DO}

Wash out the sheath thoroughly with warm water and castile soap, then dry the parts with a soft clean towel and depend upon nature to do the rest. Never put grease or oil in a sheate for they hold dust and trash thus making bad matters worse. 


\section{CHAPTER V.}

\section{DISEASES OF THE LIVER}

Though the diseases of this organ are very few and seldom occur, yet it is of great importance to us that we should study those which are of consequence and can be understood and treated successfully. We do not think that we would be justified in taking the reader's time and wasting a lot of valuable space in writing of something which can be of 110 practical worth-hence we present nothing under this head but "Inflammation of and Congestion of the Liver." One striking peculiarity with reference to the liver o ${ }^{*}$ a horse is the absence of a gall bladder, this being the reason, no doubt, for the horse not being troupled with some of the common diseases, such as gall stone, etc.

\section{Congestion of the Liver.}

This is a condition in which the blood vessels of the liver are engorged, and it is usually accompanied by an engorgement of many of the other internal organs.

Cause-Over feeding without reasonable exercise, injuries on right side over liver and the presence of foreign bodies in it. The extension of inflammation from neighboring parts may produce such a condition. 
HOW TO KNOW IT.

There is a yellowishness of all visible mucous membranes, the horse appears dull and as if suffering from some internal pain. The feces are of a gray color, hard and very offensive, the urine is scanty and highly colored. Sometimes there is lameness in the right fore-shoulder, and in some cases the patient is noticed grinding his teeth.

\section{WHAT TO DO.}

First give as a purge the following:

PRESCRIPTION.

Linseed Oil ....... I pint

Aloes Barbadoes......6 drachms

Calomel ........ I-2 drachm

Mix and give at one dose and repeat in "24 hours if necessary. When bowels have acted well begin with this:

\section{PRESCRIPTION}

Cinchona Bark (Powdered) .... I ounce Foenugreek (Powdered) ..... I ounce Blood Root (Powdered) . . . . 2 ounces Mix and divide into 12 powders, and give one night and morning in soft feed.

\section{Infammation of the Liver.}

This disease, though rare, is sometimes met with and is generally in an old horse. It may affect the covering of the liver or its glanular portion. 
Cause-The causes of inflammation are congestion and its causes.

\section{HOW TO KNOW IT}

Inflammation of the liver presents many of the symptoms of congestion. There is a loss of appetite, the patient hangs his head and usually remains standing, the feces are of a durk reddish brown color and are covered with a slimy mucous matter and there is generally tendernes's of the righı side.

\section{WHAT TO DO.}

Give same purgative reccommended in congestion, and when bowels have been thoroughly opened give the following:

\section{PRFSCRIP'TION}

Potash, Chlorate of ...... 2 ounces

Water, q. s. ad ........ 2 pints

Mix and give eight tablespoonsful at a dose 3 times a day. 
CHAP'TER VI.

\section{DISEASES OF THE BLOOD}

Under this head we will consider the general diseases of the blood alone, with those of contagious origin.

\section{Influenza and Pink Eye.}

These are one and the same and are identical with the "grip" in man. It is recognized as being a distinctly specific germ disease of an infectious character.

Cause-It is supposed to be caused by the introduction into the system of a poison of a malarious nature.

$$
\text { HOW TO KNOW I'T. }
$$

The first sign noticed is usually languor and weakness upon the part of the patient, followed by nervous prostration in a few hours; he hangs his head, the ears droop, the mouth is hot, the eyes are red and in some cases swollen, and in the corners of them is found a kind of matter. A high fever develops, the temperature running as high as $106^{\circ}$ and possibly to $108^{\circ}$. The breathing is rapid and is sometimes characterized by a snoring sound. The pulse is quick, hard and irritable.

\section{WHAT TO DO.}

Give the patient good quarters, no drafts, pure air, and soft digestable food. Leave the bowels alone, treat the 
heart mainly, look to your hygiene and depend upon nature for the rest.

As a heart stimulant and tonic this will be found efficacious:

PRESCRIPTION.

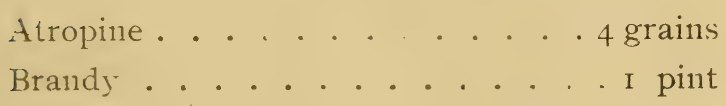

Mix and give four ounces at a dose 3 times a day.

\section{Rheumatism}

Rheumatism is a constitutional blood disease and is neither contagious nor infectious.

Cause-It is due to accumulation in the system of some unnatural acid and usually follows other disordersas influenza, chest affections and most acute troubles. It rarely appears without a forerunner.

HOW TO KNOW I'T.

The first symptoms we generally notice is lameness, which is of a peculiar kind; there may or may not be swelling; when swelling is present the patient has more or less fever. The lameness is most generally flying in character, passing from one joint to another and from one leg fto the other. The joints usually affected are the hips, shoulders, knees and fet-locks. There is great pain and soreness upon pressure- The pulse is generally hard, rapid and small. 


\section{WHAT TO DO}

First bathe affected parts well for thirty minutes in warn water, dry thoroughly and rub in well the following liniment:

\section{PRESCRIPTION}

Arnica, Tincture of . . . . . 2 ounces

Opium, Tincture of . . . . I I-2 ounces

Camphor, Spirits of .....3 ounces

Mix and apply to affected parts. Give internally this:

\section{PRESCRIPTION}

Colchicum Seed (Powdered). . . I ounce

Foenugreek Seed (Powdered). . I-2 ounce

Gentian (Powdered). . . . . I ounce

Potash, Nitrate of . . . . . . . I ounce

Mix and divide into I 2 powders and give one night and morning in soft feed.

\section{Abscesses.}

An abscess is a sac of pus in the tissues. They are sometimes large, but as a rule not painful unless near a nerve center.

Cause-Impurities in the blood from retaining in the system matter which should be eliminated either through the bowels, the kidneys or the skin. A blow, a kick or other injury may be the exciting cause, but the morbid condi- 
tion of the blood must be such as to favor the formation of an abscess ere one is produced.

HOW TO KNOW I'T.

We find great swelling, which is hard in the beginning, but as it approaches full development becomes soft in the center, but remains hard on the outer edges. It is red, hot, and after a time is painful to touch. Abscesses may occur in almost any place upon a horse.

WHAT TO DO.

When the softening of the center becomes apparent, lance well with an eye to good drainage and wash twice per day with carbolized water.

\section{Glanders and Farcy.}

These are the same disease but present themselves in different forms. When it affects the lymphatic glands between the branches of the lower jaw and breaks out in the nose it is called the glanders. On the other hand when it attacks the glands and tissues of the legs and body it is called farcy. The virus from either will produce both.

Cause-We know but little of its causes, however, it is fostered and extended by contagion. It sometimes arises apparently spontaneously in armies and on shipboard.

HOW TO KNOW IT.

An animal with acute glanders suffers from languor; 


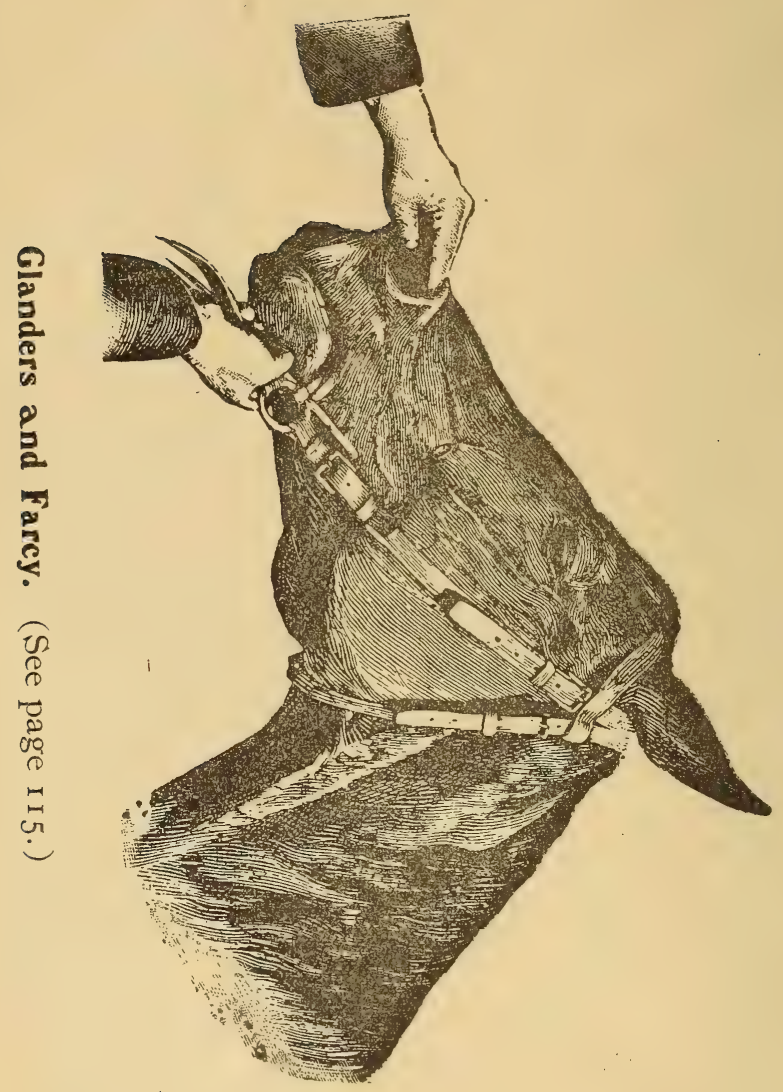


presents a dry staring coat, red weeping eyes, loss of appetite, elevated temperature, running up to probably Io6 $^{\circ}$; the pulse will be quick and breathing hurried. There will be a watery discharge from the nose which soon becomes sticky and rather yellowish in appearance. The lining membrane of the nose becomes a grayish purple in color. At this stage the discharge from the nostrils will sink in water. The nostrils become ulcerated; yellowish points with purple bases make their appearance and burst, causing the discharge to become bloody for a time. These ulcers will spread and run together, eating away the tissues as they go. In the beginning the edges of these ulcers are elevated and the centers are depressed. As the disease progresses the discharge increases and a horrible odor is emitted. Ulcers finally form in th: lungs, the breathing becomes labored and the ho se dies.

Chronic glanders runs a less rapid course, but presents the same symptoms as acute, with the exception that the appetite is less affected, the discharge from the nose is less copious and a great deal less offensive.

Farcy is distinguished by a swelling of the legs either one or all four of them. Nodules break out which discharge an unhealthy pus, these generally cure up in a few days leaving a bare spot to tell the tale. The swelling of the legs does not yield to treatment. Farcy always results in glanders ano terminates fatally. It is contagious.

WHAT TO DO.

Kill and burn the animal affected with either of these, 
quarantine all others which have been exposed, for at least sixty days, disinfect barn and clean up harness, halters, tie ropes, etc.

CHAPTER VII.

\section{DISEASES OF THE HEART AND BLOOD VESSELS}

It is very difficult to diagnose the diseases of the heart, and but few of them are influenced by treatment. For the sake of information rather than practical utility, we give this chapter.

\section{Diseases of the Endocardium.}

The endocardium is a serous sac which sur rounds the heart and secretes a fuid which keeps the heart constantly lubricated.

\section{HOW TO KNOW I'T.}

A horse with this trouble will stand around with no inclination to move, he will allow his head to hang down and will appear as if suffering. The pulse will be high, and upon placing the ear over the region of the heart 2 harsh, rasping sound will be heard.

$$
\text { WHAT TO D? }
$$

The only thing we can do is to treat constitutionally with:

\section{PRESCRIPTION.}

Nitre, Spirits of . : : : . . . I I -2 ounces 
Aconite, Tincture of ...... I drachm

Belladonna, Fluid Extract of . . . 2 drachms

Gentian, Tincture of . . . . . . I ounce

Potash, Nitrate of . . . . . . . I ounce

Ammonia, Muriate of . . . . . . I ounce

Water, q. s. ad . . . . . . . I pint

Mix and give four tablespoonsful every 2 or 3 hours

\section{Enlargement of the Heart.}

This is a condition in which the heart has increased in size, and it is generally confined to the left ventricl. It is by no means uncommon.

\section{HOW TO KNOW IT.}

Our only means of diagnosis in this disease $1 \mathrm{~s}$ mrough the pulse and temperature. The pulse will be irregular in its action with reference both to force and number of beats.

The temperature will be very uneven, one side of the body being cold and the other hot, or one leg cold while the others are warm.

\section{WHAT TO DO}

Give patient gentle exercise and use the following:

\section{PRESCRIPTION}

Potash, Iodide of . . . . . I-2 ounce.

Nux Vomica (Powdered). . . . I ounce

Foenugreek (Powdered) . . . . . . I ounce

Blood Root (Powderrd) . . . I I-2 ounces 
Mix and divide into 8 powders, and give one night and morning.

\section{Atrophy of the Heart.}

In this trouble the walls of the heart become flabby and soft, a kind of wasting away as it were of the heart substance.

HOW TO KNOW IT.

There will be pallor of the mucous membranes, languor and emaciation. Tike pulse will be weak and irregular, and often misses $t$ wo or three beats at a time.

WHAT TO DO

Use the iollowing 3 or 4 weeks:

PRESCRIPTION

Nux Vomica (Powdered) . . . . 2 ounces

Iron, Sulphate of ". . . 2 I-2 ounces

Foenugreek " . . . . . 2 ounces

Sassafras Bark " . . . . 2 I-2 ounces

Mix and divide into 16 powders and give one night and morning.

\section{Aneurism}

This is a dilatation of an artery, brought about through the weakening of the artery wall, it being subjected to the powerful pressure of the blood from the heart's action. 


\section{HOW TO KNOW IT.}

An enlargement or bulge, and distinct pulsations are observed when there is an aneurism. The aneurism is soft and compressible.

\section{WHAT TO DO.}

In case it be the large arteries in the abdominal cavity nothing can be done, but if an aneurism appears on the outside of the body apply ice or cold water and a compress to the swelling.

\section{Thumps}

This is a peculiar spasmodic action of the heart, and is brought about by over exertion. It is most likely to occur in summer.

HOW TO KNOW I'T.

The heart thumps away as if it wanted to get out, often shaking the entire body, the patient usually sweats freely and puts on an anxious expression as if in distress; the breathing is labored.

WHAT TO DO.

Give the patient rest and stimulate the heart's action with this:

PRESCRIPTION.

Brandy . . . . . . . 3 ounces 
Digitalis, Fluid Extract of . . . . 6 drops Opium Tincture of . . . . . 2 drachms Water, q. s. ad . . . . . . . . I pint Mix and give at one dose and repeat 3 or 4 times a day for several days. 
CHAPTER VIII.

\section{DISEASES OF THE BRAIN AND NERVOUS SYSTFM.}

The, nervous system of the horse is highly developed, approching in many respects that of man; this being the case he is more liable to brain affections and nervous disorders than any of the other domestic animals.

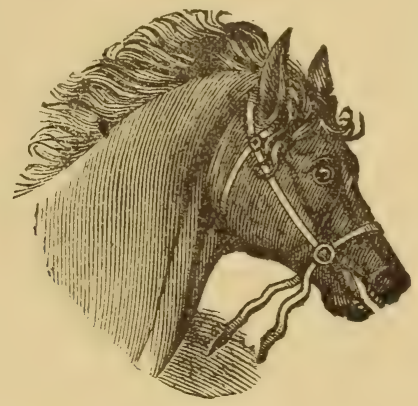

\section{Inflammation of the Brain.}

This is a very common trouble in the horse and we should study it closely. It is very essential to us that we secure well the patient for he generally struggles most violently during his mad fits.

Cans-The cause is by no means always apparent, but 
it is generally supposed to be due to extension of fever. Blows upon the head may produce it, and again it's being more prevalent in summer than in winter, gives color to the theory that exposure to the burning sun for long periods may be a prolific cause.

\section{HOW TO KNOW IT.}

The patient is apparently prostrated, the mucous membranes are very red, those of the eye being particularly so; the pulse and respiration are both quickened and the bowels are constipated. There is a peculiar delirium at first followed by stupidity. The patient will be noticed placing his head against the wall as if to brace himself; he will occasionally eat and while doing so will sometimes doze off, when awakened he will move around and paw the ground, then lay his head against the wall and doze again. A horse may go on in this way for several days, the fits, however, becoming more violent at every recurrence.

WHAT TO DO.

First give the following as a purge:

PRESCRIPTION.

Linseed Oil . . . . . . . . I pint

Aloes Barbadoes ........ 6 drachms

Calomel ........ I 5 grains

Mix and give at one dose and repeat in 12 hours if necessary.

To reduce the fever use this:

PRFSCRIPTION

Belladomna, Fluid Fxtract of . . . 2 drachms 
Aconite, Tincture of . . . . . . I drachm

Water. q. s. ad ......4 4 ounces

Mix and give one tablespoonful every hour until pulse comes down to 45 beats a minute. After this is done give the following:

PRESCRIPTION.

Potash, Bromide of ...... I drachm

Warm Water . . . . . . . I-2 pint

Mix and give at one dose 3 times a day for 4 or 5 days, then use a good tonic for a couple of weeks.

\section{Meningitis}

Meningitis is of rare occurence, difficult to treat, and a horse affected with it seldom recovers.

Cause-A general plethorie condition brought about in most instances by high feeding and but little work or exercise.

HOW TO KNOW IT.

At first the patient seems dull and listless, then he reels and stumbles and sometimes falls. The respiration is rapid and the pulse becomes quick and full; the pupils of the eyes are dilated and there is a very noticeable twitching of the muscles of the neck and head. At first patient is very nervous, but as disease progresses blindness and deafness set in and he notices no more. 


\section{WHAT TO DO.}

Apply ice poultice to the head and give same purge as recommended in inflammation of the brain. Give bromide of potash in three drachm doses 3 times a day.

\section{Apoplexv.}

This condition is brought about by sudden pressure upon the brain when a horse is healthy in other ways.

Cause- Anything which produces pressure on the brain. A horse exerting himself in a collar which is too small, causing a rush of blood to the head, is a very common cause.

HOW TO KNOW IT.

The horse staggers and falls, froths at the mouth and is insensible. There is a peculiar paralysis with twitching of the muscles. The respiration stops for a short time and occasionally there is a hemorrhage from the nostrils.

\section{WHAT TO DO.}

Remove collar instantly and give patient a chance to breathe. Bathe the head freely with cold water and suf ferer will be all right in a few minutes.

\section{Lock-jaw or Tetanus}

This is a condition in which the whole nervous system is in a state of extreme excitement, the motor, sensory and sympathetic systems all being involved. 
Cause-It may be brought about by overheating, worms in the intestines, or a common cold, but the most prolific cause is a wound, such as a nail in the foot, castration and wire cuts.

\section{HOW TO KNOW IT.}

Lock-jaw is so well known by almost every one that it seems needless for me to say much about its symptoms. First there is extension of the head and difficulty in chewing, and upon examination it will be found that the mouth cannot be opened to its full extent. There is general stiffness and fixedness in the manner of standing. By raising the head more of the haw of the eye and less of the eye itself will he seen. Elevating the head canses great nerrous excitement upon the part of the patient, increasing the spasms of the neck and jaws. The nostrils are dilared and the legs and ears are stiff. The muscles are hard and patient sweats profusely. In the course of 12 hours the jaws usually become completely locked.

WHAT TO DO

Relax the system by giving hypodermic injections of the following:

\section{PRESCRIP'TION}

Morphine, Sulphate of ..... 2 grains

Atrophine . . . . . . . . I grain

Water, q. s. ad . . . . . . r drachm

Mix and give at one dose hypodermically, and repeat every 
3 hours until muscles are relaxed. At the same time force patient to inhale sulphuric ether from a towel, allowing fresh air along with it. If cause be from a wound treat this also in a rational way.

\section{Sun Stroke.}

Sunstroke is quite common in some parts of the country, particularly in the cities.

Cause-Exposure to the hot sun and over exertion in hot weather.

\section{HOW TO KNOW IT.}

The horse is sweating and suffering from heat, when suddenly he stops and sweat dries off, then he begins to stagger, becomes weak, stupid and deaf. The surface of the body will be hot; the breathing is labored and the patient soon falls in an uuconscious condition.

WHAT TO DO.

Throw cold water over patient until he is thoroughly cooled off, then give this:

PRESCRIPTION

$$
\begin{aligned}
& \text { Brandy . . . . . . . . . . . . . . I pint } \\
& \text { Water . . . }
\end{aligned}
$$

Mix and give at one dose and in 2 hours give patient just a half dose more. 


\section{Blind StagBers}

This is one of the most serious of all brain troubles, and it is thought by some that the usefuness of the animal is impaired, even though he survives the trouble. The experience of the writer is sufficient to justify the assertion

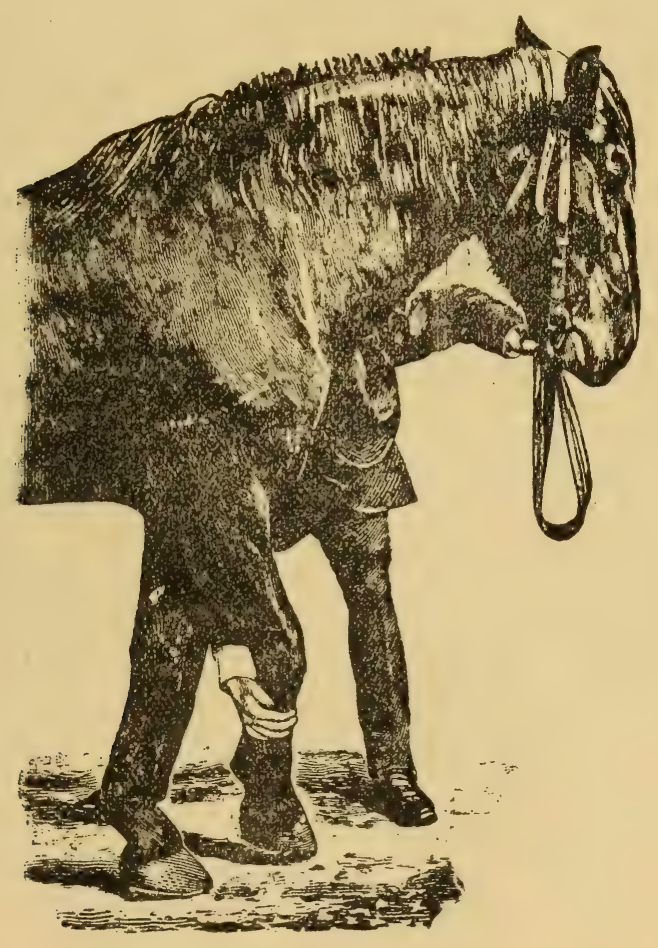

that if the proper remedies are promptly employed, 2 horse can pass through the "blind staggers" and come out as sound and healthy as though he had nerer had them.

Cause-Rupture of the meningeal blood vessels. 
HOW TO KNOW I'T.

The first symptom usually noticed is drowsiness upon the part of the horse, he will hang his head, his breathing will be hard and gait straddling; in leading he will go to one side; and if left free will lean against almost anything. As disease progresses he will be hard to manage, becoming violent at intervals. The pulse will be soit and regular, running from 50 to 80 beats per minute. The temperature will run from $103^{\circ}$ to $105^{\circ}$.

\section{WHAT TO DO.}

First bleed the patient from the nasal veins. These can be readily found with the knife by passing it through from the outside just under the point of the nasal bones. The blood will pass out the nostrils and continue to flow from 25 to 40 minutes. There is no danger in this, so allow patient to bleed all he will. In one hour after bleeding give this as a purge:

\section{PRESCRIPTI ION}

Linseed Oil . . . . . . . . I pint

Aloes Barbadoes . . . . . . 6 drachms Mix and give at one dose, and if bowels do not move in I 2 hours repeat it. To control fever use the following:

PRESCRIPTION.

Aconite, Fluid Extract of . . . . . I drachm Belladonna, Fluid Extract of ... . 2 drachms 
Water, q. s. ad ...... 4 ounces Mix and give one tablespoonful every hour until pulse

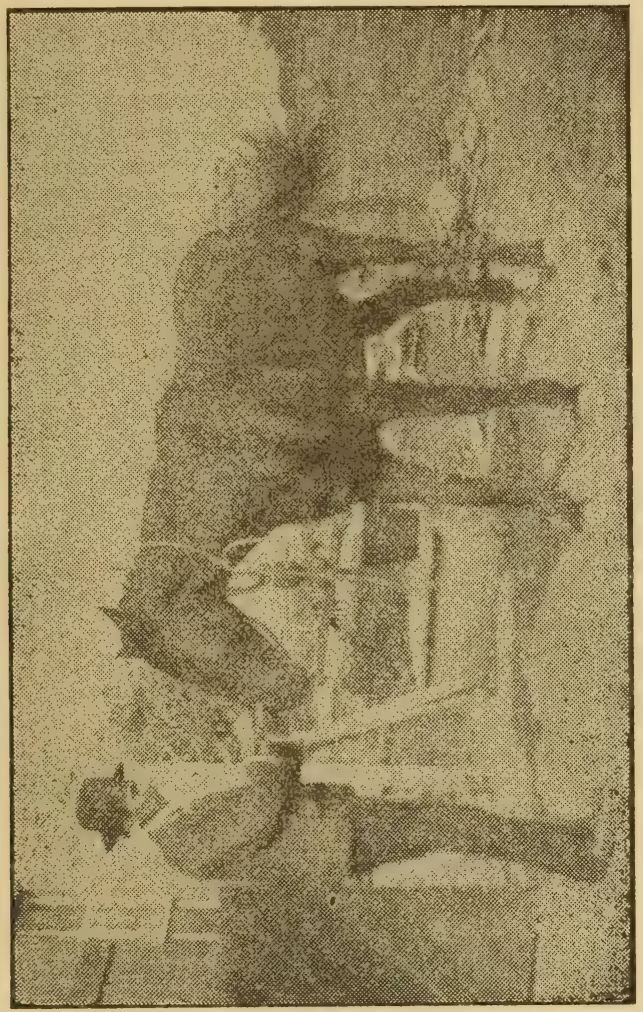

runs down to 50 beats a minute. After this give quinine in one drachm doses twice a day for 3 or 4 days.

\section{Loco Poisoning}

This is a peculiar condition of the brain produced by an animal feeding upon the dreaded loco-weed. 
HOW TO KNOW IT.

A locoed horse has fits of delirium, which begin in a mild way, but keep increasing in sererity until the animal becomes wild and unmanageable, he becomes crazy, rearing and plunging until finally he goes down and dies in convulsions.

\section{WHAT TO DO.}

Treatment is useless, but Bromide of Potash in one drachm doses might he resorted to to quiet the nervous system. 
CHAP'THR IX.

\section{DISEASES OF THE EYE}

Diseases of the eye are by no means so common in the horse as in the limman family, but some of them are of much-moment to the owner when the usefulness of the animal is taken into consideration. Any defect of the eye detracts largely from the value of a horse in the estimation of dealers, hence it is of the utmost importance that we study carefully some of the more common affections of this organ.

\section{Moon Blindness.}

In the great west multitudes of good horses lose their powers of seeing through the baneful influences of this disease.

Cause-The cause is an hereditary one.

$$
\text { HOW TO KNOW IT. }
$$

There is a swelling of the whole eye and all the parts surrounding it; it is closed or nearly so; the mucous membrane is very red, the tears run down the cheek and a whitish pus may be observed in the lower portion of the eye. In a few days the inflammation subsides, but the pupil will appear ragged, and in the course of a month or two the trouble recurs in a more aggravated form. The trouble 
continues to recur and eventually results in a cataract; when this occurs tre trouble subsides. It may affect either one or both eyes at the same time.

WHAT TO DO.

This trouble cannot be cured, but can be alleviated by using cold applications, keeping patient in a dark place, and seeing that the bowels are kept well open.

\section{Glass Eye.}

This is a paralysis of the optic nerve with no alteration of the structure of the eye, aside from the loss of power of seeing.

Cause-Injuries to the brain and pressure upon the optic nerve are the most common causes, but it may be the result of very high fevers.

\section{HOW TO KNOW IT}

The eyc thus affected usually presents a white, glassy appearance. It may be present in one or both eyes. In many cases the sight of the animal is seriously involved.

\section{WHAT TO DO}

Treatment is valueless as a cure can not be hoped for.

\section{Inflammation of the Iris.}

This is an inflammation of that portion of the eye forming the pupil of it and giving color to it. 
Cause-Constitutional disorders, exposure to and facing severe winds, extremes of light and darkness, etc.

HOW TO KNOW IT.

A pink ring is seen around the white coat forming the back part of the eye, the haw is drawn up, the eye being retracted and partially closed. There is considerable inflammation and the pupil is very small. The aqueous humor becomes turbid, and in the anterior chamber it will be noticed that white flakes are floating.

WHAT TO DO

Cover eyes of patient with a dark cloth and place nim in a darkened stall. See that bowels are well open and bathe the eye with warm water and use the following:

\section{PRESCRIPTION}

Zinc, Sulphate of ....... . 2 grains

Morphine, Sulphate of . . . 4 grains

Water, q. s. ad . . . . . . 2 ounces

Mix and drop a few drops into the eye 3 or 4 times a day.

\section{Cataract.}

This condition represents the most common termination of all the inflammatory diseases of the eye.

Cause-The cause is in almost every instance a preceding disease of the eye.

HOW TO KNOW I'T.

The trouble is so plain as to be easily recognized The 
pupil is filled with white lymph and is dilated very much. Fxamine eye 11 dark stall with a candle; if you find three reflections there is no cataract, but if one or two of them are blurred or wanting, you can be sure of the trouble.

In recent cases a strong purge with the following application to the eyes may clear them up.

\section{PRESCRIPTION}

Copper, Sulphate of . . . . 3 grains.

Water, q s ad....... . 2 ounces.

Mix and apply to eye twice per day. In the latter stages of this disease nothing can be done of benefit.

\section{Weeping Eyes.}

This is an obstruction of the tear duct, which is a small tube or passage leading from the floor of the eye into the nostri1.

Cause-Extension of inflammation in catarrh is generally the cause, but anything which closes the tear duct or causes it to be closed is sufficient to produce this condition

HOW TO KNOW IT.

The eyes look very weak and tears are constantly flowing over the cheek. It may be confined to one eye, and again both may be affected.

WHAT TO DO.

Examine the nasal opening of the tear duct and if there 
should be any obstruction remove it. If there be no mechanical obstruction throw about a tablespoonful of pulverized ginger into the nostrils, this will produce a fit of sneezing the force of which will open duct.

\section{Torn Eye Lids}

This should, to come in properly, be placed under the head of operations, but for the sake of convenience wc treat it in a brief way here.

Frequently the eyelids are torn by being caught on snags, nails, hooks, etc., and when possible we should always sew them up. Use fine silk thread, bring the severed edges neatly and evenly together and make fine stitches

Dress wound twice per day with carbolized water. 
CHAPTER X.

\section{PARASITIC TROUBLES AND EXTERNAL AFFEC- TIONS OF THE BODY.}

In this chapter we will consider. the few parasitic diseases which are of consequence, and the numerous consequences, accidents and external diseases which are of importancc to the reader.

\section{Lice.}

These insects or parasites always impoverish the animal they infest. All horses suffer from their rarages at times more or less.

$$
\text { HOW TO GE'T RID OF THEM. }
$$

The following has proven very effective in the hands of the writer:

\section{PRESCRIPTION.}

O1l of Sassafras . . . . . 3 ounces

Oil of Cedar........ I ounce

Mix and apply with sponge or woolen cloth to all parts infested by lice.

\section{Mange.}

This is also a parasitic trouble, and there are two kinds of the parasite, but the preparation which destroys one ef- 
fectually gets rid of the other, so we do not go into any further explanation along this line:

HW TO KNOW IT.

There is intense itching, followed by rubbing upon the part of affected horse, and the more he rubs the worse the itching seems to get. The hair comes off in patches and the skin becomes rough, pimply and scaly, and gets quite raw at times. Mange usually affects the neck and head first; it is contagions.

\section{WHAT TO DO.}

First wash patient, cleansing him thoroughly, with soap and water, then use the following:

PRESCRIPTION.

Oil of Tar......... 4 ounces

Oil of Cedar. . . . . I-2 ounce

Sulphur. . . . . . . . 4 ounces

Linseed Oil, q. s. ad . . . . . . I pint Mix and apply to every affected spot.

\section{Ringworm.}

The trouble is the result of filth and poverty; it is contagious and is a kind of vegetable parasitic growth.

\section{HOW TO KNOW IT.}

First we notice a circular, scruffy patch, the hairs of which may be erect, bristly, broken or split up and drop- 
ping off: Later affected spot becomes entirely bald, with hair surrounding it as above described. This bald spot grows, maintaining a circular outline. It usually appears upon the back, loins, chest and head.

\section{ẀHAT TO DO.}

Bathe off affected parts with soap suds, and paint with tincture of Iodine twice a day for ten days.

\section{Itchy Tail.}

This is an itchy condition of the root of the tail.

Cause- Worms in the rectum, filth or some parasitic trouble.

HOW TO KNOW IT.

By the actions of afflicted animal; he will be continually rubbing his tail against anything he can reach.

WHAT TO DO.

Wash root of tail with soap and water and use the following:

PRESCRIPTION .

Olive Oil ........ 3 ounces

Carbolic Acid . . . . . . I drachms

Mix and apply once a day. 


\section{Itchy Skin.}

This is an itchy condition of the skin all over the body, and a horse afflicted with it sometimes becomes frantic from the annoyance, worry and pain.

Cause-When not due to lice or mange it is a form of surfeit, and is caused by a heated condition of the body.

HOW TO KNOW I'T.

A horse with this trouble is continually rubbing, scratching and biting himself.

$$
\text { WHAT TO D) }
$$

Give an oleaginous purge and follow with a vinegar bath; when this is done give the following:

PRESCRIPTION

Epsom Salts . . . . . . 6 ounces

Gentian (Powdered) . . . . . . I ounce

Potash, Nitrate of . . . . . 2 ounces

Linseed Meal . . . . . . . 4 ounces

Mix and give one tablesponnful night and morning.

\section{Surfeit}

This simply represents a condition in which nature makes an effort to throw off effete matter and get rid of superfluous heat.

Canse-High living with but little exercise. 


\section{HOW TO KNOW IT.}

Some times there is itching and again there is none. The skin is rough and scabby, and sometimes there are blotches which may disappear in a few days or scab over.

\section{WHAT TO DO.}

Give a good purge, a change of feed and plenty of exercise.

\section{Hide Bound.}

This is a generally unthrifty condition and is not a disease within itself, but is the result of some derangement of the system.

Cause-It may be due to exposure to cold, starvation, indigestion, diseased teeth, etc.

\section{HOW TO KNOW I'T}

The hair is turned the wrong way and the skin is tight on the body, dirty and full of dandruff and the animal is usually thin in order.

\section{WHAT TO DO.}

Make a thorough examination for $t$ : 1 cause and remove it when found. Give the following:

\section{PRESCRIPTION}

Acid, Nitric ... . . . . 3 drachms

Soda, Bicarbonate of .... : : : . 2 ounces 
Potash, Nitrate of . . . . . 3 ounces

Antimony, Block . . . . . 3 ounces

Asafoetida (gum) . . . . . 3 ounces

Mix thoroughly and give one tablespoonful a day for 3 days, then every other day until four doses are given in this way. This should be followed by good tonic.

\section{Eczema.}

This is simply a scalded condition of the back of an animal and is generally due to carlessness.

Cause-A horse getting wet and the hot sun coming out scalding his bàck.

\section{HOW TO KNOW IT.}

The skin over back, neck, hips and sometimes sides and belly is covered with scabs as thick as they can stand.

WHAT TO DO

Shelter patient from sun and rain and he will be all right in the course of time.

\section{Warts.}

Warts may come on any part of the body. They are generally tough and hard but may be soft and bleed easily. Usually they possess but little vitality.

Cause-They seem to be of spontaneous origin.

$$
\text { WHAT TO DO }
$$

If wart be anywhere except direct'y over an artery cut $\mathrm{t}$ off smooth with the body; and use the following: 
Acid, Arsenious . . . . . . 2 drachms Acacia, (Gum) . . . . . . . I drachm

Cocaine, Hydrochlorate . . . I8 grains Mix and add sufficient water to make a thick paste Bind a small amount of this to curface of wart and allow it to remain two days; after this apply vaseline. If after three or four days it appears that wart is not killed, go through same treatment again.

\section{Saddle Galls}

This is a condition in which the skin is rubbed off the back in spots, leaving raw sores, and is the same as collar and harness sores when it comes to treatment.

Cause-Badly fitting saddle-back, scalded with sweat, etc.

\section{WHAT TO DO.}

Bathe affected spots with warm water and castile soap, then use the following:

\section{PRESCRIPTION.}

Sulphur . . . . . . . . I ounce

Alum, (powdered) ....... I ounce

Calomel ......... Io grains

Mix and apply to sore once a day

\section{Sit-Fasts.}

These are large tumor-like lumps on the back. 
Cause-They are the result of saddle galls not being properly treated.

$$
\text { WHAT TO DO. }
$$

Take a sharp knife and cut them out then treat as a simple wound.

\section{Poll Evil.}

This is an abscess or fistulous sore affecting the bones of the neck near the poll.

Cause-Any bruise or blow near the top of the head is liable to produce this condition.

\section{HOW TOO KNOW IT.}

There is always some swelling and a flow of pus which is seen running down the side of the neck. This pus has a disagreeable odor, and when the bone is affected we observe the odor characteristic of caries. In a week or two pipes, as we call them, form, getting thicker and thicker all the time.

$$
\text { WHAT TO DO. }
$$

First open the fistulous sore with a knife, making a free incision, then use the following:

\section{PRESCRIPTION}

Copper, Sulphate of . . . . 3 drachms Water, q. s. ad . . . . . . . 8 ounces

Mix and inject into sore twice a day for 6 days, then change to this: 


\section{PRESCRIPTION.}

$$
\begin{aligned}
& \text { Zinc, Sulphate of . . . . . . . } 6 \text { drachms } \\
& \text { Lead, Acetate of . . . . . . . I ounce } \\
& \text { Water, q. s. ad . . . . . . . I pint }
\end{aligned}
$$

Mix and inject as above and for the same length of time.

\section{Fistula of the Withers.}

The word "Fistula"' is applied to any ulcerous lesion upon the external surface of the body. Fistula may exist in any part of the body. If we have a case of the Poll Evil, that is Fistula of the poll; the same will apply to Quittor and should have about the same treatment.

Cause-This condition is produced by the Withers getting bruised from other stock biting them, or bruised by the collar or saddle; or the horse rolling on a stone or some hard substance may cause it.

\section{HOW TO KNOW IT.}

In the beginning there is an enlargement $o^{*}$ the withers. At that time it will be hard and hot and painful to the touch. If it has been there for some time it may be filled with germ, and will feel soft and not very sore to the touch.

\section{WHAT TO DO.}

In case hard, painful swelling is observed, the trouble may frequently be aborted. To do tris, it requires both general and local treatment. . At first a physic should be 
given-the physic that is given in Blind Staggers. Then give him this:

\section{PRESCRIP'TION}

Nitrate Potash . . . . . . 2 ounces

Sulphate, Iron of . . . . . . I I-2 ounce

Gentian (Powdered) . . . . . . . I ounce

Mix, divide into 12 powders and give one, night and morning, then local application of cold water to the hot swollen spot for an hour at a time 3 or 4 times a day. This very often prevents Fistula from coming and gives the patient great relief.

In course of 4 or 5 days, if this fails to give relief and the parts are swollen and hard to the touch, puncture the swollen place fifteen or twenty times with some sharp instrument, being careful not to go further than through the hide. When this is done, use the following:

PRESCRIPTION

Oil of Cedar . . . . . . I I-2 ounces

Oil, Sassafras . . . . . . . 2 ounces

Strong Ammonia . . . . . . . 3 drachms

Camphor, (Gum) . . . . . . I-2 ounce

Turpentine, Spirits of . . . . . 2 ounces

Alcohol . . . . . . . . . 3 ounces

Mix and rub in well night and morning. If this blisters much, grease with hog's lard once a day. If a discharge has made its appearance, and little pipes have formed, take a probe and make an examination of the opening to find 
the direction and the depth of the opening, and at the same time see if there is any foreign substance in it, such as a fragment of bone from the spine of the vertebra or a disease of the same. If you find any loose bone or any thing else, remove it with forceps. You will always find where the bone is affected the pus that runs from the place has a very bad odor. After you have removed the piece of bone, if there should be any, then take a strip of some kind of soft white cloth and saturate it in Butter of Antimony. Let the strip be Io or $\mathrm{I} 2$ inches long and about I-2 inch wide. Press it into the opening, then draw it out in $\mathrm{I} 5$ or 20 minutes. Then put another one in and let it stay 24 hours, then take it out and wash it out with this:

PRESCRIPTION.

Sulphate Zinc . . . . . . . . I-2 ounce

Sugar of Lead . . . . . . . I ounce

Alum . . .. . . . . . I ounce

Water . . . . . . .. I pint.

Mix and wash out the opening once a day for 3 or 4 days. If there is any little pipes in the place, use another application of the Antimony. Keep the withers well oiled with hog's lard to keep the medicine from taking the hair off of the withers and shoulders.

After it is healed up, if there is an enlargement there, use this to take it down.

PRESCRIPTION.

Cantharides (Powdered) . . . 3 Drachms

English Rosin . . . . . . . . . . I-2 ounce

Hog's Lard . . . . . . . . . .3 ounces 
Mix, and rub in well. Let it stay for 32 hours and wash off with warm water and soap. In five days apply again and so on until it is gone down. If it is a long standing case, give the tonic powder that is prescribed in Laryngitis.

\section{Caries.}

This is simply an ulceration of the bone.

Canse-Wounds of any character affecting the bones are liable to be followed by it.

\section{HOW TO KNOW I'T.}

We know it by the odor emitted, which is the same as that of decayed teeth. There is always considerable swelling and the bone feels rough to the finger.

$$
\text { WHAT TO DO. }
$$

Make an opening with a view to drainage, allowing a free escape of pus, scrape diseased surface of bone well with a dull instrument and use this:

\section{PRESCRIPTION}

Acid, Hydrochloric . . . . . 4 drachms

Water, q. s. ad . . . . . . . . I pint

Mix and dress parts twice a day with it until bone heals, then treat as a simple wound.

\section{Necrosis.}

By Necrosis is ment the death of bone.

Cause-It is caused by caries and is a result of it. 
HOW TO KNOW I'T.

We find a fistula discharging offensive pus and pieces of dead bone, the discharge excoriating the surface over which it passes.

\section{WHAT TO DO.}

Make a free opening to allow escape of pus and dead bone, and remove the latter as rapidly as possible. Keep parts clean and use the following:

\section{PRESCRIPTION.}

Acid, Carbolic . . . . . I-2 ounce

Olive Oil . . . . . . . . I-2 pint

Mix and apply to parts by means of cotton or soft, clean cloth.

\section{Wire Cut.}

In some instances wire cuts, if not properly treated, destroy the usefulness of a horse, and in other cases we may do our best and not be able to over come the damage done.

\section{WHAT TO DO FOR THEM.}

Cleanse thoroughly and often with carbolized water and use the following liniment twice a day:

PRESCRIPTION.

Turpentine ........ 6 ounces

Camphor Gum . . . . . . 3 ounces 
Raw Eggs . . . . . . . . No. 3

Vinegar q. s. ad . . . . . . . 2 pints Mix by dissolving camphor in turpentine then add eggs and shake thoroughly, when this is done, add vinegar. In case wound is of sufficient moment to require stitching do this with an eye to drainage at its lowest point.

\section{Dropsy."}

Dropsy is the result of a peculiar condition of the system rather than a disease itself, and is ordinarily the result of some disease of the kidneys.

\section{HOW TO KNOW IT}

The legs, belly and sheath swell and there is indifference to food, weakness and emaciation with languor and palor of the mucous membranes.

\section{WHAT TO DO.}

Get at the cause and remove it. Tonics which affect the kidneys directly are indicated.

\section{Rupture.}

We have different kinds of rupture depending upon the place in which the breaking away of the parts which contains the bowels takes place.

Cause-Umbilical rupture is from a natural defect, while all the rest are from blows, kicks, strains. etc.

HOW TO KNOW IT.

We find a soft puffy enlargement on a surface which 
should be smooth, and it can readily be pushed back, but will remain only so long as pressure is maintained. In the scrotum we find scrotal rupture. Inguinal rupture is found in the groin or flanks, and so on. Rupture is in some cases attended by serious results in the way of gut strangulation, inflammation of the bowels, mortification and death.

\section{WHAT TO DO.}

Push gut back and make an incision; sew up opening in abdominal walls with cat gut sutures, and treat your opening through skin and tissues in the same manner, using silk sutures. When operation is complete inject hypodermically in two or three places around incision and about an inch from it a strong solution of common salt. This is done in order that swelling sufficient may be produced to aid in supporting intestines until the walls of the abdomen begin to heal. 
CHAP'TER XII.

\section{AFFECTIONS OF THE LEGS.}

In this chapter we will consider all the important diseases and accideuts of the legs, from the fetlock to the body of the horse.

\section{Windgalls.}

These are soft swellings around the fetlock, and may put in their appearance upon either leg of the horse.

Cause- They are caused by severe labor or strain.

$$
\text { HOW TO KNOW IT. }
$$

Windgalls are easily detected as they are simply puffy swellings about the ankle, and are usually about the size of a man's thumb. They are filled with oil instead of air as many think.

$$
\text { WHAT TO DO }
$$

First use the following :

PRESCRIPTION.

Cantharides (Powdered) . . . . . 2 drachms English Rosin . . . . . . . I-2 ounce Lard . . . . . . . . . . 2 ounces

Mix and apply to windgalls, allowing it to remain for fourteen hours. After this keep it well oiled, bandaging it at night. 


\section{Scratches.}

This is a condition in which chaps and cracks present themselves around the heels and in the hollow of the pastern

Cause-Snow, slush, ice and mud are the principal causes

HOW TO KNOW IT.

Cracks and chaps extend in all directions around the heels and up the legs. The skin in the hollow of the pastern is swollen, very painful, and is hot to the touch.

WHAT TO DO.

Wash the legs in warm water, removing all mud and dry dirt, dry them carefully, and use the following:

PRESCRIPTION

V'aseline . . . . . . . . . 2 ounces

Alum (Powdered) . . . . . 2 drachms

Mix thoroughly and apply twice per day.

\section{Grease Heel}

This is an inflammation of the deeper layers of the skin of the heel, and resembles scrathes very much.

Cause-Neglected scratches and a generally bad condition of the blood.

HOW TO KNOW IT.

There is an offensive, greasy matter oozing from the pores of the legs, thes - being swollen to the knees. If neglected proud flesh puts in its appearauce through the open- 
ings made by the pus, and if neglected farther, swelling can never be reduced.

\section{WHAT TO DO.}

Look to the bowels first, and if they are not well open give purge recommended in pneumonia, and when they have been moved off begin tonic powders prescribed in laryngitis: Bathe heels in warm water and apply this :

PRESCRIPTION.

Linseed Oil . . . . . . . . 8 ounces

Camphor Gum . . . . . . I-2 ounce Oil of Tar. . . . . . . . . 4 ounces

Mix and apply to heels once a day.

\section{Cocked Ankle.}

This is a condition in which a horse is from some cause inclined to rest his heels on the lower back part of his legs.

Cause-Sprains, bruises of the heel, corns, etc.

$$
\text { HOW TO KNOW IT. }
$$

The heels are raised, the ankle joint is thrown forward and there is no soreness.

WHAT TO DO

Seek out cause and remove it is sufficient for a cure.

\section{Ring-Bone.}

This is simply a bony enlargement on the pastern. 
Cause-Any injury which sets up an inflammation on or near the pastern may produce it.

\section{HOW TO KNOW IT.}

We can feel it plainly around the pastern either in lumps or a ring running entirely around, and it may seem as if spread out on the bone.

$$
\text { WHAT TO DO. }
$$

Give patient absolute rest and use this liniment:

$$
\text { PRESCRIPTION . }
$$

Mercury, Bichloride of . . . . I ounce

Camphor Gum . . . . . . 3 d̀rachms

Ammonia Aqua ...... . 2 drachms

Turpentine q. $\mathrm{s}^{\cdot} \mathrm{ad} . . . . . .88$ ounces

Mix and apply to pastern once a day until well blistered, then grease with lard until scab falls away then blister again.

\section{Splint.}

Splint is an enlargement of the bone between the knee and pastern joint. It causes no serious trouble unless near a joint.

Cause-Bruises of any kind which sprain the ligamentous attachment between the cannon and the splint bones.

HOW TO KNOW ITT.

If near a joint some lameness is produced. Splint is 
simply a long bony lump found usually on the inside of the cannon bone.

$$
\text { WHAT TO DO. }
$$

Treat just as you would ring bone.

\section{Bone Spavin.}

By bone spavin is meant a condition in which there has been a leakage of the joint oil with ossification of it.

Cause--The cause in almost every case is a strain.

HOW TO KNOW I'T.

We find a peculiar lameness which is very noticeable when the patient has been driven and allowed to cool and started up again. Upon examining the hind leg we will find a bony enlargement just a little below the joint and on the inside of the leg.

\section{WHAT TO DO}

The following has never failed to relieve this condition when properly used:

\section{PRESCRIPTION}

Acid, Nitric . . . . . . . 2 ounces

Acid, Sulphuric ............ 2 ounces

Aconite, Fluid Extract of .......4 drops

Morphine, Sulphate of... . . . . . I grain

Calomel................. ounces

Cantharides (Powdered) ......... I drachm 
Chloroform ......... I 5 drops Arnica, Tincture of . . . . . . . ro drops

Mix. In compounding this, great caution must be exercised, it must be stirred all the time Use an earthen bowl and an earthen pestle to stir it with. Put in calomel a little at a time and do not put in the cantharides until it comes to a boil then stir until gas is nearly all out and add the chloroform and arnica. Apply this to spavin knot every other day for three or four applications, as a rule three are sufficient. After this keep it well greased with lard until it begins to heal.

\section{Bog Spavin.}

This is an enlargement of the hock.

Cause-Any sprain sufficient in character to produce inflammation of the synovial membrane.

\section{HOW TO KNOW IT.}

On the inner front of the hock we find a soft swelling resembling a windgall. In severe cases there is lameness, but in mild ones there is little if any.

\section{WHAT TO DO}

Puncture swelling with a sharp instrument just through the skin some twenty-five or thirty times. When this is done use the following:

PRESCRIPTION.

Turpentine ........ 2 ounces 
Oil of Spike . . . . . . 2 drachms

Oil of Origanum . . . . . 2 ounces

Camphor Gum . . . . . I-2 ounce

Oil of Tar . . . . . . 2 ounces

Alcohol q. s. ad . . . . . . I6 ounces

Mix and apply twice a day.

\section{Blood Spavin.}

This is a distension of a rein as it passes over the enlargement of bone spavin, the bone being constructed the blood is dammed up.

HOW TO KNOW I'T.

On the inside of the hock and just above the joint we find a soft swelling as in bog spavin, only a little higher up and father inside the leg.

\section{WHAT TO DO.}

Puncture place as in bog spavin and use liniment prescribed in wire cuts for ten days. Should "this fail to relieve the trouble an operation will be necessary.

\section{Sweeny}

Sweeny is by no means as common as a great many think for. In nine ases out of ten thought to be sweeny the trouble is either in the foot or some other portion of the limb.

Cause-It is usually caused by being bruised either from a fall or from the collar not fitting in lauling, plowghing, etc. 
There is soreness, lameness and wasting away of the muscels of the shoulder blade. A horse with "sweeny will rest his foot on the toe without extending it. Rest sometimes seems to relieve sweeney, but work brings it on again.

\section{WHAT TO DO.}

Puncture the shoulder as in bog sparin and repeat it every eight days for three or four weeks and use this liniment all the time.

PRESCRIP'TION.

Turpentine ....... . 3 ounces

Camphor Gum . . . . . 3 drachms

Oil of Cedar . . . . . . . I ounce

Oil of Sassafras . . . . . . I ounce

Alcohol q. s. ad . . . . . . 8 ounces

Mix and apply once a day and should this blister, grease once a day also.

\section{Shoulder Lameness.}

This trouble is often taken for sweeny and it does sometimes result in it when neglected.

Cause-Strains, kicks, or injury of any kind may produce it.

$$
\text { WHAT TO DO. }
$$

In the shoulder joint there is some soreness, but there is 
none in the shoulder blade as in sweeny. There is lameness and at the time the leg is being moved forward the

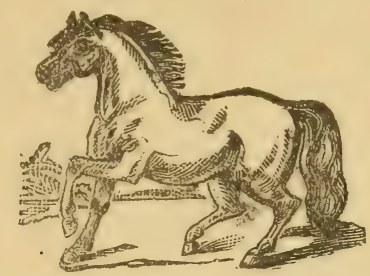

head is nodded down at the start and suddenly jerked up toward the finish of the movement.

WHAT TO DO.

First bathe off the shoulder for thirty minutes with very warm water, then dry thoroughly and apply liniment recommended in sweeny. If weather be inclement blanket after bathing with warm water.

\section{Stifled}

This is a condition in which there is a dislocation of the pulley bone; but any derangement of the stifle joints is generally referred to as "stifled."

HOW TO KNOW I'T.

The leg is apparently stiff and the horse is unable to move it forward. The horse can be made to back when he will swing himself over injured limb without raising his foot from the ground. In case the trouble be a strain instead of a true stifle, the patient will carry the leg farther forward than usual, but he will do it carefully and with seeming labor, bending the stifle joint as little as possible; 
there will be soreness and swelling and the injured horse will be noticed resting his leg.

\section{HOW TO KNOW IT.}

If the trouble be true stifle, tie a rope above the fetlock and pull the foot upward, outward and forward, raising it about eighteen inches from the ground, and while this is being done pressure by the hand sufficient to force the pulley bone in place should be exerted over stifle joint. When pulley bone goes in place it will be with a "pop" which can be easily heard. Cord the opposite leg above the hock, this being done to force patient to stand on affected one. The stifle shoe is often used to advantage. Buthe affected joint with cold water for ten or fifteen minutes at a time, twice a day, and dry thoroughly, after which rub in well the liniment recommended for wire cuts. If the trouble be merely a strain the liniment is all that is necessary aside from rest.

\section{Hip Lameness and Hipped}

Cause-Hip lameness is caused by straining the muscles and ligaments around the hip joints. Hipped is caused by anything which strikes the hip with sufficient force to knock it down.

\section{HOW TO KNOW IT}

In hip lameness there is usually soreness directly over the joint and often some swelling can be observed from behind. On affected side the step will usually be much 
shorter than on the sound one. The patient may rest affected leg in standing, and again he may only give signs of lameness while traveling. In hipped a sight of the patient is sufficient.

\section{WHAT TO DO.}

For Lipped we can do nothing but give rational reliei from pain. In hip lameness bathe affected hip twice per day with hot rinegar and follow this with the wire cut liniment. 
CHAPTER XII.

\section{DISEASES OF THE FEET.}

The feet are subject to many diseases and injuries which often render a horse unfit for work. In this chapter we will consider the most common and important affections of the feet.

\section{Corns.}

Corns most frequently occur in the front feet and are nearly always on the inside,

Cause-High heels, contracted heels, long feet, weak feet, bruises, etc.

\section{HOW TO KNOW IT.}

There is lameness and soreness upon pressure over the corn. In paring the foot for examination we notice an

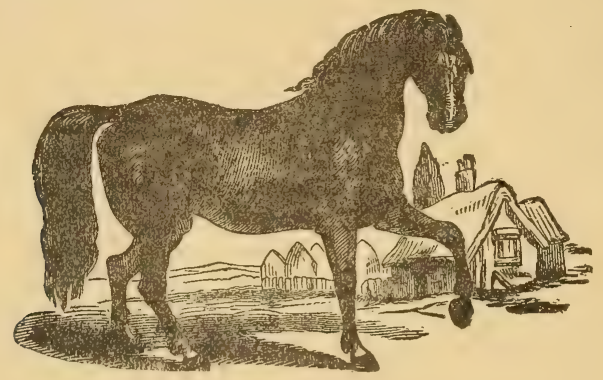

apparently blood-shotten spot, about the size of a dime. When this spot is present we know it to be a corn 
If there is a shoe on the foot remove it, and pare out the quarter until it is almost ready to bleed, when this is done apply carbolic acid full strength to corn once a day, and poultice with flaxseed meal. Should proud flesh make its appearance use powdered bluestone once a day for two or three days, then use this:

PRFSCRIPTION.

Oil of Tar......... 4 ounces

Oil of Origanum ...... I ounce

Linseed Oil . . . . . . . 6 ounces

Alcohol .......... 7 ounces

Mix and apply freely twice a day to the bottom of the foot.

\section{Quittor.}

This is a condition in which a sore has worked up through the foot and broken out around the top of the hoof.

Cause-Neglect of corns, nails in the feet, etc.

$$
\text { HOW TO KNOW IT. }
$$

There is swelling at the top of the hoof, this breaks in a few days, discharging pus. The pain, which is very severe in the beginuing, is relieved some by the breaking. In a few days after discharge begins the flesh around the opening gets soft and turns purple and in the course of 
two weeks pipes will form. The longer it runs the worse it gets.

\section{WHAT TO DO.}

Open freely and effectively and inject into all parts of the quittor the following:

PRESCRIPTION.

Copper, Sulphate of . . . . 2 drachms Water q. s. ad . . . . . . . 8 ounces

Mix and inject night and morning for six days then change to this:

\section{PRESCRIPTION .}

Zinc, Sulohate of . . . . . 4 drachms

Lead, Acetate of . . . . . . . I ounce

Water q. s. ad . . . . . . . . I pint

Mix and use as directed above.

\section{Pricking}

This is a condition brought about by a horse stepping upon a nail or other sharp things and at times produces serious results.

\section{HOW TO KNOW IT.}

The patient suddenly goes lame; a careful and painstaking examination of the foot will no doubt reveal the cause. 


\section{WHAT TO DO}

Keep the foot and wound cleaned out and use the following:

\section{PRESCRIPTION}

\begin{tabular}{|c|c|}
\hline Oil of Tar & 2 ounces \\
\hline Oil of Origanum & I-2 ounce \\
\hline Linseed Oil . . & 4 ounces \\
\hline Turpen & 2 ounces \\
\hline
\end{tabular}

Mix and fill prick wound with it twice per day.

\section{Quarter Cracks.}

These come on the quarters, usually on the inside, that quarter being weaker than the outer.

Cause-They are due to a lack of elasticity in the fibers and a brittle condition of the hoof.

HOW TO KNOW IT.

A sight of the split or crack in the hoof is sufficient

$$
\text { WHAT TO D I }
$$

If crack extends to the quick, pare down its edges to relieve pinching and make it more pliable. Then take a sharp knife and cut across the crack at the top on through to the quick. This is done to start a new hoof. If crack does not extend to the quick it is not necessary to pare the edges. We may know when it reaches the quick by horse going lame. Pare the foot in such a way as that the 
weight of the horse will tend to close instead of open it. Blister coronet with the following:

\section{PRESCKIPTION}

Cantharides (powdered) . . . . I-2 ounce English Rosin . . . . . . I-2 ounce Lard . . . . . . . . . 4 ounces

Mix and apply two or three times, or until well blistered. Use the same prescription as in corns, pouring the frog of the foot and cracks full twice a day.

\section{Thrush.}

This is a kind of ulceration of, and rotting away of the frog of the foot.

Cause- Standing in fflthy stables.

HOW TO KNOW IT.

We find a black watery discharge and very offensive smell from the heels.

WHAT TO DO

Put patient in clean stall and trim out frog, cleaning it thouroughly. Use in the frog the same prescription recommended in corns.

\section{Narrow Heel.}

Lameness of long standing always produces this condition the foot being rested every opportunity. 
Cause-Corns, founder, sprains of the muscles, ligaments and tendons of the leg and shoulder, etc. Leaving the shoes on too long is one of the most common causes.

\section{HOW TO KNOW I'T.}

A look at the foot will satisfy us.

WHAT TO DO.

Pare the foot down liberally; open the heel up to the soft parts, rasp off the quarters thin and do not touch the frog at all. Use the same hoof liquid as in corns and turn animal on soft pasture. If it is desired the shoes may be put on, but they shou!d be plain, without any calks, of medium weight, level on bearing surface and beveled off to avoid bearing on the sole. Quarters should be reduced to relieve them of any bearing on the shoe, and frog should be allowed to come to the ground. The shoes should be reset every three or four weeks.

\section{Gravel in the Foot.}

Gravel sometimes get into the feet of horses causing - lameness and much irritation.

Cause-The primary cause may be a nail hole but any wound of the foot is liable to get a gravel in it.

HUTV TO KNOW IT

The wound will appear black and unhealthy and by probing we distinguish a hard feeling. 
- WHAT TO DO.

For the sake of room trim hoof away around the opening. Then remove the gravel in a careful way and cleanse wound thoroughly with carbolized water, after this fill wound with liniment prescribed in wire cuts. If much inflammation be present a flax seed meal poultice will not hurt anything.

\section{Stone Bruises.}

Cause-These are in most cases caused by a brnise from stepping upon a round or projecting stone.

\section{HOW TO KNOW I'T.}

There is lameness, the tender spot being found upon either frog, sole or heel.

$$
\text { WHAT TO DO. }
$$

Poultice injured foot with linseed meal for twenty-four hours, after this pare the foot down directly over the bruise being careful not to cut into the quick. Then use the following:

PRESCRIPTION.

$$
\begin{aligned}
& \text { Turpentine . . . . . . . . . . . } 4 \text { ounces } \\
& \text { Tallow . . . . . . . . . . } 2 \text { ounces } \\
& \text { Bees Wax . . . . . . . . . . } 2 \text { ounces } \\
& \text { Pine Tar . . . . . . . . . . } 1 \text { ounce }
\end{aligned}
$$

Mix well by heating and apply to bruise twice a day. 


\section{Canker}

Cause-Neglect and attempts at treating wounds in dirty, filthy stables. Badly treated wounds are a cause.

$$
\text { HOW TO KNOW. IT. }
$$

There is a sprouting up of a ragged, shreddy, leathery, substance which looks as if it ought to grow together and form hoof, but it remains soft and tender.

$$
\text { WHAT TO DO. }
$$

Wash thoroughly with carbolized water, then apply a poultice of charcoal, to which a little carbolic acid has been added, remove this on the third day and pare canker down almost to quick and apply powdered blue stone for several days.

\section{Side Bone.}

This is an ossification of the lateral cartilages of the fore feet.

Cause-The most common cause is a bruise, but almost any disease of the foot can produce it.

$$
\text { HOW TO KNOW I'T. }
$$

The quarters are elastic, hard as a bone and are enlarged upwards from the hoof; the patient being very lame.

$$
\text { WHAT TO DO }
$$

Puncture the enlargements in ten or fifteen places with a 
common pegging awl just through the skin. Then use the following liniment:

\section{PRESCRIPTION}

Mercury, Bichloride of ...... I ounce

Camphor, Gum ...... I-2 ounce

Ammonia, Aqua ...... 2 drachms

Turpentine, q. s. ad . . . . . 8 ounces

Mix and apply every other day until well blistered and then grease with lard.

\section{Founder.}

From the nature and cause of founder, it might seem proper to have considered it under the head of diseases $\mathrm{cf}$ the stomach, but this trouble being in every instance referred to the feet, we take it up here and treat it under the heads of acute and chronic founder.

\section{Acute Foinder.}

This is a condition in which the symptoms are all aggravated in the beginning.

Cause-The presence of grain and too much cold water in the stomach at the same time, this leading to and producing a suspension of digestion. As a horse has no gall bladder, founder is the result when digestion ceases. We hear of road and water founder and the like, but no true case of founder can be produced without the presence of tco much grain and water in the stomach, 
Hi) T() KNOVIV IT.

The horse is in great pain, standing as if riveted to the ground; wnen he moves at all he appears as if walking on

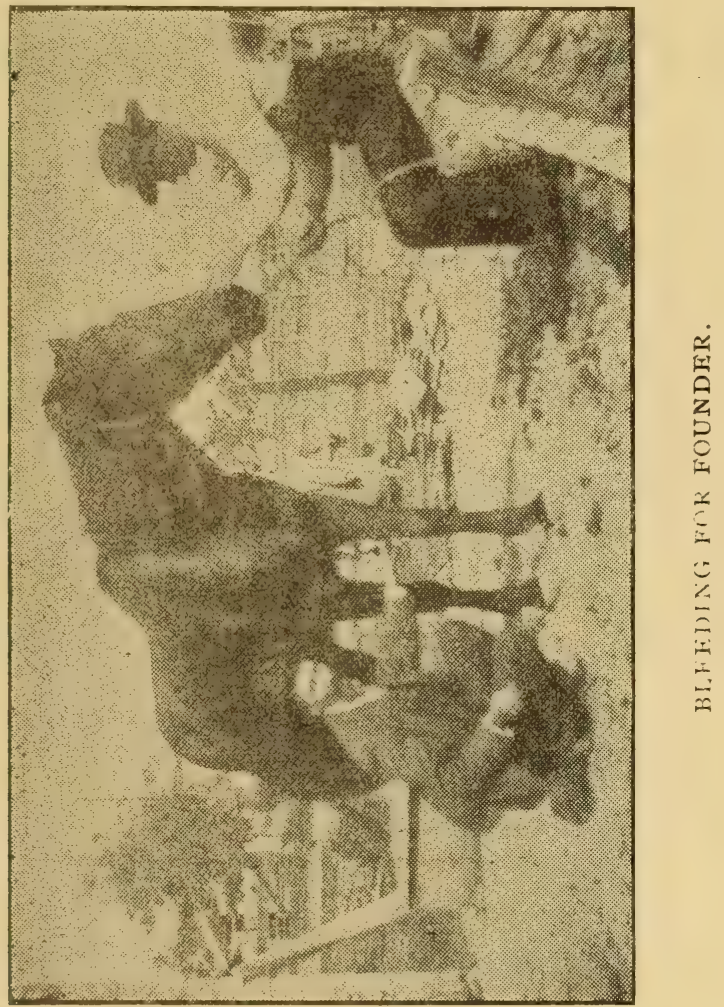

pins. A foundered horse can not back. The patient sweats profusely, his pulse and breathing are quickened and temperature is elevated. 
IVHAT TO DO.

First bleed from pluter veins just half way between the knee joint and caster wart, taking a quart of blood from ea h fore leg. When this has been done use the following internally.

A'oes Batbadoes. . . . . . I cunce

Potash, Nitrate of . : . . . . I-2 ounce

Gentian (Powdered) . . . 2 drachms

Ginger (Powdered) . . I-2 ounce

Mix and give at one close. Keep patient in dry lot and allow water in sparing quantities for a few days. Should patient have much ferer fluid extract of aconite in ten drop doses should be given every two or three hours.

\section{Chronic Founder}

This trouble represents a condition which is the resuit of neglect of acute founder.

Cuns-Improper treatment of acute founder and neg'ect.

$$
\text { HO W TO KNOW I'T }
$$

The patient goes with a short, shambling gait as if he was a confirmed cripp'e, his feet are always tender and hoofs are brittle with rough rings around the top.

\section{WHAT TO DO}

Pare out sole of foot, and should pus be found, release it. Then use one tablespoonful of the hoof liquid prescribed in corns in all four of the feet once a day. Give internally one tablespoonful of pulverized alum once a day, 
CHAP'TER XIII.

\section{DISEASES OF THE ORGANS OF GENERATION}

Horses are as a general rule freer from diseases of these organs than almost any other order of animals; these cases being no doubt due to their usual activity. In this chapter we will treat of nothing save the most important affections, these being the most common.

\section{Inflammation of the Testicles}

Cause-External injury and excessive copulation are the most common causes.

$$
\text { HOW TO KNOW IT }
$$

There will usually be some fever, much soreness and swelling of the parts, and a peculiar straddling gait.

\section{WHAT TO DO}

First bathe for thirty minutes with warm water and follow with the liniment recommended in wire cuts.

\section{Evil Results of Castration.}

This is a condition in which the cord is left too long, the ends falling between the edges of the wound in the surotum and adherring to them, both scrotum and cord swelling together, forming a tumor, like moss, often of large proportions. 


\section{WHAT TO DO.}

Cast the horse and dissect the enlarg, ment out as though it was a tumor.

\section{Wound of the Penis.}

Occasionally the penis is injured in teasing and covering mares.

\section{WHAT TO D?}

Bathe the penis in warm water, adding atout an ounce of the acetate of lead to the pint.

\section{Inflammation of the Womb.}

This trouble is usually brought about by injury during parturition and follows it two or three days.

\section{HOW TO KNOW IT.}

There is some ferer, colicky pains and almost continual straining as if to pass a foal, with a black discharge from the womb.

\section{WHAT TO DO}

If bowels are constipated give an oleaginous purge, and without waiting fr.r purge to act wash out womb with a half gallon of warm water to which a half drachm of bichloride of mercury has been added. Should the fever run high give the following. 
Aconite, Fluid Extract of . . . . I drachm Belladonna, Fluid Extract of . . . 2 drachms Niter,Spirits of . . . . . 2 ounces Water q. s. ad ....... 8 ounces Mix and give a tablespoonful in a pint of water every hour.

\section{Inflammation of the Ovaries.}

Though met with once in a while this trouble is very rare.

\section{HOW TO KNOW IT.}

It usually occurs at the time of heat and aggravates the passions. There is some fever though slight, soreness in the lumbar region and a disinclination to move around.

\section{WHAT T DO}

Give a half ounce of spirits of niter twice a day in a half pint of water. Do this for three days.

\section{Mares Hard to Foal.}

This is a condition met with when the mare wont foal.

Causc-From a diseased ovaro or contracted? womb, or the womb being turned to one side, or in a low state of health and etc.

\section{HOW TO KNOW IT.}

By the mare being put to the horse without becoming in foal. In a case of this kind make an examination of the womb. 
WHAT TO DO.

If the neck of the womb is closed up pass your hand into the neck of the womb, and if you find it contracted or closed, open it by working your fingers around in it until it opens, if it is very hard to dilate, saturate a sponge with a I-2 ounce of extract Belladonna and pass the sponge into the neck of the womb with yonr hand, and squeeze out the medicine around the neck of the womb, leave the mare quiet for one hour, then pass your hand up and remove the sponge and open up the neck of the womb with your finger, as it will be easy done after the medicine has relaxed the parts, after the neck of the womb is open let the horse on her at once. She will generally get in foal. If it is a case where the neck of the womb is turned to one side, try and straighten it with your hand and have the mare immediately put to the horse. If in case where the ovaries are diseased, there can not be much done. Only give her constitutional treatment.

Mares will start to breeding as young as two years old, and some mares will breed until they get twenty years old. The mare carries the colt I m months and some times a few days over. Old mares carry a colt a few days longer then a young mare.

\section{How to Tell When a Mare is With Foal.}

At first the mare becomes quieter in disposition, and thrives better; the belly gradually becomes distended, and at the end of the fifth or sixth month, after the mare has taken a drink of cold water, or by putting your hand over 
her nose so she can't breath for a minute you can see the colt move around, on the left side of the mare. Another way and the only sure way to tell is to oil your hand and arm and pass it up to the neck of the womb. If she is with foal the neck of the womb will be sealed and tight. In some cases you can feel the colt in the womb. Some mares will stay in season all the time and take the horse every three weeks and still be with foal.

\section{Parturition.}

The mare gets through with parturition very quickly when everything is all right, but in case oi malpresentation malformation of the pelvis they often need careful and intelligent assistance. No general rules can be laid down to follow in cases of this kind. Every thing depends upon the mare and the nature of her trouble, the foetus whether dead or alive, the time we have to work in, etc. Good common sense must be depended upon, and our best judgment exercised in the light of conditlons as they exist.

The natural presentation of a foal is for the fore feet to come first with the head resting upon and between them. If all means fail to deliver the foal alive we can cut it away piece by piece, opening its bowels first and taking them out and then proceeding as our best judgment would indicate. The lives of many valuable mares have been saved by this means.

\section{Abortion.}

But few mares abort without sufficient cause. It may be brought about by extra hard work, external violence, falls 
etc. As a rule everything passes off naturally and with but little outward signs of trouble aside from nervous prostration and a slight elevation of temperature and pulse.

\section{WHAT TO DO.}

Give absolute rest and watch patient closely. Give the following internally:

\section{PRESCRIPTION.}

Potash, Nitrate of ..... 2 ounces

Sassafras Bark (Powdered) . . . 2 ounces

Gentian (Powdered) . . . . . I ounce

Flaxseed Meal........ 8 ounces

Mix and give a tablespoonful 3 times a day.

\section{Puerperal Fever.}

This usually comes on about the second or third day after parturition, and is very fatal when neglected.

The organ becomes swollen, the temperature runs high, the pulse and respiration are rapid, the ears and legs are cold, the urine is scouty and highly colored, the bowels are constipated and the secretion of milk is suspended.

WHAT TO DO.

Protect the patient from exposure and see that the bowels are kept well open. Wash out the womb with a solution of boric acid, (about an ounce to the quart of water) and use same fever preparation as in inflammation of the womb. 


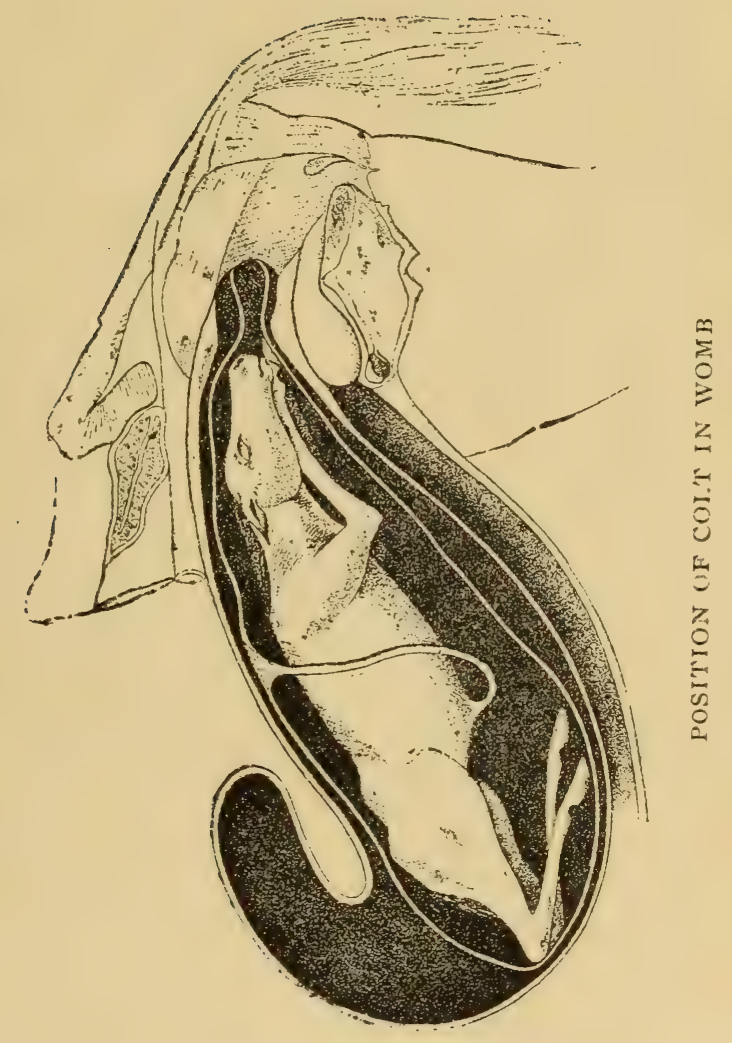





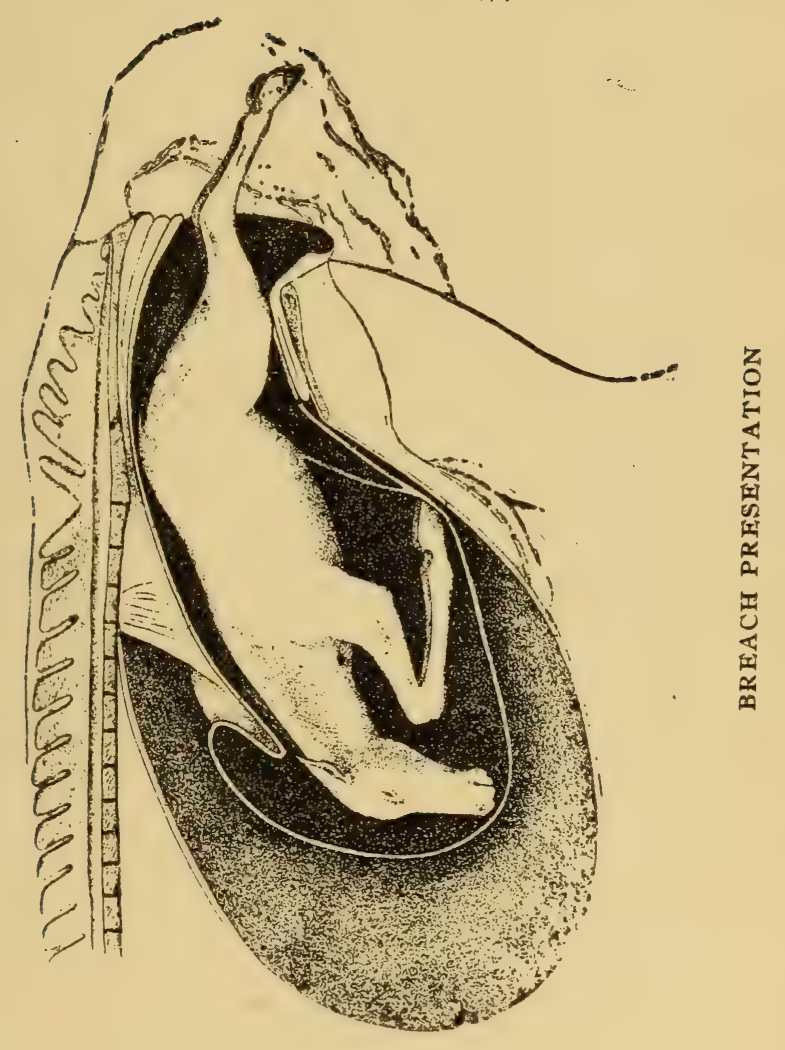





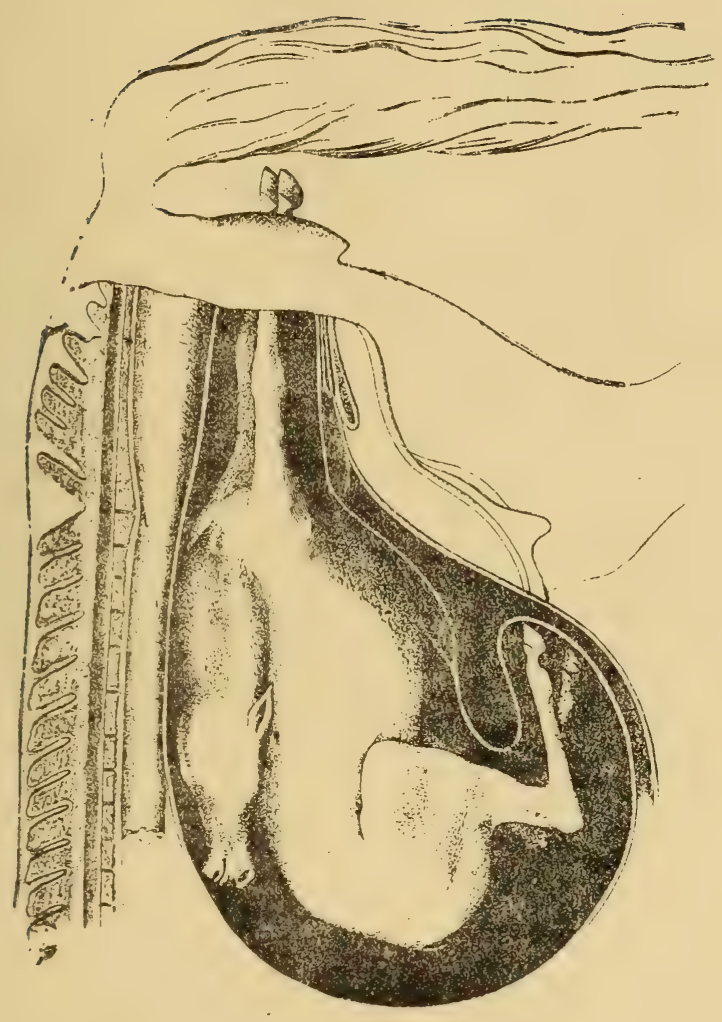

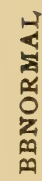

-

告

告

E

A

红

田

${ }_{0}^{2}$

告 



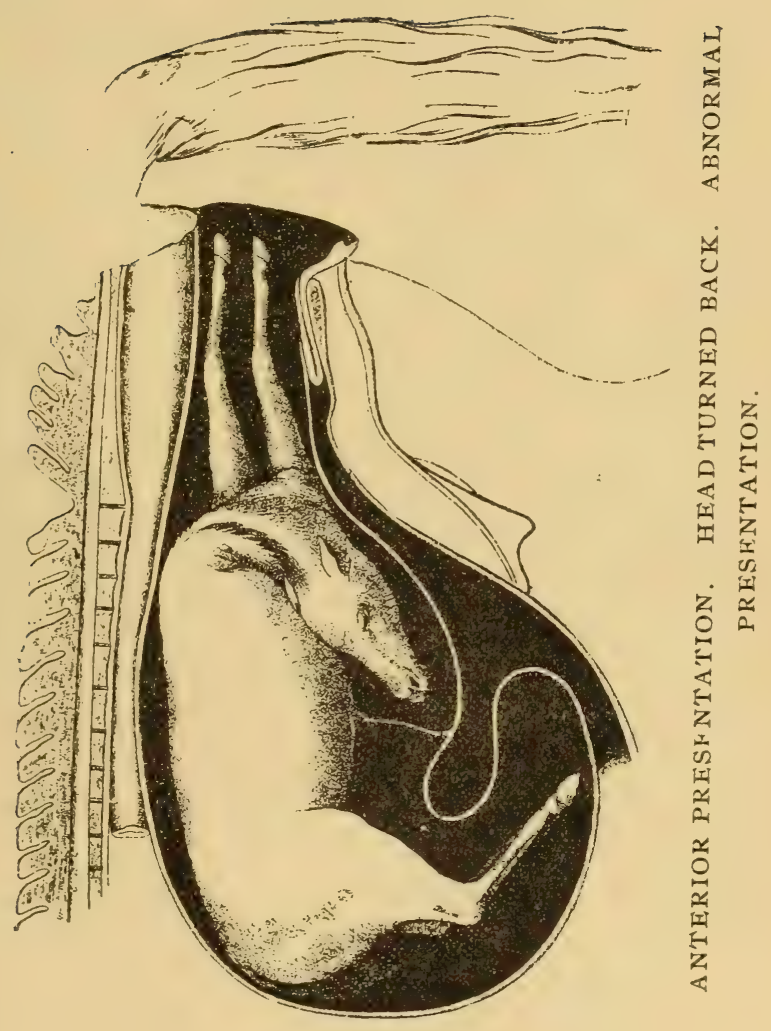



CHAPTER XIV.

\section{OPERATIONS ON THE HORSE.}

Some of the more simple operations can be readily performed by the commonality of people if they will but exercise a reasonable amount of care, but we can lay down no fixed rules in this connection, every case demanding its own peculiar treatment.

\section{Bleeding.}

This is almost an obsolete practice, but is still employed with beneficial results in some instances. Under no circumstances would I advise bleeding unless the pulse be full and strong. Bleeding in the nose has been fully described in blind staggers. Sometimes bleeding in the mouth is necessary, but it is not a good idea to make incision farther back than the second bar. To deplete the entire system we bleed from the jugular vein. This we do by cording the neck so as to fill the vein, then place the blade of fleam on it and strike it a good smart blow with a round stick. Always catch blood in some vessel so as to know how much you draw. Take anywhere from three to five quarts 
of blood, depending upon the size of horse. When patient has bled sufficiently remove the cord and bleeding usually stops, if it does not pass a pin through edges of wound and wind a hair or thread around it in a figure 8

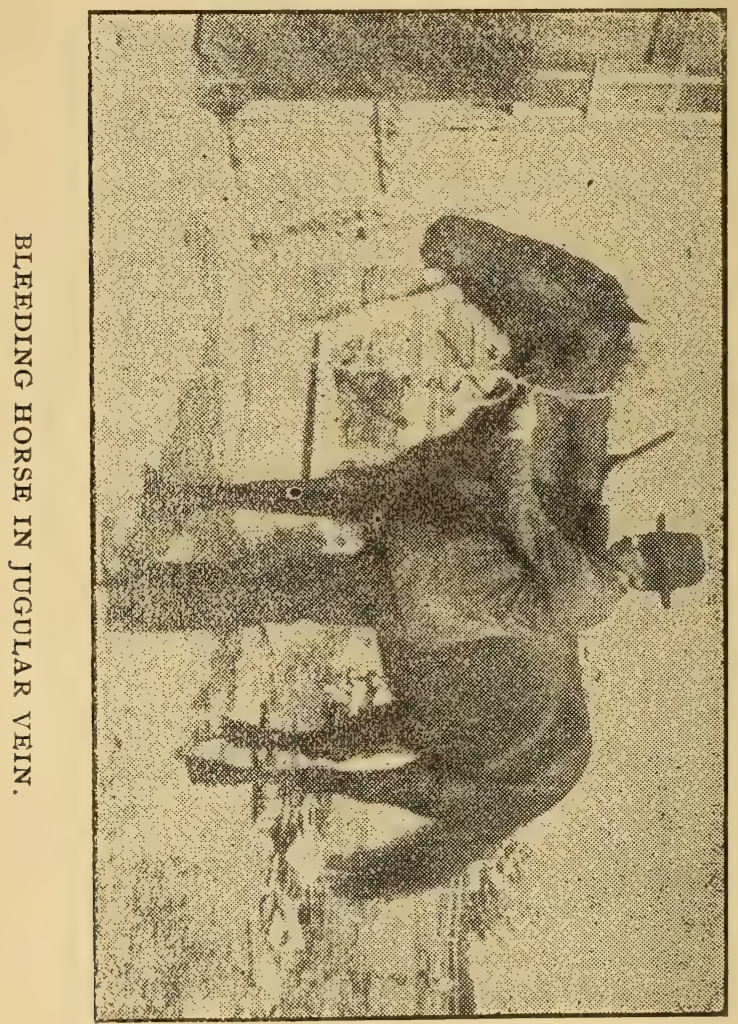

shape. In bleeding from legs in founder the legs are not corded, but the bleeding is stopped with the pin as just described. 


\section{Stopping Blood.}

To stop blood from wounds, such as wire cuts, castration, etc., we should take up.the severed artery and ligate it if possible; when this cannot be Idone apply Monsel's solution of iron on absorbent cotton, or dry tanic acid to wound. Should this fail apply iron at white heat.

\section{Extracting Teeth.}

This operation is entirely mechanical and requires forceps made for the purpose. Place forceps on tooth to be extracted and exert lateral pressure,until you feel it give in the socket then lift it out.

\section{Removing Tumors.}

Tumors are fatty, fibrous, fungoid, bony, etc., and nearly always require an operation. To remove a tumor make an incision through the skln and down to the tumor proper, dissect it out carefully and treat as a simple wound.

\section{Opening an Abscess.}

This is a very simple operation, but should always be done carefully and intelligently. Always open an abscess at its lowest point, (this is done for the sake of drainage,) make a free incision for the escape of pus. The idea in every instance is to get rid of pus and broken down tissues.

\section{Operating in Blood Spavin.}

To perform this operation it is best to cast the horse. Make an incision about four inches long through the enlargement and sufficiently deep to deplete it. Then place 
a sponge on the spavin knot and bandage tightly. Remove and replace this every twenty-four hours for several days.

\section{Tapping the Colon.}

This operation has been sufficiently described under the head of flatulent or wind colic.

\section{Tapping the Chest.}

This operation sometimes becomes necessary when there is an effusion in pleurisy. Remove the hair by clipping from the spot where you intend operating, which is about three inches back of elbow and about five from bottom of chest. Use a sharp scalpel, and cut between the ribs through skin and flesh and insert a trochar or quill and drain off all the water and repeat as often as it collects.

\section{Castrating.}

The best age for castrating is from two to three years, this usually admitting of a good development of the neck and fore parts. The mild days of early spring are best for operating on horses. Cast the horse and tie him securely, take the scrotum in one hand and draw it over one of the testicles so that the dividing line can be seen and avoided; make a slit in scrotum about three inches long and parallel with the dividing line, split open inner coverings one by one until testicle pops out, (do not wound testicle with knife, ) seperate tunics from the small end and scrape the cord into with knife about an inch and a half from testicle. When this is done remove the second testicle in the same way. Should there be much hemmorage from castration, use a strong solution of alum water in the scrotum. 


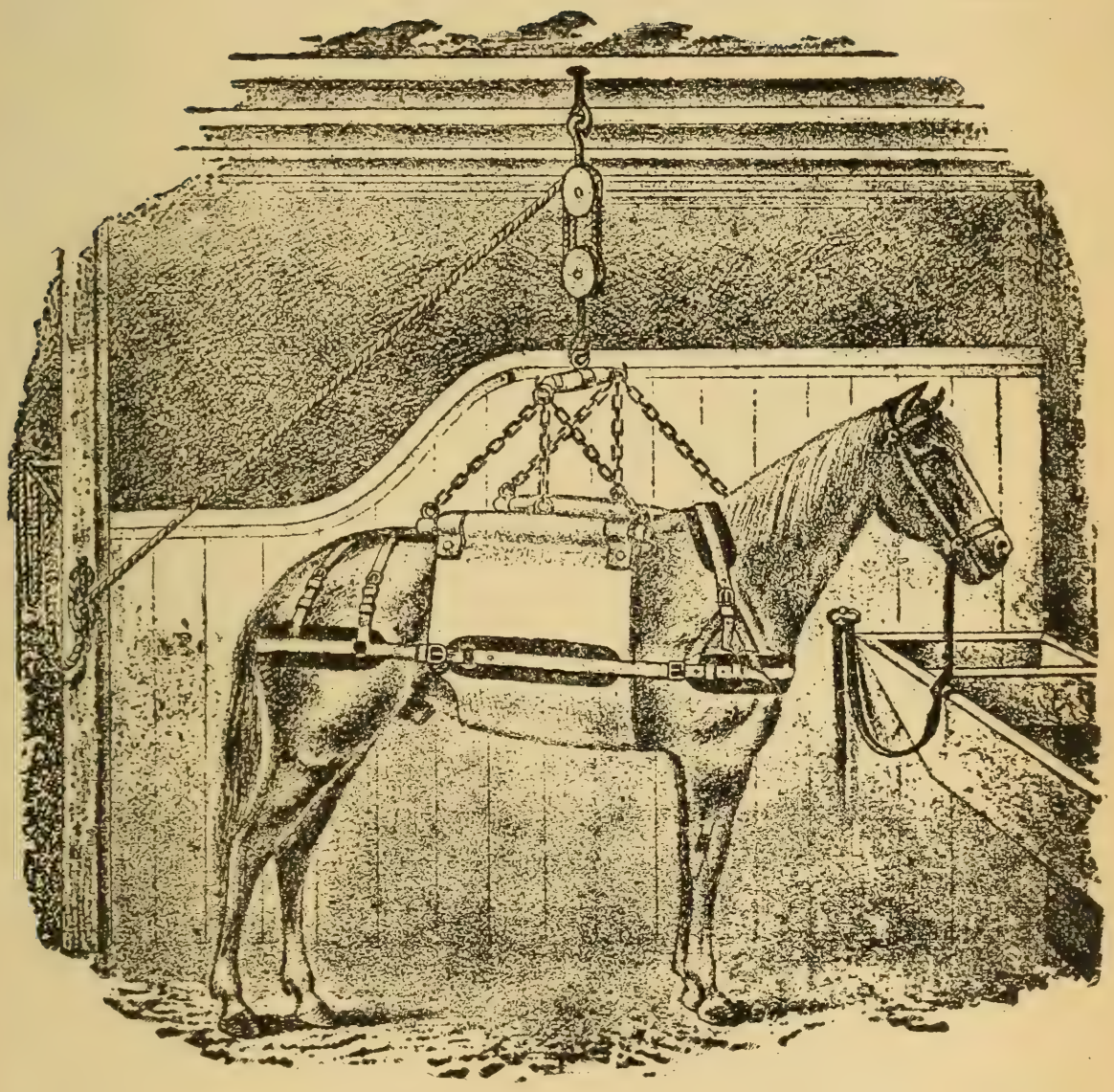

THE SIING IN USE. 



\section{CHAPTER XV. \\ JOCKEY TRICKS.}

It is not the purpose of the writer to furnish in this chapter information through which the dishonest may defraud his unsuspecting neighbor, but merely to give the reader some idea of the deception and fraud which is constantly being perpetrated by the unscrupulous horse trader upon a more innocent and honest public.

An old horse is often jockeyed up until he looks young again. This is done by means of "doctoring" the teeth as it is communly called, and by making a slight incision at the side of and just below the ear, into which a small quill is introduced, and the surrounding parts just beneath the skin are blown full of air. This incision is then sewed up with silk thread. By rubbing the parts freely with the hands this air passes into and fills out all the shrunken places around the eyes and ears, making the animal appear young again.

Old horses are often given apparently new life by the following:

PRESCRIPTION

Oil of Cloves . . . . . . . . I ounce

Oil of Anise Seed . . . . . . I ounce 
Asafoetida, Tincture of . . ... 2 ounces

Oil of Rosemary . . . . . . . . . I ounce

Mix and shake well and give 5 drops a day in a bucket of water. This will give life to all that are not dead, and a horse to which it has been given will need a good rider for he is very lively.

There is a quick process of fattening horses for trade, it can be done in six days by $\mathrm{u}$ ing the following:

\section{PRESCRIPTION}

Nitric Acid 3 drachms

Bicarbonate of Soda 2 ounces

Nitrate of Potash 3 ounces Black Antimony 3 ounces Asafoetida Gum 3 ounces

Mix and give a tablespoonful twice a day for 6 days in soft feed. The flesh acquired through this means is of a poor quality and the horse will not hold it but a few days, being left in a worse condition than in the beginning.

A horse is sometimes made lame for reasons usually best known to the jockey, by taking a hair from his mane or tail and passing it beneath the back tendon of the fore leg by means of a common sewing needle, and clipping the ends off close so as not to be noticeable. In a short time the horse will be very lame, but when the hair is removed he is all right again.

One of the meanest tricks to which a jockey stoops is in making a good horse appear as if going blind when there is no trouble with the eyes. This is done by plugging up the nasal openings of the lachrymal ducts with bees 
wax. The trouble passes away as soon as the wax is removed.

A horse is sometimes made to quit eating by covering his teeth with tallow, he will starve when this is done before he will eat a bite. Remove the tallow from the teeth and he will eat as before.

We have explained how the heaves are "shut down" in our treatment of the trouble.

\section{List of Medicines to Keep on Hand.}

The following is a list of medicines that every farmer and stock owner should keep on hand, for cases of emergen'y, that is where he has an animal take sick with colic or kidney trouble or should get hurt by accident, or any other disease that requires his immediate attention, he can often save the life of a good horse or cow or some other animal, while if he had to go to the drug store for the medicine; by that time it may be too late. As this list doesn't cost much, I would advise you to keep this list on hand.

Linseed Oil (Raw). . . . . . 2 quarts

Sweet Spirits of Nitre . . . 4 ounces

Tincture of Opium . . . . . 2 ounces

Tincture of Aconite, Root . . . . I-2 ounce

Alcohol . . . . . . . . 4 ounces

Aloes Barbadoes . . . . . . . 2 ounces

Nitrate Potash . . . . . . . 4 ounces

Ginger (Ground) . . . . . . 4 ounces

Gentian (Powdered) . . . . 2 ounces

Chloroform . . . . . . . . 2 ounces

Oil Turpentine . . . . . . . 6 ounces 
Carbolic Acid . . . . . . . 2 ounces

Wire Cut Liniment . . . . . . I pint

Cleansing Powders . . . . . . I pound

Epsom Salts..... . . . 2 pounds

The cost of this list of medicine is very small to compare with a hundred dollar horse. Keep the bottles well corked and labled,

Notice-All the doses of medicines which are mentioned in this part of the book are intended for an average size horse, unless otherwise mentioned. So in giving doses to young and small stock, you must regulate the dose to suit the age and size of the animal.

\section{PRESCRIPTIONS}

As a matter of convenience to the reader to whom time will often be precious. I will add this chapter of prescriptions on the diseases of horse, for convenience.

PURGATIVE.

Barbadoes Aloes ...... 4 drachms

Linseed Oil (Raw) . . . . . . . I pint

Mix and give at one dose, repeat in 15 to 20 hours if necessary.

CLEANSING POWDERS.

Mustard, (Ground . . . . 4 ounces
Sulphur . . . . . . 3 ounces
Sassafras Bark (Powdered)... 2 ounces
Gentian . . . . . . . . I ounce
Foenugreek . . . I ounce 
Black Antimony . . . . . . . I-2 ounce Mix and give one tablespoonful once a day. This is the best condition powder known to the profession.

HEALING POWDERS.

Boric Acid . . . . . . . . . 2 ounces

Iodoform . . . . . . 4 drachms

Subnitrate of Bismuth . . . . 3 drachms Mix and dust on 2 or 3 times a day.

SPASMODIC COLIC.

Chloroform . . . . . . 2 drachms

Ether, Sulphate of . . . . I-2 ounce

Opium, Tincture of ...... I-2 ounce

Canibus Indica, Fluid Extract of . . I 5 drops Water . . . . . . . 6 ounces Mix and as one dose repeat every 3 minutes.

\section{WIND COLIC.}

Bicorbonate of Soda . . . . . . . I ounce

Oil of Peppermint .. . . . . . . I drachm

Opium Tincture of . . . . . . I-2 ounce

Water . . . . . 4 ounces

Mix and give at one dose in warm water.

\section{COMMON COLIC}

Opium, Tincture of . . . . . I-2 ounce Asafoetida, Tincture of . . . I-2 ounce Ammonia, Aqua . . . . . . 2 drachms Ether, Sulphate of . . . . . I ounce Mix and give at one dose in I-2 pint of warm water. 
POWDERS FOR COLLAR AND SADDLE SORES.

Sulphur, Pulverized ..... I-2 ounce Alum, Pulverized . . . . . I-2 ounce Calomel . . . . . . . . Io grains Mix and dust on 3 times a day.

COLLAR AND SADDLE GALLS.

Oil of Tar . . . . . . . . . I ounce

Oil of Organum . . . . . . . . I-2 ounce

Gum Camphor . . . . . . 2 drachms Tallow . . . . . . . . 2 ounces

Mix and apply night and morning.

SNAKE BITES.

Whiskey . . . . . . . I pint

Ammonia, Aqua . . . . . . 2 drachms

Water . . . . . . . I-2 pint

Mix and give at one dose, repeat in one hour, but only onehalf the quantity.

HOOF LIQUID.

Oil of Tar . . . . . . . 4 ounces

Oil of Organum . . . . . . . . . I ounce

Linseed Oil . . . . . . . . 6 ounces

Alcohol . . . . . . . . 7 ounces

Mix and apply once a day.

INFLAMMATION OF THE BOWELS.

Aconite, (Root) Fluid Extract of . . 20 drops

Opium, Tincture of $. \quad: \quad: \quad: \quad$ : $\quad$-2 ounce 
Digitalis, Tincture of ro drops Water ....... 4 ounces Mix and give at one dose in one-half pint of warm water. INFLAMMATION OF THE KIDNEYS.

Opium, Tincture of ..... . I-2 ounce Sweet Spirits of Nitre. . . . . I ounce Cubebs . . . . . . . . I drachm Water . . . . . . . . 2 ounces

Mix and gire at one dose in one-half pint of warm water. LUNG FEVER.

Aconite, (Root) Tincture of . . 20 drops Opium, Tincture of . . . . . I-2 ounce Digitalis, Tincture of . . . . . . Io drops Nitre, Spirits of ...... I-2 ounce Water . . . . . . . . 2 ounces Mix and give at one dose, repeat every hour.

EYE LOTION.

Atropine Sulphate of . . . . . . 2 grains

Water (Distilled) . . . . . . 2 ounces

Mix and drop in the eye 3 or 4 times a day.

HEAVES IN FIRST STAGE.

Aloes Barbadoes . . . . . . . . I I-2 ounce Potash, Chlorate of . . . . . . 2 ounces Potash, Nitrate of . . . . . 2 ounces Tartar Emetic . . . . . . 6 drachms Gentian . . . . . . . . I ounce Nux Vomica . . . . . . 3 drachms Mix and divide into 12 powders; give one a day. 


\section{TONIC FOR INFLUENZA.}

Sulphate quinine...... I 2 cunce Gentian . . . . . . . . . I I-2 ourc-s Sulphate of Iron. . . . . 2 ouvces

Nitrate of Potash . . . . . . 2 ounces

Mix, divide into ro $\mathrm{p}$ wders, gire one night and morning.

GARGLE FOR SORE THROAT.

Tincture Iron. . . . . I-2 ounce Ch!nratis of Pota.h . . . . . . I ounce Glycerine . . . . . . . 2 ounces Wa'er to make. . . . . . . . I pint Mix, use 1 or 2 ounces at a time every 2 or 3 hours in I-2 pint of warm water.

TO KILL SCREW WORMS.

Pine Tar. . . . . . . . 4 ounces

Crude Carbolic Acid . . . . . . I ounce Oil Cedar. . . . . . . 3 ounces Alcohol . . . . . . . . 3 ounces Mix and apply.

\section{MY FAVORITE LINIMENT.}

Oil of Ceder. . . . . 2 ounces.

Sulpbate Ether........ I-2 onnces Oil of Sas afras . . . . . . 4 ounces Aqua Ammonia. . . ... I-2 ounce Gum Camphor. . . . . . 3 drachms Alcohol . . ...... . 8 ounces Mix, and apply. This is a good liniment for man or beast. 
LINIMENT FOR WIRE CUTS.

Turpentine . . . . . . 6 ounces

Gum Camphor......2 2 I 2 ounces

Eggs . . . . . . . . . . No 3

Vinegar to make. . . . . . . I quart

Mix and shake well. App'y 2 or 3 times a day. This is a fine liniment for bruises, sprins, sore throat in man or beast.

\section{FOR GRAVEL.}

Sweet Spirits of Niter ... . . . . I ounce

Water..........3 ources

Mix and give at one dose.

FOR SORE MOUTH.

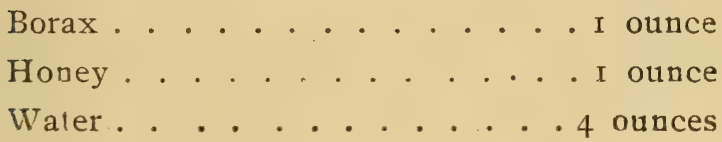

Mix and use as a mouth wash.

\section{PROUD FLESH}

Sulphate Zinc........6 drachms

Sugar of Lead . . . . . I ounce

Water . . . . . . . . . I pint

Mix and apply 2 or 3 times a day.

\section{BLISTER.}

Spanish Flies...... 3 drachms

Rosin . . . . . . . . I-2 ounce

Hogs Lard ........ 4 ounces

Mix and apply. 
EYE WATER.

Sulphate Zinc....... . 4 grains

Sulphate Morphine...... 6 grains

Distilled water to make... . 3 ounces Mix, drop in the eye 3 or 4 times a day.

FEVER MIXTURE.

Tincture Aconite Root . .... . 2 drachms Fluid Extract Belladonna. . . 3 drachms Water to make....... 4 ounces Mix and give one tablespoonful every hours.

\section{CHRONIC COUGH.}

Balsam Fir . ....... 2 ounces

Balsam Capaiva....... 2 ounces

Tincture L belia. . . . . . I-2 ounce Mix and give one tablespoonful once per day.

\section{RING BONES}

Corrosive Sublimate... . . . . I ounce

Gum Camphor......... I ource

Hartshorn . . . . . . . I-2 ounce

Turpentine to make....... I pint Mix, apply once a day for 5 days then grease well with hog's lard.

SHUT DOW N HEAVES.

Oil of $i$ ar . . . . . . . 2 ounces

Fluid Extract Lobelia..... I ounce Water ........ . 3 ounces

Mix and give at one dose. R peat for 3 mornings. 
CHRONIC DIARRHOEA.

Sulphatis Iron........ I ounce

Nux Vomica . . . . . . 4 drachms

Bismuthi Sub carbonatis . . . . 2 ounces

Bi Carbonat is of Soda . . . . . . 2 ounces

Mix and divide into 8 powjers. one powiter night and morning.

\section{PURGING BALL.}

Barb ddensis Aloes.....5 drachms

Calomel ........ I 2 drachm

Extract Belladonia..... I 2 drachm

Ginger, pulverized...... I ounce

Mix, make into a ball and give at one dose.

MERCURY BLISTER.

Biniodid of Mercury ..... 2 drachms

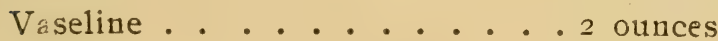

Mix and apply once a day for 3 days. Then grease the parts well for a week. This is a good blister for spavin or splint knots or any kind of enlargement.

\section{HOOF OINTMENT.}

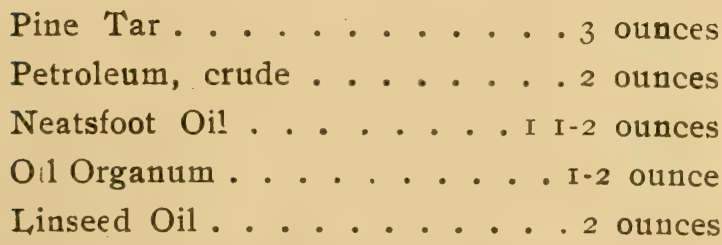

Mix and apply to bottom of foot once a day. 
FOR WORMS IN HORSES.

Santonin . . . . . . . 20 grains Oil Turpentine. . . . ... . I ounce Barbadoes Aloes...... 4 drachms Linseed Oil . . . . . . . . I pint Mix and give at one dose.

CHRONIC BRONCHITIS-OR WHAT SOME PEOPLE CALL HEAVES.

Barbadoes Aloes....... I I-2 ources Nitrate Potash . . . . . . . 2 ounces Chlorate Potash . . . . . . . 2 ounces Blood Root (powdered). . . . I I-2 ounces Lobelia Seed (powdered)...... I ounce Tartar Emetic. . . . . .6 drachms Nux Vomica (powdered) . . . 3 drachms Mix, divide into 16 powders and give one at night FOR LOCK IAW.

Fluid Extract Belladonna... . 2 ounces Prussic Acid (diluted) . . . . ounces Water to make....... 8 ounces Mix and give 2 tablespoonful 3 times a day.

\section{HORSE LINIMENT.}

Turpentine ......... 2 ounces

Oil of Spike......... . 2 ounces

Oil of Organum . . . . . 2 ounces Spirits Camphor ...... . . 4 ounces 
Oil of Tar. . . . . . . 2 ounees

Ammonia water....... 2 ources Mix and apply 2 or 3 times a day.

LINIMENT FOR SPRAINS.

Oil of Organum . . . . . 2 ounces Oil of Cedar. . . . . . . . I ounce Alchol . . . . . . . 4 ounces Aqua Ammonia . . . . . . I drachm Water to make....... I2 ounces Mix and apply once a day.

\section{ANTISEPTIC WASH.}

Carbolic Acid....... . 2 drcahms Water . . . . . . . . I quart Mix and apply freely.

MANGE ON HORSES.

Sulphur . . . . . . 4 4 ounces Oil of Tar........ 2 ounces

Gum Campbor . . . . . 3 drachms Linseed Oil . . . . . . . 8 ounces Mix and rub in well once or twice a day.

\section{WIITE LOTION}

Sulphate Zinc........ I-2 ounce Sugar of Lead . . . . . . . I ounce

Water to maze......... I pint

M ix and apply 2 or 3 times a day. 
THUMPS.

Whiskey ........ 4 ounces Spirits of Niter...... I-2 ounce Tincture Digitális...... I5 drops Water to make........ I pin Mix and give at one dose. Repeat in one hour.

STIMULATING MIXTURE.

Whiskey .........4 4 ounces

Extract of Ginger . . . . . I ounce

Water to make........ I pint Mix and give at one dose. Repeat as needed.

COOLING LOTION.

Muriate of Ammonia . : . . . I ounce

Nitrate of Potash . . . . . 2 ounces

Water to $\mathrm{M}+$ ke . . . . . . I quart Mix and apply 3 limes a day.

PASTE FOR OPEN JOINTS.

Carbolic Acid . . . . . . . I dractm Glycerine. . . . . . 2 drachms

Flour enough to make a $\mathrm{p}^{3}$ ste.

Mix and app'y to the cut twice a day.

FOR RHEUMATISM

Colchicum Seed (powdered).... I ounce Nitrate Putash . . . . . . 2 onnces Blood Root . . . . . . . . I $\frac{1}{2}$ ounce Foe 11 reek Seed (powdered) : : I I $\frac{1}{2}$ ounce 
Mix, divide into twelve powders, and give one night and morning.

\section{COUGH POWDERS}

Gum Camphor . . . . . 2 ounces Powdered Digitatis . . . . I I-2 ounces Powdered Lob-lia Seed. ..... I ounce Linseed Meal. . . . 31.2 ounc s Mix, divide into 12 powd rs and give I or 2 a day.

DIARRHOEA MIXTURE.

Prepared Ch $1 \mathrm{k} . . . . . . .$. I ounce

Ginger (powd red) . . . . . . I onnce

Opium (p wdered). . . . . . I dr chm Turpentine. . . . . . . . I 2 trachn Starch Gruel ......... . I pint Mix and give at one dose. R peat in $20^{-} 3$ hol: $\mathrm{s}$ if necessary.

ANTISEPTIC OIL FOR WIRE CUT AND SORE.

Gum Camphor........ I ounce Iodoform . . . . . . 3 drachms Olive Oil to make....... . 8 ounces Mix and apply 2 or 3 times a day.

\section{CARBOLISED OIL.}

Carbolic Acid . . . . . . I drachm Olive Oil ........6 6 ounces Mix, apply twice a day. 


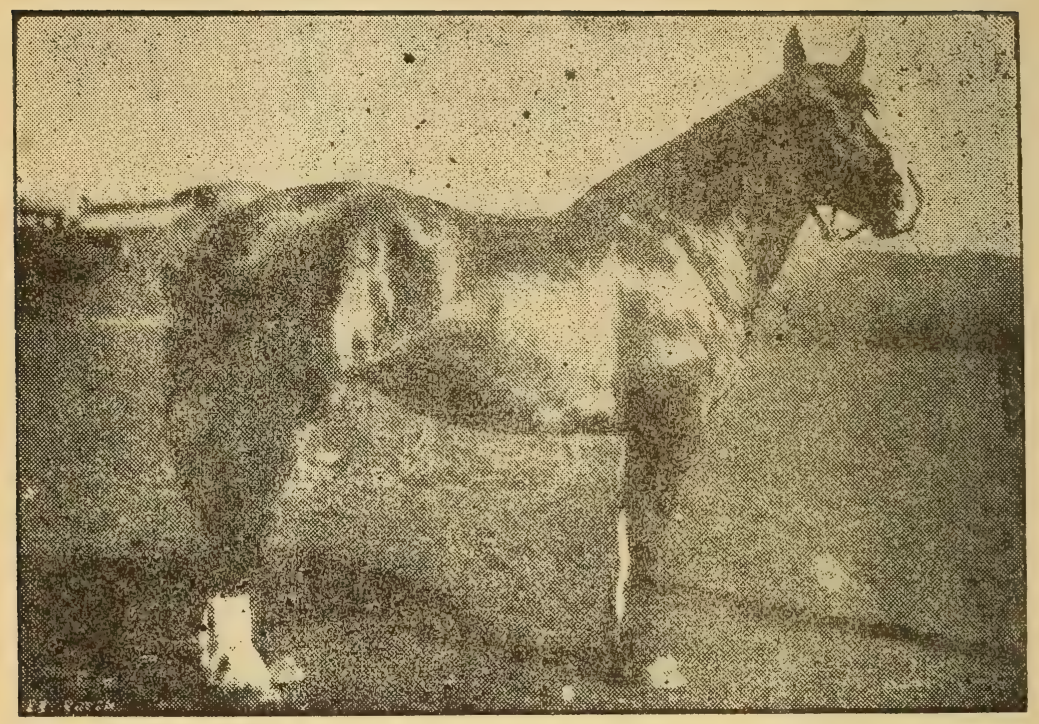

THE MODEL HORSE OF THE WORLD

"Nebraska Queen," said to be the model horse of the world, was born, bred and reared on the plains of Nebraska. She was fouled March 22, I900, and now stands 20 hands and one inch high, measures II feet, 8 inches in length, 9 feet, 2 inches girth, 42 inches shoulder, 38 inches collar, 20 inches throat, 35 inches length of head, and weighs 2530 pounds. 
DART TWO

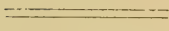

DISEASES

$\mathrm{OF}=$.

CATTLE 


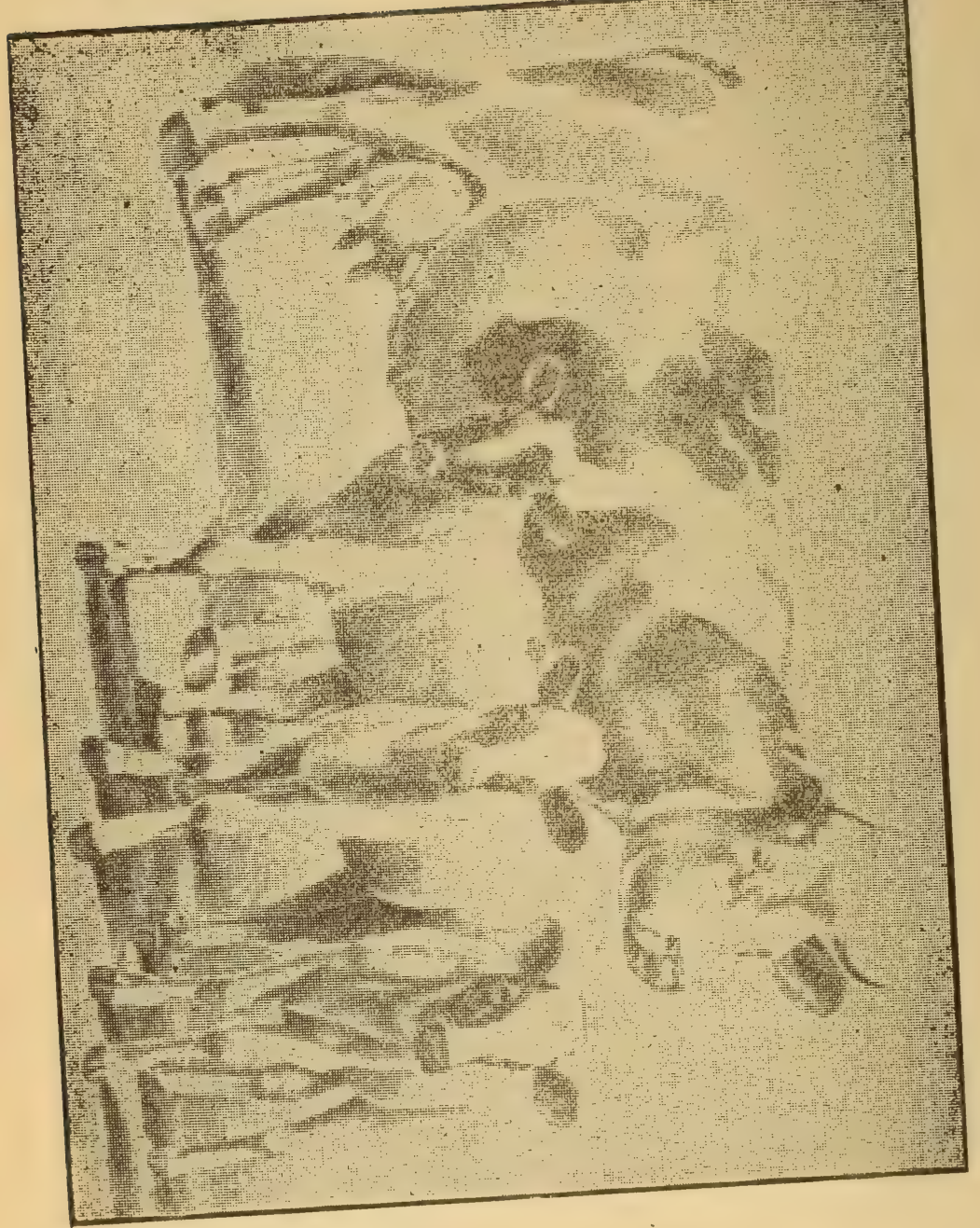




\section{CHAPTER I.}

\section{cATTLE}

In furnishing as they do our milk, butter, beef and cheese, cattle affect directly the happiness and comfort of more homes than all the rest of the animal kingdom combined, and when we take into consideration their secondary products in the way of leather, tallow, glue, etc., the conclusion forces itself upon us that in her cattle the United States possesses a most wonderful and far-reaching source of wealth. Representing, as they do, one of the country's most valuable assets, it can prove no waste of time to study the wants of cattle when afflicted, no matter how insignificent they may appear. But it is not necessary to go over .again the ground we did in the first chapter in this work on the horse; the same general instructions imparted there applying with equal force in this instance.

Cattle, though very similar in almost every essential feature to the horse, present some differences which compel our atterition; the greatest divergence in the two being in the upper portion of the alimentary canal, or that part of it forming the stomach. In the stomach of cattle we find 
four separate and distinct apartments, each of which performs its own peculiar function in the economy of the animal. In administering medicaments to these creatures we must keep in mind the fact of the existence of these four stomachs, as we will refer to them. From the very nature of cattle and the presence of so much stomach surface over which all medicines must pass and be acted upon, it is decidely best, when possible, to give them in a liquid and bulky form and accompany them, when the bowels are the objective point, by a mild stimulant along with our medicine, there is a strong probability that every particle of it will be taken up in the first two or three stomachs, and that none of it will produce the effect sought in its administration.

In the treatment of cattle the bowels are of first moment and always demand serious consideration from the start, they being the means through which we effect a cure. The first act upon our part should always be in the direction of a regulation and control of the bowels. If a patient is constipated we must give a purge, and if there is an apparent diarrhoea, or running off at the bowels, we must endeavor to check it.

\section{Signs of Disease.}

With cattle, as in horses, the pulse, temperature and respiration are our best indexes, but every sign of disease must be closely studied and weighed for all that it is worth. As in the horse the actions and inclinations, along with a study of the coat and visible mucous membranes as well as of the nature and quantities of excretions, are our depen- 
dence and most reliable source of information in arriving at correct conclusions.

\section{Pulse}

The pulse in cattle is softer than we find it in the horse; the best place for securing it being from an artery beneath the tail, or else from one passing over the middle of the first rib. In range cattle the pulse makes 50 beats a minute, while in four year old beef steers it only makes 44 .

A general rule, whitch it will be found profitable to follow, is to never begin the administration of medicine for any internal disease in cattle, until the pulse reaches 60 beats a minute, but when medication is once begun keep it up until pulse goes down to 55 to the minute.

\section{Temperature}

The normal temperature of full grown cattle is $\mathrm{IOO} I-2^{\circ}$. Some depend upon guessing at the temperature after feeling of the ears, legs, skin and roots of horns, and with the experienced it can be closely approximated in this way, but the only means of securing the correct temperature is through the use of the thermometer. The temperature is of vital importance in treating febrile conditions.

\section{Respiration.}

Cattle, in health, breathe from Io to I4 times a minuteThese can be readily counted by the heaving of the chest. The sounds heard in auscultation and percussion are about the same as in the horse, the only difference, if any, being in the distinctness of those of cattle. 
CHAPTER II.

\section{DISEASES OF THE ORGANS OF RESPIRATION}

In this chapter we will consider all of the simple and most common diseases of the air passages:

\section{Bleeding From the Nose.}

Cause.-It is generally caused from an injury to the mucous membranes, or else violent exertion in sneezing or coughing.

$$
\text { HOW TO KNOW IT. }
$$

There is no frothing of blood, which usually drops from one nostril and is accompanied by sneezing, the blood being dark red.

\section{WHAT TO DO.}

In severe cases tie the patient's head up and apply cold water or ice, Should this fail, inject monsels solution for iron into bleeding nostril and if the desired effect is not secured, give the following as constitional haemostatic: 
PRESCRIPTION

Gallic Acid. . . . . I I-2 drachms

Water, q. s........ add I pint

Mix and give one dose and repeat every hour as indicated.

\section{Bleeding From the Lungs}

Cause.-This is caused by a breaking down of the lung substance, or is a result of a previous congestion of the lungs.

HOW TO KNOW IT.

Bleeding from the lungs comes from both nostrils and mouth; there is a cough and the blood is a bright red and frothy.

\section{WHAT TO DO.}

Use cold applications to the sides and give, as a drench the same haemostatic prescribed in bleeding from the nose.

\section{Catarrh or Cold In the Head.}

Cause.-Exposure to cold wet weather is the most common cause.

HOW TO KNOW IT.

The animal gets dull and has no disposition to move around, the appetite is generally indifferent and the eyes are red and watery. The mucuous membranes of the nose are at first red and dry, but later a watery discharge makes 
its appearance, which becomes mucopurulent in serere cases. If in a cow giving milk the secretion of it diminishes very much. The pulse will be rapid and rather hard, and temperature may run high.

\section{WHAT TO D I}

House the patient comfortably and turn your attention to the bowels, first.

If the patient be constipated give this as a purge:

PRESCRIPTION.

Epsom Salts . . . . . . . I pound

Gentian, (Powdered) . . . . . I ounce

Ginger, (Powdered) ... : ... . . I ounce

Mix and give at one dose in a quart of water. Should the bowels be too loose, the following will generally prove effective in checking them:

PRESCRIPTION .

Alum, (Powdered). . . . . . I ounce

Opium, (Powdered)...... 2 drachms

Starch, (Powdered)..... 4 ounces

Ether, Sulphuric...... . 2 ounces

Water, q. s. . . . . . . . . add I quarts

Mix and give at two doses 2 hours apart.

The patient can be forced to inhale the steam from very warm water to relieve the lightness in the head. Should the temperature run as high as $\mathrm{IO}^{\circ}$ give the following fever mixture: 
PRESCRIPTION.

Aconite, Tincture of . . . 3 drachms Belladonna, Fluid Extract of . . I-2 ounce Potash, Nitrate of . . . . . . 2 ounces

Linseed Infusion, q. s. . . . . . . I pint Mix and give two ounces at a dose every 2 hours until fever subsides.

\section{Largyngitis.}

This is an inflammation of the larynx, and organ situated at the upper part of and is continuous with the wind pipe.

Causc--Exposure to storms, cold rains, etc., or a sudden change from warm to colder quarters, may produce it.

\section{HOW TO KNOW IT}

The pulse is raised, the breathing is quickened and the temperature is elevated. There is pain on pressure being applied in the region of the larynx. There is considerable difficulty in swallowing, respiration is noisy and difficult, and violent fits of coughing are not uncommon. The nostrils are distented and the animal has a frightened expression.

WHAT TO DO.

First, rub in well mustard paste on the throat over the larynx and repeat this every hour until at least three applications have been made, then cleanse the parts with tepid water and apply freely and rub in well, the liniment for 
wire cuts in horses, recommended in this work. The following is often used advantageously:

PRESCRIPTION.

Potash, Chlorate of . . . . . 2 ounces

Acid, Carbolic. . . . . . . 20 drops

Water, q. s........ . . add I pint

Mix and mop or swab out throat 3 or 4 times a day.

\section{Diptheria}

This trouble resembles largynitis very much, about the only noticeable difference in the symptoms of the two being in the presence of dark gray patches in the fauces in diphtheria, where there is none in largyngitis. The treatment in both troubles is the same. A word of caution-be careful where you have a case of diphtheria, for it is often communicated to the human family in this way, and when it is it becomes very contageous.

\section{Bronchitis}

This is an inflammation of the mucous membrane of the bronchial tubes, these being the small air passages leading into the lungs.

Cause-The cause is most generally from "catching" cold but any irritant may prodnce it.

\section{HOW TO KNOW I'T.}

The pulse will be soft and full running from 50 to 80 beats a minutes. The temperature will be in the neighborhood $105^{\circ}$, The inspiration is short, painful and incom- 
plete, while the expiration is prolonged. There is a faroxysmal but incomplete and painful cough present. At first we hear a dry, grating sound on placing the ear to the chest; which beccmes a kind of gurgling one in three or four days.

\section{WHAT TO DO.}

Give the patient a warm, clean and well ventilated stall. Keep the bowels open with half or broken doses of the $\mathrm{ep}$ som alts purge recummended in catarrh in cattle. To control fever use the following.

PRESCRIPTION.

Niter, Spirits of ...... 2 ounces Aconite, Fluid Extract of . . . 2 drachms Belladonna, Fluid Extract of . . 4 drachms Opium, Tincture of ...... I ounce Water, q. s. . . . . . add I pint Mix and give four tablespoonsful at a dose every 3 or 4 hours. When the fever give ; away use this for a week or ten days:

PRESCRIPTION.

Iron, Sulphate of . . . . 3 ounces

Gentian. (Powdered)..... 2 ounces

Foenugreek, (Powdered).... I ounce

Flax Seed Meal ....... 8 ounces

Mix and give two tablespoonsful at a dose twice per day. 


\section{Pneumonia.}

This is an inflamation of the tissues of the lungs, or lung substance and is very common among cattle. The right lung is most commonly affected.

Cause-The cause of preumonia is about the same as that of any of the other inflamma ory diseaseas of the res. piratory organs.

\section{HOW TO KNOW IT.}

Pneumonia usually comes on with a chill, followed by a rise in temperature, running up to ro5 degrees or even higher, the pul e is full and soft, ranging from 60 to 80 beats a minute. The breathing is quick and shallow, the nose being hot and dry. The skin is rough, dry and harsh and the coat is staring, the urine is scanty and highly colored, and in milk cows the secretions are suspended to a great extent. On tapping the side a dull heavy sound is heard and on placing the ear to it we observe an absence of the murmur of health in affected parts Some times thre is a dry hacking cough which becomes frequent and painful as disease progresses The patient is usually found standing with fore legs wide apart and elbows turn. ed outward.

WHAT TO DO.

Move the bowels off freely by using the following PRESCRIPTION. Epsom Salts . . : : : : : : . I pound 
Gentian (powdered)...... I ounce

Gingr r . . . . . . . I ounce

Calome1 . . . . . . . I drachm

Mix and give at one dose a d repeat in 6 hours if bowels do not move freely.

Affer adminis'ering the second dose give an injection into the rectum of warm water every thirty minutes until de-ired ac $\mathrm{i} n$ is secured

To control ferer use the same prescription as in bronchitis. Should latient become rery weak a stimulant is indicated A balt pirt of brandy in a quart of gruel three or four times a day is good.

\section{Pleurisy.}

This is an inflammation of the pleura, which are serous memb:anes lining the chest and lungs.

Cause-The cause; of broncbitis and pnemmonia are also the caus's of pleurisy.

HOW TO KNOW ${ }^{\circ}$ IT.

The muzzle is dry and hot, the mouth shiny and secretions scant. There is great pain from the inflamed surface of the pleura rubbing together and a kind of írictional murmur. The inspirations are short and incomplete, while the expirations are prolonged. There is a cough which is sharp, painful and suppressed. By exerting pressure in the interdostal spaces the animal will flinch and grunt. The pulse is small, hard and frequent, and the temperature will range from 104 to Io5 degrees. If there is an 
effusion the pulsa will b s soft and a dull sound will be heard on percussion as high up as the fluid goes in the chest.

WHAT TO DO.

The same general treatment employed in pneumonia is advised. The bowels must be kept open and the kidneys acting freely. In case there is a' effusion put mustard plaster over affected side and give the following interna1ly.

PRESCRIPTION .

Digitalis, tincture of . . . . . 4 ounces

Potash, iodide of ..... 3 drachms

Water, qs....... add 8 ounces

Mix and give two tablespoonsful at a dose 3 times a day.

\section{Chronic Cough.}

In some sections of the country chronic coughs are very common among cattle, and it is very essential that we give them careful attention for if allowed to run in their course they often result in heaves.

Cause-The most common cause is from cold, but dust and smut in feed sometimes produces it.

HOW TO KNOW IT.

There is a persistent cough and patient will lose flesh and present a haggard appearance. The breathing is rurried and in severe cases there is heaving of the flanks. 
WHAT TO DO

Feed on soft feed and use the following.

PRESCRIPTION.

Camphor Crum . . . . . . I ounce

Niter, spirits of ...... 4 ounces

Ginger, tincture of . . . . . 2 ounces

Potash, nitrate of ...... I I 2 ounces

Water, $q s . . . . .$. add 2 pists

Mix and give one teaspoonful 3 times a day. Give in connection with the above this

\section{PRESCRIPTION}

Mustard (ground)...... 4 ounces

Sulphur . . . . . . . 3 ounces

Gentiau (powdered)..... 2 ounces

Ginger (powdered) . . . . . . 3 ounces

Flax Seed Meal. ...... . 8 ounces

Mix and ge two tablespoonsful at a dose twice a day.

\section{Heaves}

As in the horse this is a rupture of the air cells of the lungs.

Cause-It is a result of chronic conghs, bronchitis, efc.

HOW TO KNOW IT.

Respiration is interspersed with, the expiration being pro'onged while the inspiration is short and incomplete. 
As a rule the patient is hide-buund, presents a s'aring coat and becomes emaciated. The cough is bard and is follow. ed by heaving of the flanks and the chest sound; are exaggerated.

\section{WHAT TO DO.}

Heaves are incurable, but can in a measure be relieved by persistent use of the following:

\section{PRESCRIPTION.}

Mustard (ground) . . . . $\therefore 4$ ounces

Gentian (powdered). . . . , 2 ounces

Foenugreek (powdered)...... I ounce

Lobelia Seed (powdered) . . . 2 ounces

Blood Root (powdered). . . 2 I-2 ounces

Potasb, nitrate of ..... 3 ounces

Mix and give two tablespoonsful at a dose twice a day: 
CHAP'TER III.

\section{DISEASES OF THE DIGESTIVE ORGANS}

Under this head we will consider cvery ailment and affection of the alimentary canal which is of consequence or benefit to the farmer or cattle man.

\section{Sore Mouth.}

Though of but little moment this trouble of en occurs and sometimes requires treatment.

Cause-Irritating substances in eitler food or medicine

$$
\text { HOW TO KNOW IT. }
$$

The mucous membanes of the mouth will appear red and inflamed and saliva dribbles from it.

$$
\text { WHAT TO DO }
$$

Use the following as a kind of mouth wash:

\section{PRESCRIPTION}

Potash, chlorate of ....... 2 drachms Hydrastics, pulverized ... 3 drachms 


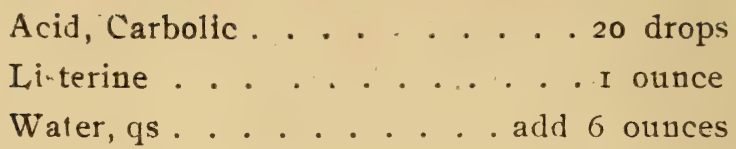
Mix and swab out mouth with it $t$ wice a day.

\section{Loss of Cud}

This is by no means a disease within itself, but merely a symptom of a great many diseases." It is a sign of suspended rumination and shows that the digestive organs are not performing their proper functions When we observe that an animal is apparently without a "cud" we must look for nther symptoms of disease upon. which we can base a correct opinion as to the true character of the trouble.

\section{Choking.}

This condition is usually produced by an auimal's at tempting to swallow too large an object, or by chaff or brau lodging in and filing up a port on o! the gullet

HOW TO KNOW IT.

The onimal is restess and shows signs of pain, and saliva runs fiom the mouth; there ale fryent effort: at swa'lowing and a cough.

WHAT TO DO

If obstruction can be reached remove it with the band and in case this cannot be done pursue the same course as advised in "Choked Horses," 


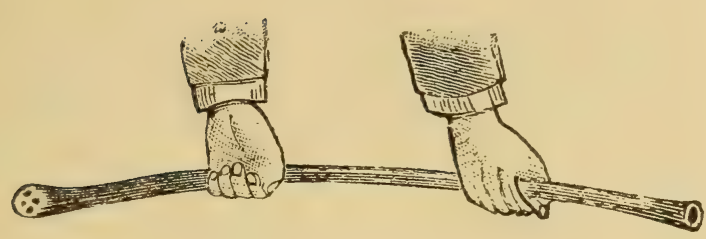

THE PROBE.

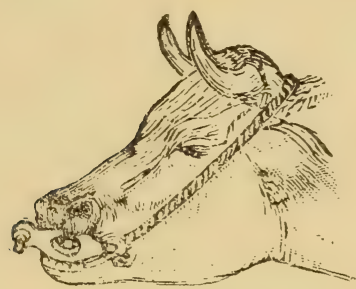

THF GAUGE IN THE MUTH

\section{Hoven.}

Cause-Anything which produces indigestion. It commonly follows a heavy fecd on clover, cane or other succulent diet.

HOW TO KNOW IT.

The animal moves about uneasily and presents an anxious expression The swel!ing in the flank is very marked and often rises above the level of the backbone. The breathing is difficut and gas a d ford are belchel up from the stomach.

WHAT TO DO.

First give the following: 


\section{PRESCRIPTION}

Epsom Salts . . . . . . . I pound

Opium, tincture of .... 4 drachms

Niter, spirits of ... . . . . . I ounce

Mix and give in a quart of warm water.

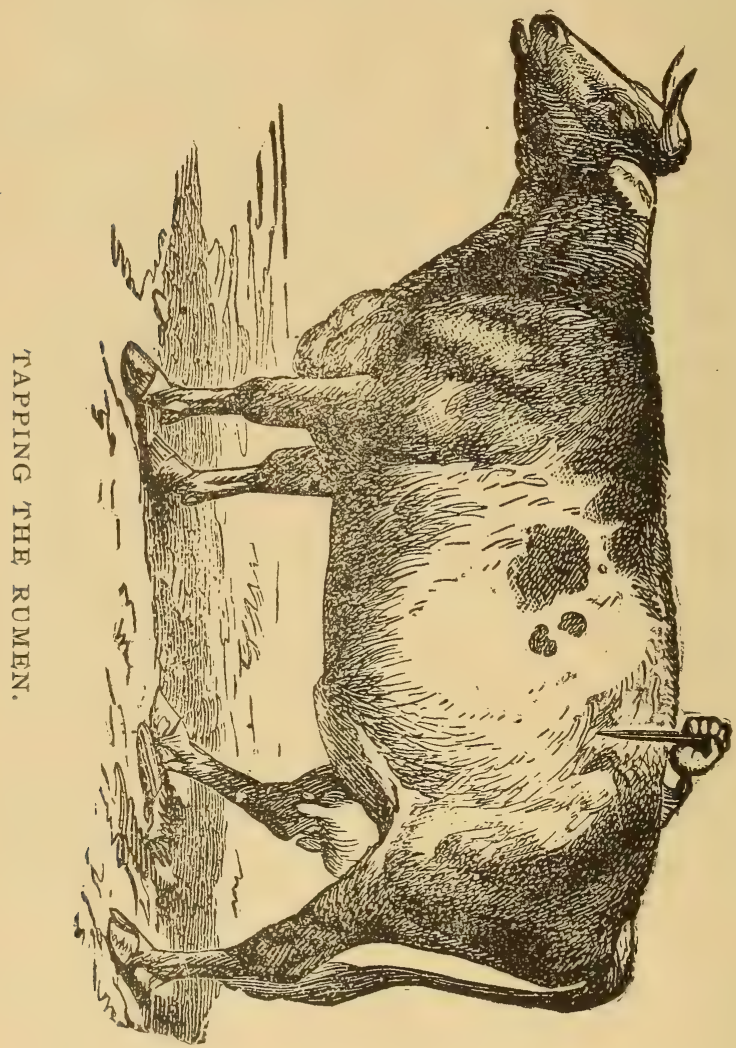

In case there is great swelling in the beginning or at any time afterwards "tapping" the rumen must be resorted to. (See chapter on operations.) 


\section{Impaction of the Rumen}

This is a condition in which the food taken lays in a mass in the stomach or becomes impacted as it were, causing a kind of paralysis of that organ.

Cause.-Excessive feeds of almost any kind of feed. will produce.

\section{HOW TO KNOW IT}

The animal presents the same general appearance as in hoven. On pressing the flank with the closed hand, indent remains for a short time or rises slowly.

WHAT TO DO.

First give the following as a purge:

\section{PRESCRIPTION}

Fpsom Salts . . . . . . . I pound

Gentian, (Powered). . . . . I onnce

Ginger, (Powdered) . . . . . . I nunce

Aconite, Tincture of . . . . . 20 drops

Water, q. s. . . . . . . add I quart

Mix and give at one dose and repeat in 12 hour if necessary. If patient seems to be in great pain give this:

\section{PRESCRIPTION}

Opium, Tincture of ...... I ounce

Nitre, Spirits of . . . . . I ounce

Aconite, Tincture of . . . . . 40 drops

Water, q. s. . . . . . . . add I pint 
Mix and give at two doses an hour a part in quart of warm water.

Should our efforts fail and we should despair of relieving the trouble through the agency of medicines at the end of twenty-four hours the rumen may be tapped (see chapter in operations) and contents mechaically removed.

\section{Impaction of the Omasum or Dry Murrain}

This is a condition in which the third stomach (omasum) suffers from want of water, and food becomes impacted between the leaves of it.

HOW TO KNOW IT.

This trouble comes on gradually, with signs of abdominal pain, the animal looks around to the right side and has no disposition to move about. Just below the ribs on the right side can be felt a hard round substance, which is very tender. The fever, which begins with the trouble, progresses with it, and towards the end patient makes many efforts at passing dung.

WHAT TO DO.

Just as soon as we learn what the trouble is we should employ the following as a cathartic:

Epsom Salts . . . . . . I I-2 pounds

Ginger, Powdered .. . . . . 2 ounces

Gentian, Powdered . . . . . 2 ounces

Calmomel . . . . . . . . . I drachm

Syrup, Simple....... . . 8 ounces 
Mix and give at one dose in two quarts of warm water. To hasten the action of above give rectal injections of warm water every thirty minutes, and give per stomach a stimulant as follows:

PRESCRIPTION

Brandy . . . . . . . . I 2 ounces

Ginger, tincture. . . . . . 2 ounces

Water, q. s. . . . . . . add I quart

Mix and gixe one teacupful at a dose every 2 hours in a quart of water.

\section{Chronic Indigestion.}

This trouble occasionally occurs in cattle and is the same as dyspepsia in the human family.

Cause-Irregular and improper feeding are the most common causes.

\section{HOW TO KNOW IT.}

The appetite is rather freakish, at times being dainty and again depraved. There is belching from the stomach; a dry, glazed appearance of the dung is noticeable along with a marked decrease in quantity, the flanks drop in, the skin and hair feel dry and rough and the animal loses flesh rapidly.

$$
\text { WHA'T TO DO. }
$$

Be careful in feeding (soft and easily digestable food being indicated) and give the following: 
Soda, bi-carbonate of . . . . . 4 ounces

Gentian (powdered)..... . 3 ounces

Ginger (powdered)..... 2 ounces

Skunk Cabbage (powdered) : . . 2 ounces

Mix and give one tables poonful at a dose niSht and morning.

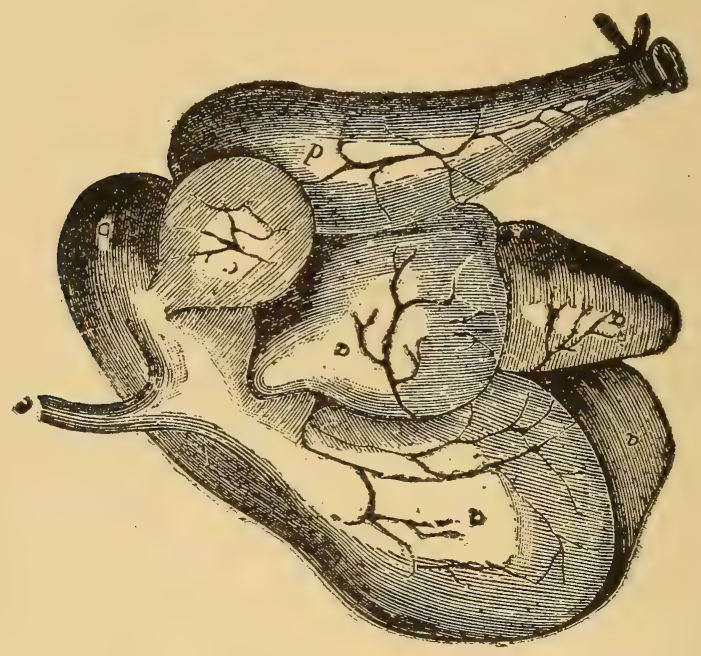

THE STOMACH.

Should the dry, glazed appearance of the dung continue it would be a good.idea to give the purge prescribed in Catarrh or Cold in the Head.

\section{Constipation.}

We regard constipation rather as a symptom of disease 
than a disease in itself. It is a result of an insufficient amount of moisture in the stomach and bowels.

\section{HOW TO KNOW IT.}

The dung is dry, hard and often glazed and its passage is accomplished in a tardy manner. The animal is sluggish and shows signs of not feeling well.

In mild cases a handful of salt in half a pound of flax seed meal is generally sufficient, but when the trouble is severe resort must be had to the following:

PRESCRIPTION

Epsom Salts . . . . . . . Io ounces

Ginger (powdered). . . . . I ounce

Nux Vomica (powdered)....2 drachms

Mix and give at one dose in a quart of water.

\section{Diarrhoeea.}

This is a condition in which there is a watery discharge from the bowels. It is often referred to as scours.

Cause- Inferior and improper food along with irregular feeding are usually the causes when it is not brought on by some other disease.

\section{HOW TO KNOW IT}

The passages from the bowels are frequent and consist of thin dung in the beginning, but become watery and offen- 
sive as disease progresses. The patient is dull and generally very thirsty. As a rule there is some fever and great depression and the animal loses flesh rapidly.

WHAT TO DO.

In most cases it is best to begin treatment by giving a pint of castor oil, but this is not always necessary. After waiting two hours upon the oil, give the following:

PRESCRIPTION.

Alum (powdered)......2 ounces

Opium (powdered) . . . . I-2 ounce

Gentian (powdered)...... I ounce

Chalk (precipitated)..... 4 ounces

Ether (sulphuric) . . . . . . I ounce

Water, q. s. . . . . . . . add I pint

Mix and and give four tablespoonsful every 3 hours.

Should this fail to give relief in twenty four hours try this:

PRESCRIPTION.

Chalk, precipitated...... . 2 ounces

Cateches, powdered...... I ounce

Ginger, powdered . . . . . . I-2 ounce

Opium, powdered....... I drachm

Water, q. s......... I pint

Mix and shake well, and give four tablespoonsful at a dose night and morning.

\section{Dysentery.}

This condition represents the same cattle as bloody flux 
does in man. It is an inflammation of mucous membranes or lining of the bowels and usually follows diarrhoea.

HOW TO KNOW IT

The discharge from the bowels is watery, bloody and offensive and is accompanied in its passage by severe straining. The patient has no appetite but is very thirsty and has a high fever: If the trouble be with a milk cow the secretion of milk ceases. There is sometimes a discharge from the eyes and patient always decreases in flesh rapidly.

WHAT TO DO.

Give as a laxative the following:

PRESCRIPTION

Epsom Salts . . . . . . . 6 ounces

Ginger, powdered . . . . . I ounce

Opium, powdered ....... 2 drachms

Flax Seed Meal...... . 4 ounces

Mix and give in a quart of warm water.

Wait on this a few hours and then treat as a simple case of diarrhoe. Should the fever run very high use same fever mixture as in bronchitis.

\section{Inflammation of the Bowels.}

Cause -Drinking very cold water. Eating poultry food or acid plants and leaves which are infested with caterpillers are the most common causes. 
HOW TO KNOW IT.

The animal shows signs of pain by getting up and down very often and looking at its flanks. Soon we notice it pawing the ground with its front feet and directly it will be seen occasionally striking at the abdomen with one of its hind feet. There is a partial or total cessaticn of rumina"tion and the tail is raised. The animal frequently attempts to urinate but can pass only small quantities. This discharge from the bowels is dry, hard and covered with mucous. All symptoms of fever are present.

\section{WHAT TO DI}

First give the same purge as recommended in impaction of rumen and without waiting begin the following:

PRESCRIPTION.

Opium, tincture of ...... 3 ounces

Aconite, tinctnre of . . . . 2 drachms

Niter, spirits of. . . . . 3 ounces

Potash, nitrate of . . . . . I ounce

Water, q. s. . . . . . . add I pint

Mix and gire at four doses 2 hours apart in a quart of warm water.

\section{Intestinal Worms.}

It is seldom neressary to doctor cattle for intestinal parasites for they rarely have them, but in some sections of the country tape worms are not the most uncommon thing in the world. 
HOW TO KNOW THEM.

This is hard to do. The animal keeps eating and always seems hungry, but gradually falls away. The only means by which we can be certain of the presence of a tape worm is by finding joints of it in the dung.

\section{WHAT TO DO.}

For tape worm give an ounce of oil of male fern (for three days) morning, noon and night in a pint of sweet milk. On the fourth day give a pint of castor oil.

Round worms can readily be gotten rid of by giving small doses of sulphate of iron three times a day for three days and following with castor oil as above. 


\section{CHAPTER IV.}

\section{Diseases of the Urinary Organs}

The uninary apparatus in cattle is by no means as subject to derangement as that of the horse, but occasionally disease lays a withering hand upon some portions of it and when it does our best efforts with a perfect understanding of the nature of the trouble are required to relieve it.

\section{Inflammation of the Kidneys}

This is an inflammation of the substance of the kidneys and is the only affection of these organs proper of any consequence.

Cause-Blows of external violence of any kind in the region of the kidneys; diuretic medicines and feeding upon diuretic plants are the most common in enumerating the list of causes.

HOW TO KNOW IT.

This trouble is in some instances hard to diagnose. In well marked cases the animal shows great uneasiness and passes urine often, in small dribblets, it being thick and 
highly color d and attended by much straining. There is in some cases high fever, accelerated pulse and hurried breath ng. In all cases we find texderness over the lions and a tradcling gait, occasionally there is lameness in either one or toth hind legs and the animal when forced to move dre-so with a groan. Sometimes there is swelling over the loins. By introducing the hard into the rectum and txerting pessure on the kidneys great pin will $b=$ proluced and the circular muscular fibres of the rectum will contract in an effort at expelling the hand.

WHAT TO DO.

Give pitient comfortible quarters and if suffering great pain apply hot blankets to the loins and give the following:

PRESCRIPTION .

Opium, tincture of ......4 4 ounces

Aconite, fluid extract of . . . I drachm

B. l'adonna, fluid extract of . . 2 drachms

Nit $T$, spirits of. . . . . . 4 onnces

Mix and give hree tablespoonsful in a pint of linseed tea every 3 hours.

\section{Retention of the Urine.}

Cause-The cause may be spasm of the neck of the bladder, paralysis of the body of the bladder or an obstruction in the way of a stone.

HOW TO KNOW IT.

The animal shows sigus of colicky pains and strains in 
its freque $t$ and futile eff orts at pascing urine, it looks around to the flık a $d$ raises and moves its hind legs in a restless manner.

WHAT TO DO

Draw the urine with a cathe'er and if the trouble be caused by a stone, try to remove it. Should the retention come from some other cause, use the folowing, after the bladder has been wasbed:

PRESCRIPTION.

Opium, tincture of . . . . . I cunce Belladonna, fluid extract of . . . 30 droks Gentian, tincture of . . . . . I 2 cunce Mix aud give at one dos: in a pint ot linse d tea.

\section{Incontinence of Urine}

Cause-The cause is gen $r 11 y$ an ing to the posterior part of the spinal cord.

HOW TO KNOW IT.

The urine dribbles away continually and by introducing the hand into the rectum or vagina we can feel the half filled bladder below and may empty it by pressure.

WHAT TO DO.

If injury to the spinal cord be permanent, nothing can be done. We may use fly blisters on the loins with good results, and the following internally will tend to restore tone to the injured nerves: 
PRESCRIPTION

Belladonna, solid extract of . . . I ounce

Cantharides, powder d . . . 25 grains

Mix and make into 8 powders and give one a day.

\section{Bloody Urine.}

Cause.-Structural disease of the kidu'ys or urinary tract.

HOW TO KNOW IT.

The appearance of the urine is all that is neces'ary tu satisfy us of the trouble.

WHAT TO DO.

Give clean, wbolescme fcod and the following:

PRESCRIPTION.

Gentian, tincture of .....4 drachms

Muriate of Iron, tincture of . . . 2 drachms

Aconite, tincture of . . . . 20 drops

Water, q. s. . . . . . . add I pint

Mix and give at one dose and repeat 3 times a day for one week.

\section{Inflammation of the Bladder.}

This is an inflammation of the mucous membrane or lining of the bladder and is very uncommon.

Cause.-Strong diuretics, a stone in the bladder and eating poisonous herbs are the most common causes. 


\section{HOW TO KNOW IT}

The animal shows by its acts that it is in pain, there is apparent prostration and some efforts at vomiting, the urine in its passage seems to give much pain and may be either increased or reduced in amount and the sufferer swe ts profusely. In the male the testicles are drawn up towards the body.

$$
\text { WHAT TO DO. }
$$

If the cause be from diuretics, stop their use, and if from stone in the bladder, remove it if possible. In case the cause can not be determined or gotten at, give the following:

\section{PRESCRIPTION}

Opium, fincture of ...... I ounce Aconite, tincture of . . . . . 20 drops Mindererus, spirits of..... 2 ounces Mix and give at one dose in a pint of linseed tea and repeat every two hours until better.

\section{Stone in the Bladder.}

These may occur in any number in the bladder and of all sizes, but is not common to find one more than an inch in diameter.

- Cause-These stones appear to be an accumulation of lime salts and may be a simple mechanical gathering of them, but it is more probable that they are the result of chemical changes tazing place in the body. 
HOW TO KNOW IT.

The stone acting as an irritant causes the b!adder to contract and by this means frequent passages of the urine come about which are small in qualtity but very painful. By introducing the hand into the rectum the sone in the bladder can be felt.

WHAT TO DO.

First remove stones as descr $b$ : $d$ in "Tapping the Bladder" (see chapter on operations). Then gire the following:

PRESCRIPTION.

Hydrochloric Acid . . . . . 20 drops

Gentian, tincture of .... 4 drachms

Linseed Tea, q. s. . . . . add I pint

Mix ar d give at one d se twice a day for six days. Then give this:

PRESCRIPTION

Silphur . . . . . . . . 4 ounces

Mutarl ......... 4 ounces

Sass fra; Balk, powder d... 2 ounces

Gertian, powdered...... I ounce

Foe ugreek, powdered . . . . I ounce

Shunk Cabbage, powdere 1. . . 2 ounces

Mix an 7 give two tablesp son-ful at a dose once per day in soft feed. 
CHAPTER V.

\section{GENERAL BLOOD DISEASES.}

In this chapter we will treat all those diseases which work through the medium of the blood, no matter what their origin or nature may be.

\section{Blood Poisoning.}

This condition is a result of poisonous matter or pus being absorbed into the system.

Cause-Using unc'ean instruments in a wound of any kind, and the absnrption of pus from ulcers and suppurating surfaces are the most common causes:

HOW TO KNOW I'T.

Rumination has stopped and the coat is staring, the appetite is lost and emaciation has begun. The breathing is quickened, the puise is fast and hard and the animal has much fever. 
WHAT TO DO.

Liberate the pus from wound or ulcer, as the case may. be, and cleanie th roughly with carbolized water 2 or 3 times a day and give, internally, this:

\section{PRESCRIPTION.}

Chloride of Iron, tincture of . . I-2 ounce Opium, tincture of . . . . . 3 ounces Aconite, tincture of . . . . . 2 drachms Mix and give one tablespoonful at a cose erery 2 hours

\section{Tuberculosis and Phthisis Pulmonalis}

This trouble resembles phthisis in the human tamily and is a condition in which the poison from supfurasion bas been $a b$ orbed into the $y: t+m$, the poison yathering in cheese-like tumors of smal! dim-nsions, these tumors being fou $d$ in the lungs. pleur $\rightarrow$, sides of diaphragn and variou: gla di These tumors may partake of a semi fluid nature a $d$ when they $d$, ihe flesh of the animal is unfit for food. If they are of a calcareous character, no bad effect resul from eating it.

Cause-Any inflummation of a suppurative characier through which poison is absorbed into the syst $\mathrm{m}$.

HOW TO KNOW I'T.

The first sympiom usually observed is an unthrify condition, accompanied by a husky cough. This is followed by a dull appearance o: the hair and skin The animal 
no longer licks itself as of old. If the touble be in a milk cow the milk though not decre st $d$ in yuantity is thin and watery and of a poor quality. A cow wi h calf unually aborts. As disease promresses the crugh gets much worse and emaciation is rapid. Diarriora generally devel ps in the last stage of the troubl:. The animal always remains standing. In severe crses tubercles sometimes break out on the body.

\section{WHAT TO DO}

There is no cure for this trubbl:s, hut some wriers recommend rapid fattending and butchering as a $m$ ans to avold financial loss. Epeaking for mys lf, I can only say that I would not relish beef in any shape under th se circumstances.

\section{Rheumatism}

This is a constitutional blood disease of a very poculiar kind and is neither contagious nor infec ious.

Cause-The cause is by no means well urderstond, but it is supposed to be due to an accumulati in of a peculiar acid in the system which has a tendency to settle around the joints.

HOW TO KNOW IT.

The animal has no disposition to move around and presents a staring crat. When forced to mive ne observe that he is stiff and lame. As disease progress $s$ one or more joints begin to swell and will be found hot and pain- 
ful. This swelling travels from one joint to another and from one leg to another. The temperature is elevated, the pulse runs high, the bowels are usually constipated and the urine is scanty and of a high color. The patient seems to prefer laying to standing.

\section{WHAT TO DO}

Give patient warm stall with good bed and a good purge, such as recommended in Pneumonia. When bowels have acted well begin the following:

PRESCRIPTION.

Cinchona Bark, powdered . . . . . I ounce Potash, nitrate of ..... I I-2 ounces Foenugreek ......... I-2 ounce Calchicum . . . . . . . I ounce Mix and divide into four powders, give one night and morning. Continue this treatment for several days and use in connection with it locally the following liniment:

PRESCRIPTION.

Turpentine . . . . . . . 2 ounces

Camphor Gunı. . . . . . . . I ounce

Opium, tincture of ..... I ounce

Water, q. s. . . . . . . . add I pint

Mix and rub in well on all swollen parts.

\section{Contageous Pleuro-Pneumonia}

This trouble is commonly known as "lung plague" and 
is contageous, but it only comes about by contact with an affected animal or the virus in stalls, cars, etc.

Cause - The cause insofar as we are concerned may be stated as being from actual contact with an affected animal or else the living virus.

\section{WHAT TO D I}

The early symptoms are such as we would expect in lung troubles, the temperature rising possibly to $106^{\circ}$ and the breathing becomes difficult and rapid, with a kind of moan with each expiration. There is a short, hard, husky cough, the head is drooped and the back arched, the urine is scanty and dark in color, the horns are hot at their roots but cold at the tips and the pulse is weak and rapid. As disease progresses the symptoms become more marked, there is bloating and often a severe diarrhoea. From the eyes and nose comes a watery discharge or one of even more pronounced character. In the first stage the sounds leard in the chest are dry and crackling but as trouble progresses this is all changed and we observe a rough whistling sound. Violent cases of pleuro-pneumonia never appear in the United States except in warm weather.

WHAT TO DO.

Destroy infected animal and quarantine every one which has been exposed for at least three months. Some writers recommend inocculation of exposed animals, but we consider this of questionable utility, even though good results have seemed to accrue from it in some instances. The only safe plan to be pursued is to isolate every suspect. 


\section{Rinderpest.}

We hardly feel justified in passing this without a word and yet we realize that it is a waste of time and space insofar ns the American people are concerned, for a case of it has never yet visited our shores. We will let the subject go by simply and briefly telling what it is. It is generally known as "cattle plague" and has proven a veritable bovine scourge. From the best information at hand it has existed in Asia for all time, and has been perpetual by a continual infection of fresh animals. The virus is said to retain its vitality for months or even years outside of the body in a moist state. Cattie are most susceptible to it, and it is claimed by some that every animal exposed to it becomes infected.

\section{Texas Fever.}

This trouble appears under various names in different sections of the country. It is sometimes called acclimation fever, Spanish fever, black water and murrain, but more commonly splesutic fever.

Cause- - The cause is a matter of conjecture, innumerable theories being offered, none of which are by any means satisfactory.

\section{HOW TO KNOW IT.}

The first sign of this trouble usually observed is a disposition on the part of the infected animal to leave the herd and be alone, next there is a dullness and loss of appetite with dry, staring coat, the patient stands with his head 
down and ears drooped. The temperature runs anywhere from $104^{\circ}$ to $108^{\circ}$ and the pulse and breathing are very rapid. The urine is scanty and highly colored in the beginning, on about the third day it will be red wine color and will in a day or two more appear much like red blood. The dung is drip, scanty and of a brownish color and is usually mixed with a kind of bloidy mucous.

\section{WHAT TO DO.}

But few writers recommend a line of treatment in this trouble, but the author has had much experience and has met with considerable success in treating animals affected with it. Our attention must be directed to the bowels first which are always found constipated. Give the following as a purge:

PRESCRIPTION.

Epsom Salts . . . . . . . I pound

Gentian, powdered ...... I ounce

Ginger, powdered ..... . 2 ounces

Calomel ... . . . . . . I drachm

Common Salt ....... 3 ounces

Syrup . . . . . . . 8 ounces.

Mix and give at one dose in two quarts of cold water and repeat every eight hours until bowels move freely. Injections into the rectum of warm water and soap will aid us in securing desired action. Do not wait for purgative to act, but begin at once the following fever mixture:

PRESCRIPTION.

Niter, spirits of ...... 3 ounces 
Aconite, tincture of .....2 drachms

Belladonna, fluid extract of. . . I.2 ounce

Potash, ritrate of ...... 2 ounces

Ammonia, muriate of .....2 ounces

Water, q. s. . . . . . . . add 2 pints

Mix and give a half teacupful at a dose in a quart of water every two hours.

Keep patient in the shade and apply b!a! ke!s which are wet with cold water to the bea 1 and over the loins.

\section{Anthrax or Black Leg}

This trouble is known under the various names of black leg, charbon, quarted ill and bloody murrain, and is one of the most cireaded scourges of animal life.

Cause.-It is due to an organism known in the scientific world as the anthrax bacillus.

HOW TO KNOW IT.

In the apoplectic form the animal, without bowing any signs of disease, suddeniy drops down and dies of convulsions. Often an animal thought to be well at night is found dead in the morning. Simple anthrax is most common in yuung cáttle which are in good flesh. It begins with ftver, the temperature running to $106^{\circ}$ or $108^{\circ}$ and the pulse is very rapid, beating from 80 to 100 times per minute, the appetite is lost and rumination is suspended. The animal is dull and stupid atd asi e from manifesting great weakness, often seems to get lame in one of bis legs The coat is staring and the roots of horns are cold. As 
disease progresses dullness gives way to restlessness, there are spasms of the limbs, pawing the ground and kicking, with champing of the jaws, the breathing becomes very labored and the mucous membranes bluish in color.

\section{WHAT TO DO.}

First bleed in the legs, taking a half pint of blood from each leg. Then open bowels with one pound doses of Epsom Salts. This is sufficient as fever subsides when bowels move. To prevent a spread of this trouble confine cattle in pasture where grass is short or else keep them in lot most of the time. Nearly all animal; affected with this disease die, but if the simple treatment advised is employed a valuable animal will occarionally be saved by it. 
CHAPTER VI.

\section{DISEASES OF THE BRAIN AND NERVOUS SYSTEM}

In this chapter we will consider some of the more common affections of these organs, but will not devote time nor space to a lot of matter which might come in here, but is of little or no practical worth.

\section{Inflammation of the Brain.}

This is an inflammation of the snbstance of the brain and is often referred to as mad or sleepy staggers.

Cause.-Food containing ergot or other fungi containing narcotic principles are the most common cause, but it may be the result of an injury or the presence of an irritant.

$$
\text { HOW TO KNOW IT. }
$$

We can detect some derangement of the nervous system with certainty. At first the animal is dull and sleepy and shows no indication to move around, the body may be 
leaned against the wall as if for support, the eyes are red and watery and the mucous membrane shows a condition of inflammation. The urine is darker in color than natural and is passed in small quantities and the bowels are constipated. Delirium eventually comes on when the animal runs about wildly and grates her teeth, stamps her feet, froths at the mouth and often bellows. The animal may fall in a violent convulsion with the muscles twitching and jerking and raise the head and dash it against the ground until blood issues from the nose and mouth. The symptoms of brain trouble are varied and it may be that but few of these will be seen in any particular case.

\section{WHAT TO DO.}

First give the same purge as in Texas fever and without waiting for the bowels to move, begin the administration of the following:

\section{PRESCRIPTION}

Potash, bromide of . . . . . 2 ounces

Aconite, tincture of . . . . . 2 drachms

Belladonna, fluid extract of . . . 3 drachms

Water, q. s. . . . . . . add 8 ounces

Mix and give two tablespoonsful at a dose every 2 hours. Keep cold applications on the head and should the bowels not move inside of twelve hours give one pound of Epsom Salts.

\section{Concussion of the Brain.}

Cause-Striking the head against some hard substance 
in running or falling and severe blows inflicted upon the head are the cummon causes.

HOW TO KNOW IT.

There is usually a complete loss of sensation and power, the animal being perfectly oblivious to his surroundings and laying prostrate upon the ground. The bones of the head may be fractured and depressed, psoducing pressure upon the brain.

WHAT TO DO.

If any depression of the cranial bones be observed we mu.t elevate them. This is easiest accomplished by means of a thin piece of steel slipped under depressed bone. Apply coll water or ice to the head and as soon as consciousness r.turns give a good saline purge. Watch for inflammation of the brain and treat accordingly.

\section{Prostration from Heat}

Cause.-Long drives in very hot weather when cattle have be: n kept up for any time being crowded together in cars are the most common causes.

HOW TO KNOW IT.

The signs which indicate approaching prostration are panti:g, the tngue havging out, uneasiness, palpitation, dullness, exhaustion and frothing at the mouth. After this the animal sways from side to side and falls, when it strugg: es for a while and then becomes quiet. In some 
cas:s the animal tries to regain its feet after falling. Once in a great while an animal suddenly collapses, becoming unconscious without any noticeable premonitory symptoms.

\section{WHAT TO DO.}

When first symptoms are observed, rest with shelter and a few days quiet are all that are niecessary. Where complete prostration must be dealt with, apply ice water to the hear and if patient is not past swallowing give at once an ounce and a haff of aqua ammonia in a quart of water and repeat this every thirty minutes until thrte doses bave bet $n$ given. In case the patient can not swallow increase aqua ammonia to $t$ wo ounces and inject it into the rectum. Keep giving amm nia every three hours as long as the patient shows signs of weaki.ess. Give plenty of cool water but limit diet for several days.

\section{Paralysis.}

The only paralysis of any consequence to us in the study of cattle is that preceding and following calving.

Cows are sometimes affected with a peculiar paralysis which seems to altack them about a month before calving but usually gives way a few days previous to it. This is due to the enlarged condition of the womb, creating pressure Jn the nerves of the hind parts Good care is all that is necessary in a condition of this kind. When the troable does not give way before calving it will in all probability a few days afterwards. In this event the bowels must be 
walched closely and if paralysis shows no signs of disappearing on the tbird day, give a saline purge, such as prescribed in Catarrh and the following:

\section{PRESCRIPTION.}

Nux Vomica, powdered .. . . . 6 drachms Gentian, powdered....... I ounce Flax Seed Meal ...... . 4 ounces Mix and divide into four doses and give one night and morning.

Cows are sometimes attacked by a kind of paralysis after calving, which is thought to be due to ir jury to the nerves. The reatment of it is the same as ju-t described.

\section{Lock Jaw.}

This is a rare affection among cattle It is a kind of general and continued spasm of the muscles and is called tetanus by many writers.

Cause - Ir juries to the feet, exposure and bad food are the most common causes A wound on any part of the body may produce or be followed by lock jaw.

HOW TO KNOW IT

The first symptoms usuaily observed are duliness and general stiffuess, farticularly in the manner of carrying the head, the ears are as a rule carried very stiffly. The haw is forced over the eye from the inner corner, the slightest noise will startle the patient and generally increase the intensity of the spasm, the legs are almost rigid, 
the muscles stand out and seem to be in a contracted state all the while. The joints which were stiff in the beginning become more so as disease progresses until they are finally "set" or locked. The pulse is hard and the breathing is labored and rapid.

$$
\text { WHAT TO DO. }
$$

If the trouble is recognized ere the patient is past swallowing, give this at once:

PRESCRIPTION

Epsom Salts........ I2 ounces Common Salt....... 6 ounces Gentian, powdered ...... I ounce Ginger, powdered . . . . . I ounce Calomel ......... I drachm Mix and give at one dose in a quart of water. If a wound is found on the body or in the feet no matter how slight it may be, give it prompt attention and clease it thoroughly and often with carbolized water.

Treatment is valueless after joints have once become securely locked. 


\section{CHAPTER VII.}

\section{DISEASES OF THE EAR}

But few affections can $b=$ trested with any degres of success, an in not whing to burden the reader with anything unless it is prictical, this chaptor wil! n 'cessa'ily be a short one.

\section{Inflammation of the Eye.}

This is simply sore eyes or inflammation of the lids and may be the result of foreign bodic sin the eye, injury to the lids, exposure, etc. In severe cases the deeper coats of the eye become involved and the trouble is most serious.

HOW TO KNOW IT.

There is intolerance to light, the eve being closed, and the ball retracted with protrusion of the haw and a profuse flow of tears. The lids are swollen and lining mem- 
brane is injected with an excess of blood. The white of the eye is blool-shotten.

\section{WHAT TO DO.}

Keep patient in comfortable stall that is darkened considerably. Give a mild purgative, bathe the eyes freely three times per day and use the following lotion:

PRESCRIPTION.

Zinc, sulphate of ..... 5 grains

Morphine, su'pate of .....6 grains

Water, q. s. . . . . . . . 2 ounces

Mix and use 15 or 20 drops, three times a day, in affected eye.

\section{Foreign Substances in the Eye}

Often we find an animal suffering from the presence of pieces of weeds, corn stalks, twigs or straw in the eye, which set ur an inflammation and result in blindness or other serinus trouble unless attended to.

WHAT TO DO.

Examine closely and remove carefully any foreign body found in the eye. When this is done treat just as you would simple inflammation of the eyes.

\section{Cataract.}

In this condition the crystalline lens loses its transparency and becomes opaque, the power of refraction being lost. It is a result of inflammation of the deeper struc- 
tures of the eye or else a defect in the nurition o the lens. The pupil still dilates and comracts, but the jens has turned white and lost its transparency.

No treatment will be of benefit in these cas's

\section{Torn Eye Lids.}

This is by no means au unrommon trouble-and any one of a thousand things may be the cause.

\section{WHAT TO DO.}

Bring the severed 6 dges of the licis together in as even and smo'h a way as possible, sewing them with fine silk thread Dress wound diily wi h carbolized water and remove stitches when in your judgment such a course is indicated. 
CHAPTER VIII.

\section{DISEASES OF THE ORGANS OF GENERATION}

In this chapter we will consider some of the most common and yef the most important affictions of cattle. A knowledge of the diseases of these organs is essential to the success of every cattle man.

\section{Congestion and Inflammation of the Testicles}

Cause.-Excessive service or direct injury in the way of kicks or blows are usually the cause.

$$
\text { HOW TO KNOW IT. }
$$

The side of the scrotum in which the injured testicle lies is swollen, red and tender.

$$
\text { WHAT TO DO. }
$$

Give absolute rest and see that the bowels are kept open. Bathe scrotum freely and often with warm water and apply the tincture of Opium to it to relieve the pain. Should an 


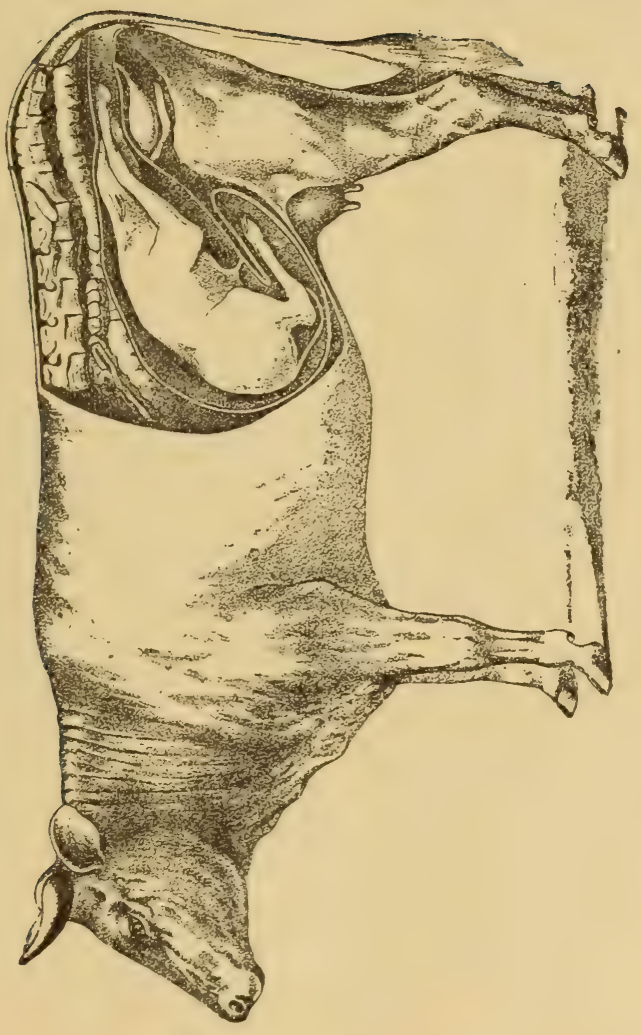


abscess form and stow signs of pointing, let the pus out with small knife and dress wound with carbolized water. In case the animal is not one that is desired for purpose of procreation I would suggest castration.

\section{Parturition}

The period of gestation with cows is two hundred and eighty days but there are some slight variations in this. As time for delivery draws near the space between the root of the joints of the haunch drops, the hips spread, the vulva enlarges and the udder increases in size. A cow fixing to calve hides herself away if possible, the pains come on gradually but increase in force as labor progresses, the cow lies down, the water bog is expelled or may be broken in its passsage, the front feet come next and then the head lying between the feet. At the next effort the shoulders are expelled and delivery is practically over. If labor is prolonged more than an hour, I would advise close attention and help when necessary.

The numerous malpresentations that often present themselves must be treated as the case requires and good judgement dictates. No fixed rules can be laid down along these lines for every individual case presents its own peculiarities.

\section{Prolonged After Pains}

These are uncommon but sometimes occur after continued and severe labor in delivery and are a result of failure upon the part of the womb to contract or else retention of the after birth. 
WHAT TO DO.

If pains come from a retention of the after birth. assist animal in delivering it and if from a failure upon the part of the womb to contract, inject cold water into vaginal cavity and give internally the following:

\section{PRESCRIPTION}

Opium, Tincture of . . . . . . . I ounce

Aconite, Tincture of . . . . 20 drops

Water, q. s. ad . . . . . . . . I pint

Mix and give at one dose and repeat every hour until relief is secured.

\section{Retention of the After-birth.}

The cow is more susceptible to this trouble than any of the domestic anima!s. The only satisfactory reason which can be given for this is supposed to be the connections established between the foetal membrane and the follicles or

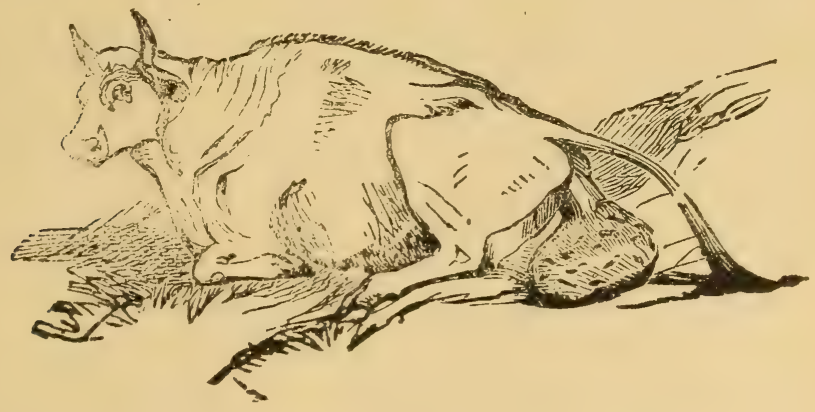

buttons of the womb. The after-birth should come in at least thirty minutes after the delivery of the calf and when it does not come in this time we may suspicion something 
wrong. If at the expiration of three hours after-birth has not been shedded (this we can tell by its being suspended and hanging from the vaginal), give the following:

\section{PRESCRIPTION}

$$
\begin{aligned}
& \text { Epson Salts } \\
& \text { Niter, Spirits of . . . . . . . . I pound } \\
& \text { Beliadonna, Fluid Extract of . } 2 \text { drachms } \\
& \text { Water, q. s. ad . . . . } 2 \text { pints }
\end{aligned}
$$

Mix and give at one dose. If at the expiration of thirtysix hours the after-birth still clings to the womb it must be removed mechanically. This is accomplished by passing the hand (well oiled and greased) into the womb and gently unbuttoning as it were the after-birth, being careful not to pinch off any of the buttons, or otherwise wound the womb. When after-birth has been delivered cleanse womb thoroughly with carbolized water once per day for three days and give the following:

PRESCRIPTION.

Flaxseed Meal . . . . . I 2 ounces

Potash, Nitrate of . ..... 2 ounces

Gentian, (Powdered). . . . . I ounce

Mix and give two tablespoonful at a dose twice per day.

\section{Abortion and Miscarriage.}

As in retention of the after-birth, cattle are very susceptible to troubles of this kind. Some writers speak of a contagcous form of these troubles, but we feel that we are safe 
in making the assertion that it is simply a maiter of sympathy or else subjection to the same conditions: These troubles are brought about most commonly by accidents or violence of some kind and it may be as claimed by some, that certain properties in the food are the cause.

\section{HOW TO KNOW IT.}

The animal shows a desire to be alone, rumination is suspended, there is a dull but anxious expression on the countenance. In a course of a few hours a small water bog will be passed followed shortly by a foetus, and this in turn is followed by a discharge of apparently bloody mucous.

\section{WHAT TO DO}

This trouble is seldom discovered until about completed hence, but little if anything aside from after attention can be given. It might be well to cleanse womb with carbolized water for several days and give the same tonic as in retention of the after-birth.

\section{Flooding.}

This trouble may follow either protracted labor or rapid calving and is due to a failure upon the part of the womb to contract.

WHAT TO DO.

Throw cold water over the loins or cool the hand in a bucket of ice water and insert it in the womb; this will of- 
ten induce contraction. Cold water injections may be resorted to as well as solutions of alum or tannic acid. Internally, one ounce doses of Fuid Extract of Ergot given every hour acts well.

\section{Eversion of the Womb.}

The after-pains are in some instance of so violent a character as that the womb is forced out through the vagina and is turned inside out.

\section{WHAT TO DO}

If the after-birth is still attached remove it carefully, and if the womb has any dirt on it wash clean in tepid water to which a little carbolic acid has been added; when this has been done sponge surface with tincture of opium and carefully return it to its original position. Place patient in a stall where she is compelled to stand with hind parts elevated at least eight inches above the fore part. Should the womb not show a disposition to remain in its natural position we must bring onr ingenuity into play devising some kind of compress for the outer opening which will prevent the womb protruding.

\section{Puerperal Fever.}

This is an inflammation of the uterus and peritonium.

Cause- Difficult parturition and retention of the afterbirth are the most common among the causes.

\section{HOW TO KNOW I'T}

The animal appears uneasy and of ten turns its head to. 
wards its belly and gives a plaintive low. The muzzle is dry and rumination is suspended, pressure upon the flanks produces pain, the animal gets $n \mathrm{p}$ and down often and

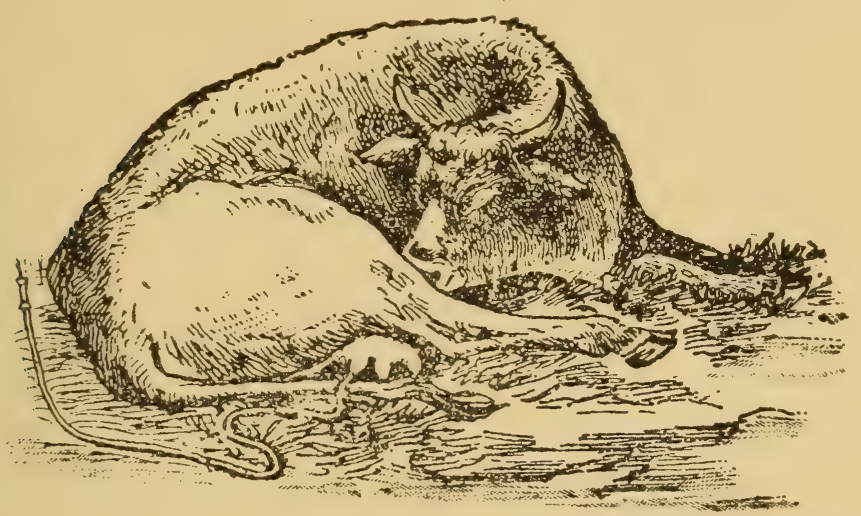

COD WITH FEVER.

sometimes remains on her knees for several minutes, the evacuations from the bowels are dry and hard, the temperature is elevated, the breathing is rapid and the pulse is quick and hard. As trouble progresses it increases in sererity and patient is prostrated.

\section{WHA'T TO DO}

First give the same purge as in Catarrh and follow with injections of warm water every thirty minutes until bowels move freely. To control the fever use:

\section{PRESCRIPTION}

Aconite, fluid extract of . . . . 2 drachms 
Belladonna, fluid extract of . . . . I-2 ounce

Niter. spirits of . . . . . 3 ounces.

Mix and give two tablespoonful every 2 hours in a pint of linseed tea. 
CHAPTER IX.

\section{EXTERNAL AND PARASITIC TROUBLES}

In this chapter we will consider some troub es which it may seem proper to consider in other consections, but coming in as they do and studying the matter at han 1 as we bave it, is but natural to place thr $m$ here.

\section{Lump Jaw.}

This trouble is also known as big jaw to many. It is not very common Some make the mistake of thinking that every enlarged jaw is lump jaw, when of en the trouble is due to mechanical injury.

Cause - The cause of this trouble is by no means well understood. but it is supposed to be due to a living parasite.

$$
\text { HOW TO KNOW IT. }
$$

It may be ill one or both jaws. There is mucts swe'ling 
which is very hard, there may be an external opening to this swelling, when this opening is found we kuow the trouble is of long standing. A thorough examination should be made in the beginning to make sure that the swelling is not caused by the presence of a m-chanical irritant.

WHAT TO DO.

If there is no opening, puncture swelling thrugh to jawbone teu or fifteen times and apply for five days the following linimen!:

PRESCRIPTION.

Oil of Spike......... I ource Camphor Gum . . . . . . 3 drachms Mercury, bi-chloride ot..... I ounce Hartshorn . . . . . . . . I drachm Turpentine, q. s. . . . . add 8 ounces Mix and apply once a day.

Should there be an opening, make an incision through to jawbone and take an iron at white beat and sear all the honey combed portion of the bone; when this is done treat as a simple wound.

\section{Eczema}

This is an inflammation of the skin usually terminating in a watery discharge which becomes crusty or scalcs off. There is intense itching and the animal often rubs until the skin is raw in places. 
WHAT TO D I.

Give an active purgative and the following blood purifier:

PRESCRIPTION.

Iron, sulphale of . . . . . 2 ounces Sulphur ......... 3 ounces Sassafras Bark, powdered... 2 ounces Gentian, powdered....... I ounce Potash, nitrate of ..... 2 ounces

Mix and give a tablespoonful twice a day. Give a complete change of feed and bathe body twice or three times a week with carbolized water.

\section{Water Blisters.}

This trouble, as its name would indicate, is characterized by the formation of irregular shaped water blisters. It is a kind of inflammatory skin disease which can not be satisfactorily accounted for The blisters are preceded by congestion or swelling of the skin and appear in a succes. sion of crops; as soon as one is gone another is ready to take its place. Each crop runs its course in about a week's time. There is intense itching and much rubbing on the part of afflicted animal.

WHAT TO DO.

Open blisters as fast as they form and bathe affected suriaces with a 5 per cent solution of chloride of zinc. Give internally the following: 
PRESCRIPTION .

Sulphur . . . . . . . 3 ounces

Blood Root, powdered . . . . .2 ounces

Polash, nitrate of . . . . I I-2 ounces

Gentian, powciered...... I ounce

Crram of Tartar. . . . . . 2 ounces

Mix and give one tablespoonful twice a day.

\section{Boils.}

Cause-Boils are the result of poverty of the blood, kidney troubles bruists, etc, and are easily recognized.

\section{WHAT TO DO FOR THEM.}

As soon as ihe central portion $b$ crm s : oft the boil shonld be opened o release the core, when this is done it should be cleaused with carbolized water. To clease the blcod and build up the system, give same powders as recommesded in Water Blisters.

\section{Warts}

These are peculiar growths of the skin and are due to increased energy and abnormal nutrition of the skin

\section{WHAT TO DO FOR THEM}

Cut them off smocth with the body or dissect out when neces ary, and then cauterize with nitrate of silver. After cutti $g$ wart anay, instead of cauterizing, the foll, wing can be used with even b tier results in many cases: 


\section{PRESCRIPTION}

Zinc, sulphate of . . . . I-2 ounce Acid, nitric . . . . . I-2 ounce Acid, sulphuric . . . . . I.2 ounce Mix and apply once a day until wart is dead.

\section{Snake Bites.}

An animal bitten by a poisonous repti'e soon shows signs of extreme prostration and becomes partially uncomscions, the body gets cold and the pulse is so weak as to be almost imperceptible. ¿nake bi es seldom kill an animal, yet recovery is slow, large soughs often forming.

$$
\text { WHAT TO DO FOR THEM. }
$$

To keep up vitality give the following:

$$
\text { PRESCRIPTION. }
$$

$$
\begin{aligned}
& \text { Whiskey . . . . . . I piut } \\
& \text { Ammonia, aqua . . . . . . . . } 2 \text { drachm } \\
& \text { Water, q. s. . . . }
\end{aligned}
$$

Mix and give at one dose and repeat in one hour with . half dose. Keep cotton saturated with aqua ammonia to wound.

\section{Mange}

Mange is due to a parasite which induces irritation and incrustation on the skin. This trouble is not common but is contagenus. Mange usually begins at the top of the shoulders and rnot of the tail and extends from here, causing much suffering and worry to afflicted animal. 
WHAT TO DO FOR IT.

First give patient a thorough scrubbing with soap and water and then apply the following:

\section{PRESCRIPTION.}

Sulphur ......... 2 ounces

Oil of Tar....... 2 I-2 ounces

A cid, carbolic,(crude) . . . . I.2 olince

Linseed Oil, q. s. . . . . . add I pint

Mix and apply once a day to every infected sfot.

\section{Rinǵworm.}

This trouble is common in cattl $\mathrm{a}$ and prestnts itself in round bald spots cov red in white scales, the hair sur. rounding spots being bristly and split and there may $b$. some skin erupinns.

\section{WHAT TO DO FOR IT.}

Give a tborougb scrubbing as in mavge, an i paint affected spots with tincture of iodine. Salty grease applied to : pots once per day will often relieve this condition.

\section{Lice}

These parasites are very commo' in cattle and manifest themselves more particularly in early spring. The animal infested with lice rubs it=elf constantly, often excoriatirg the skin An examination will reveal the trouble. 
WHAT TO DO FOR THEM.

A decoction from tobacro applied to infested spots is good, but Oil of Sassafras is better. Equal parts of Olive Oil, Kerosene, Stlphur and lard properly applied will most certainly rid any animal of lice.

\section{Ticks.}

Ticks attach themselves in great numbers to the thighs, flanks and necks of cattle and are a source of much annoyance to them.

\section{WHAT TO DO FOR THEM.}

The application of almost any kind of oil or grease will destroy them.

\section{Grubs in the Back.}

These are easily recognized on account of the tumors in the skin along the back.

\section{WHAT TO DO FOR THEM.}

Enlarge the opening which is always present with the grub, and press the grub out.

\section{Buffalo Gnats.}

The buffalo gnat is so-called on account of its shape, they infect certain sections of the southern country and are a perfect scourge to cattle. The bites of a few of these gnats does but little damage to an animal, but when attacked by 
swarms they rapidly weaken from loss of blood and many die from exhaustion or blood poisoning.

\section{WHAT TO DO FOR THEM.}

Kerosene applied twice a day will generally prevent an attack but the best plan is to build fires of wet wood and rags creating as much smoke as you can and drive cattle as close to it as possible.

Where an animal has suffered a severe attack from these pests and become weakened from loss of blood and the shock, give the following:

PRESCRIPTION.

Ammonia, carbonate of :. . . 2 drachms Whiskey ........ . 4 ounces

Mix and give at one dose in a pint of water and see that patient does not suffer another attack.

\section{Horn Fly.}

These insects, or rather these pests, obtain their name from the fact that they collect at the root of the horns when at rest. When feeding we find these flies on the back, flanks and legs. While irritating to some the bite of these flies is not poisonous, but cattle are annoyed by very much by them.

\section{WHAT TO DO FOR THEM.}

Common axle grease or fish oil applied to roots of horn and skin will keep them away. 


\section{Screw Worms}

These are maggots from the screw worm fly, which burrow in the wounds and prodnce much inflammation and in some instances death.

$$
\text { IVHAT TO. DO. }
$$

No time should be lost when screw worms are found to be present in a wound. Turpentine, chloroform or curbolized water poured or injected into wound will kill the:e worms. The following will be found to give better resu'ts than either of the above.

\section{PRESCRIPTION}

$$
\begin{aligned}
& \text { Pin Tar . . . . . . . . } 4 \text { ounces } \\
& \text { Carbolic Acid, crude. . . . . . } 1 \text { ounce } \\
& \text { Oil of Cedar. . . . . . . . . } 2 \text { ounces } \\
& \text { Alcohol . . . . . . . } 3 \text { ounces }
\end{aligned}
$$

Mix and apply.

\section{Fleas}

These sometimes annoy cattle when present in great numbers. An ounce of carbolic acid to a half gallon of water applied to skin will destroy them. 
CHAPTER X.

\section{AFLICTION PECULIAR TO COWS IN MILK}

This chapter will prove of special interest to the dairyman as well as to those who keep cattle for milking purposes.

\section{Conjestion of the Udder}

This condition usually, in fact almost always, presents itself before and just after calving. The mammary gland is intense and tender, hot and swollen. This congestion usually gives away when the secretion of milk has been established. In some cases the congestion is rather persistent and seems inclined to hang on, in this erent it is a good plan to rub the udder thoroughly in the milk from it or better still, in linseed oil.

\section{Inflammation of the Udder.}

This may be the result of congestion, injury, insufficient stripping or some serious disturbance of the general health. 
In this trouble the gland swells in one, two, three, or all four quarters and becomes firm and solid, the temperature is elevated, the pulse is fast and full and the milk may be entirely supressed in affected quarters or else sparing and tinged with blood. This condition must have prompt attention or else the result will be a "spoiled bag", and permanent injury.

It is best to begin treatment with a mild purge. Milk the cow hald a dozen times per day and bathe the bag freely in the warm milk. Continued fomentation with warm water is very beneficial. Use the following and be sure to rub it in well, not only on affected quarters, but over entire udder.

PRFSCRIPTION.

Camphor Gum . . . . . . . . I ounce

Linseed Oil. . . . . . . 8 ounces

Mix and shake until camphor dissolves and apply to bag four or five times a day.

\section{Chapped and Sore Teats}

These troubles are quite common and though not serious yet they deserve attention in many instances.

The following will be found soothing and healing in these troubles:

\section{PRESCRIPTION}

Olive Oil . . . . . . 8 onnces

Camphor Gum . . . . . . 2 ounces

Acid, Carbolic.... . . . I drachm

Mix and apply twice per day to chap or sore. 


\section{Suppression of Milk.}

Innumerable troubles can produce a suppression of milk, but sometimes it comes about without any appreciable cause. When a condition of this kind arises I would suggest a change of food and the following:

\section{PRESCRIPTION}

Anise Seed, powdered..... 2 ounces Gentian, powdered . . . . I ounce Sassafras Bark, powdered . . . 2 ounces Blood Root, powdered. . . . 2 ounces Skunk Cau bage, powdered . . . I I-2 ounces

Mix and give two tablespoonsful at a dose twice a day. If milk be suppressed on account of some appreciable disease treat disease and milk will get right.

\section{Bitter and Bloody Milk.}

At times milk is found to have a peculiar bitter taste, and again it is bloody when drawn from the cow or becomes streaked with blood after standing for awhile. These conditions are in some instances brought about by the cow eating poisonous herbs, but generally the trouble is a disordered liver.

$$
\text { WHAT TO DC }
$$

Give the following:

PRESCRIPTION.

Musta1 1, ground . . . . . . 4 ounces

Sulphu, . , , , , , 2 ounces 
Potash, nitrate of ..... 4 ounces

Potash, chlorate of . . . . . I ounce

Sassafras Bark, powdered . . . . 2 ounces

Gentian, . . . . . . . . 2 ounces

Skunk Cabbage. . . . . . . 2 ounces

Mix and give two tablespoonsful at a dose once or twice per day as indicatied. This prescription in one tablespoonful doses is a splendid tonic and blood purifier.

\section{Milk Fistula.}

We will only consider the fistula that is the result of a wire cut or other wound. It is always best to wait until cow is dry, pare edges of fistula and stitch up evenly and smoothly, having previously introduced a small tube or quill into teat. When this is done treat as a simple wound, removing tube or quill when a healthy union has taken place. Congenital fistula is not as a rule successfully overcome. 


\section{CHAPTER XI. \\ DISEASE OF CALVES}

In this chapter we will consider the method of treating the most common troubles met with in young calves.

\section{Joint III}

This trouble occurs in calves generally less than a month old and is usually connected wih some navel trouble.

\section{HOW TO KNOW IT.}

The calf is stlff and lame and lies down all the time showing no desire to suck; one or more joints are swollen and are hot and tender. There is a purulent discharge from the navel and high fever.

\section{WHAT TO DO}

Paint affected parts daily with iodine Cleanse navel with carbolized water and sprinkle surface with Salicylcic acid and give internally the fo lowing: 
PRESCRIPTION.

Sodium, salicylate of . . . . . 2 drachms

Blood Root, (powdered) . . . 2 dracbms

Flaxseed Meal . . . . . 2 ounces.

Mix and make into 6 powders and give one morning, noon and night.

\section{Abscess of the Navel.}

We know no satisfactory reason for these. They present themselves as large, firm swellings which sof en in $t$ e center and even iually discharge.

WHAT TO DO.

Open with a free incision and cleanse twice a day with carbolized water.

\section{Navel Rupture}

This trouble is often present at birth and is due $10 \mathrm{im}$ perfect closing of the muscles around opening. We know it by its being a soft swelling, which can be returned into the abdomen by pressure. The contents of this swelling gurgle on handling.

\section{WHAT TO DO.}

As a rule calves over come this trouble without our help but it is a good idea to bandage for ten or fifteen days Should bandaging not reduce the rupture an operation is necessary. To operate is simple. Cut through the walls of the abdomen over rupture, pare all edges and sew up 
inside first with cat gut then sew up skin with silk, and bındage. In te $\mathrm{n}$ days remove silk ligatures but kee $\mathrm{p}$ bandige on for five days more then remove it.

\section{Constipation.}

At birth $1 \mathrm{~h}$ : bowels contain a yellowish-brown gluey matter which mus $b$ = expelled before they are ready to purform their duty. The cows first milk serves as a laxation in $x$ xpelling th s material and the calf should always have it If from any reson or any cause the ca'f does not pasi this nffensive $m$ tter, and is observed straining without any pissage from the bowels, we should at once give an ounce dose of castor oil and follow with injections into the rectum of warm soap suds.

\section{Scouring}

This is a very common trouble with calves and one

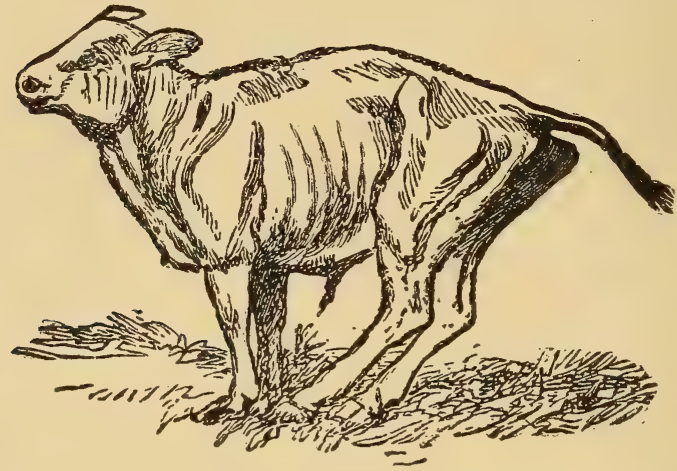

which deserves clo e attention It may be brought on by the calf being allowed too much milk and again the cause 
may be due to some trouble in the mother. The condition of the cow has much to do with the health of the calf.

$$
\text { WHAT TO DO. }
$$

Look to the health of the cow and give the following to the calf

\section{PRESCRIPTION}

Iron, sulphate of . . . . I-2 drachm

Chalk, (precipated) :.... 2 drachms

Lump Starch . . . . . . . 2 drachms

Jamaica Ginger . . ... . . 20 dro $\mathrm{s}$

Nux Vomica, tincture of . . . . 2 diops

Opium. tincture of . . . . . I 5 drops

Mix and give at one do:e in new milk or three raw eggs. 


\section{CHAPTER XII.}

\section{OPERATIONS.}

But few operations can successfully be performed by anyone aside from an accomplished veterinarian. Under this head we will give some of the more simple ones, that is a few vibich can be done by the common run of people.

\section{Setting Broken Limbs.}

When a limb is broken the first thing with us is to determ:ne whether or not treatment is advisable After treatment has been decided upon, our first step is to restore parts to their natural position, and find some means of retaining them there The best mears of securing a frac ur ed limb is through a plaster paris bandage, the limb having bee:s previously set and splinted with damp paste board. Should there be much swelling the plastor paris bandage can be cut and a common cloth bandage applie 1 over it to hol! in place. An animal should a'ways be suspended to get the best results in treating a broken limb. 


\section{Dehorning.}

This is a simple but a very painful operation and is c nsidered by snme to be an inhuman practice, but the results attained from it are so satisfac ory that cattlemen ereywhere employ it as a means of prot ctinn to the lives of their cat:le.

A calf but a few days old can be preveuted from tver growing horns by applying caustic potash to the slight prominences on the fruntal bone, which mark the place where the horn will come. The hair sbould first be clippdd from these prominences and then dip your stick of caustic in co:d water and apply for a tew seconds, let it dry a moment and app'y again.

In dehorning proper the nippe s are ex'ensively used and very satisfactorly so, particularly in cattle under three years of age. In older cattle the horns become brittle and the bones are sometimes injured by the use of the nippers. The safest method of dehorning is through the use of a common hand saw. Secure the animal well in any manner that may suit the operation best and prevent injury of any kind, always avoiding as much worry to the animal as possible. Take the saw and remove the horns as quietly and quickly as possible, being careful to get close up to the frontal bone. Should there be much hemorrhage use alum water or Monsels solution to stop blood. When the horus have been removed and bleeding checked it is a good plan to apply pine tar to wounds. The best seasons for dehorning is either early spring or late in the fall. 


\section{Tapping the Chest.}

The occasion for this upration $m$ st alwiys nc ur i, cases of pleurisy where there is an effusion.

Clip off the hair tro $n$ a space $a b$ iut thre : inches back of and on a line with the joi it of the elbow and maize an

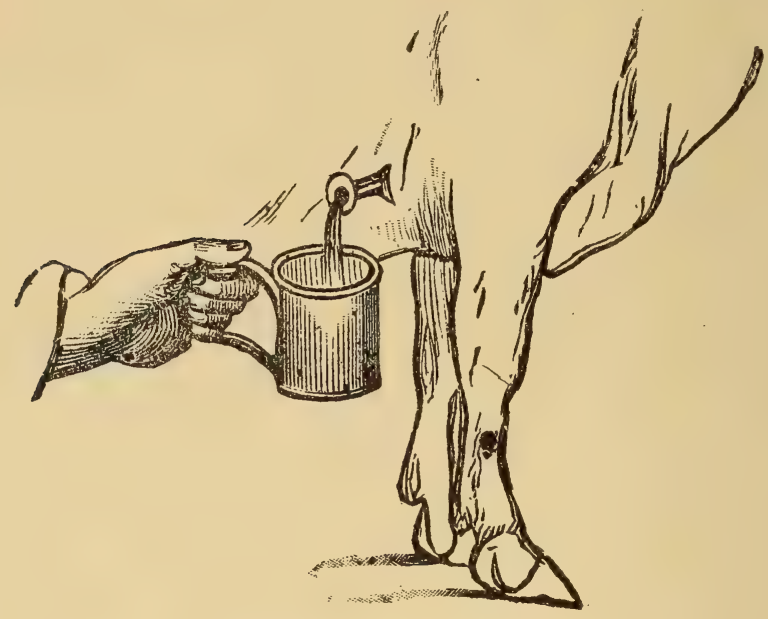

TAPPING THE CHEST.

incision between two ribs about two inches deep or until the pleural cavity is reached, introduce a quil or cannula and allow fluid to escape. Should quill become clogged from any cause open it with a probe.

\section{Tapping the Paunch.}

This operation is usually performed to relieve hoven in cattle when other means have failed. To tap the paunch stand nn right side of a timal taze a sharp and slender but rather ling bladed knife and plunge it quickly into left 
side half way between the last short rib and point of the hip bone, directing the point downward and inward and it will pass into the paunch; introduce a quill and gas will escape.

\section{Tapping the Bladder of Bull or Steer.}

To ap the bladder of male cattle it is necessary to make an pening at the point where the penis turns over the angle of the $\mathrm{p}$-1vis. The opening should be made just large enough to admit the instrument desired for use Tbe cathet-r or stone forceps can be introduced from here, which is imposs'ble from any other place on account of the curve in the urethral canal. When work in bladder is complete take a stich in opening and dress daily with carbolized water.

\section{Castration.}

To castrate a bull is a very simple operation. Many have their own peculiar ideas in regard to how it should be done; we simply give here nne of the safest and best methods. Lay bull on his back and secure him well, cut away end of bag and pull out testicles, scrape cord high up until it falls awav, release animal and he will bz all right. 


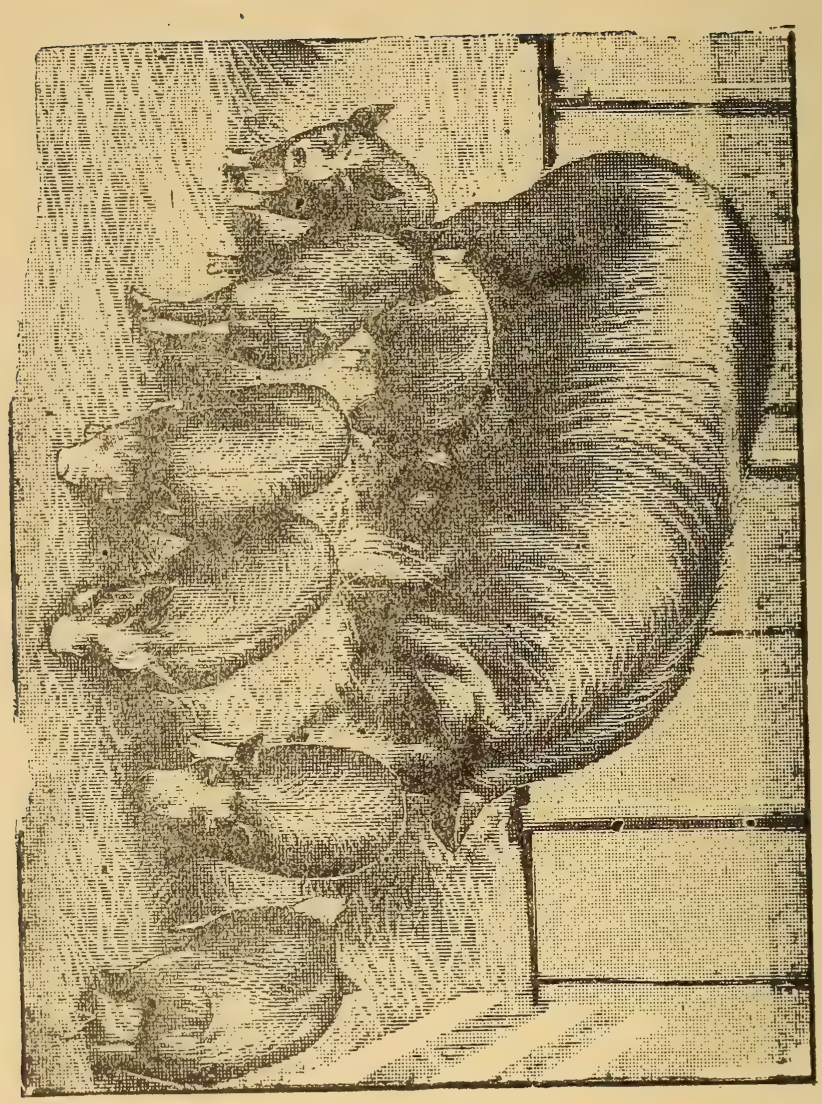




\section{$S \mathbb{W} \mid N E$}

The maintenance of health in his herds should be a matter of most serious consideration with every swine breeder for it is the one thing which is of first importance to him. It is always much easier to prevent disease in this branch of the animal kingdom than to cure it after it has once secured a foothold. "An ounce of prevention is worth a pound of cure" in every herd of swine, and the breeder or fancier who feeds for profit or pleasure will do well to take this old adage for his guide.

Every precaution should always be taken to prevent the introduction of disease of any kind among healthy hogs. No new comers should ever, under any circumstances, be permitted in pens or pastures until we are perfectly satisfied that they are free from disease of every character. Should disease appear at any time every infected animal should be isolated and the pens, barns and sheds where they use, disinfected and fumigated thoroughly. The most heroic methods for their prevention should often fail to even check 
the spread of epidemics, but this should not hinder us in employing the only scientific and rational means of escape ot our command. No man can afford to sit idly by and see death drawing upon his herds and financial loss staring him in the face without engaging in and battling to the end. Care, energy and perseverence are an absolute necessity to the success of every man who raises hogs for profit.

Swine being naturally unclean, revel in dirt and filth, but even though this is the case their pens, stalls and sheds should have studied attention and be kept as clean and tidy as possible. No hog should ever be allowed to swallow in the excrement from his own body, disease sometimes arises spontaneously by this being permitted. Disinfectants and germicides being our strongest weapon and principle reliance aside from cleanliness and care in the fights to prevent disease, we should use them freely and often.

An ounce of Carbolic Acid to the gallon of water makes a splendid disinfectant for walls, floors of pens, etc. The best means of ridding barns and closed sheds of infectious germs and parasites of all kinds is to take two quarts of pine tar to the pound of sulphur and place this upon a common tow sack and ignite, letting the fumes go into every part of the structure. When this is being used all outlets for the fumes should be closed as near as possible.

Hogs are natural gluttons but it is always best to have a certain feed and give it regularly, unless you desire to fatten, when I would advise a gradual increase in the food to a point where to fatten will be profitable and hold it at that. Overcrowding with reference to feeding is by no means profitable in every instance. 
Many make the mistake of watering their swine from a mud-hole in the pen. If we will but think for, a moment the folly of such a course becomes apparent. It is almost as essential to the thrift and health of a hog that he be served with pure, clean water as that he should have any at all. No hog could be expected to thrive when he is forced to secure his daily supply of water from a veritable cesspool of disease, where all imaginable parasites propagate and every atom of water is infected with the death dealing germs of destruction.

Swine are subject to but few diseases in comparison with other domestic animals, but some of these present themselves in very malignant forms and are extremely difficult to treat. A hog is always hard to treat where he can not or will not take the medicine along with his feed.

The best method of administering medicines to swine where you have to pour it into them is by means of a horn. The animal is placed upon his back, the horn inserted in his mouth and the medicine poured slowly into the throat always giving the patient time to swallow.

As a last word we repeat: It is always better to try to prevent the spread of disease than to waste valuable time in futile attempts at doctoring. It is often economy to kill and burn a hog or two in order to prevent any further spread of disease and it will always pay to employ preventatives judiciously.

The following has stood the test of time as a preventative in many of the more malignant troubles.

PRESCRIPTION

Sulphur ......... . 4 ounces 
Iron, sulphate of ....... . 3 ounces Gentian, powdered....... I ounce Antimony, black ....... I ounce Potash, nitrate of . . . . I I-2 ounces Arsenic . . . . . . . . . . I drachm Mix and give one tablespoonful at a dose once a day in soft feed. Aside from being a good preventative, this will prove to be a splendid tonic for all hogs not thriving as they should.

\section{Quinsy.}

This is an inflammation of the gland of the throat and is very common as well as fatal in hogs.

Cause- The most prolific cause is from taking cold.

$$
\text { HOW TO KNOW IT }
$$

The hog (or pig, as is most generally the case) will be noticed sneezing or coughing, and it will be observed that swallowing is difficult. The throat will be sore and there will be swelling under the lower jaw and neck.

$$
\text { WHAT TO DO }
$$

Paint the swelling with tincture of iodine or poultice with flaxseed meal and if patient will eat give the following:

PRESCRIPTION

Turpentine

Sulphur

Potash, nițrate of
I drachm

I drachm

I drachm 
Mix and give at one dose in some tempting feed. If patient can not eat give as an injection:

\section{PRESCRIPTION}

Magnesia, sulphate of .... . 3 ounces Turpentine . . . . . . . . I drachm Water, q. s. . . . . . add 8 ounces Mix and inject into rectum.

\section{Choking.}

This condition is sometimes met with in pigs, but is rare in older swine.

\section{HOW TO KNOW IT.}

There is a continual cough and effort at expulsion with a peculiar bowing of the neck and frothing at the mouth.

\section{WHAT TO DO}

If obstruction can be reached remove it, if this can not be done try to work it down with the hand on the ontside of throat and in the event this fails take a soft rubber tuke or probe of some kind (a smooth stick with the end protected with folds of sort muslin is good) and after oiling well, insert it in the throat and exert gentle pressure upon obstruction, forcing it gradually into the stomach.

\section{Stunt.}

This is a very common trouble and is usually a result of early weaning and strong feed which the stomach of 
the big cannot digest. Sometimes worms are responsible for this condition. A stunted shoat usually takes his feed all right but does not thrive.

WHAT TO DO.

To prevent a pig being stunted he should have slop and soft feed until at lesast three months of age when grain or hard corn may be given, in limited quantities at first, gradually increasing it, until the desired amount is reached. Ashes in which there is some charcoal mixed with plenty of salt is good for either stunted or growing pigs. A change of feed from hard to soft is necessary in securing results in cases of "stunt." Cooked and soured feed is always best in this trouble. Give the following tonic:

PRESCKIPTION

Sulphur . . . . . . . . 2 ounces

Potash, nitrate of ........ I ounce

Iron, sulphate of . . . . . . . 2 ounces

Antimony, black .... . . . . I ounce

Arsenic . . . . . . . . I drachm

Soda, Bi-corbonate of . . . . . . 2 ounces

Mix and give one tablespoonful at a dose twice a day in soft feed.

\section{Worms.}

These are often found in pigs but are rare in older swine. A pig with worms generally has a good appetite but does not thrive as he should, 
WHAT TO DO FOR THEM.

Place a plenty of salt and ashes mixed where pig can get to them and help himself. Give half a tablespoonful of sulphur twice a day in connection with tonic recommended in stunt.

\section{Constipation}

This trouble is by no means common and when it does occur it is usually in a stunted hog. It may be caused by worms in the stomach or indigestion.

HOW TO KNOW IT.

The patient will appear rather full even though he refuses his feed, and will lay around and be very dull. He will strain some in his effort at passing dung but nothing comes.

$$
\text { WHAT TO DO. }
$$

Give the following as a drench:

PRESCRIPTION.

Epsom Salts . . . . . . . . I ounce

Ginger, (powdered) ... . . . 2 drachms

Gentian, (powdered)..... 2 drachms

Water q. s. ad . . . . . . 3 ounces

Mix and give at one dose to 6 mouths old shoats. For older hogs increase the dose and for younger ones decrease it according to age. Give same tonic as in stunt for two weeks. 


\section{Diarrhoea}

This is another very uncommon trouble among swine. It is a watery discharge from the bowels and is generally caused from a change in feed particularly from a poor feed to a very rich one.

HOW TO KNOW IT

The patient is very thirsty and dull and refuses to eat. There is a watery discharge or one of very soft manure from the bowels.

\section{WHAT TO DO.}

Give ashes in which there is much charcoal and salt. This the hog will eat if it is placed by him. In the allowance of water, which should be given three times a day in half gallon lots. place about 4 ounces of lump starch. When bowels begin to check begin the use of a good tonic.

\section{Staggers.}

This is a kind of congestion of the brain and is most common in fat hogs.

HOW TO KNOW IT.

The bowels are constipated, the eyes are red and there is a general dullness at first; these are followed by partial blindness in which the patient is noticed to move in a circle, run against fences and walls and at last fall unconscious.

$$
\text { WHAT TO DO. }
$$

Give at once the same injection as in quinsy, and if pa- 
tient can be made to swollow, give internally 2 ounces of Epsom Salts. When the bowels move the trouble will pass pway.

\section{Fits in Pigs.}

This appears to be a brain trouble, but the real cause is wolms. The pig will grate or champ his teeth, its neck will bend back and its legs will jerk, soon it falls over as if dea 1 but gets up again and seems all righr until another fit comes on.

WHAT TO DO.

Treat at once for worms.

\section{Pneumonia.}

This is an inflammation of the tissues of the lungs and is caused from cold. In it the hog has no appetite but is troubled with a continual a ugh. The breathing is laborious and rapid, and the limbs and body seem to shiver:

WHAT TO DC

Rub in mustard paste on side and chest and give the following either in soft feed or drench.

PRESCRIPTION

Soda, bi-sulphate of . . . . 2 ounces

Potash, nitrate of ...... 2 ounces

Mix and give at one dose and repeat every 4 hours. 


\section{Mange.}

This is a very common trouble in some sections of the country and while not very dangerous it is quite detrimental to the thrift of a hog. Almost every hog raiser is thoroughly acquainted with the mange.

\section{WHAT TO DO FOR IT.}

Give the following internally.

\section{PRESCRIPTION}

$$
\begin{aligned}
& \text { Sulphur . . . . . . . . . } 4 \text { ounces } \\
& \text { Potash, nitrate of . . . . I-2 ounce } \\
& \text { Antimony, black . . . . . . I-2 ounce }
\end{aligned}
$$

Mix and make into 8 powders and give one night and morning in soft feed.

Apply externally this:

PRESCRIPTION.

$$
\begin{aligned}
& \text { Kerosene } \\
& \text { Sulphur. . . . . . . . . . . . . . . . I I ounce } \\
& \text { Lard . . . . . . . . . . . I ounce }
\end{aligned}
$$

Mix and apply to all mange spots once a day for two days.

\section{Lice.}

These pests are quite common but are easy to get rid of. An ointment of common lard and Scotch snuff will move them and oil of sassafras will do the same.

\section{Black Teeth}

These are found in a pigs mouth when it comes and 
grow for a time when they drop out. They sometimes present themselves in such a way as to wound the tongue and p: oduce sufficient soreness to prevent eating. When this happens they should be removed at once or the pig will die.

\section{Hog Cholera.}

This is an infectious disease of the blood and is very fatal.

\section{HOW TO KNOW IT}

First we notice a dullness with drooping of the ears and loss of appetite, then a feverish eondition arises and the hog shows signs of pain in the bowels. As trouble progresses the skin of the nose, throat and belly turns purple and a diarrhoea sets in, the dicharge being black, thin and very offensive. A hog with cholera may hang on a day or two but more commonly dies in a few hours.

\section{WHAT TO DO}

Isolate every infected hog and give the following:

PRESCRIPTION.

Epsom salts ........ I ounce

Potash, nitrate of . . . . . . I drachm

Ginger, (powdered) . .. . 2 drachms

Water, q. s. ad . . . . . . 8 ounces

Mix and give at one dose, and when bowels act give $\mathbf{2}$ teacupful of parched rice every 6 hours if patient will eat it. A few valuable hogs have been saved by this means but all treatment in cholera is uncertain. 


\section{Pigging.}

Sows should be watched after very closely at pigging time. It is seldom they reed any assistance in bringing forth but occasionly may require it and we should always be ready to render it. Sometimes a pig gets lodged in the passage from cause and assistance is necessary. No fixed rule of action can be laid down in cases of this kind; good judgement is about all that is required. After the second day a sow should have plenty of food and a good tonic to tone up the system.

\section{Bustles}

When we speak of bustles it is with reforence to pigs ruptured in the bog.

\section{WHAT TO DO FOR THEM.}

Castrate very young, to do this, elevate the hind parts and press Lowels back remove testicles as in simple castration. When this is done sew up cuts with deep stitches close together and turn the pig loose to roam at will.

\section{Notes}

A11 medicines and doses of them prescribed in this chapter are for pigs and shoats about five months old unless otherwise specified. The reader should be governed in their administration accordingly. 



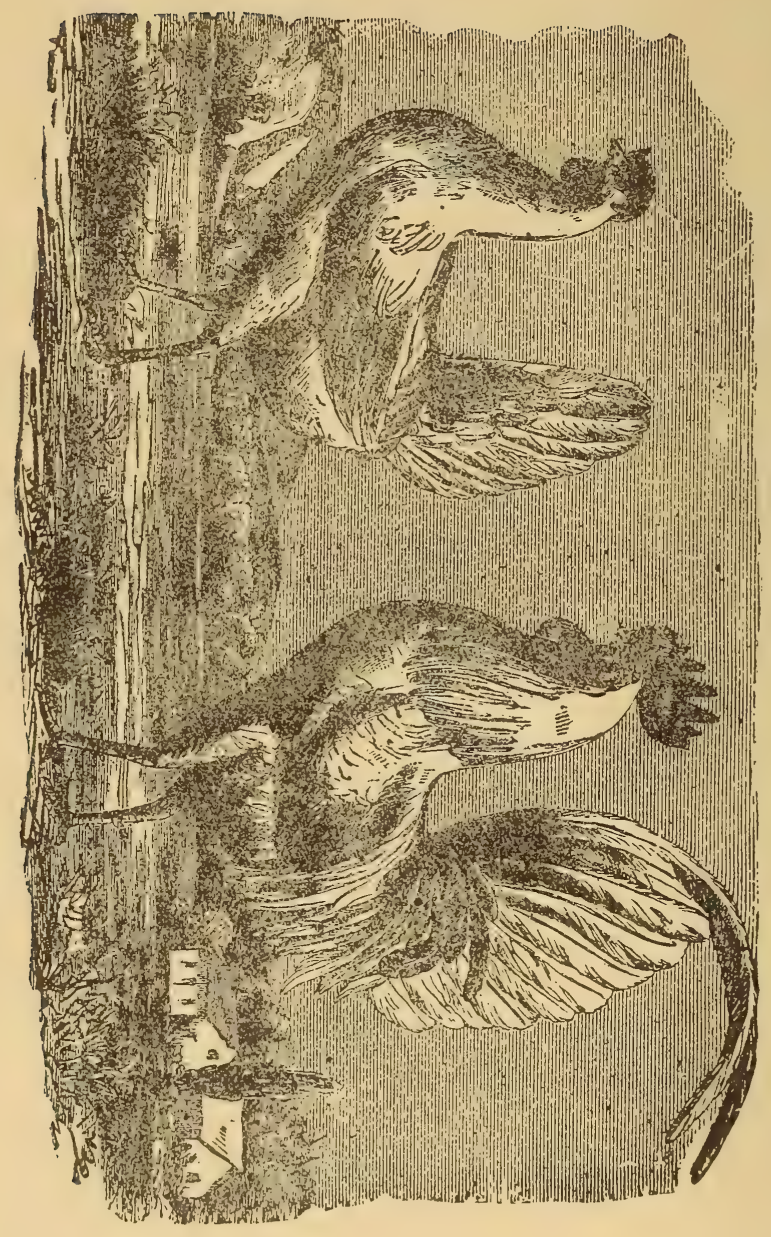




\section{DOULTRY.}

Health is essontial to the success in the breeding of poul. try. Every flock should have the careful attention of an intelligent keeper. ho prevent disease is always the wiser plan, for after it once secures a foothold, the be: $t$ remedies often fail to re'ieve until arter severe loss has been sustained. The yards should be kept clean and all coops and houses should have at least two coats of white wash per year. Liberal quantilies of slacked lime and common salt thoroughly distributed over floors of pens and houses will keep down many parasites and insec!s of an aggravating nature. All houses should be so constructed as that fowls may be kept warm in winter and cool in summer, and every roosting bar should be at least four inches wide to insure a perfect development and healthy growth of young fowls. Food should be of a wholesome character and given at regular intervais, but never in excessive quantities, and pure, clean water should be kept by all the time. Exercise upon the part of every fowl must be encouraged; 
a good plan is to p'ough in grain and let them scratch for it. Where fowls run at large gravel and sand are no object, but with penned stuff sharp gravel must be supplied.

When disease makes its appearance every infected fowl should be isolated and cared for according to the nature of the trouble, and the remainder of the flocks should bave attention to prevent any further ravages o the disease. As a preventative in most troubles the following has proven to be of untold worth:

PRESCRIPTION.

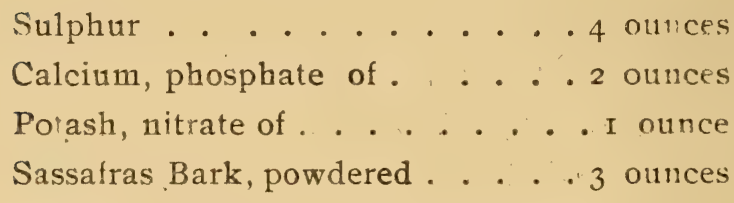

Mix and give one tablespoonful in feed for $6 \mathrm{hen}$.

Cooked feed along with their grain will always be found best in either sick or well fowls.

\section{Egg Production.}

The production of eggs and how to induce an increase of them is of much moment to every poultry man. If the flocks are healthy and the following is emploved the increase in eggs will be surprising:

\section{PRESCRIPTION}

Calcium, phosphate of . . . . I2 ounces

Capsicum, powdered. : : : . . 3 unnces 
Ginger, powdered......2 ounces

Cantharides ........ I drachm

Potash, nitrate of . . . . . . I ounce

Sulphur . . . . . . 2 ounces

Mix an 1 give one tablespoonful in feed for every 6 hens.

\section{Crop-Bound}

This is a condition in which the contents of the craw become an impacted mass and is most commonly a result of irregular feeding, but the cause may be from the fowl having swallowed some substance which obstructs the passage.

HOW TO KNOW IT.

The fowl acts as if choked or trying to swallow a large body of food, and the craw gets larger all the while.

WHAT TO DO.

The best treatment is to make a slit in the upper part of the craw, divide mass and remove it. When this is done sew up slit and feed soft feed for ten days. Orce in awhile a half tablespoonful of castor oil [will relieve this trouble without an operation.

\section{Diarrhoea}

This is a watery discharge from the bowels and is often taken for cholera, but if we will watch it closely and examine the discharge we notice that it has no resemblance to the "sulphur and water" appearance of the cholera dis- 
charge; another differenc: the craw in cholera feels as if full of wind, whi'e in diarrhoe $\mathrm{x}$ this does not appear.

\section{WHAT TO DJ}

Give the following:

PRESCRIPTION.

Opium, powdered ...... 3 grains

Ipecac, powdered . . . . . 3 grains

Capsicum, powdered ..... . 2 grains

Mix and give at 3 doses four hours apart.

\section{Cholera.}

This a very contageous disease among poultry and is one which is not so well understood by poultry men as it shoul be The cause is most generally due to bad sanitary conditions, over crowding, etc.

HOW TO KNOW I'T.

The affected fowl gapes often, is very droopy and drinks mud water. A i disease progresses fowl gets weak, the comb and wattles generally turn pale and the craw fills with wind and mucous. There is a discharge from the bowels which is either greenish, or resembles "sulphur and water."

WHAT TO DO.

The best thing to do is to prevent cholera by keeping all buildings and runs clean and healthy. The following is a good preventative in Cholera: 
PRESCRIP'TION.

Soda, hyposulphite of . . . . . I I urce

Gentian, powdered..... I ounce

Water, q. s. . . . . . . add 2 pints

Mix and add enough corn meal to make a good stiff feed a:d give one feed of this each month during the summer.

All affected fowls shou'd be isolated and given tl e following:

\section{PRFSCRIPTION .}

Lime, slacked . . . . . . Io ounces

Gentian, powdered . . . . . . I ounce

Capsicum . . . . . . . . . . I ounce

Gi ger, powd red . . . . . 2 ounces

Sas afras Bark, pow dered . . . . 2 ources

Sulphur . . . . . . . . . . I ource

Mix and giv i iwo tablesp onsful three times a day in soft feed to every six fowls Give lime water in sp iring quantities to drink

\section{Roup.}

This is the most $d$ angerous and fatal of all the diseases with which fowls are affecte $d$, and every precaution shou'd always be taken to prevent its spreading

$$
\text { HOW TO KNOW IT. }
$$

The eye lids sw 11 and sometimes the eyes are complete ly closed with a kind of froth in the corners. The face is swollen at the sides and the fowl gets weak very fast. 
There is a p ${ }^{\circ} \mathrm{C}$ liar d schaige from the nostrils which is opaque and very offensive.

\section{WHAT TO DO.}

Place affected fowl in warm quarters and feed on soft stimulating fond and give at once (if grown) a tablespoonful of castor oil. Syringe out nostrils with the following:

PRESCRIPTION.

Olive O11 . . . . . . . 2 ounces

Camphor frum . . . . . 2 drachms

Mix and fill small syringe and insert in the slit in the roof. of mouth and inject with gentle force.

\section{Catarrh.}

Th s trouble is sometimes mistaken for roup cn account of the swelling of the eye lids and sids s of face. The discharge from the nostrils in catarrh is watery instead of being thick and opaque as in roupe.

WHAT TO DO.

Give warm food in which there is much pepper and protect from co:d.

\section{Bronchitis.}

This is an affec ion of the air passages and is recognized by a cough and peculiar raising of tie head in the act of breathing.

WHAT TO DO.

Swab the throat with equal parts of powdered borax and 
chlorate of po'a h and $1+t$ p ti-nt drink of the followi $g$ : PRESCRIPTION

$$
\begin{aligned}
& \text { Putash, chl r de of . . . . . I d achm } \\
& \text { Water, q. s...... . . add } 2 \text { pints }
\end{aligned}
$$

Mix and put conven e tiy by.

\section{Gapes}

This is a peculiar trouble and affect imore directly the windpiye. Tre cause of it is by no means thoroughly understood, but $i$ is pretty $w$. 11 :et led that it is a parasitic worm. It usual!y occurs in chicks from two to three month $\div$ (1).

HOW TO KNOW I'T.

There is a contant cough and sneez: with continual gaping.

\section{WHAT TO DO.}

Dip a feather into an ounce of turpentine in which a drachm of gum camphor has been dissolved and with it swab out the opening to the windpipe which cau be plainly seen at the root of the ongue One application is generally sufficient.

\section{Pip}

This is by no means a disease within it: elf, bu: merely the result of one. All that is necessary in a case of pip is to remove the crust at the tip of thatongue. 


\section{Sore Head.}

This is a peculiar condition which makes its appearance seemingly without any cause and runs through an entire flock unless promptly dealt with. It resembles roup, but is quite different to it.

HOW TO KNOW IT.

Knots appear about the head and eyes, and the swelling and inflammation of these keep increasing until the eyes are closed and the head is apparently one solid sore. The fowl goes blind and eventually dies unless treatment is resorted to.

$$
\text { WHAT TO DO. }
$$

Use the following:

PRESCRIPTION.

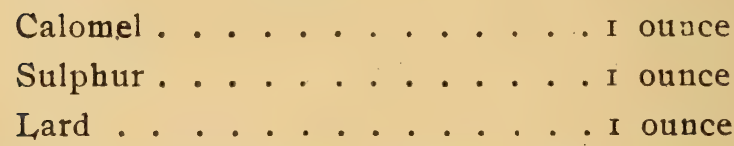

Mix and apply all over head and face. In a few days the inflammatiun subsides, the eyes open up and the fow 1 is all right. Extra care should be used in feeding fowls while they are so they cannot see.

\section{Leg Weakness}

This is a common trouble with the young of some of the larger breeds and it may be readily overcowe by feeding meats and cracked grain with the followirg tonic: 
PRESCRIPTION.

Iron, citrate of ....... I drachm Sulphur . . . . . . . . I ounce

Calcium, sulphate of . . . . . . I ounce

Mix and give a half teaspoonful to each fowl twice a didy in oat or barley meal.

\section{Lice.}

Hen lice are a nuisance for which there in but litlle excuse. Always be sure that every new towl brought into the flock is free fr m lice, and keep honses and run: $i: 1$ good condition from a sanitary tandpint, and lice will never make their appearance

\section{HOW TO GE'T RID OF THEM}

When lice have once made their appearance we may get rid of them by sprinkling hens and nests every third day with Scotch suuff mixed with sulphur. When lice infest the heads and wings of 1 tte chicks, use the following:

PRESCRIPTION.

\section{Sulphur. . . . . . . . I ounce \\ Lard ... . . . . . . . I ounce}

Mix and grease head and wings thoroughly. This wlll also take fleas off of fowls without the slighest danger.

\section{Fleas.}

Mexican fleas, or "stick tights" as they are called by some, are multitudious in some parts of the country and are very annoying to fowls. 
WHAT TO DO FOR THEM.

To rid a place of these agerating insects first coop al ${ }^{1}$ fowls and grease their heads with the following:

PRESCRIPTION

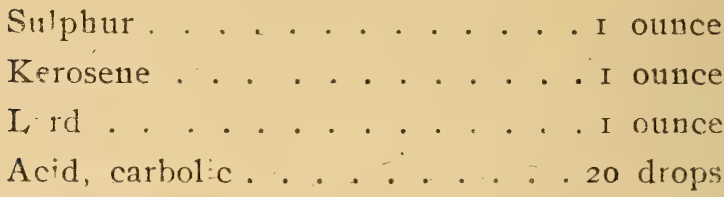
Mix and apply.

When this is do e take common salt and scatter it thin all over the floors of houces, cons, etc; th $\mathrm{n}$ spri kle with sufficiert $\mathrm{wa}$ er to melt the salt.

\section{Mites.}

These are vtritabie pests in some parts of the country, but they may be gotten rid of if the meani employed in getting rid of lice and fleas are : e ort $d$ to and the wall, floors and and ccirings are painted with the following:

PRESCRIPTION.

Verdigris . . . . . . . I drechm Alcohol ........ . 3 ounces Acid, carbolic (crude).... . 3 ounces Oil of Tar. . . . . . 3 ounces Ammonia, aqua...... 3 ounces Kerosene . . . . . . . . I 2 ounces Mix and paint every part of building thorougbly. 



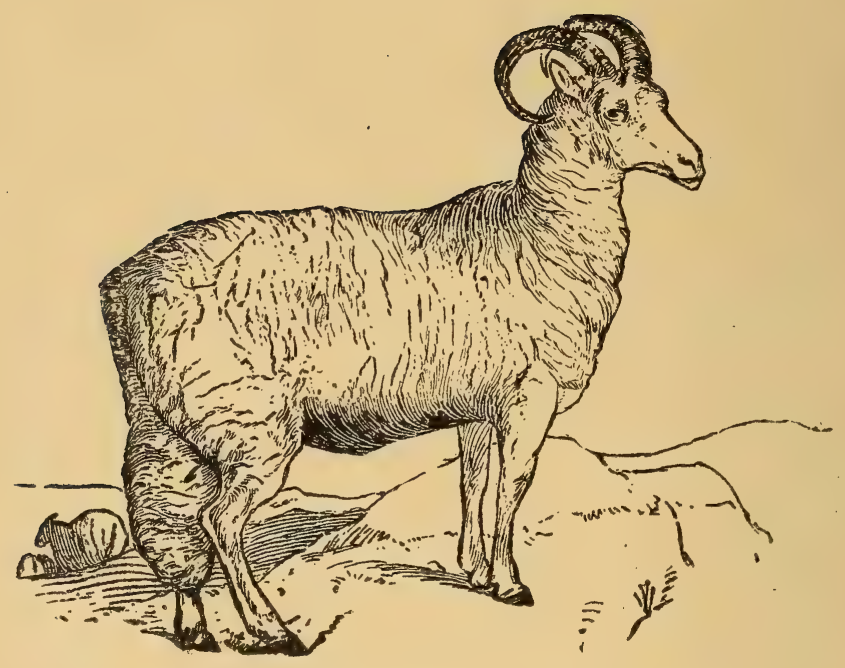




\section{SHEED.}

Though incomplete in some respects, this part of the work comprises all of the more common diseases and remedies which may be easily and successfully employed in this class of ruminants.

\section{Travel Sore.}

This is a common trouble in sheep that have been driven on the roald.

\section{HUW 'TO KNOW I'T.}

The actions of the sheep in traveling coupled with an exanimation of the feet will disclose the character of affection.

WHAT TO DO.

Cleanse foot thoronghly with soap and water being particular as to cleft, then touch thin or tender with sulphuric acid and cover with tar. If any signs of foul are prescint apply a strong solution of sulphate of copper to cleft. 


\section{Gravel and Swollen Foot.}

This is a condition in which the canal in the upper part of, and front of hoof is swollen and much inflamed.

\section{WHA'T TO DO.}

If graveled remove the gravel and apply any soothing medicament, always protecting the foot until it has time to heal. If an ulcer or abscess has formed release the pus and dress with tincture of myrrh.

\section{Foot Rot.}

This is a common and fatal affection when not given prompt attention.

\section{HOW TO KNOW IT.}

First the skin over the heels and top of the clefts of the hoofs becomes moist, warm red and rough, this is followed by ulceration and the discharge of purulent matter, the foot soon becomes a mass of corruption, sometimes filled with maggots.

\section{WHAT TO DO.}

Remove all diseased parts with a sharp knife, when this is done bathe for fifteen minutes in a saturated solution of sulphate of copper and cover hoof with chloride of lime, Give internally the following: 
PRESCRIP'TION.

$$
\begin{aligned}
& \text { Iron, stlphate of . . . . I-2 onnce } \\
& \text { Potash, nitrate of . . . . I-2 ounce } \\
& \text { Sodium, chloride of . . . . } 2 \text { drachms }
\end{aligned}
$$

Mix and make into 8 powders and give one a day

\section{Maggots.}

To get rid of maggots cleanse wound thoroughly with carbolized water remove every one that can be found and apply the following to wound:

PRESCRIP'TION

Creosote.......... I ounce Alcohol .......... . 2 ounces

Mix and touch wound all over with it

\section{Worms.}

Intestinal worms in sheep do but little damage, and our only means of telling when a herd is infested with them is by finding them in the bowels of a sheep which has been butchered or died and the intestines subsequently examined.

$$
\text { WHA'T TO DO FOR THEM. }
$$

Give the following:

\section{PRESCRIPTION.}

Sodium, chloride of ..... I6 ounces Magnesia, sulphate of . . . . 8 ounces 
Iron, sulphate of ...... . 2 ounces

Gentian, (porvdered) . . . . . 4 ounces

Mix and give to 50 sheep once every two weeks.

\section{Liver Fluke}

This is commonly known as simple "rot". It is due to the presence of small flat worms in the liver.

How TO KNOW IT.

The skin is soft and flabby and there is a crackling sensation when it is taken between the thumb and finger. The eyes are yellow, the belly is enlarged and there is tenderness about the loins and signs of weakness are apparent.

WHA'T TO DO.

Place sheep in high dry pasture and give. the following:

\section{PRESCRIPTION}

Magnesia, stiphate of . . . . . 2 ounces

Turpentine ........ 2 drachms

Water, q. s. arl . . . . I 2 ounces

Mix and give at one dose and repeat every other day until 3 doses have been given. When this is done use the following:

I'RISSCRIP'TION.

Flaxscel Meal . . . . I6 onnces

Gentian (pordered ..... $\because$, , I ounce 
Sodium, chloride of

2 ounces

Iron, sulphate of 2 drachus

Mix and give at two feeds one a day and keep it up for a week, then discontinue for two weeks and repeat.

\section{Lung Worms.}

This disease is marked by the presence of worms in the wind pipe, bronchial tubes or lungs, and is recognized by a husky cough, rapid breathing and loss of appetite. The sheep will place his nose on the ground and rub it. There may be a diarrhoea.

\section{WHAT TO 10}

Have sheep to breathe fumes from burning turpentine and give internally the following:

\section{PRESCRIPTION}

Magnesia, Sulpliate of . ..... 3 ounces

Potash, Nitrate of ........ 2 onnces

Iron, Sulphate of . . . . . . 2 ounces

Gentian (Powdered). . ... : 2 ounces

Sulphur . . . . . . . . . 3 ounces

Mix and give two tablespoonsful at a dose once a day in corn meal and keep this up for a week, then discontinue for two weeks and repeat.

\section{Bloating}

This is a condition in which the pannch is distended with gas or wind. 
HOW TO KNOW IT.

The sheep keeps getting up and down, is uneasy and shows signs of pain. The left side will be found distented and when tapped upon gives a hollow drum like sound.

$$
\text { WHAT TO DO. }
$$

Give at once the following:

PRESCRIPTION.

Soda, bicarbonate of . . . . . . I drachm

Niter, spirits of ...... I-2 ounre

Epsom Salts . ...... 4 ounces

Ginger (powdered)......2 drachms

Mix and give in a pint of warn water and repeat in two hours if necessary. Should this fail to relieve, tapping must be resorted to. To tap, clip wool from a spot half way between point of hip and last rib and about three inches from back bones, insert a sharp but small blade through into paunch and gas will escape. The wound will heal of its own accord.

\section{Colic}

Colic in sheep is the same as it is in any other animal. The sheep lies down and strikes his feet against his belly, moans and and gets up, only to repeat these acts at the next pain.

WHAT TO DO.

Give the following: 
PRISCRIPTION .

Opium, tincture of . . . . 2 drachms Aconite, tincture of . . . . . . . 5 drops

Soda, bicarbonate of . . . . . . I drachm Mix and give at one dose, and repeat every hour so long as necessary: If the ingredients of above are not at hand give this:

\section{PRESCRIPTION.}

Turpentine . . . . . . 2 drachms Lard . . . . . . . . . 8 ounces Mix and give at one dose.

\section{Inflammation of the Bowels.}

This is a common trouble in the colder sections of the coutrtry, and is supposed to be due to the eating of frozen or faulty food. The sheep with inflammation of the bowels acts very much as if he has the colic, but there is no intermission in the pain; he paws the ground, his ears and legs are cold, and pressure on the belly brings forth a moan of pain.

\section{WHAT TO DO.}

First give the following as a purge.

PRESCRIPTION.

Epsom Salts . . . . . 5 ounces Ginger . . . . . . . . I drachm 
Ni er, spirits of . . . . . . 4 drachms Mix and giv: at one dose and begin at once the following:

\section{PRESCRIPTION}

Opiam, tincture ef . . . . . 2 drachms

Aconice, tincture of . . . . 4 drops

Water q s. ad ........ 8 ounces

Mix and give at one fuse and repeat every hour so long as indicated.

\section{Grub in the Head}

This is a comm '11 trouble in some parts of the c.un $\mathrm{m}$. The cause $i$ not und $\cdot$ r.tiod but it is $11 \cdot \mathrm{s}$ : common among she p pastured on sw mpy lands

\section{HOW TO KNOW IT}

Th ' heep act: very s'!ang; it will hold its head to o: e si fe and a little higher than natural at first, then a kind of fit comes on in which the sheep will run against fences, into ditch s, ec Sometimes the sheep falls ove I and is in a $\mathrm{p}$ rfect $\mathrm{j}$ rk for a moment, thea it is all right again for a few minutes

\section{WHAT TO DC}

Place she $p$ in a close 1 it where it can not hurt itse'f. and notice the had each day for a s ift spot in the bone at the top. Wi en sofi spot app ars remcve skin over it first and then diseased bone being careful not to louch the brain; the grub wil rice up and r lieve pressure from brain. Do $n t$ atlempt to remove grub na'ure will thow it off at the right time 


\section{Scab.}

This trouble might properly be called mange $f \mathrm{r}$ it is nothing else. It is a parasitic disease, and very contagious.

\section{HOW TO KNOW IT.}

The sheep is continually rubbing itself, the wool falis off in spots and it loses flesh rapidly. An expression akin to anguish is noticable.

WHAT TO DO.

To treat this disea ie a large tank or reservoir is necessary for dipping purposes. The following makes a splendid dip.

PRESCRIPTION.

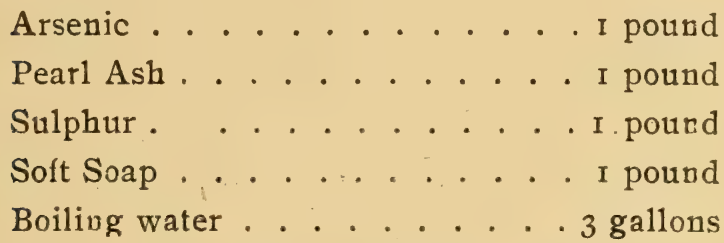

Mix and add 35 gallons of cold water. Dip the sheep all but the head retəining him for a minute in the fluid. It is always best to cllp the wool close before dipping. After dipping wash the heads every day for a week with this:

PRESCRIPTION.

Creoline ......... 2 ounces

Water ......... 2 pints.

Mix and wash the head thoroughly. Ticks and lice may be gotten rid of by a liberal use of this 


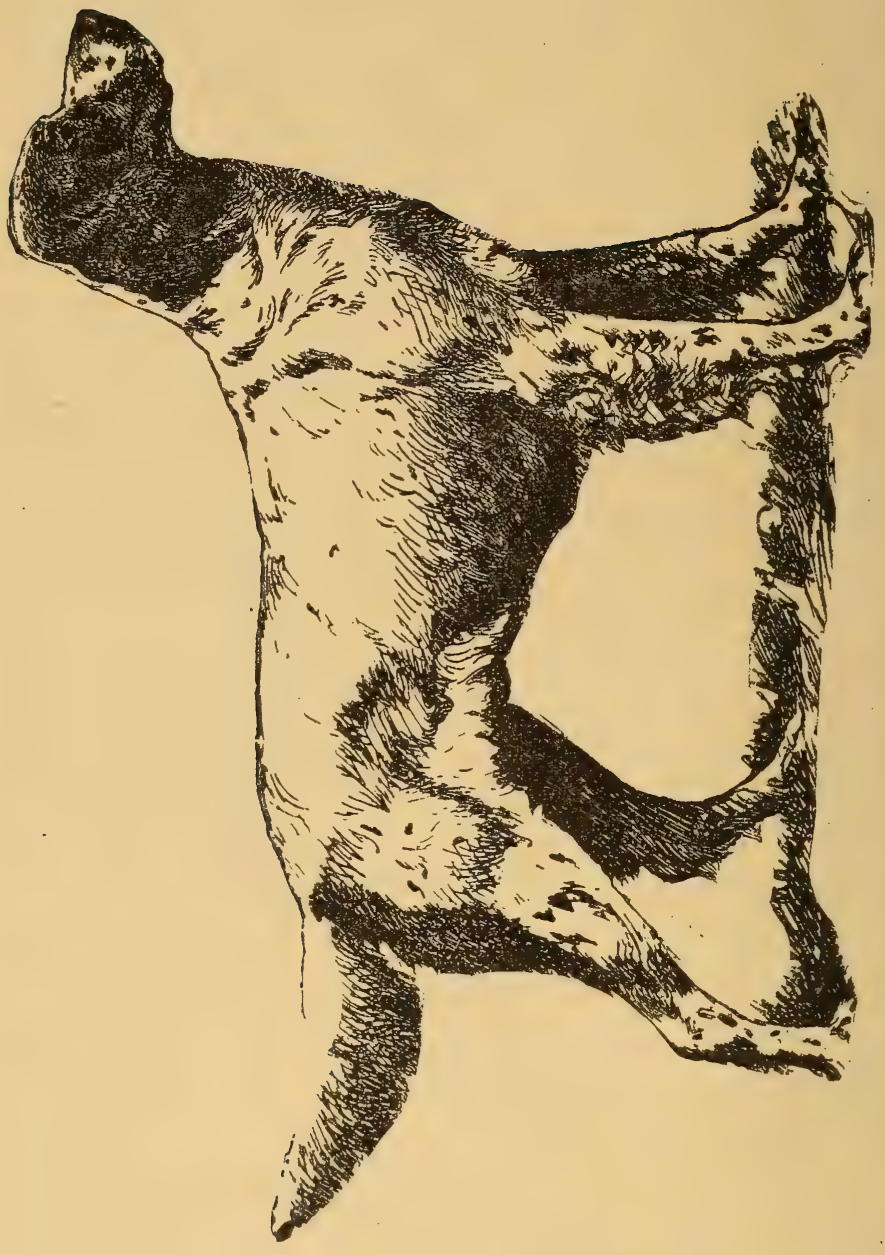




\section{DOGS.}

The writer feels that his work would be inconp'ete, did he not devo'e a few pazes to man's best friend. Dogs are by $s$ me cousidered valutless, while of hers appreciate them beyond their worth. In the clis-ing pages of this work we will give some of the more common affection; am ing dogs and their treatment.

\section{Mange.}

Mange is a stin disase and is due to a prasite or mit 'like organism

\section{HOW TO KNOW IT.}

There is intense itching which often incites frantic scratching. The hair is generally worn off of either o: e or both haunches. Xhe itching generally makes its appearance first around the eyes, fore legs and eibows, then on the belly, in the flanks and inside the thigbs, soon covering the whole body. There is loss of hair, pimply eruptions with scaly ratches between. 
WHAT TO DO.

Give the dog a thorough scrubbing with soap and water and use the following:

PRESCRIPTION.

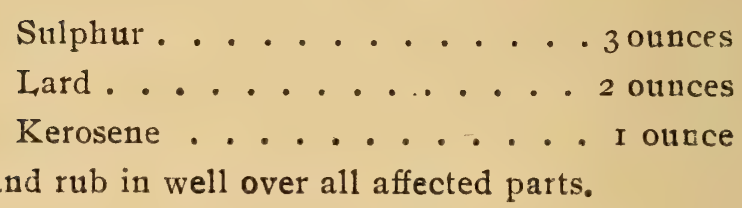

Fleas.

These are a source of much annoyance to a dog. They can be readily killed with this:

\section{PRESCRIPTION}

Oil of Anise seed ....... I 2 ounce Olive Oil ........ 3 ounces

Kerosene q. s. ad ...... 4 ounces. Mix and rub in well.

\section{Lice.}

There are several kinds of lice which infest the coat of dogs, either of which may be gotten rid of by oiling the dog with whale oil.

\section{Ringworm.}

Ringworm is a kind of vegetable parasitic disturbance and is recognized by an elevation of the skin in the shape of a ring, which increases in size. There is much local 
irritation; the hair drops off showing the skin scaly and rough.

\section{WHAT TO DO.}

Wash affected parts in soap and water, cleansing them thoroughly. and then use this:

PRESCRIPTION.

Oil of Tar........ 3 drachms

Whale Oil . . . . . . . 6 ounces

Mix and rub in well on ringworm.

\section{Inflammation of the Eyes}

This is what is commonly known as sore eyes, a condition in which the eyes are red and inflamed, with the lids swollen and tears flowing down the face.

\section{WHAT TO DO}

If a mechanical irritant be present, remove it and bathe in cold cream. Should the trouble be other than mechanical, use the following:

PRESCRIPTION.

Lead, acetate of . . . . . I5 grains

Zinc, sulphate of ..... I 5 grains

Morphine, sulphate of . . . . Io grains

Water, q. s. ad ...... 8 ounces

Mix and bathe eye twice per day, being sure to get the wash into the eye. 


\section{Ear Canker.}

This trouble is seldom found in dogs not accustomed to the chase. It consists of an offensive discharge from the ear. With it a dog holds his head to one side and shows much uneasiness as well as unwillingness to be examined.

\section{WHAT TO DO}

Cleanse the ear with warm water.and use the following:

$$
\text { PRESCRIPTION. }
$$

Lead, Acetate of . . . . . 2 drachms

Zinc, Sulphate of ....... 2 drachms

Alum . . . . . . . . 2 drachms

Water, qs. ad ........ . I pint

Mix and inject into ear once a day.

\section{Distemper.}

This is one of the most common diseases in the canine family, and it seems that every dog must have it. In many instances the scenting qualities are impaired and sometimes the trouble proves fatal.

\section{HOW TO KNOW IT}

The eyes are red, the nose is hot and dry, there is loss of appetite and great languor; the urine is highly colored and the bowels are uncertain, with offensive forces always. The breathing is usually accelerated. In a day or two the eyes and nose begin to run water, but this discharge becomes 
purulent directly. The eyes and nose sometimes become so gummed as that breathing through the nose is impossible, and the dog cannot see. Distemper is often complicated with other troubles.

WHAT TO DO FOR IT.

In a fox hound give a tablespoonful of syrup of buckthorn every twenty-four hours until the bowels move. (A1ways regulate dose according to size of dog.) Give the following from beginning of troubles and continue it's use until all is over:

PRESCRIPTION

Sulphur . . . . . . . . I ounce

Potash, Nitrate of . . . . . I ounce

Gentian (powdered). . . . . . 1/2 ounce

Blood Root (powdered). . . . 3 drachms

Mix and give a scanty teaspoonful twice a day to a fullgrown fox hound. A dog with distemper should always be fed lightly.

\section{Constipation.}

A frequent trouble with dogs is the accumulation and hardening of the falces in the bowels.

\section{HOW TO KNOW IT.}

The belly usually seems rather full, the dog is dull and will not eat much, there are frequent efforts at evacuation in which there is much straining with but slight passages if any at all, and these are diy and hard. 


\section{WHAT TO DO.}

Give at once (to grown hound) two tablespoonsful of castor oil and repeat twice per day until trouble is passed. Rectal injections may be employed advantageously in this trouble.

\section{Diarrhoea and Dysentery.}

These troubles are very uncommon in dogs. Dysentery is distinguished by the presence of blood in the excretions.

$$
\text { WHAT TO DO FOR THEM. }
$$

First give a tablespoonful of castor oil and in one hour begin the following:

\section{PRESCRIPTION.}

Opium, Tincture of . . . . . . . $\frac{1}{2}$ ounce

Aconite, Tincture of . . . . . 20 drops

Gum Arabic . . . . . . . 2 drachms

Chalk, precipitated . . . . . . $\frac{1}{2}$ ounce Mix and give a tablespoonful at a dose every 4 hours.

\section{Worms.}

Worms as a rule improve the appetite, but the dog does not seem to do well, the coat has a dry, dirty and dusty appearance, and sometimes a worm is passed in the falces. Warm fits are by no means uncommon where a dog is badly affected.

$$
\text { WHAT TO DO }
$$

Give the following: 
PRESCRIPTION

Oil of Male Shield Fern . . . I drachm Olive Oil . . . . . . . . . I-2 ounce Mix and give at one dose and repeat on third day.

\section{Fits.}

On account of the high development of the nervous system, fits are quite common among dogs. They may be brought on by worms, over-eating, indigestion or worry:

\section{HOW TO KNOW THEM}

The dog usually falls, is delirious and works his legs violently. There is frothing at the mouth and champing of the jaws. The fit soon passes off and the dog is all right until another comes on.

\section{WHAT TO DC}

If worms are suspected look after them. If cause of fits is not perceptible give at once a good dose of castor oil and follow in thirty minutes with:

\section{PRESCRIPTION}

Potash, bromide of ..... 2 drachms

Water, q. s. ad . . . . . .6 ounces

Mix and give a tablespoonful three times a day for three days.

\section{Chorea}

This is a nervous trouble and is recognized by a continual jerking of the muscles: 
WHAT TO DO.

The bromide prescription used in fits is good in the beginning of this trouble. Nothing can be done after it has once secu.ed a good foothold.

\section{Hydrophobia}

This is the most dangerous and worst dreaded of all the diseases with which the canine family is afflicted. It may arise spontaneously or be introduced into the system by inocculation, and is always communicable to man and other animals. The usual period of incubation is from two to four weeks, but it may be a year or even longer.

\section{HOW TO KNOW IT}

At first the dog seems rather timid and very thirsty; he will make some efforts to drink, but cannot swallow, his food he cannot chew and he will snap or bite when punched with a stick. Next the dog becomes delirious, froths at the mouth, runs about and bites everything with which he comes in contact. The eyes are blood-shotten, the lower jaw is usually dropped and the tongue commonly hangs out. A mad dog has seldom boen known to go out of his way to attack anything.

WHAT TO DO

The safest way is to kill not only the dog but every ani. mal it has come in contact with. 


\section{Poison and Their Antidotes}

Dogs frequently get poisoned from eating noxious plants or by getting hold of poisonous substances left out for some other purpose-sometimes by malicious persons and sonmetimes by overdose of strong drug. It is well to know something about the common poisons, with their modes of action and their antidotes, as the loss of a few minutes will in some cases cost the dog's life. A few general directions on this line will pay the reader to commit to memory some of the following remedies. If the dog is poisoned on an alkali, give an acid such as vinegar, etc., in one tablespoonful doses every 15 or 20 minutes. If poisoned by acid give alkali, such as common cooking soda, one teaspoonful every 20 minutes until you give 3 or 4 doses.

\section{Strychnine Poison}

This is a very common occurrence in the dog. They can get hold of this poison in various ways.

SYMPTOMS.

This is an irritating poison, manifesting itself by tetanic spasms and general convulsions, convulsion of the diaphraghm, causing labored breathing. In this case give something to make him vomit as quick as possible. Probably the handiest thing will be this:

PRESCRIPTION .

Ground Mustard . . . . . . . . 2 ounces Common Salt : : . . . . . . 3 ounces 
Mix, give at one dose in a little warm water; repeat every Io or 5 minutes. Then give this: Hydrated Chlorate ten grains in water every 30 to 40 minutes till 3 or 4 doses have been given. 


\title{
PRESCRIPTIONS FOR CA TTLE.
}

\author{
TONIC POWDERS
}

Sulphur ........ 3 ounces

Mustard, powdered . . . . . 4 ounces

Sassafras Bark, powdered . . . . 2 ounces

Gentian, powdered ....... I ounce Foenugreek, powdered ..... I ounce

Skunk Cabbage, powdered...2 ounces Mix and give two tablespoonsful a day.

\section{PURGATIVE.}

Epsom Salts........ I6 ounces Gentian, powdered...... I ounce Ginger, powdered ....... I ounce Mix and give at one dose in 2 quart of water.

\section{FEVER MIXTURE}

Aconite, Tincture of . . . 3 drachms Belladonna, Fluid Fxtract of ... . I 2 ounce 
Potash, Nitrate of . . . . . 2 ounces

Linseed Infusion. . . . . . . I pint Mix and give two ounces at a dose every two bours.

FEVER MIXTURE No. 2.

Nitre, spirits of . . . . 3 ounces

Aconte, Tincture of . . . . 2 dráchms

Belladonna, Fluid Extract of ...2 ources

Potash, Ni rate of ...... 2 ounces

Ammoni $;$, Muriate of ..... 2 ounces

Water, q. s. ad ........ 2 pint;

Mix and give a haif teacupful at a dos every two lour.

SORE THROAT.

Potash, Cblorate of . . . . 2oulces

Acid, Carbolic.......20 dirps

Wate q s ad ........ I pint

Mix and mp out throat 3 or 4 times a day.

CHRONIC COUGH

Camp'or Gum......... I ource

Nitre, Spirit of ...... 4 runces

Ginger, Tincture of . . . ... . 2 ounces

Potash, Nirate if. . . ... r I-2 unces

Water q. s ad ........ 2 pints

Mix and give a teacupful three times a day.

\section{HEAVES}

Mustard, ground . . . . . . 4 ounces

Gentian, powdered...... 2 onuces 
Goenugreek (powdered)..... I ounce Lobelia Seed "، . . . .2 ounces Blood Root " . . . . 2 ounces

Pota 4 h, Nitrate of . . . . 2 I-2 ounces Mix and give 2 tablespoonsful twice a day.

TO RELIEVE PAIN.

Opium, Tincture of . . . . . . I ounce Aconite, Tincture of . . . . I-2 drachm Water q. s, ad.......... I piat Mix and give at two doses one hour apart.

\section{STIMULANT.}

Brandy ......... I 2 ounces

Ginger, Tincture of . . . . 3 ounces Water q. $\mathrm{s}$ ad........ 2 pints Mix and give half a pint at a dose as indicated.

\section{CHRONIC INDIGESTION.}

Soda, Bicarbo rate of . . . . 4 ounces

Gentian, powdered . . . . . 3 ounces

Ginger, powdered....... 2 ounces

Skunk Cabbage, powdered....2 ounces Mix and give one tablespoonful at a dose night and morning.

\section{CONSTIPATION.}

Epsom Salts . . . . . . Io ounces

Ginger, powdered . . . . . I ounce 
Nux Vomica, powdered . . . . 2 drachms Mix and give at one dose in a quart of water.

\section{DIARRHOEA.}

Chalk precipitated......2 ounces Catechu, powdered....... I ounce Ginger Opium ". ..... 2 ounc $\mathrm{s}$ " ..... 2 drachms Mix with a pint of water and give a half $t \rightarrow a c u p f u l$ tight and morning.

INFLAMMATION OF THE KIDNEYS.

Opium, Tincture of .....4 onces Aconite Fluid Extract of . . . . I drachm Belladonna, Fluid Extract of . . 2 drachms Niter, Spirits of . . . . . 4 ounces Mix and give three tablespoonsful every three hours in linseed tea.

\section{BLOODY URINE.}

Gentian, Tincture of . . . I-2 unnce Muriate of Iron, Ti cture of . . . 2 drachms Aconite, Tinc!ure of . . . . . 20 drops Water $q \mathrm{~s}$ ad ......... I pini

Mix aud give at one dose and repeat three times a day for one week

INFLAMMATION OF THE BLADDER.

Opium, Tincture of . . . . . . I ounce Aconite, Tincture of . . . . 20 drops. 
Mindererus, Spirits of . . . . 2 ounces.

Mix and give at one dose in a pint of linseed tea and repeat e very 2 hours.

\section{RHEUMATISM.}

Cinchona Bark, powdered . . . . I ounce.

Potash, Nitrate of . . . . I I-2 ounces.

Foenugreek, powdered . . . I-2 ounce.

Colchicum . . . . . . . . . . I ounce.

Mix and give at 4 doses, two a day.

INFLA MMATION OF THE BRAIN.

Potash, Bromide of ..... 2 ounces.

Aronite, Tincture of . . . . . 2 drachms.

Belladonna, Fluid Extract of . . 3 drachms.

Water, q. s. ad . ...... . 8 ounces. Mix and give two tablespoonsful at a dose every 2 hours.

\section{HEAT PROSTRATION.}

Amonia, Aqua . . . . . I I-2 ounces.

Water q. s. ad . . . . . 2 pints.

Mix and give at one dose and repeat in 30 minutes.

\section{PARALYSIS.}

Nux Vomica, powdered . . . . 4 drachms.

Gentian, powdered . . . . . . I ounce.

Flaxseed Meal . . . . . . . . 4 ounces.

Mix and divide into four doses and give one night and morning. 


\section{RETENTION OF AFTERBIRTH.}

Epsom Salts . . . . . . I 2 ounces Nitre, Spirits of .... . . . . . I ounce

Belladonna, Fluid Extract of . . . 2 drachms Water q. s. ad . . . . . . . 2 pints Mix and give at one dose.

\section{FLOODING.}

Ergot, Fluid Extract of . . . . I ounce Water q. s. ad . . . . . . . . . . I pint Mix and give at one dose and repeat in one hour.

\section{LUMP JAW LINIMENT.}

Oil of Spike. . . . . . . . . I ounce Camphor Gum . .. . . . . . 3 drachms Mercury, Bichloride of . . . . . I ounce Hartshorn .. . . . . . . . . I drachm Turpentine q. s. ad . . . . . . 8 ounces Mix and apply once a day.

WARTS.

Zinc, Sulphate of . . . . I-2 ounce

Acid, Nitric ...... I-2 ounce

Acid, Sulphuric. . . . . I-2 ounce Mix and apply once a day until wart is dead.

SNAKE BITES.

Whisky......... I pint. 
Amonnia, Aquae ....... I drachm.

Water, q. s. ad ....... 2 pints. Mix and give at one dose.

MANGE.

Sulphur . . . . . . . . 4 ounces.

Oil of Tar . . . . . . 2 I-2 ounces.

Acid, Carbolic (crude) . . . . 1/2 ounce.

. Linseed Oil . . . . . . . . . I6 ounces.

Mix and apply once a day.

LICE.

Olive Oil . . . . . . . . I ounce.

Kerosene . . . . . . . I I ounce.

Sulphur . . . . . . . . . . I ounce.

Lard . . . . . . . . . I ounce.

Mix. One application is generally sufficient.

SCREW WORMS.

Pine Tar. . ....... 4 ounces.

Acid, Carbolic (crude). . . . I ounce.

Oil of Cedar . . . . . . 2 I-2 ounces.

Alcohol . . . . . . . . . 3 ounces.

Mix and apply.

INFLAMMATION OF THE UDDER.

Camphor Gum . . . . . . . . I ounce.

Linseed Oil . . . . . . . 8 ounces.

Mix and rub in well 3 or 4 times a day. 
CHAPPED AND SORE TEATS.

Olive Oil. ....... . 4 ounces.

Camphor Gum . . . . . . . . . . I ounce.

Acid, Carbolic . . . . . . I drachm.

Mix and apply twice a day.

BITTER AND BLOODY MILK.

Mustard, Ground . . . . . 3 ounces

Sulphur . . . . . . . 2 ounces.

Potash, Nitrate of . . . . .4 ounces.

Potash, Chlorate of . . . . . $\frac{1}{2}$ ounce.

Sassafras Bark; Powdered. . . . 2 ounces.

Gentian, Pow lered . . . . . I ounce.

Skunk Cabbage, Powdered . . . 2 ounces.

Mix and give two tablespoonsful once or twice a day as indicated.

JOIN'T ILL.

Sodium, Salycilate of . . . . 2 drachms.

Blood Root, Powdered . . . . 2 drachms.

Flaxseed Meal ... . . . 2 ounces.

Mix and divide into 6 powders and give one morning, noon and night.

SCOURING IN CALVES.

Iron, Sulphate of . . . . . . $\frac{1}{2}$ drachm. 
Chalk, Precipitated . : . . . 2 drachms. Lump Starch . . . . . . . . 2 drachms. Jamaica Ginger . . . . . . 20 drops. Nux Vomica; Tincture of . . . . 2 drops. Opium, Tincture of . . . . . I.5 drops. Mix and give at one dose in new milk. 



\section{INDEX \\ Part I. Horses.}

A

Abortion . . . . . . . . . . . . . . . . . . . . . .

Abcesses . . . . . . . . . . . . . . . . . . . . II4

Abcess, Opening . . . . . . . . . . . . . . 19r

Actions . . . . . . . . . . . . . . . . 15

Age of the Horse . . . . . . . . . . . . . . 22

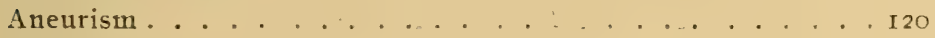

Ankle, locked . . . . . . . . . . . . . 155

A poplexy . . . . . . . . . . . . . . . . I26

\section{3}

Bladder, Evtrsion of . . . . . . . . . . . . . . . . 99

Bladder, Inflimm t on of . . . . . . . . . . 94

Bladder, Pa alysis cf . . . . . . . . . . . . . 98

Bladder, Rupture of . . . . . . . . . . . . 100

Bladder, $\mathrm{S}_{\mathrm{i}}$ asm of the Neck of $\ldots \ldots \ldots . . . .98$

Bleeding. . . . . . . . . . . . . . . . . . . . i89

Bleeding the Horse . . . . . . . . . . . . . Igo

Blood, Stopping . . . . . . . . . . . . . IgI

Bots . . . . . . . . . . . . . . . 70

Bowels, Inflammation of $\ldots \ldots \ldots . . . . .87$

Brain, Inflammation of . . . . . . . . . . . . I23

Bronchitis, Acute . . . . . . . . . 45

Bronchitis, Chronic ............ . . . . 47

Blind Stagger................... I29

Bowels, Inflammation of . . . . . . . . . . I87

Blood Diseases.................... II2

Breathing of the Horse ............. 16

C

Canker. . . . . . . . . . . . . I7I

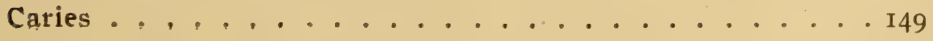


Page

Castrating . . . . . . . . . . . . . . . . I92

Castrating, Evil Results of . . . . . . . . . I75

Cataract... . . . . . . . . . . . . . 135

Catarrh, Arute . . . . . . . . . . . . . . 37

Catarh, Chronic........ . . . . . . . 39

Chest, Tapping the . . . . . . . . . . . . . I92

Choked llorse . . . . . . . . . . . . . . 34

Colic, Billious .................. . . 72

Colic, Spasmoric . . . . . . . . . . . . . 73

Colic, Wind . . . . . . . . . . . . . . 75

Colon, Tapping the . . . . . . . . . . . . . . . I92

Coustipation . . . . . . . . . . . . . . 80

Corns . . . . . . . . . . . . . . . I64

Cough, Acute . . . . . . . . . . . . . . 662 62

Cough, Chronic............... . . 63

CONTENTS . . . . . . . . . . . . 6 6

Congestion, of the Liver . . . . . . . . . . . . . . . rog

Cocked Ankle . . . . . . . . . . . . . . . I55

D

Diabttes . . . . . . . . . . . . . . . . 997

Di九phragm, Rupture of . . . . . . . . . . . 79

Darrhoæ . . . . . . . . . . . . . . . 82

Distemper . . . . . . . . . . . . . . 52

Drenching the Horse . . . . . . . . . . . . 2 20

Dropsy . . . . . . . . . . . . . . . I57

Dysentery .................. . . . 84

Dribbling of Urine . . . . . . . . . . . . . . IO2

E

Fndocardium, Diseases of ............ II 8

Eczema .. . . . . . . . . . . . . r43

Extracting Teeth ................ . r9I

Erelids, Torn ................. . . I37

Fye, Weeping . . . . . . . . . . . . . 136 
Page

Eyes, Glass . . . . . . . . . . . . . . . . I34

Farcy . . . . . . . . . . . . . . II5

Feeding . . . . . . . . . . . . . . 2 21

Fever, puerperal ................ . . I80

Fistulous, Withers . . . . . . . . . . . . . I46

Foul Sheath. . . . . . . . . . . . . . . . Io8

Founcer . . . . . . . . . . . . . . . I72

Founter, Acute . . . . . . . . . . . . I72

Founder, Chronic .............. . . I74

Foot, Gravel in . . . . . . . . . . . . . . 169

Foal, How to Tel1 . . . . . . . . . . . I78

Foal, Mares Hard to . . . . . . . . . . . . I77

G

Gut Tie . . . . . . . . . . . . . . . 86

Gastritis . . . . . . . . . . . . . 66

Glanders . . . . . . . . . . . . . II5

Glass Eye . . . . . . . . . . . . . . I34

Gleet . . . . . . . . . . . . . . . 39

Gonorrhoea .. . . . . . . . . . . . . . . 105

Gravel, in Foot . . . . . . . . . . . . . . . I69

Crease Hesl . . . . . . . . . . . . . . . . . . . . 154

H

Heart, Atrophy of . . . . . . . . . . . . . . . I20

Heart, Enlargement of . . . . . . . . . . . . . II9

Heaves. . . . . . . . . . . . . . . 55

Hide Bind . . . . . . . . . . . . . . . I42

Hip Lameness . . . . . . . . . . . . . . . 162

Hipped . . . . . . . . . . . . . . . . I62

How to Fatten a Horse Quick . . . . . . . . . . . Ig6

How to Make a Horse Go Lame . . . . . . . . . . . I95

How to Make a Slow Horse Peart. . . . . . . . . . . . I95

Heaves, How to Shut them down . . . . . . . . 55 


\section{I}

Page

Incliuations . . . . . . . . . . . . . . . I I3

Indigestion . . . . . . . . . . . . . . . 69

Influenza . . . . . . . . . . . . . . . II2

Inflammation, of Bowels . . . . . . . . . . 87

Inflammation, of Brain ............... . . I23

Inflammation, of Kidneys.............. 9I

Inflammation, of Iris . . . . . . . . . . . . . . I34

Inflammation, of Ovaries. . . . . . . . . . . . I77

Inflammation, of Liver . . . . . . . . . . . . . . IIO

Inflammation of Bladder . . . . . . . . . . . . . . 94

Inflammation, of Testicles . . . . . . . . . . . I75

Itchy Skin . . . . . . . . . . . . . . . . I4I

Itchy Tail . . . . . . . . . . . . . . . . I40

J

Jockey Tricks . . . . . . . . . . . . . . I95

K

Kidney, Congestion of . . . . . . . . . . . . 93

Kidney, Inflammation of . . . . . . . . . . . . . 91

Know What You are Treating. . . . . . . . . . . . . I8

I

Lampas .. . . . . . . . . . . . . . . . 29

Laryngitis . . . . . . . . . . . . . . . 4 4 I

Lice . . . . . . . . . . . . . . I I 38

Liver, Congestion of ... . . . . . . . . . . Io9

Liver, Inflammation of . . . . . . . . . . . . IIo

Lock Jaw . . . . . . . . . . . . . . . I26

Loco Poisoning................. . . I3I

Lungs, Congestion of . . . . . . . . . . . 59

M

Mange . . . . . . . . . . . . . . . . 138

Medicine, How to Give : , . . . : : : : : : : $: 20$ 
Medicine, to Keep on Hand . . . . . . ... . . . . . I97

Medicine, When Indicated

Meningitis

Moon Blindness

Mouth, Sore 30

Mares IFard to Foal' . . . . . . . . . . . . . I77

Mares in Foal, How to Tell ........... . . I78

\section{$\mathbf{N}$}

Narrow Heel. . . . . . . . . . . . . . . . . . 168

Necrosis . . . . . . . . . . . . . . . . I49

Nursing . . . . . . . . . . . . . . 2 2 I

Nasal Glert . . . . . . . . . . . . . . . . 39

$\mathrm{O}$

Operating on Bloot Spavin ............. I9I

Ovaries, Inflammation of . . . . . . . . . . I77

Opening an Abcess . . . . . . . . . . . . . . I9I

Opera'ion on the H. rse . . . . . . . . . . . . . . r r89

\section{$\mathbf{P}$}

Parturition . . . . . . . . . . . . . . . I79

Penis, Wounds of . . . . . . . . . . . I76

Pharyngitis . . . . . . . . . . . . . . 32

Pinkeıe . . . . . . . . . . . . . . . II 2

Pleurisy . . . . . . . . . . . . . . . . 60

Pn umonia . . . . . . . . . . . . . . . 48

Poll Evil . . . . . . . . . . . . . . . . . I45

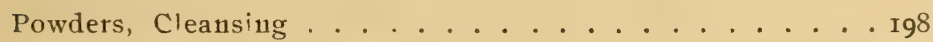

\section{Prescriptions for Horses . . . . . . . . . . 198209}

Pricking the Foot . . . . . . . . . . . . . . I66

Prompt Trsatmett, Impottance of . . . . . . . . . I7

Pulse, How to Take Them . . . . . . . . . . . I4

Prescriptions for C'attle 


\section{Q}

Page

Quarter Cracks . . . . . . . . . . . . . . I67

Quinsy :. . . . . . . . . . . . . . . 44

Quittor ................... . . . . . . . . . . . . . .

\section{R}

Respiration .................. . . . . 6

Rheumatism ................... . . . . . . . . . . . . .

Ringbone . . . . . . . . . . . . . . . . I55

Ringworm . . . . . . . . . . . . . . I9I

Rupture, of the Stomach ............ . . 79

Ruptures . . . . . . . . . . . . . . . . I5I

S

Stifled . . . . . . . . . . . . . . . 16r

Stomach, Rupture of . . . . . . . . . . . 79

Superpurgation . . . . . . . . . . . . . . . 85

Surfeit . . . . . . . . . . . . . . . . . I4I

Sweeney . . . . . . . . . . . . . I59

Saddle Galls . . . . . . . . . . . . . . . . . . I44

Scratches . . . . . . . . . . . . . . . 154

Shoulder Lameness . . . . . . . . . . . . . . . 160

Side Bones . . . . . . . . . . . . . . . . I7I

Set-Fasts . . . . . . . . . . . . . . . I44

Spavin Bog . . . . . . . . . . . . . . 158

Spavin Bone . . . . . . . . . . . . . . . . I57

Spavin Blood . . . . . . . . . . . . . . I59

Splints . . . . . . . . . . . . . . . . I56

Stopping Blood ................. IgI

Staggers, Stomach . . . . . . . . . . . . 68

Staggers, Blind ................... I29

Stone Bruise . . . . . . . . . . . . . . . I70

Sunstroke ................... . . . . I28

Stricture of the Urethra . . . . . . . . . . . . 104

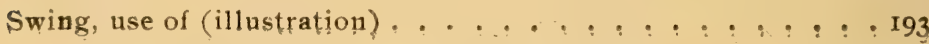


Sore Mouth ........................ 30

$\mathrm{T}$

Teeth Extracting............... r . . .

Teeth. Flon sated ................ 27

Teeth, Irregular. . . . . . . . . . . . 27

Teeth, Sharp.................. 27

Teeth, Uneven.................. . . . 28

Temperature ........................ I5

Thumps. . . . . . . . . . . . . . . . . I2I

Tongue, Laceration of ............. 3I

Toothache. . . . . . . . . . . . . . 28

Tumor in False Nostril . .... . . . . . . . . 37

Testicles, Inflammation of . . . . . . . . . I75

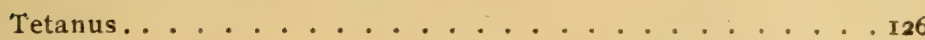

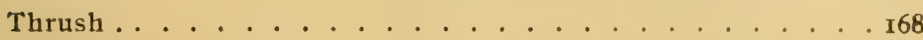

Tumors, Removing of ............... I9I

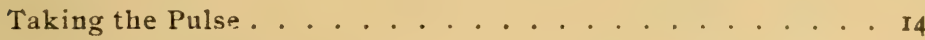

Tapping the Chest. . . . . . . . . . . . . . . I92

Tapping the Colon . . . . . . . . . . . . . . . 192

$\mathbf{U}$

Uretha, Stricture of . . . . . . . . . . . . . I04

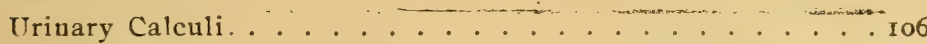

Urine, Bloody.................... . IOI

Urine, Dribbling of . . . . . . . . . . . . . 102

W

Worm . . . . . . . . . . . . . 88

Warts................... . . . I43

Weeping Eyes. . . . . . . . . . . . . . . I36

Wind Galls. . . . . . . . . . . . . . . . . I53

Wire Cuts................... . . I50

Withers Fistula................ . . 446

Wounds of the Penis............. . . . . . 76

Womb, Inflammation of . . . . . . . . . . I76 


\section{INDEX \\ Part II. Cattle}

A

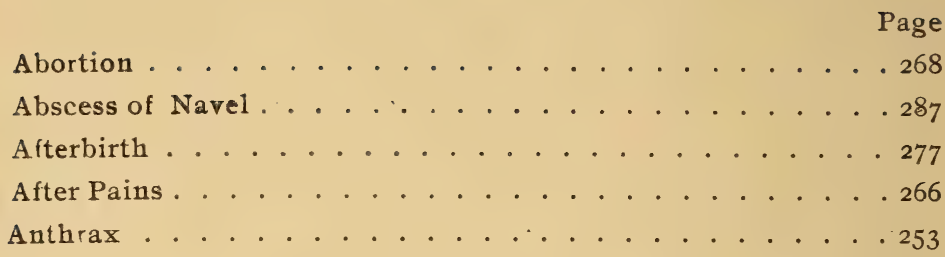

B

Bites, Snake............ . . . . . 277

Bitter Milk . . . . . . . . . . . . . . . . . . 284

Bleeding from the Nose............... . 216

Bleeding from the Lung. . . . . . . . . . . . 2I7

Back, Grubs in . . . . . . . . . . . . . . 279

Bladder Stone in . . . . . . . . . . . . . . . . 244

Bladder, Inflammation of . . . . . . . . . . . . . . 243

Blosd Poisoning. . . . . . . . . . . . . . . 246

Bloody Urine. . . . . . . . . . . . . . . . . . 243

Bloody Milk .. . . . . . . . . . . . . . . . 284

Boils . . . . . . . . . . . . . . . . . 276

Blisters, Water. ................. 275

Black Leg. . . . . . . . . . . . . . . . . . . . 253

Brain, Inflammation of . . . . . . . . . . . . 255

Bronchitis. . . . . . . . . . . . . . . 220

Broken Limbs. . . . . . . . . . . . . . . . . . . . 290

Brain, Congestion of. . . . . . . . . . . . . . . 256

Bowels, Inflammation of. . . . . . . . . . . . 237

C

Cattle...................... . . 213

Catarrh .................... . . 2 217

Cataract . . . . . . . . . . . . . . . . 262 
Page

Ca-tratiug. . . . . . . . . . . . . . . . 293

Chroni: Inligestion . . . . . . . . . . . . . . 233

Choking . . . . . . . . . . . . . . . . . 228

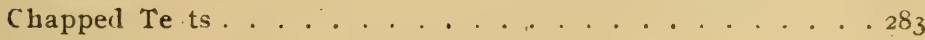

Constip tion . . . . . . . . . . . . . . . 288

Congestion of the Uilder. . . . . . . . . . . . . 282

Concussion of the Brain . . . . . . . . . . . . 256

Congestion of the Testicies . . . . . . . . . . . . . . . 264

Constipation . . . . . . . . . . . . . . . 234

Contageous Pieuro Pneumnnia. . . . . . . . . . . 249

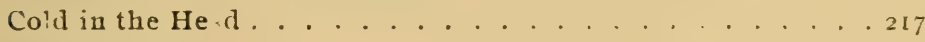

Cough, (hronic. . . . . . . . . . . . . . 224

Cud, Loss of . . . . . . . . . . . . . . . . . . . . . 228

$\mathrm{D}$

Dehorning . . . . . . . . . . . . . 29I

Diarrhoza. . . . . . . . . . . . . . . 235

Diphtheria . . . . . . . . . . . . 220

I)ry Murri n . . . . . . . . . . . . . . 232

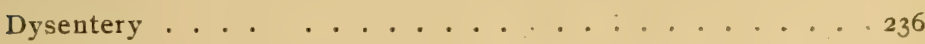

E

Eczema . . . . . . . . . . . . . . 274

Eversion of the Urine .................... 270

Eye, Inflammation of . . . . . . . . . . . . . 26r

Eye, Foreign Substance in . . . . . . . . . . . . 262

Eye, Lids Torn . . . . . . . . . . . . . 263

Fever, Texas..................... 25I

Fever, Puerperal . . . . . . . . . . . . 270

Fistula, Milk Glands. . . . . . . . . . . . . 285

Flooding. . . . . . . . . . . . . . . 269

Fleas .................... . . 28r

Flies, Horn . . . . . . . . . . . . . 280

Eoreign Substauce in the Eye... . . . . . . . 262 
G

Gnats, Buffalo... . . . . . . . . . . 279

Grubs in Back. . . . . . . . . . . . . 279

H

Heaves . . . . . . . . . . . . . . . 225

Heat, Prostration From . . . . . . . . . . . . . . 257

Hoven . . . . . . . . . . . . . . . . . . 229

Horn Flies. . . . . . . . . . . . . . . . . . 280

Incontinence of Urine. . . . . . . . . . . . . . . 242

Indigestion, Chronic . . . . . . . . . . . . . 233

Intestinal Worms ... . . . . . . . . . . . 238

Impaction of the Omasum . . . . . . . . . . 232

Impaction of the Rumen . . . . . . . . . . . 23I

Inflammation of the Brain. . . . . . . . . . . 255

Inflammation of the Bladder. . . . . . . . . . . . 243

Inflammation of the Testicles . . . . . . . . . . . . . . 264

Inflammation of the Eye... . . . . . . . . .26I

Inflammation of the Udder . . . . . . . . . . . . 282

Inflammation of the Kidney . . . . . . . . . . . . . . . . 240

J

Jaw, Lump . . . . . . . . . . . . . . . . . 273

Joint, Ill . . . . . . . . . . . . . . . . 286

$\mathbf{K}$

Kidney, Inflammation of . . . . . . . . . . 240

I

Laryngitis ........... . . . . . . 2 I9

Lice . . . . . . . . . . . . . . . . . 2 278

Loss of Cud.................. . . . . 228

Lock Jaw . . . . . . . . . . . . . . . . . 259

Lump Jaw . . . . . . . . . . . . . . . . 273 
Mange . . . . . . . . . . . . . . . 277

Milk, Blocdy .................... . . . 284

Milk, Bitter. . . . . . . . . . . . . . . . . . 284

Milk, Suppression of . . . . . . . . . . . . . 284

Miscarriage. . . . . . . . . . . . . . . . 268

Mouth, Sore ................. . . 227

N

Narel, Abscess . . . . . . . . . . . . . . . 287

Navel, Rupture . . . . . . . . . . . . . . . . . 287

O

Operations on Cattle..... . . . . . . . . . 290

Omasum, Impaction of . . . . . . . . . . . . . . . 232

P

Parturation . . . . . . . . . . . . . 266

Paralysis . . . . . . . . . . . . . . . . . 258

Philisis, Pumonalis . . . . . . . . . . . . . . 247

Pleurisy . . . . . . . . . . . . . . . . 223

Prolonged After Pains. . . . . . . . . . . . . . . 266

Prostration from Heat... . . . . . . . . . 257

Pneumonia . . . . . . . . . . . . . . . . 222

Pneumonia, Contageous Pleuro . . . . . . . . . 249

Poisoning, Blood . . . . . . . . . . . . . 246

Puerperal Fever . . . . . . . . . . . . . . . 270

Pulse . . . . . . . . . . . . . . 215

PRESCRIPTIONS . . . . . . . . . . . . 34 I

$\mathbf{R}$

Respiration .. . . . . . . . . . . . . .2 2 I5

Retention of the Urine . . . . . . . . . . .24I

Retention of the Afterbirth. . . . . . . . . . . 267

Rheumatism . . . . . . . . . . . . . . 248

Ringworm . . . . . . . . . . . . . . 278

Rinderpest . . . . . . . . . . . . . 25I 
Rumen, Impaction of ... . . . . . . . . . 23I

Rupture of the Navel . . . . . . . . . . . . . 287

s

Scouring. . . . . . . . . . . . . . 288

Screw Worms . . . . . . . . . . 281

Signs of Disease . . . . . . . . . . . . . 214

Suake Bites... . . . . . . . . . . . . . . 277

Sore mouth . . . . . . . . . . . . . . . . . 227

Sore Teats. . . . . . . . . . . . . . 283

Stone in the Bladder . . . . . . . . . . . . . . . 244

\section{$\Gamma$}

Tapping the Rumen................ . . 230

Tapping the Chest . . . . . . . . . . . . . . . . 292

Tapping the Paunch . . . . . . . . . . . . . 292

Tapping the Bladder . . . . . . . . . . . . . 293

Teats, Sore . . . . . . . . . . . . . 283

Temperature . . . . . . . . . . . . . . 215

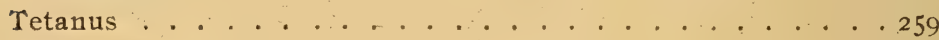

Texas Fever................ . . 25I

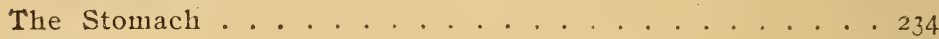

Ticks ............. . . . . . . 279

Torn Fyelids . . . . . . . . . . . . . . . . . . . 263

Tuberculosis . . . . . . . . . . . . . . . . 247

U

Udder, Congestion of . . . . . . . . . . . . . . . 282

Udder, Inflammation of . . . . . . . . . . . . 282

Urine, Incontinence of . . . . . . . . . . . . . . . . 242

Urine, Retention of . . . . . . . . . . . . . .24I

Urine, Bloody . . . . . . . . . . . . . . . . 243

\section{W}

Water Blisters .... . . . . . . . . . . 275

Warts . . . . . ............ 276 
Womb, Eversion of . . . . . . . . . . . . . . . 270

Worms, Intestinal. . . . . . . . . . . 238

Worms, Screw ................. . . $2 \mathrm{SI}$

\section{Part III. Swine}

Black Teeth .................. . . . 304

Bustles . . . . . . . . . . . . . . . 306

Coustipation . . . . . . . . . . . . . . . . 30

Diarrhoez . . . . . . . . . . . . . . . . 302

Fits in Pigs . . . . . . . . . . . . . . . . 303

Hog Cholera . . . . . . . . . . . . . . . 350

Lice . . . . . . . . . . . . . . . . 304

Pigging. . . . . . . . . . . . . . . . 306

Mange... . . . . . . . . . . . . . . 304

Preumonia ....... . . . . . . . . . 303

Nates . . . . . . . . . . . . . . . . 306

Swine . . . . . . . . . . . . . . . 295

Staggers . . . . . . . . . . . . . . . . 302

Worms .................. . . . 300

\section{Part IV. Poultry}

Bronchitis .................... . . 314

Catarrh ....................... 314

Cholera................... . . $3 \mathrm{I} 2$

Crop Bound .................... . . 3II

Diarrhoea . . . . . . . . . . . . . . . 311

Egg Production ....... . . . . . . . . 310

Fleas ................... . . 317

Gaps . . . . . . . . . . . . . . . . . 315

Leg Weakness . . . . . . . . . . . . . . 316

Lice................... . . . . 317

Mites ................... . . 318

Pips.................... . . . . . . . . . . . . 
Pou'try. . . . . . . . . . . . . . . 309

Roup . . . . . . . . . . . . . . . . 313

Sore Head.. . . . . . . . . . . . . . . . . 316

\section{Part V. Sheep}

Bloating . . . . . . . . . . . . . . 325

Co'ic . . . . . . . . . . . . . . . 326

Foot Rot . . . . . . . . . . . . . . 322

Gravel in Foot . . . . . . . . . . . . . . 322

Grub in llead . . . . . . . . . . . . . . . 328

Iuflammation of the Bowels . . . . . . . . . . . 327

Liver Fluke . . . . . . . . . . . . . . . 324

lung Worms : . . . . . . . . . . . . . 325

Mange.................... . . 323

$\mathrm{Scab}$. . . . . . . . . . . . . . . . 329

Sheep . . . . . . . . . . . . . . . 321

Swollen Heet. . . . . . . . . . . . . . . . . 322

Travel Sore . . . . . . . . . . . . . 32I

Worms . . . . . . . . . . . . . . 323

\section{Part VI. Doǵs}

Antidotes to Poison . . . . . . . . . . . . 339

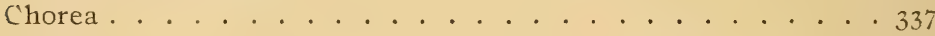

Constipation . . . . . . . . . . . . . . . . 335

Diarrhoea . . . . . . . . . . . . . . . 336

Distemper . . . . . . . . . . . . . . . 334

Dog . . . . . . . . . . . . . . . . . . . 33 I

Dysentery .................. . . . . 336

Ear, Canker of . . . . . . . . . . . . . 334

Fits . . . . . . . . . . . . . . . . 337

Fleas .. . . . . . . . . . . . . . . 332

Hydrophobia . . . . . . . . . . . . . 338

Inflammation of the Eye . . . . . . . . . . . . 333 
I VDFX-PART VI. IOGS.

- Page

Lice . . . . . . . . . . . . . . . . . . . 332

Mange . . . . . . . . . . . . . . . . . . 33 I

Poisons . . . . . . . . . . . . . . . . . . . . . . . . . 339

Riugworms : . . . . . . . . . . . . . . . 332

Strichnine Poison. . . . . . . . . . . . . . . . . 339 


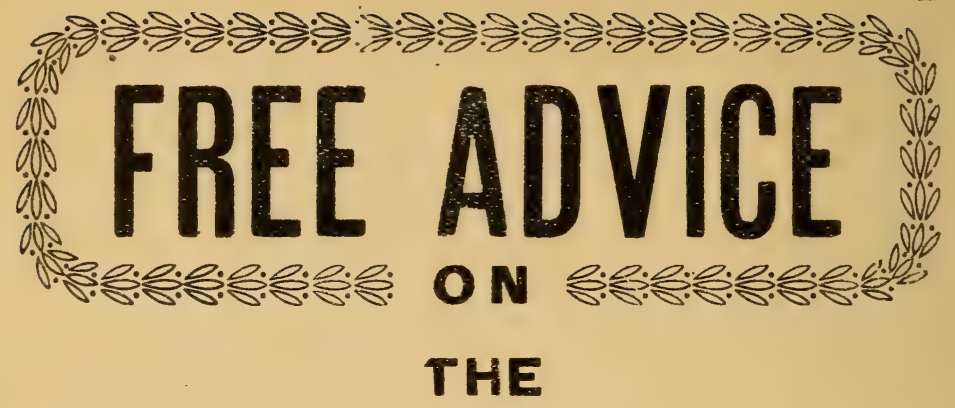

DISEASES OF STOCK

Any person buying a copy of PRIVATE PRESCRIPTIONS AND LECTURFS from one of my authorized agents or ordering one from my office will have the privilege of free advice on any discases they do not understand or anything in the book they want more information about. In cases where a new disease should break out, by sending the symptoms of the case in full and cause of trouble, as near as you cantel, I will furyish you by return mail, advice and prescription in full free of charge. In writing for free advice give the number of the book you have bought which will be found on the first page. Also send $2 \mathrm{C}$ postage stamp for reply. Address all cornespondence to

\section{I. Lowrey; V. S.,} Weatherford, Texas.

Agents wanted to sell my works in every locality. I want the services of Farmers and Farmers' sons. Write for particulars. 


\section{PRIVATE PRESCRIPTIONS}

AND

\section{E C T U R E S \\ ON \\ DISEASES OF THE HORSE}

I have classified this work under sixteen different heads, have arranged the different diseases under appropriate heads, and have treated each in such a simpie way that any child who can read may understand. This book is the result of years of labor and contains the best of all there is in science and in practice. It is plainly written, printed in bold type, on good paper, finely. illustrated and perfectly indexed. It tells you the causes of every malady, how to know them and distinguish one disease from another in the horse and just exactly what to do at every stage of disease. Every prescription is written in plain English: No worthless patent medicines are recommended to you for purchase. Every line of this book is of practical worth; it is complete in every respect. To this work I have added a Supplement and in its pages will be fond some of the most valuable prescriptions for cattle known to the profession.

This book contains I68 pages and is nicely bound in tag board, and will be sent post paid to any address on receipt of One Dollar. Address all orders to

\section{I. Lowrey, V. S.,}

Weatherford, Texas. 


\section{Ready Prepaied Creatments}

Since the publication of my book, "Private Prescriptions and Lectures on Diseases of the Horse," in I902, I have received numerous requests for the remedies prescribed, prepared by myself, from patrons who wanted the utmost care and the purest drugs in the preparation of their prescriptions. In response to this demand I have decided to keep on hand a number of these remedies oftenest used, compounded of the purest of drugs and with full directions as to their use. Prices as follows:

COLIC CURES: I will send to any address on receipt of 5 OC 4 oz bottle or IO Oz for \$1.OO.

COLLAR AND SADDLE GALL, CURE: 2 oz for $25 \mathrm{c}$ or $5 \mathrm{oz}$ for $5 \mathrm{OC}$ in powder form or in the salve. In ordering please say which is wanted.

BONE SPAVIN CURE: Will send you enough to cure 3 or 4 cases for $\$$ I.OO.

BOG SPAVIN: $50 \mathrm{C}$ and $\$ \mathrm{I} .00$ bottles.

HEAVE CURES FOR HORSES: Will send you 20 day treatment for $\$ \mathrm{I}$.OO.

HEAVES IN CATTLE: Will send I5 day treatment for $\$$ I.OO.

LINIMENT FOR WIRE CU'TS: $50 \mathrm{OC}$ and \$I.OO per bottle.

KIDNEY CURE FOR HORSES: $50 \mathrm{O}$ and \$I.OO.

TO TAKE WAR'TS OFF HORSES AND CATTLE: $25 \mathrm{c}$ and $5 \mathrm{Oc}$.

CONDITION POWDERS FOR HORSES: 25c per $1 \mathrm{~b}$.

CONDITION POWDERS FOR CATTIE: $30 \mathrm{c}$ per $1 \mathrm{~b}$. in any quantity. 
ANTICEPTIC POWDERS FOR WOUNDS AND SORES- $25 \mathrm{C}$ and 5 Oc per box.

BLIND STAGGERS TREATMENT: $75 \mathrm{C}$ and \$I.OO. SORE EYES IN HORSES: 3 ounce bottle $25 \mathrm{C}$.

Prescription for any remedy not named above will be promptly filled from drugs of guaranteed purity, and forwarded by mail or express, on applications.

Prices for filling any of these prescription in this book will be sent to any address on application Address a!l orders to D. J Lowery, V.S, Weatherford, Texas 
MEMORANDUM. 
MEMORAMDUM. 


\section{NEW BOOK 1905 \\ Private \\ Preseriptions \\ and Leetures \\ ON \\ DISEASES OF STOCK}

Containing thirty-four Plain and Common-Sense Lectures on Diseases of the Horse, Cattle, Poultry, Hogs, Sheep and Dogs, and their Treatments, together with Indispensable Information to the Farmer and Stock Man, and hundreds of the best Prescriptions known to the Veterinary Profession. This work is nicely illustrated and perfectly indexed. Contains nearly 400 pages and is substantially bound in fine cloth, and will be sent to any address on receipt of $\$ 2.50$, post paid.

Address all orders to

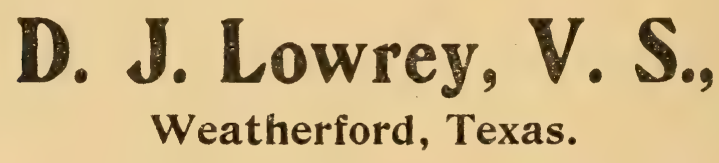




\section{MEMORANDUM PAGES.}

The following blank pages are inserted for the purpose of giving space for memoranda relative to the treatment of your stock. If you will keep a careful record of each case you treat, showing the date, animal, age, disease, or symptoms and their progress, with the remedies used and their -effect, it will prove very valuable to you for future reference.

MEMORANDUM. 
MEMORANDUM. 
MEMORANDUM. 
MEMORANDUM. 






3

-

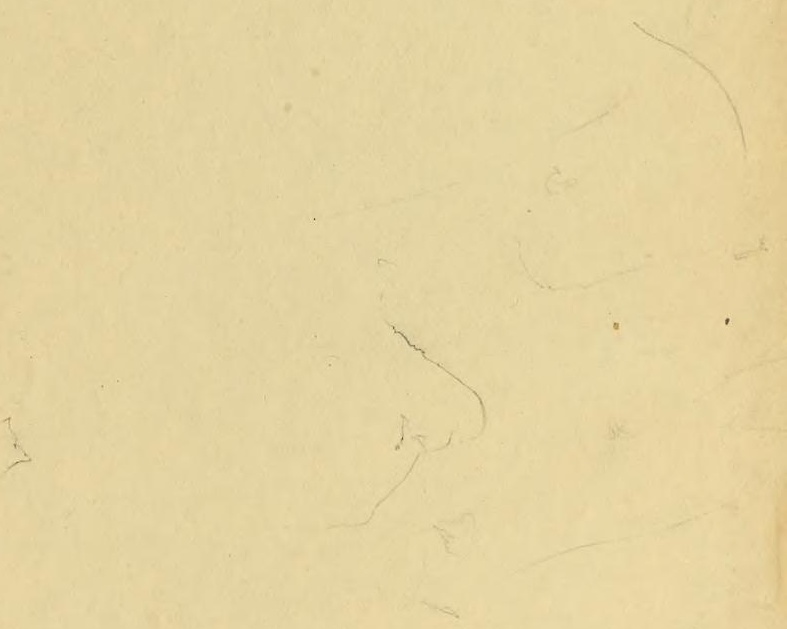


LIBRARY OF CONGRESS

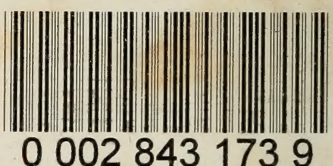

3 